\title{
WestVirginiaUniversity
}

THE RESEARCH REPOSITORY @ WVU

Graduate Theses, Dissertations, and Problem Reports

2001

\section{Wood deck bridges-stress laminated wood panels on steel beams}

Bryan Lin King

West Virginia University

Follow this and additional works at: https://researchrepository.wvu.edu/etd

\section{Recommended Citation}

King, Bryan Lin, "Wood deck bridges-stress laminated wood panels on steel beams" (2001). Graduate Theses, Dissertations, and Problem Reports. 1119.

https://researchrepository.wvu.edu/etd/1119

This Thesis is protected by copyright and/or related rights. It has been brought to you by the The Research Repository @ WVU with permission from the rights-holder(s). You are free to use this Thesis in any way that is permitted by the copyright and related rights legislation that applies to your use. For other uses you must obtain permission from the rights-holder(s) directly, unless additional rights are indicated by a Creative Commons license in the record and/ or on the work itself. This Thesis has been accepted for inclusion in WVU Graduate Theses, Dissertations, and Problem Reports collection by an authorized administrator of The Research Repository @ WVU. For more information, please contact researchrepository@mail.wvu.edu. 


\title{
WOOD DECK BRIDGES-STRESS LAMINATED WOOD PANELS ON STEEL BEAMS
}

\author{
Bryan L. King \\ Thesis submitted to the \\ College of Engineering and Mineral Resources \\ at West Virginia University \\ in partial fulfillment of the requirements \\ for the degree of \\ Master of Science \\ in \\ Civil Engineering
}

Hota GangaRao, Ph.D., Chair

Udaya Halabe, Ph.D.

Roger Chen, Ph.D.

Department of Civil and Environmental Engineering

\author{
Morgantown, West Virginia \\ 2001
}

Keywords: Composite, Timber, Fatigue, Bridge, Prestress

Copyright 2001 Bryan L. King 


\section{ABSTRACT \\ Wood Deck Bridges-Stress Laminated \\ Wood Panels on Steel Beams}

\section{Bryan L. King}

The objective of this research project was to gain a further understanding about certain strengths and limitations regarding specific interactions associated with positioning a prestressed glued-laminated timber decking on top of supporting steel stringers. The main focus was to monitor certain aspects associated with the structural efficiency of the deck-stringer system.

The single most important topic resulting from this experiment was the composite action associated with the timber deck and steel stringers. Comparison of this attribute is performed with recordings of applicable strain and deflection measurements. Maximum differences regarding global deflection containment were found to be 21.6 percent. Maximum differences reflective to global strain encounters were observed to be 75.2 percent. Further testing included load distribution, fatigue response, global deflection, local deflection, global strain, prestress attainment, and allowable bending stress evaluation.

Based on the results incorporated in this report, some general recommendations can be established regarding the best approach for constructing future timber bridges. In general, short span prestressed timber bridges appear to be a reliable alternative in rural bridge design. Incorporating steel stringers offer adequate stiffness effects, while lowering project costs and nominal space requirements. Additional stringer implements, along with increased timber deck thickness should satisfy imposing design equations. 


\section{ACKNOWLEDGEMENTS}

I am forever indebted to John Bargo because his guidance and direction has led me further than ever imagined. Our friendship started in the very first semester of undergraduate studies and it has only grown stronger over the years. It was John who convinced me to continue my education in the graduate program after attaining my bachelor's degree. John also introduced me to Dr. Hota V.S. GangaRao and convinced him to give me a chance. He was always there whenever I needed his help, and he never gave up on me despite the circumstances.

I am also very grateful for my advisor Dr. Hota GangaRao. Under his direction, my knowledge and confidence in the field of structural engineering has increased significantly. His passion for his work has only inspired me to try to do the same. I have so much admiration and respect for this man that it would only be an injustice to try and describe it with mere words. I am repeatedly humbled by his vast knowledge, and honored by the confidence he has for me. I can only hope that one day I will make him half as proud of me for being his student as I am for him being my teacher.

I also want to express my appreciation to Barry Dickson and Hemanth Thippeswamy. Having both acted as advisors at different stages of my research, they not only helped along the way, but also entrusted in me the opportunity to figure the majority of things out for myself.

I would especially like to thank everyone in the CFC office. This includes Sharon Santos, Sharon Chadderton, and Anita Pyles. The patience and tolerance they displayed in the dealings with me did not go unnoticed. I can never seem to accomplish things according to procedure, and they were often willing to go out of their way to accommodate me.

I also want to thank Dana Humberson for all of his help in the laboratory. His knowledge of equipment and machinery came into consideration on several occasions of this research project.

Finally, I want to acknowledge Travis Miller and Jeremy Lawrence. They are both undergraduate students that assisted on this project and several others. They repeatedly helped with every facet of the research. Their interests challenged me, and their commitment inspired me.

Without the help of these eleven people and the countless others that I have failed to mention, this project would have been impossible for me to complete. I will always be appreciative for their support. Thank You. 


\section{TABLE OF CONTENTS}

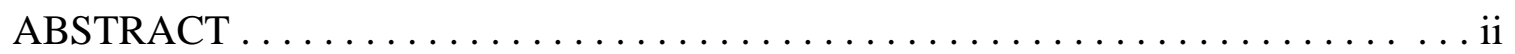

ACKNOWLEDGMENTS. .......................... . ii

TABLE OF CONTENTS $\ldots \ldots \ldots \ldots \ldots \ldots \ldots \ldots \ldots \ldots \ldots \ldots \ldots \ldots \ldots \ldots$

LIST OF TABLES $\ldots \ldots \ldots \ldots \ldots \ldots \ldots \ldots \ldots \ldots \ldots \ldots \ldots \ldots \ldots \ldots \ldots$

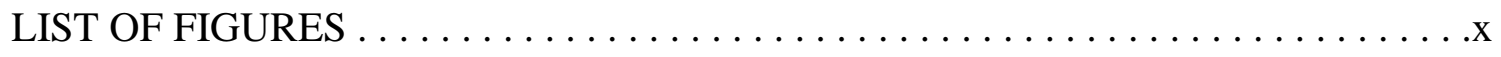

\section{CHAPTER 1 INTRODUCTION}

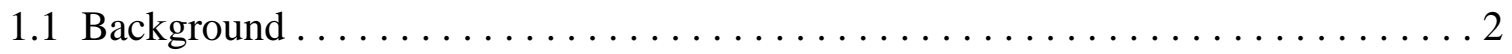

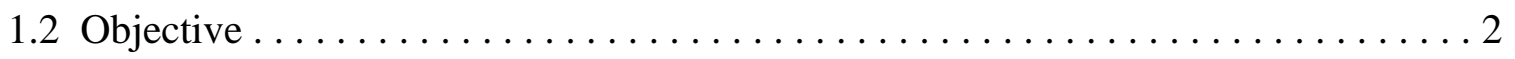

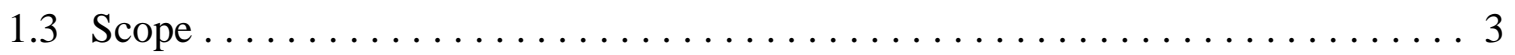

\section{CHAPTER 2 LITERATURE REVIEW}

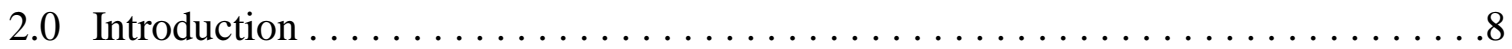

2.1 Analysis and Design of Stress-Laminated Timber Bridge Decks . . . . . . . . 8

2.2 Behavior of Timber Deck-Steel Stringer Bridges

Subjected to Gravity Loads . . . . . . . . . . . . . . . . . 9

2.3 Experimental and Theoretical Evaluation of

Stress-Laminated Timber T-, Bulb T-, and Box-Systems . . . . . . . . . 10

2.4 Modern Timber Bridges of West Virginia $\ldots \ldots \ldots \ldots \ldots \ldots \ldots \ldots \ldots \ldots \ldots \ldots \ldots \ldots \ldots \ldots$

2.5 Monitoring of Stress Laminated Bridges $\ldots \ldots \ldots \ldots \ldots \ldots \ldots \ldots \ldots \ldots \ldots$

2.6 Performance of Stress-Laminated Wood Deck on Steel Stringers . . . . . . . . . . 11

2.7 Standard Specifications for Highway Bridges $\ldots \ldots \ldots \ldots \ldots \ldots \ldots \ldots \ldots$ 
2.8 Structural Monitoring of Stress-Laminated

Timber Bridges in West Virginia (1995) . . . . . . . . . . . . . . . 13

2.9 Structural Monitoring of Stress-Laminated

Timber Bridges in West Virginia (1996) . . . . . . . . . . . . . . . . . 14

2.10 The Behavior of Bolt Anchors for

Timber Deck on Steel Stringers ............................. 14

2.11 Timber Bridges-Design, Construction,

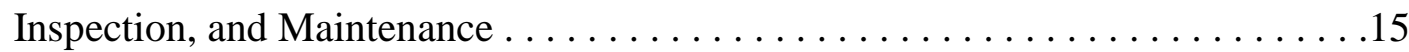

\section{CHAPTER 3 DESCRIPTION OF MODELS}

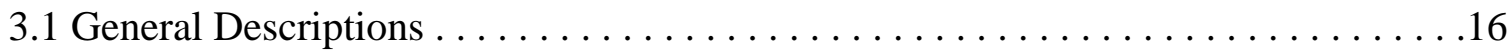

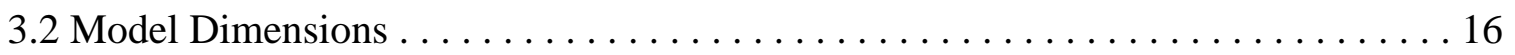

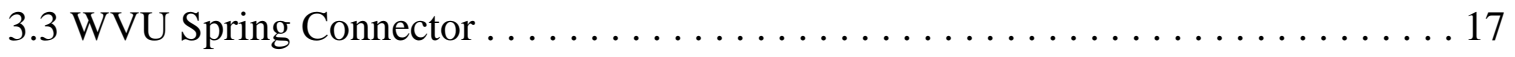

3.4 Connection Detail ........................................ 19

\section{CHAPTER 4 EXPERIMENTAL SETUP AND TESTING}

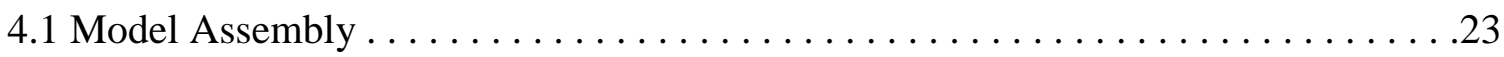

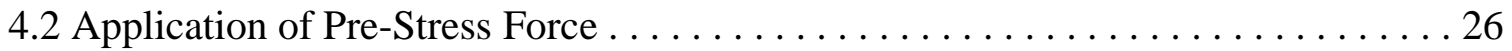

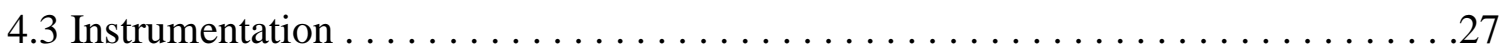

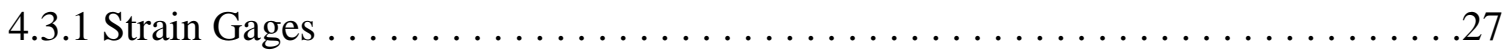

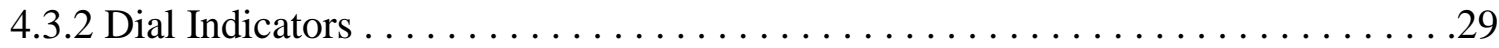

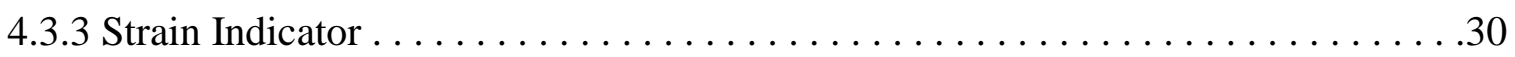

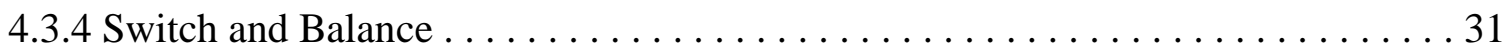


4.3.5 MTS Load Cell . . . . . . . . . . . . . . . . . . . . . . 31

4.3.6 Hydraulic Actuator for Fatigue Load Application . . . . . . . . . . . . . . . . 31

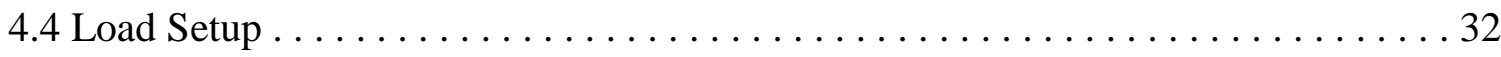

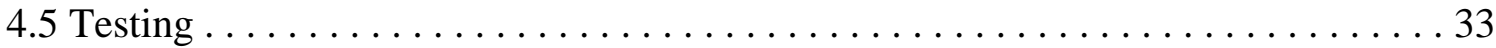

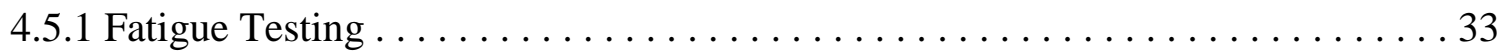

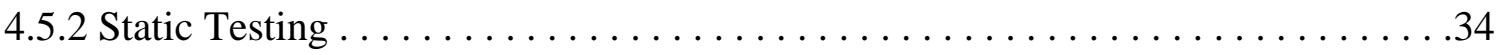

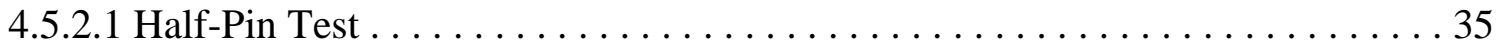

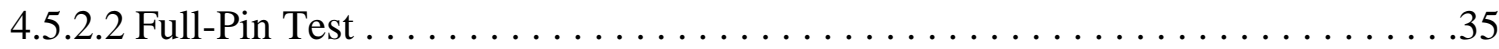

\section{CHAPTER 5 EXPERIMENTAL RESULTS}

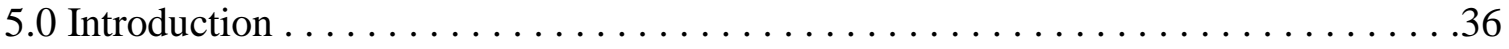

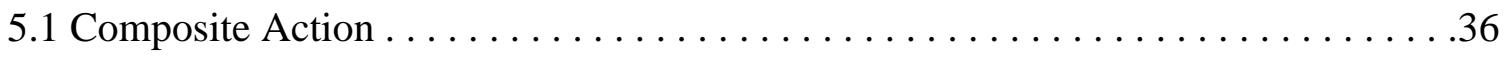

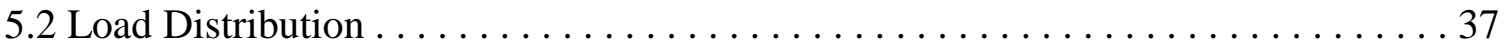

5.3 Performance Results . . . . . . . . . . . . . . . . . . . . . . . .

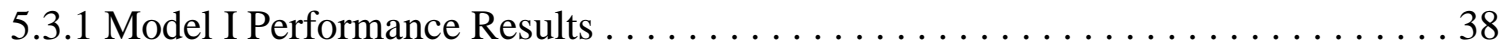

5.3.2 Model II Performance Results . . . . . . . . . . . . . . . . . . . . .50

\section{CHAPTER 6 ANALYSIS AND DISCUSSION}

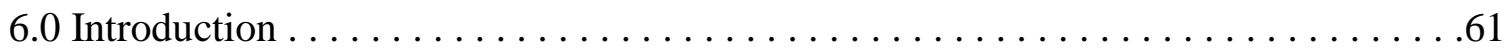

6.1 Composite Action Evaluation $\ldots \ldots \ldots \ldots \ldots \ldots \ldots \ldots \ldots \ldots \ldots \ldots \ldots \ldots \ldots \ldots \ldots \ldots \ldots \ldots$

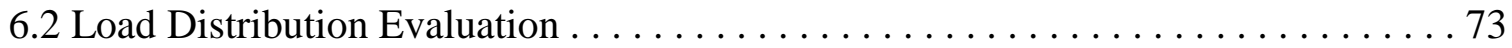

6.3 Fatigue Response Evaluation $\ldots \ldots \ldots \ldots \ldots \ldots \ldots \ldots \ldots \ldots \ldots \ldots \ldots$

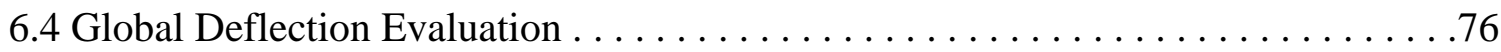


6.5 Local Deflection Evaluation $\ldots \ldots \ldots \ldots \ldots \ldots \ldots \ldots \ldots \ldots \ldots \ldots \ldots \ldots$

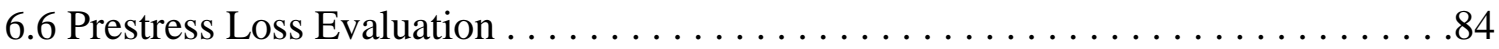

6.7 Allowable Bending Stress Evaluation $\ldots \ldots \ldots \ldots \ldots \ldots \ldots \ldots \ldots \ldots \ldots \ldots \ldots \ldots \ldots$

\section{CHAPTER 7 CONCLUSIONS AND RECOMMENDATIONS}

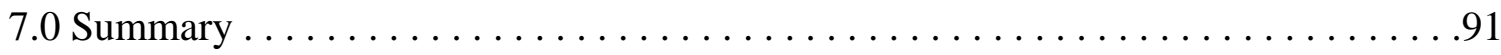

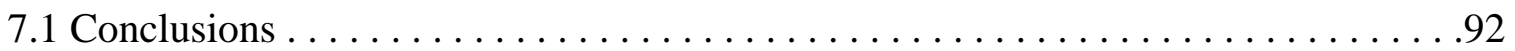

7.2 Recommendations . . . . . . . . . . . . . . . . . . . . . .

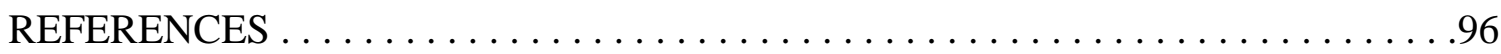

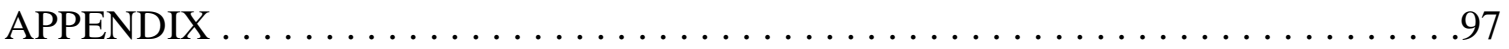




\section{List of Tables}

Table 3.2.1 Dimensions for Bridge Models $\ldots \ldots \ldots \ldots \ldots \ldots \ldots \ldots \ldots \ldots$

Table 4.2.1: Sample Calculation of Initial Force $\ldots \ldots \ldots \ldots \ldots \ldots \ldots \ldots \ldots \ldots$

Table 5.3.1.1: Strain Comparison for Gage \#3 and \#4

of Bridge \#1 (Half Pin) for 10 kip Centered Loading . . . . . . . . . . . . 40

Table 5.3.1.2: Strain Comparison for Gage \#4 and \#5

of Bridge \#1 (Half Pin) for 10 kip Centered Loading . . . . . . . . . . . . 41

Table 5.3.1.3: Deflection Comparison of Bridge \#1 (Half Pin)

for 10 kip Centered Loading . . . . . . . . . . . . . . . . 43

Table 5.3.1.4: Strain Comparison for Gage \#3 and \#4

of Bridge \#1 (Full Pin) for 20 kip Centered Loading . . . . . . . . . . . 46

Table 5.3.1.5: Strain Comparison for Gage \#4 and \#5

of Bridge \#1 (Full Pin) for 20 kip Centered Loading . . . . . . . . . . . . . 47

Table 5.3.1.6: Deflection Comparison of Bridge \#1 (Full Pin)

for 20 kip Centered Loading . . . . . . . . . . . . . . . . . . . . . . 49

Table 5.3.2.1: Strain Comparison for Gage \#3 and \#4

of Bridge \#2 (Half Pin) for 10 kip Centered Loading . . . . . . . . . . . . 51

Table 5.3.2.2: Strain Comparison for Gage \#4 and \#5

of Bridge \# 2 (Half Pin) for 10 kip Centered Loading . . . . . . . . . . . . .52

Table 5.3.2.3: Deflection Comparison of Bridge \#2 (Half Pin)

for 10 kip Centered Loading $\ldots \ldots \ldots \ldots \ldots \ldots \ldots \ldots \ldots \ldots \ldots \ldots \ldots \ldots \ldots \ldots \ldots$ 
Table 5.3.2.4: Strain Comparison for Gage \#3 and \#4

of Bridge \#2 (Full Pin) for 20 kip Centered Loading . . . . . . . . . . . 56

Table 5.3.2.5: Strain Comparison for Gage \#4 and \#5

of Bridge \#2 (Full Pin) for 20 kip Centered Loading . . . . . . . . . . . . 56

Table 5.3.2.6: Deflection Comparison of Bridge \#2 (Full Pin)

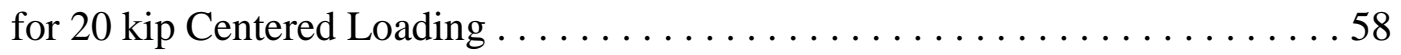

Table 6.1.1: Comparison of Exp. Deflection

vs. Theoretical Deflection for Respective Models . . . . . . . . . . . . . . 68

Table 6.1.2: Comparison of Global Exp. Strain

vs. Theoretical Strain for Respective Models . . . . . . . . . . . . . . . . . 72

Table 6.5: Comparison of Local Exp. Deflection

vs. Theoretical Deflection for Respective Models . . . . . . . . . . . . . . 82 


\section{List of Figures}

Figure 3.3.1 Profile View of WVU Connector $\ldots \ldots \ldots \ldots \ldots \ldots \ldots \ldots \ldots \ldots$

Figure 3.3 .2 Plan View of WVU Connector $\ldots \ldots \ldots \ldots \ldots \ldots \ldots \ldots \ldots \ldots \ldots \ldots$

Figure 3.3.3 Profile View Comparison Between

Lewis Ever Tight and WVU Connector . . . . . . . . . . . . . . . . 19

Figure 3.3.4 Plan View Comparison Between

Lewis Ever Tight and WVU Connector . . . . . . . . . . . . . . 19

Figure 3.4.1: Cross-Section View of Bridge Assembly . . . . . . . . . . . 20

Figure 3.4.2: Overhead View of Bridge Assembly $\ldots \ldots \ldots \ldots \ldots \ldots \ldots \ldots \ldots \ldots$

Figure 3.4.3: Schematic of Plates and Rod Positioning $\ldots \ldots \ldots \ldots \ldots \ldots \ldots \ldots$

Figure 3.4.4: Photograph showing some of the different sizes plates $\ldots \ldots \ldots \ldots 22$

Figure 4.1.1: Schematic Display of Resulting Forces . . . . . . . . . . . . 24

Figure 4.1.2: Plan View of Connection Detail $\ldots \ldots \ldots \ldots \ldots \ldots \ldots \ldots \ldots \ldots \ldots \ldots \ldots \ldots \ldots$

Figure 4.3.1: Plan View of Strain Gage Location $\ldots \ldots \ldots \ldots \ldots \ldots \ldots \ldots \ldots \ldots$

Figure 4.3.2: Plan View of Strain and Dial Gage Locations $\ldots \ldots \ldots \ldots \ldots \ldots \ldots$

Figure 4.4.1: Profile View of Location for Patch Load . . . . . . . . . . . . 32

Figure 4.4.2: Profile View of Patch Load with

Respective Strain Gage Location . . . . . . . . . . . . . . . . 33

Figure 4.5.2: Beam Diagram and Equations for

Three-Point Bending Test . . . . . . . . . . . . . . . . . 34

Figure 5.3.1.1: Initial Static Test (Half Pin) Graph for Bridge $\# 1 \ldots \ldots \ldots \ldots \ldots \ldots$.

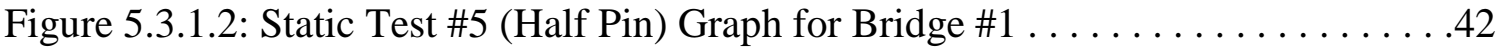


Figure 5.3.1.3: Initial Deflection (Half Pin) Graph for Bridge \#1 . . . . . . . . . . 44

Figure 5.3.1.4: Deflection Test \#5 (Half Pin) Graph for Bridge \#1 . . . . . . . . . . 45

Figure 5.3.1.5: Initial Static Test (Full Pin) Graph for Bridge $\# 1 \ldots \ldots \ldots \ldots \ldots \ldots$

Figure 5.3.1.6: Static Test \#5 (Full Pin) Graph for Bridge \#1 . . . . . . . . . . . . 48

Figure 5.3.1.7: Initial Deflection (Full Pin) Graph for Bridge \#1 . . . . . . . . . . . .49

Figure 5.3.1.8: Deflection Test \#5 (Full Pin) Graph for Bridge \#1 . . . . . . . . . 50

Figure 5.3.2.1: Initial Static Test (Half Pin) Graph for Bridge \#2 . . . . . . . . 53

Figure 5.3.2.2: Static Test \#10 (Half Pin) Graph for Bridge \#2 . . . . . . . . . . 53

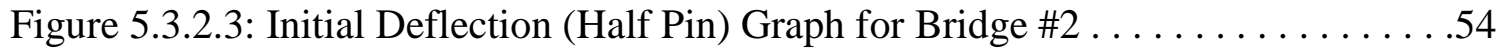

Figure 5.3.2.4: Deflection Test \#10 (Half Pin) Graph for Bridge \#2 . . . . . . . . 55

Figure 5.3.2.5: Initial Static Test (Full Pin) Graph for Bridge \#2 ....................57

Figure 5.3.2.6: Static Test \#10 (Full Pin) Graph for Bridge \#2........................57

Figure 5.3.2.7: Initial Deflection (Full Pin) Graph for Bridge \#2 $\ldots \ldots \ldots \ldots \ldots \ldots \ldots \ldots . .59$

Figure 5.3.2.8: Deflection Test \#10 (Full Pin) Graph for Bridge \#2....................59

Figure 6.1.1: Deflection Diagram and Equation for Simply Supported Beam...........62

Figure 6.1.2: Moment of Inertia Equation for Non-Composite Section . . . . . . . . . .65

Figure 6.1.3: Moment of Inertia Equation for Totally Composite Section . . . . . . . . .65

Figure 6.3.1: Fatigue Response Graph for Model \#1 (Half-Pin) ......................74

Figure 6.3.2: Fatigue Response Graph for Model \#1 (Full-Pin).....................75

Figure 6.3.3: Fatigue Response Graph for Model \#2 (Half-Pin) $. . \ldots \ldots \ldots \ldots \ldots \ldots \ldots \ldots . . .75$

Figure 6.3.4: Fatigue Response Graph for Model \#2 (Full-Pin)......................76 


\section{Chapter 1}

\section{Introduction}

A resurgence of timber bridges can be detected across rural portions of North America. In West Virginia alone, a total of 53 timber bridges were constructed during the period of 1989 to 1994 . Credibility for this resurrection is in large part due to two separate contributors. Accountabilities were first established with the National Timber Bridge Initiative, sponsored by the USDA Forest Service in 1989. The second case of display was performed in accordance with the Intermodal Surface Transportation Efficiency Act of 1991 (ISTEA), which was administered by the Federal Highway Administration. With the support of these two distinctive sponsorships, the West Virginia Department of Transportation has led an aggressive program regarding provisions accounting for effective design and construction techniques for the resurrected timber bridge.

Currently, there are four different approaches implemented in standard timber bridge design in West Virginia. The two timber decks originally created were the stresslaminated deck (Type A), and the stress-laminated box beam (Type B). Following this inception, was the development of the stress-laminated T-beam (Type C), and eventually the glued-laminated panel and beam bridge (Type D). 


\subsection{Background}

The original concept for stress-laminated decks was developed by Canada in the early 1970s. Canadian engineers found this approach to be an effective tool for refurbishing dilapidated nail-laminated decks. Post-tensioning of highly stressed steel bars through old loosened planks gave comparable performance results relative to completely new naillaminated decks. Further development into this concept eventually led to the design of new stress-laminated bridges. Continuing development in this area led to the enlistment of pertaining bridge code modifications in the Ontario Highway Bridge Design Code (OHBDC) in 1983. It was not until 1991, before a listing by the American Association of State Highway Transportation Officials (AASHTO) was reported in the Standard Specification for Highway Bridges. This code was brought forth largely due to the considerable contributions made by the Constructed Facilities Center, at West Virginia University, which fully embellished in research focusing stress-laminated deck design technology in 1989.

\subsection{Objective}

The objective of this research project is to gain some additional understanding of the strengths and limitations associated with stress-laminated bridge deck design. To be more precise, an in-depth analysis shall be conducted on the approach of constructing stresslaminated wood panels on top of supporting steel wide flange stringers. All bridges in this project will be erected within the testing center at West Virginia University. After

assembly, they will then undergo an extensive series of testing procedures equivalent to actual highway load conditions conducted in a reduced time frame. 
Test plans for this project are designed to demonstrate specific abilities of longitudinally stress-laminated wood decks on steel beams to:

(1.) provide the load carrying capacity necessary for highway truck loads

(2.) retain adequate bar force necessary to distribute loads from the point of application to a sufficient number of other deck laminations

(3.) maintain original camber (resist any camber loss or sag)

(4.) compete economically with other bridge construction methods

\subsection{Scope}

To accomplish the four listed project objectives, a work plan was originally proposed. The work plan was divided into separate categories. Each of these categories are provided in the form of individual tasks, followed with a brief description of proposed tasks.

Task 1 - Design and Procure Test Specimens:

Designs of the experimental bridge models will be based on actual field applications of existing bridges. Actual size and spacing of each model will be as closely related to typical timber bridge dimensions as conceivably possible. This information will have to be attained from WVDOH engineers. 
Task 2 - Construct Lab Models:

All models associated with this research project will be constructed inside the confines of the structural testing (major units) laboratory at West Virginia University. Each model will be entirely assembled, cautiously tested, and then properly disposed immediately following completion of testing.

\section{Task 3 - Conduct Tests:}

Each model will undergo a rigorous series of testing. Test appropriations are based on previously identified problems reflective of timber bridge deck systems. This series of testing is intended to evaluate the performance of respective experimental models. Essential testing required for this type of research has been broken down into individual categories. Each of these categories are listed below as subtasks and are also followed with a brief description.

\section{Subtask 3.1 Load Carrying Capacity:}

Subtask 3.1.1 Stiffness - A series of static load tests will be performed on each model to determine the deck's abilities towards resistance of inhibiting deformations. Strain and deflection monitoring apparatus will be installed at several key positions to allow for continuous monitoring throughout the experiment. 
Subtask 3.1.2 Load Sharing - The series of static load tests mentioned in Subtask 3.1.1 will also contribute to determining the load sharing characteristics of individual steel stringers. Employing the services of strain and deflection monitoring devices also assists in the performance of this procedure. Relative load distributions can then be implemented in model revisions in efforts to improve overall effectiveness aspects.

Subtask 3.1.3 Fatigue - A simulated truck loading of at least one million cycles will be induced on each model. This test approach establishes expected service life of subsequent model assemblies. Along with the performance evaluation from relative stress data, the structural integrity of bridge models and service life will also be established through extrapolation.

Subtask 3.2 Bar Force Retention -

Conservation of bar forces is essential to the performance of existing structures. Periodic checks will therefore be conducted to monitor the overall retention of bar force after the completion of a predetermined number of fatigue cycles.

Subtask 3.3 Camber Retention -

During static load testing procedures, measurements will be taken to account for loss of camber. In regards to basic design procedures, camber loss is 
proportional to the stiffness of the material. In this type of setup, the prestressing force applied to the bars can contribute to the stiffness of the entire system. Substantial bar force losses described in Subtask 3.2 will be inversely proportional to the camber retention. An extensive amount of camber loss will eventually create sagging conditions in the deck. This situation can create other difficulties.

Task 4 - Data Analysis:

Data from our test program will be analyzed to establish the most effective stressed timber deck system stiffened by steel stringers. Conclusions will then be drawn detailing supporting evidence from the outcome of the experiments. The analysis will be categorized into subtasks as:

\section{Subtask 4.1.1 Analysis of Load Carrying Capacity -}

Recordings taken from the strain and deflection monitoring devices will be transferred into a series of tables and graphs. From these two forms, comparisons can immediately be drawn determining the stiffness of respective models. Values resulting from this series of comparisons will also be checked with acceptable tolerances for deflection regulations associated with practical design applications concerning modern bridge decks. 
Subtask 4.1.2 Analysis of Load Sharing -

Individual stringers may contribute differently regarding the load sharing responsibilities. This phenomenon is based on the geometric location of the loading in combination with stringer spacing. Performances exhibited by supporting stringers can help arrive at design procedures of the entire structure; therefore, calculations must be performed to determine desirable stringer spacing for typical stressed timber deck models.

Subtask 4.2 Analysis of Bar Force Retention -

Prestressing forces exerted on the retaining bars offer additional support by providing externally induced compressive forces to the timber decking. This confinement contributes in the structural strength of the deck during repeated loadings. To be effective, considerable amounts of bar forces must be retained during the life span of the structure. Load cells placed directly on the stressing bars will reveal the percentage of stress losses as a function of fatigue load range and number of cycles.

Subtask 4.3 Analysis of Camber Retention -

The addition of steel stringers will assist in the prevention of camber loss as compared to other timber decks erected as solid stress laminated sections, and certain other T-beam and Box-beam applications. Sag conditions, however, can still develop in steel members under grossly inadequate design conditions, and will eventually become a serious problem if left unchecked. 


\section{Chapter 2}

\section{Literature Review}

\subsection{Introduction}

There have been numerous studies previously performed on glued-laminated timber bridge decks. The Constructed Facilities Center has done extensive testing on projects very similar to this one over the years. Along with this wealth of experimental information, there are a series of codes and regulations that must be followed in any form of bridge design. Therefore, several reports regarding this subject have been reviewed and listed herein.

2.1 Analysis and Design of Stress-Laminated Timber Bridge Decks, Petro, Samer,

Thesis, West Virginia University, 1993

This project deals primarily with the design and analysis aspects regarding stresslaminated decks. Primary objectives for this research project include the determination of effective widths associated with individual systems. Equations displayed in this thesis separately account for symmetric and also asymmetric loading conditions. For validation purposes, experimental field measurements were compared with proposed macroflexibility solutions along with integral amounts of finite element analysis. Results from this project reflect fairly close values between the two separate analysis techniques for 
both loading conditions. Conclusions attained from this project were reflective to a conservative approach necessary in regards to design procedures for stress-laminated timber bridge decks. This is primarily due to the uncertainty associated with different loading conditions in combination with naturally orthotropic timber materials.

\subsection{Behavior of Timber Deck-Steel Stringer Bridges Subjected to Gravity Loads,}

Kalomallos, Dimitrios, Thesis, West Virginia University, 1989

This project studied the performance of different connectors used on both gluedlaminated and nail-laminated specimens. Types of connectors used were the C-clip, Gclip, and stud connector. During the first four series of tests, three stringers were positioned at a spacing of 48 inches. For twenty-three other experiments, five stringers were situated allowing for a stringer spacing of 22.5 inches. Two of the test specimens in this experiment were glued-laminated, and the resulting specimens were nail-laminated. For both cases of the glued-laminated specimens, C-clip connections were used along with five stringers at 22.5 inch spacing. Procedures for this research involved static tests conducted at varying positions along the longitudinal centerline of each specimen. Results from this project revealed an equivalent comparison among the performance of the three different connectors under gravity load cases. 


\subsection{Experimental and Theoretical Evaluation of Stress-Laminated Timber T-, Bulb}

T-, and Box-Systems, L. Shelton, Barger, Jr., Thesis, West Virginia University, 1995

This research project was primarily conducted to gain a better understanding of the performance of stress-laminated T-Beam and Box-Beam timber bridge applications. This research included a series of specimens tested under static load conditions at varying dimensions. An important variation among the test specimens was the consistency of prestressing. Initial portions of the bridges were controlled at pre-stress levels of $50 \mathrm{psi}$, with the residual specimens maintaining 100 psi levels. Results of this experiment yielded that Box-beam systems obtained significantly higher stiffness ratios over T-Beam models of equivalent dimensions. The increase in stiffness of the Box-Beam over the T-Beam was reported to be approximately 2.5 times greater, and the contributing factor for this phenomenon was the increase in moment of inertia pertaining to the Box-Beam geometric configuration.

2.4 Modern Timber Bridges of West Virginia, Vol. I and II, Dickson, Barry, 1995

This is a two part series put together by Dickson with the primary focus of informing engineers and the general public about the benefits of modern timber bridge applications. The first volume in the series consists primarily of pictures featuring the unique timber bridges located throughout West Virginia. Along with the pictures, is a directional map detailing locations of each specific bridge. This particular volume accomplishes the task of demonstrating the aesthetics associated with modern timber 
bridge designs. Volume II depicts associated research studies for the four relevant timber bridge designs implemented in West Virginia. This is followed with data sheets of pertaining bridges listing relevant figures including material species, design loadings, total project costs, and other pertinent information.

2.5 Monitoring of Stress Laminated Bridges, GangaRao, Hota; Dickson, Barry; Raju, Penmatsa, CFC Report \#91-156

This report described the performance of three existing timber bridges. The three associated bridges were the Coal Yard Bridge, East Lynn Bridge, and Rover Bridge. All three pertaining bridges were stress-laminated, and only the bridge in the first case (Coal Yard Bridge) consisted of a single lane. Field tests performed in this experiment monitored live load deflections, long term elevation losses, bar force losses, moisture content levels, and visual defects. This project was conducted on some of the first bridges designed under the Timber Bridge Initiative program of 1989. Results showed deficiencies with respect to longitudinal stiffness, long-term elevation losses, and assumed transverse stiffness ratios.

\subsection{Performance of Stress-Laminated Wood Deck on Steel Stringers,}

Vijayachandran, Vijith, Thesis, West Virginia University, 1996

Of all the selected reports included in this review, this one contains the most pertinent information associated with the previously described tasks. In this experiment, 
four different models were subjected to a series of fatigue testing under specified cyclic load cases. The first model consisted of five 1.5 inch wide transversely directional gluedlaminated panels. The second model was comprised of five 6 inch wide transversely directional glued-laminated panels. The third model was a 1.5 inch wide longitudinally laminated single panel; and the fourth model was a transversely laminated single panel with a 1.5 inch width. The purpose for this experiment was to determine the composite action between the steel stringers and the four different types of timber decks. In the experimental setup, two distinctively different types of connection details were used for bridge assembly. The first type of connector is referred to as a Lewis Ever Tight. This is the typical type of connector used in timber bridge design. The second type of connector used was the WVU connector. This type of connector was designed by the Constructed Facilities Center at West Virginia University. Fatigue tests were performed on the four models with a static test performed after every 100,000 completed cycles. At these stoppages, strain and deflection readings were performed up to 1,000,000 cycles. Results from the first model revealed that the maximum percentage of tension loss in the bolt occurred during the first stage. The first stage represents the completion of 100,000 fatigue cycles. This incident was repetitive for the other three cases.

2.7 Standard Specifications for Highway Bridges, $16^{\text {th }}$ edition, 1996, American Association of State Highway and Transportation Officials (AASHTO)

This expansive set of guidelines deals directly with every possible aspect of bridge design. Chapter 13 of this guidebook characterizes wood structures. This chapter 
contains a detailed listing of the safety factors and design strengths reminiscent of NDS (National Design Specification for Wood Construction). Familiarization of these principles is essential in any type of bridge design.

\subsection{Structural Monitoring of Stress-Laminated Timber Bridges in West Virginia,}

Dickson, Barry, CFC Report \#93-164, 1995

This report is similar to CFC Report \#91-156, where three timber pre-stressed bridges were field-tested. In this report, the three pertaining bridges were Fieldcrest, Barlow Drive, and Maple Street. This set of bridges was monitored for creep effect losses, live load stresses/deflections, bar force losses, moisture content levels, and visual defects. Comparisons could then be formulated between the experimentally attained figures versus the theoretical calculations. Results obtained from this test procedure revealed less than anticipated values for measured live load deflections and strains. Values of bar forces proved to be adequate, and moisture content levels were recorded as approaching equilibrium. The only negative affects were associated with camber losses, which were evident in every case. This figure was determined to be significantly greater than previously anticipated values. 


\subsection{Structural Monitoring of Stress-Laminated Timber Bridges in West Virginia,}

Dickson, Barry, CFC Report \#96-238, 1996

This report is also similar to CFC Report \#91-156 and CFC Report \#93-164. Subtle differences in this report include the addition of two more bridges raising the value to five bridges assigned for selective field-testing. Bridges associated with this report are Camp Arrowhead, Left Hand Run, Lightburn, Nebo, and Six Mile Creek. Similarly, this set of bridges was monitored for creep effect losses, live load stresses/deflections, bar force losses, moisture content levels, and visual defects. Results from this series of testing depicted adequate values concerning live load deflections and bar force losses. Moisture content was again approaching equilibrium; however camber losses were only apparent in one of the five cases. This reflected to the possibility that the issues regarding camber had been corrected once the problem was identified.

2.10 The Behavior of Bolt Anchors for Timber Deck on Steel Stringers, Wu, Shaojie, Thesis, West Virginia University, 1990

This report demonstrates the capabilities of the WVU connecter previously mentioned in Section 2.5. This project was a contributing factor for the approach of fastening timber decks to steel stringers. Experiments were conducted on three types of connections for comparison purposes. The first type of connector used in this experiment was denoted as a flat plate spring. The second type was referred as a short leaf spring that 
had an overall length of 14 inches. Finally, the third type of connection was called a long leaf spring, and it was 27 inches long. A series of static and dynamic tests were conducted on each spring, allowing for associated computations regarding effectiveness ratios. Static testing was performed directly on the head of each bolt in the assembly, while dynamic testing involved the rolling wheel load machine. This apparatus simulates the load of a truck wheel as it passes over the connection. Results from this project detailed the overall effectiveness of the short leaf spring, and initiated the development for the current WVU connector.

\subsection{Timber Bridges-Design, Construction, Inspection, and Maintenance, Ritter,}

Michael, 1990

This book details associated many items with timber design. Ritter is thorough with the inclusion of items relevant to using wood as a construction material. This book was completed several years ago and therefore does not contain some of the more recent technological advances associated with timber bridge design. This book does serve the purpose of being an excellent reference. 


\section{Chapter 3}

\section{Description of Models}

\subsection{General Descriptions}

As detailed in the objective section of Chapter 1, the concept behind this project was to construct longitudinally stress-laminated wood decks on steel beams for performance testing. For this experiment, two different bridges were consecutively constructed, tested, and then disassembled.

\subsection{Model Dimensions}

The first timber bridge deck erected consisted of five glued-laminated panels. Each panel was $2 \mathrm{ft}$. $\mathrm{x} 6 \mathrm{ft}$ x 7.5 in. When assembled, the overall length of the deck was approximately 10 feet. The material selection incorporated in this model consisted of 1.5 inch thick southern yellow pine laminates.

The second deck was also comprised of five 1.5 inch thick boards making up the glued-laminate panels. Dimensions for this deck were $2 \mathrm{ft}$ x $6 \mathrm{ft}$. $\mathrm{x} 6$ in. This deck was also 10 feet in length, and was composed of southern yellow pine lumber. Table 3.2.1 displays the dimensions for the two bridge models. 
Table 3.2.1: Dimensions for Bridge Models

\begin{tabular}{|c|c|c|c|c|c|}
\cline { 2 - 6 } \multicolumn{1}{c|}{} & $\begin{array}{c}\text { Length } \\
(\mathrm{ft} .)\end{array}$ & $\begin{array}{c}\text { Width } \\
(\mathrm{ft} .)\end{array}$ & $\begin{array}{c}\text { Depth } \\
(\mathrm{in} .)\end{array}$ & $\begin{array}{c}\text { Stringer } \\
\text { Spacing (ft.) }\end{array}$ & $\begin{array}{c}\text { Stringer } \\
\text { Dimensions }\end{array}$ \\
\hline MODEL I & 10 & 6 & 7.5 & 9.5 & W8x24 \\
\hline MODEL II & 10 & 6 & 6 & 9.5 & W8x24 \\
\hline
\end{tabular}

* After the completion of performance testing for Model I, the bridge was disassembled and all applicable steel hardware was incorporated in the erection of the second model. This includes the connection detail, pre-stressing rods, and the two supporting stringers.

\subsection{WVU Spring Connector}

The WVU spring connector was used for both models in this experiment. The design of this connection was developed by the Constructed Facilities Center at West Virginia University. This type of connection was given quality performance rating for every different series of testing procedures. Dimensions of this spring include a 17 inch length, $2-1 / 2$ inch width, and 3/16 inch thickness. Along the longitudinal centerline of the connector is a hole that accommodates the shaft of the bolt. An accompanying nut can then be used to lock together the connection. Holes in the connector are slotted to allow for any necessary adjustments in the alignment process. After proper hole insertion, deck bolts are strategically positioned throughout the laminate panels of the timber deck. With the bolts in position, the connection detail conveniently slides over the shaft of the bolt prior to being firmly positioned under the top flange of the steel stringer. Once this apparatus is properly secured, the steel stringer and laminate deck are transcended into a single entity. This affiliation between two separate materials is generally considered as a composite action, and this occurrence was closely monitored during the course of this 
experiment. Figures 3.3.1 and 3.3.2 show different views of a schematic denoting the WVU connector.

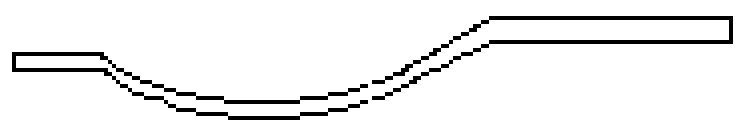

Figure 3.3.1: Profile View of WVU Connector

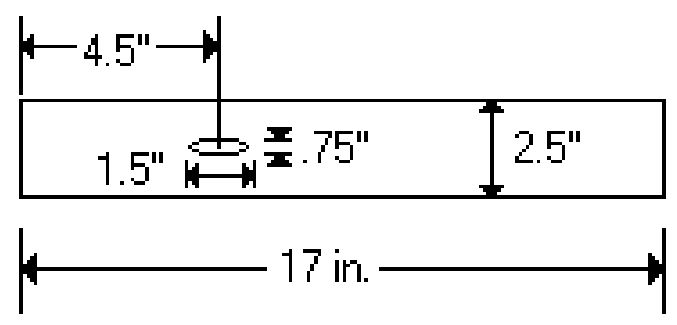

Figure 3.3.2: Plan View of WVU Connector

Figures 3.3.3 and 3.3.4 are photographs showing the WVU connector along with the Lewis Ever Tight bolt assembly. The first figure displays a profile view of the two different connectors, while the second figure corresponds to a plan view. Digital pictures were used to allow for identification and comparisons to be simplified. 


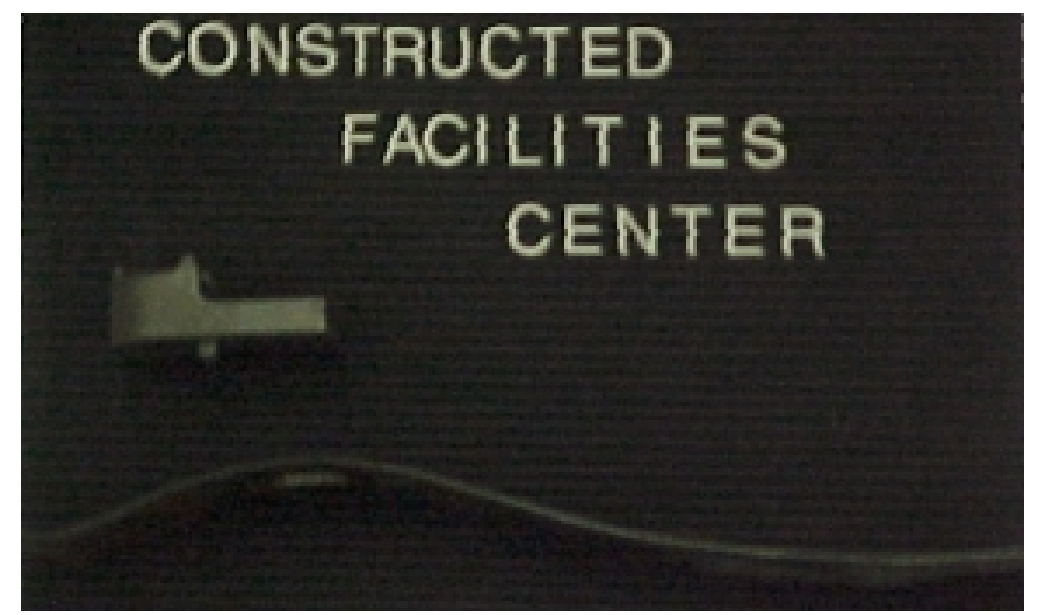

Figure 3.3.3: Profile View Comparison Between Lewis Ever Tight and WVU Connector

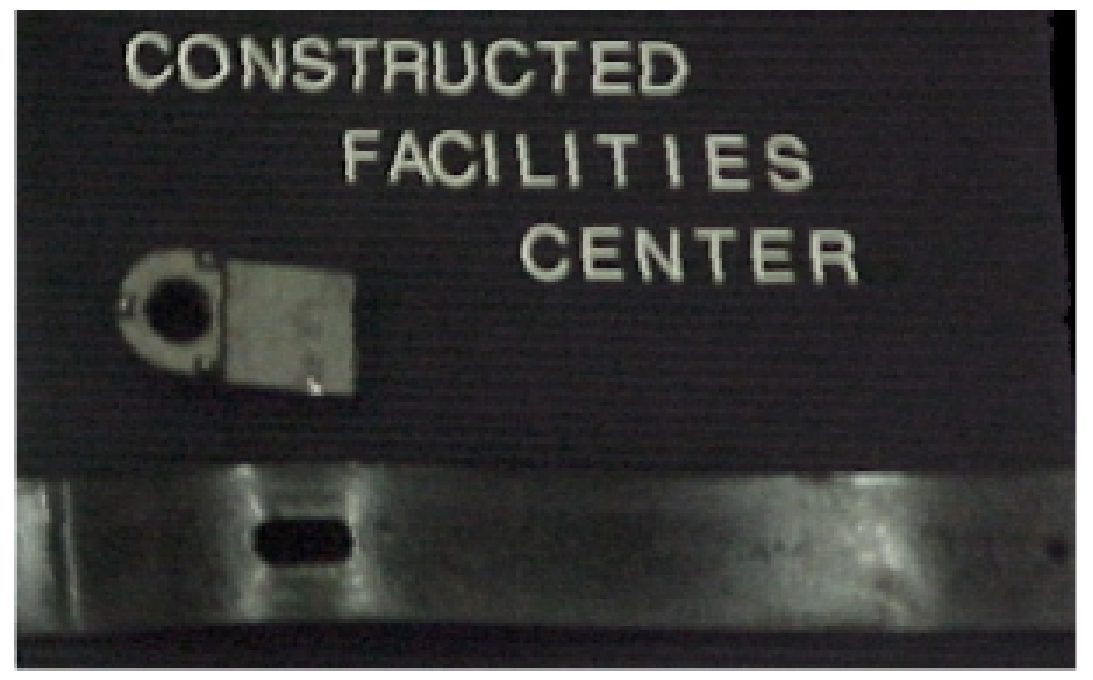

Figure 3.3.4: Plan View Comparison Between Lewis Ever Tight and WVU Connector

\subsection{Connection Detail}

Construction of the two separate bridges was performed in the location where the testing was scheduled to take place. Proper positioning of the supports was inevitably the first task. When this was accomplished, the steel stringers were then set in place. The five panels were then individually stationed on the supporting stringers. Dywidag bars 
(commonly referred to as stressing rods) were pushed through the pre-drilled holes of the panels during installation to verify proper alignment. After all five panels were in position; an anchor plate was attached to opposite ends of the Dywidag bar. Anchor plates act as bearing plates distributing pre-stressing forces uniformly over prescribed areas. Accompanying nuts were then installed to fasten together the entire assembly. Figure 3.4.1 and 3.4.2 display two different views of the entire compilation.

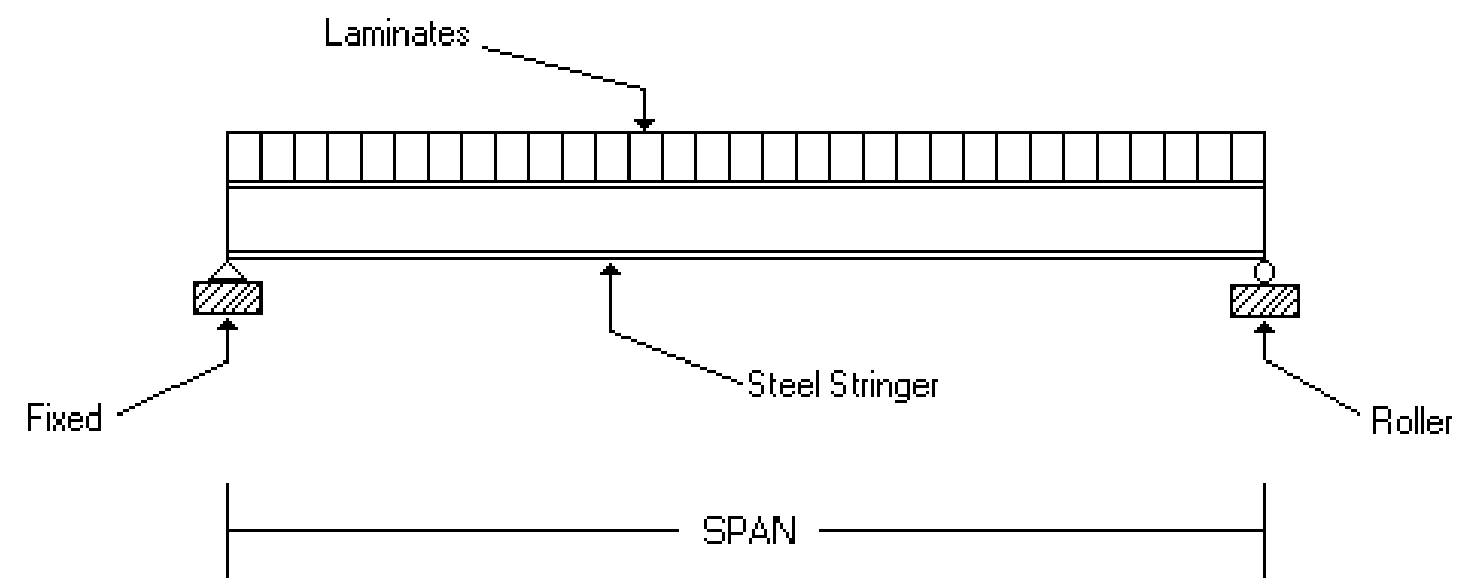

Figure 3.4.1: Cross-Section View of Bridge Assembly

Figure 3.4.3 is another version of the bridge deck, but this time it is displayed with a skewed angle. This view illustrates the actual positioning of both anchor and bearing plates along with the Dywidag rod. Responsibility of the bearing plate is to inhibit excessive damages to the timber, while subjected to compressive forces. 


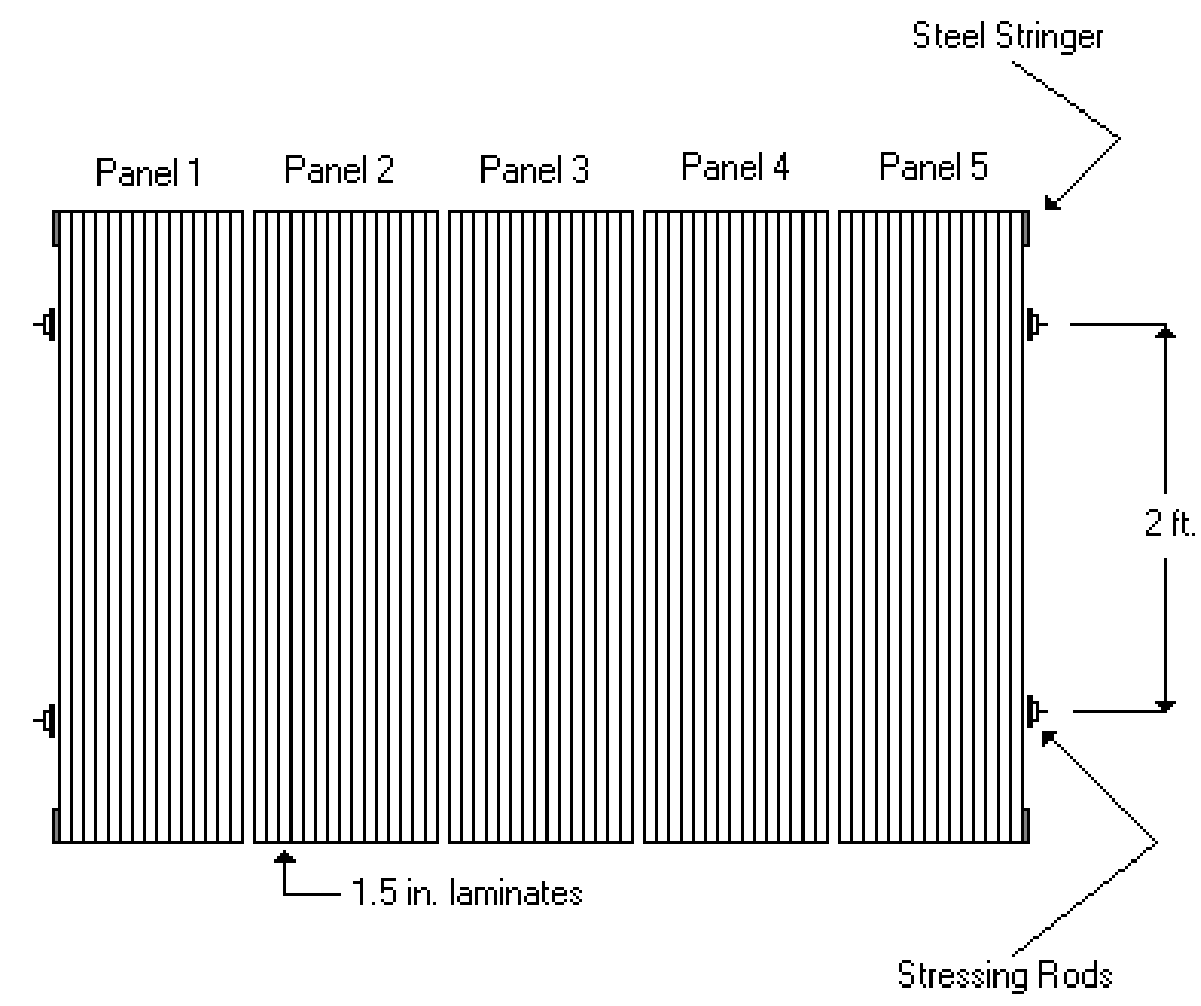

Figure 3.4.2: Overhead View of Bridge Assembly

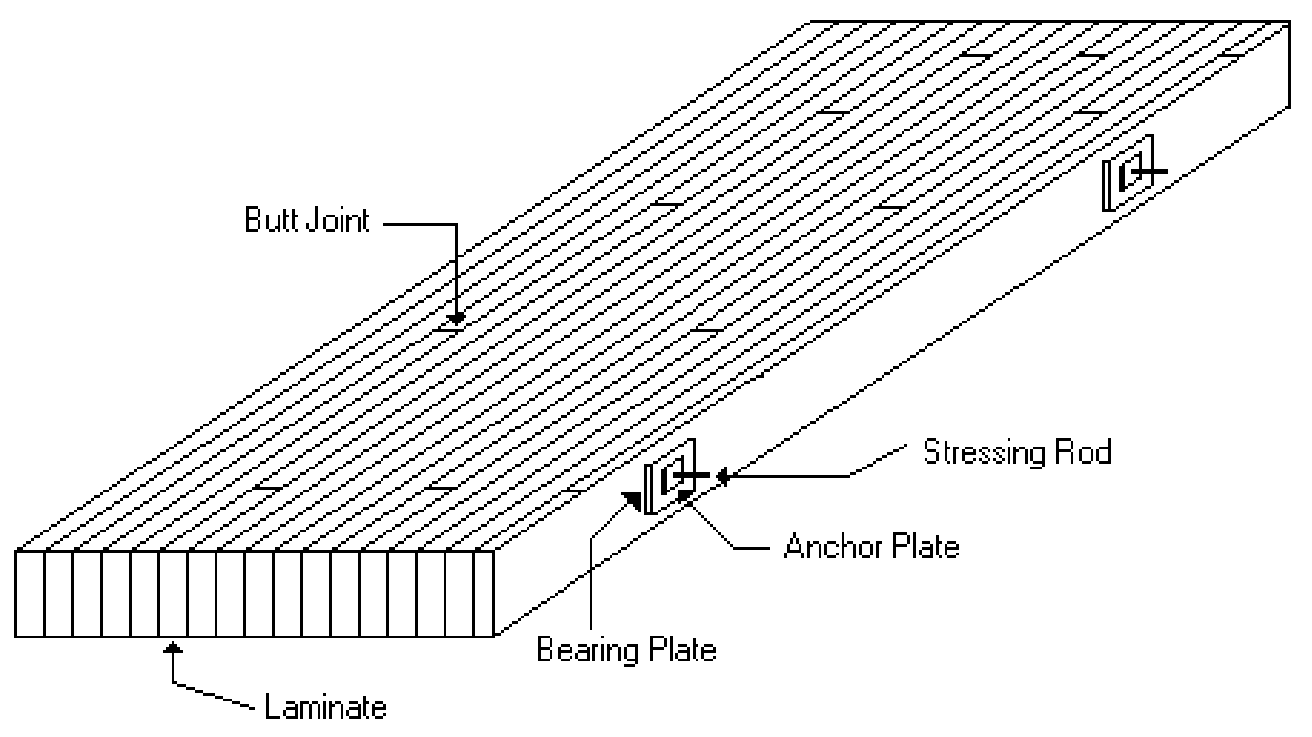

Figure 3.4.3: Schematic of Plates and Rod Positioning 
Actual sizes of the bearing and anchor plates will vary according to the dimensions of the decking. Some typical plates are shown in Figure 3.4.4.

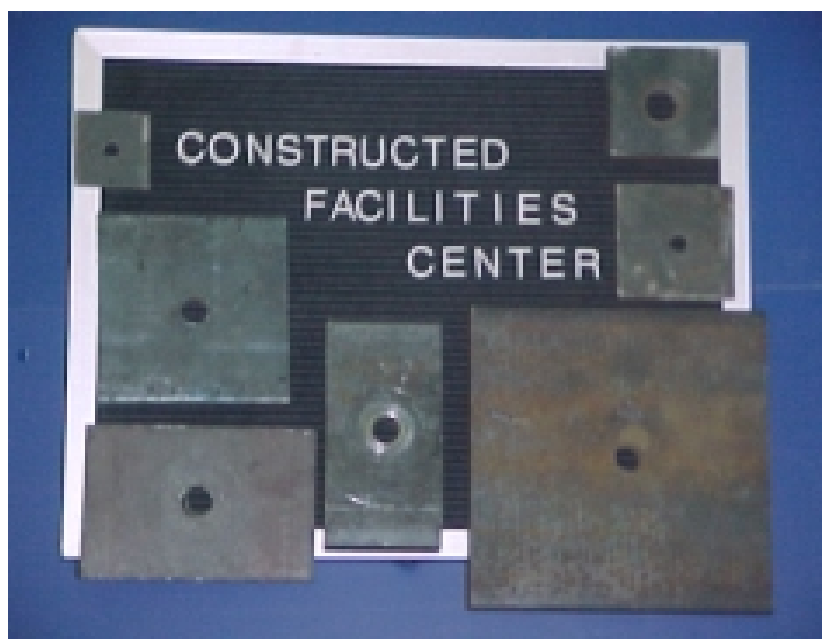

Figure 3.4.4: Photograph showing some of the different sizes plates 


\section{Chapter 4}

\section{Experimental Setup and Testing}

\subsection{Model Assembly}

The two bridge models used in this experimental project were assembled following the same procedure. The only dimensional variable out of the two decking systems was the depth. The first deck had a depth of 7.5 inches, while the second deck only measured 6.0 inches. An equivalent surface area of 60 square feet $(6 \mathrm{ft}$. base x $10 \mathrm{ft}$. length) was calculated for both decks, and the steel stringers implemented in this design were also 10 feet in length to accommodate the decking. Initial assembly began with recorded dimensions being transposed into actual markings at the base of the testing apparatus. Marked outlines simplified the process of positioning the two supports. Each support consisted of an oversized stringer in combination with a steel roller mechanism. The oversized stringers were heavily stiffened throughout the web to inhibit the majority of unwarranted deflections. These stringers had previously been modified for testing purposes and were necessary in this case to raise the height of the bridges ensuring proper performance from the testing apparatus. Once the massive stringers were set into position, two steel rollers were then centered directly on top. The rollers were identical dimensionally, however one roller was allowed to move, while the other was fixed. The fixed roller is a simulation of a pin connection, and it allows for translational forces while 
preventing rotational forces. The free roller accommodates both translational and rotational forces. This situation is demonstrated in Figure 4.1.1.

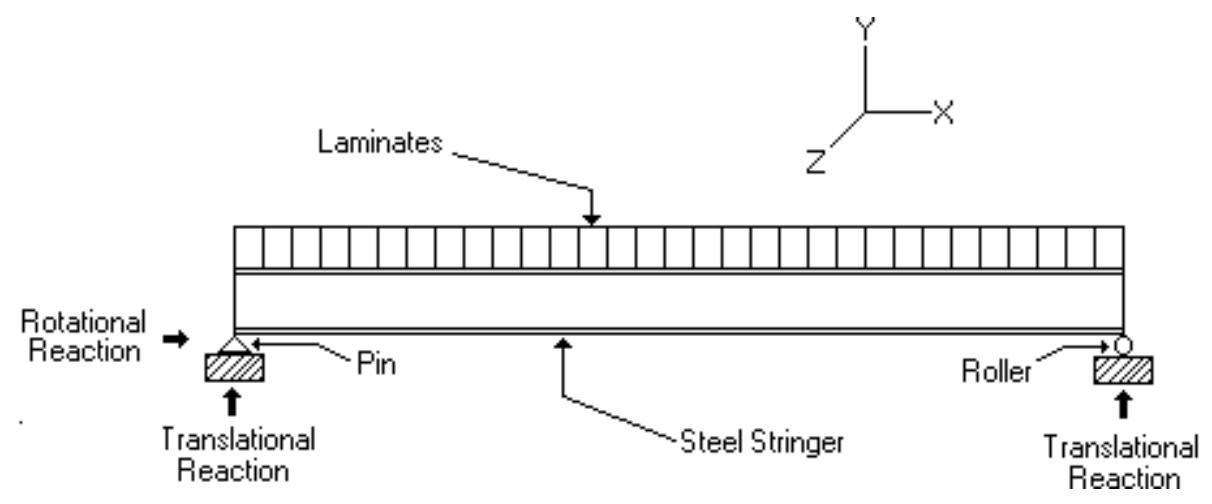

Figure 4.1.1: Schematic Display of Resulting Forces

This type of roller set up is representative of typical bridge applications. Concepts behind this procedure are very rudimentary, but vary effective. The roller allows the superstructure to move uninhibitedly in a horizontal direction, allowing for adjustments in the bridge due to incessant thermal loadings. In other words, temperature fluctuations force bridges to continually expand and contract. The inability to accommodate for this pattern of dimensional changes inevitably creates a series of residual stresses. The stresses will steadily increase and eventually lead to the formation of minute cracking. The cracks partially relieve the induced stress, but only temporarily because the reoccurrence of similar stresses eventually force these diminutive cracks to propagate. This pattern will continue to failure. The roller accounts for this problem, and therefore eliminates this additional stress. The pin on the other support prevents the entire bridge 
from simply rolling out of position during incidences of expansion or contraction, or even under horizontal forces, induced by acceleration or braking of vehicles.

Once the supports were properly aligned, the steel stringers were simply situated directly on top of the supports. When this task was completed, individual laminate panels were then appropriately positioned into place. This process began by laying the first panel on the far end of the stringer and working back towards the stack. Immediately after an individual panel was placed, two separate stressing rods were placed through allotted holes for proper alignment verification. Slight overhang in the rods served as guide pins in the positioning of preceding panels. With the completion of this phase, the next task was to secure the timber deck to the steel stringers. The assistance of a large drill and several drill bits (varying in size) were required for the initiation of this phase. Holes must be drilled through the timber deck accommodating deck bolts that must pass down through to the substructure. Drilling was initiated with a smaller drill bit, followed with ascending increments of drill bits, until the necessary size was attained. For the two bridge models in this experiment, six evenly spaced holes were drilled on opposing sides of the deck. This amount will vary accordingly to the physical dimensions of individual decks. Once the deck bolts were placed, WVU connectors were then positioned on the shaft of the bolt until one end rested on the top flange of the steel stringer and the other end brushed up against the underneath section of the timber deck. In the models tested in this experiment, springs were then placed under the connectors prior to the nut that fastens everything together. This setup is not typical compared to previous projects, but went unnoticed until the completion of the literature review. A plan view of a schematic 
representing both models displays the general assignment of the connection detail in Figure 4.1.2.

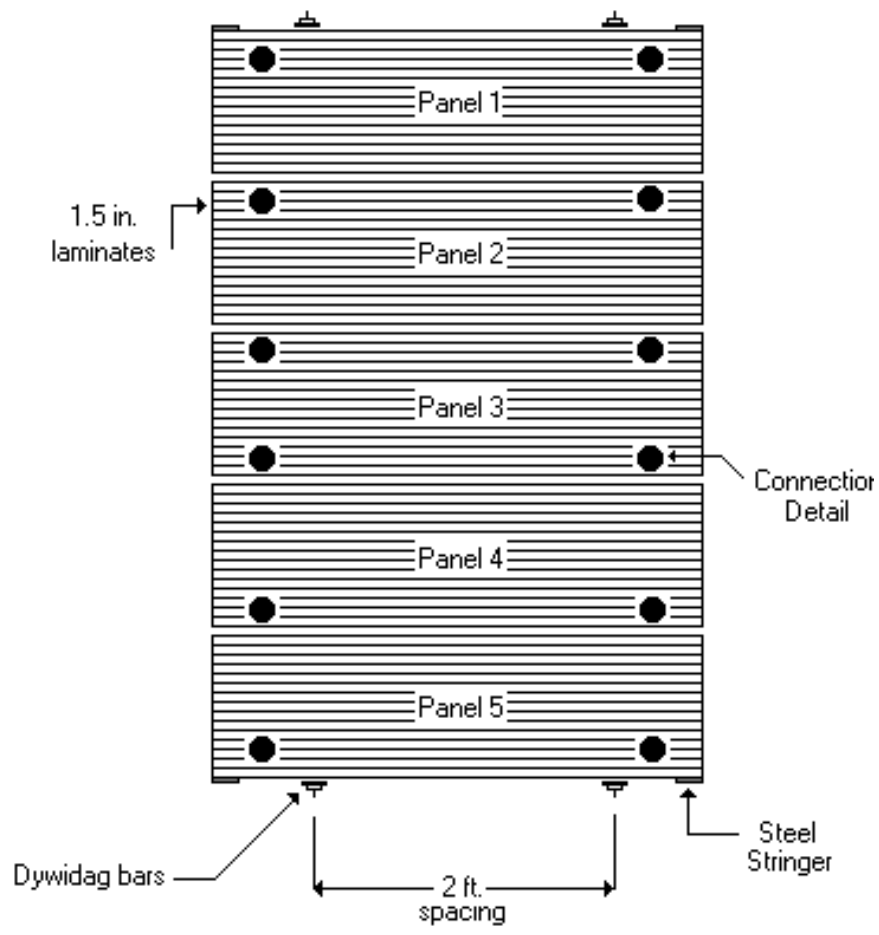

Figure 4.1.2: Plan View of Connection Detail

\subsection{Application of Prestress Force}

With the assembly of the model completed, the next phase of the project was to apply an initial stress to the Dywidag bars. Initial (jacking) forces applied to the deck cause some contractions between individual laminates; therefore the connection detail was allowed to remain loose until this procedure was performed. Jacking forces were applied a total of three times allowing for the stabilization of initial prestressing constraints. This method was applied to both models, but actual prestress values varied 
for particular decks due to differences in respective depths. Table 4.2.1 demonstrates the procedure for calculating the force required to induce an initial stress of 100 pound per square inch (psi). This value was predetermined before construction of the model began, and actual stress levels can vary for other decks accordingly.

Table 4.2.1: Sample Calculation of Initial Force

\begin{tabular}{|c|c|}
\hline \multicolumn{2}{|c|}{ FORCE = STRESS x AREA } \\
\hline Model I & Model II \\
\hline Force $=100$ psi x (24 in x 7.5 in) & Force $=100$ psi x (24 in x 6.0 in $)$ \\
\hline Force $=18,000$ lbs x (1000 lbs / 1 kip) & Force $=14,000$ lbs x (1000 lbs / 1 kip) \\
\hline Force $=18.0$ kips & Force $=14.4$ kips \\
\hline
\end{tabular}

* The value of $24 \mathrm{in}$. used in this formula corresponds to the nominal dimension existing between the actual Dywidag bars.

\subsection{Instrumentation}

Instrumentation required for performance monitoring of the two models was standard for this type of setup. Proper instrument selection chosen for this experimental project was based on typical practices performed by previous researchers at the Constructed Facilities Center. A list and brief description of the basic instrumentation associated with this project is listed in the preceding sections.

\subsubsection{Strain Gages}

Strain gages were installed at certain key locations to periodically monitor the performance of the two bridges. Strain gages are electrically resistive transducers that send out certain signals when under any type of duress. Placement of the gages was 
identical for both test models. A total of five strain gages were incorporated for each model; three were placed on the timber deck, while the other two went on the steel stringers.

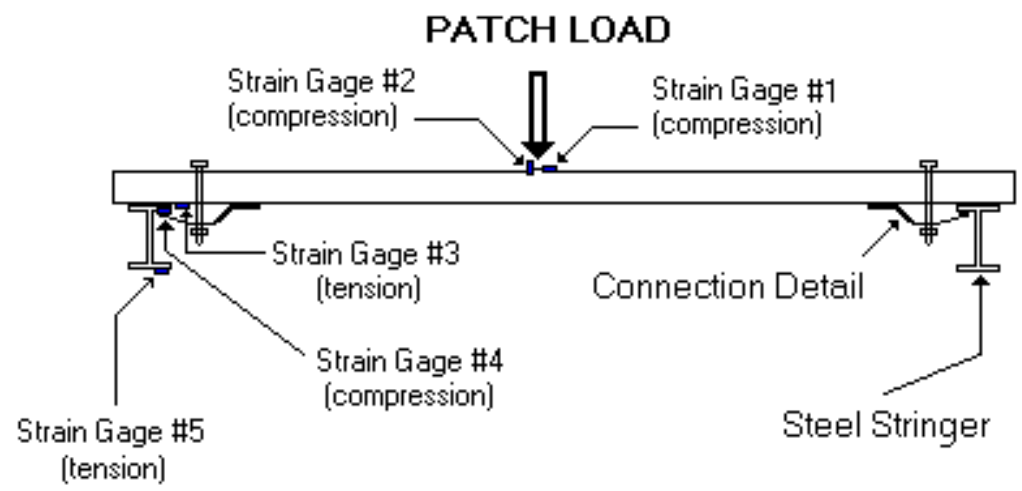

Figure 4.3.1: Plan View of Strain Gage Location

Strain gage \#1 was positioned to monitor the compressive strain induced on the timber deck in the transverse direction, while strain gage \#2 monitored the compressive strain in the longitudinal direction. These two gages were placed perpendicular to each other on the top surface of the deck. Positioning of the gages was geometrically centered according to the longitudinal and transverse dimensions of the deck, accounting for the maximum possible strain assertion. Strain gage \#3 was placed on the bottom surface of the decking to monitor the respective tensile force. This gage was also centered accordingly in the longitudinal direction, however transverse positioning was in close proximity to the steel stringer. Strain gage \#4 was placed on the underneath side of the top flange directly adjacent to strain gage \#3. Gage \#4 measured the compressive force exerted on the steel stringer. Gages \#3 and \#4 were strategically positioned in the same region to account for composite action contributions established between the timber deck 
and steel stringer. Strain gage \#5 was placed on the under side of the bottom flange of the steel stringer. Gage \#5 was placed parallel to gage \#4 to monitor the tensile force exertion transferred over to the supports. Figure 4.3.1 displays a schematic detailing the relevant positioning of respective strain gage assemblies.

\subsubsection{Dial Indicators}

Dial indicators were installed at three separate locations for additional monitoring of the two bridges. Setup of this type of instrumentation was also identical for both test models. Dial indicators are used to measure the deflection exhibited by the specimen under different loading conditions. For the indicators associated with this experiment, a reading of 1,000 units was equivalent to a deflection of 1 inch. The first dial indicator was positioned on the top surface of the timber deck. Indicator \#1 was placed adjacent to an external connector. The corresponding corner to the external connector was of no consequence due to symmetrical loading performance of each model, however readings associated with indicator \#1 reflected any rise or lifting/peeling action at the extreme edges of the models. Dial indicator \#2 was positioned underneath the model in the exact center of the deck. Theoretical principles dictate that this region accounts for the maximum local deflection values associated with this type of arrangement. Indicator \#3 was set underneath the stringer near strain gage \#5. The methodology associated with this setup was to observe the maximum global deflection generated by the overall system acting as a single unit.

It should be noted that the other stringer was not monitored with either type of gage because of the symmetrical conditions existing in the structure. All further 
mentioning of forces regarding the stringers are assumed equal in every aspect. Figure 4.3.2 shows the plan view regarding locations of the strain gages and dial indicators for the two test models.

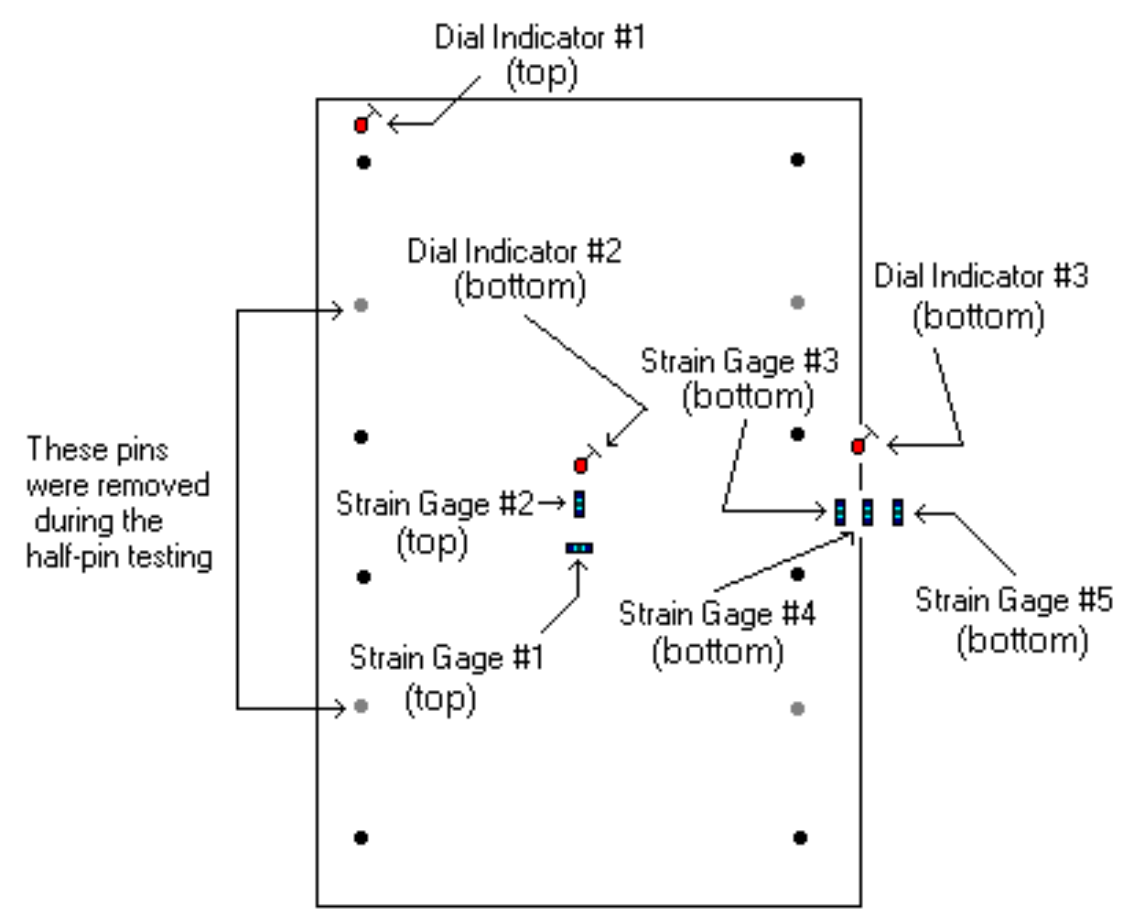

Figure 4.3.2: Plan View of Strain and Dial Gage Locations

\subsubsection{Strain Indicator}

A strain indicator is required to monitor the five separate strain gages that were placed on the two test models. Applied loadings cause a resistance exerted on the gages. This occurrence is essentially reflected with a corresponding variable on the strain indicator. Values are then systematically recorded for further comparisons between individual test models. Strain indicators used in this procedure were model P-3500. Model P-3500 is a digital indicator manufactured by Micro Measurements. 


\subsubsection{Switch and Balance Unit}

A switch and balance unit was also utilized in association with the strain indicator. This piece of equipment allows for continual monitoring of up to ten strain gages concurrently. A switch and balance unit works in tandem with the digital strain indicator, conveniently monitoring the five strain gages utilized in this experiment.

\subsubsection{MTS Load Cell}

The bridge models were fatigue tested in order to evaluate the structural integrity over a simulated life cycle. At certain intervals, the fatigue testing was paused to conduct separate static tests. These tests were needed for additional performance monitoring of the bridges. The MTS load cell was used to measure the applied loads during both static and fatigue testing procedures. The MTS load cell can institute prescribed loading circumstances up to a maximum value of $55 \mathrm{kips}$, and this piece of equipment was manufactured and calibrated by MTS Systems Corporation.

\subsubsection{Hydraulic Actuator for Fatigue Load Application}

A hydraulic actuator was employed to create all critical loading conditions applied on the two experimental bridges. The actuator created a sinusoidal cyclic series operating at 1.2 Hertz, while randomly generating continuous loading situations ranging between 2 and 26 kips. The actuator used in this experiment was also manufactured and calibrated by MTS Systems Corporation. 


\subsection{Load Setup}

A patch loading setup was incorporated for this experiment. The geometry for patch loads are typically rectangular in shape to simulate loads procured from truck tires. An elastomeric bearing pad and steel plate were acquired to perform this type of simulation. The bearing pad is made out of rubber and used in this project for a damping effect of the steel plate. The pad is first placed on the deck where the external loading is to be applied. This is followed by the placement of a steel plate that is situated directly over the pad. This technique inhibits damages to the surface of the decking caused by continuous impacts of the steel plate. Patch loads were placed directly in the geometric center for both test models. Figure 4.4.1 shows the correlation between the patch load, the steel stringers, and the connection detail. Figure 4.4.2 displays the location of the patch load pertaining to the locality of applied strain gages.

\section{PATCH LOAD}

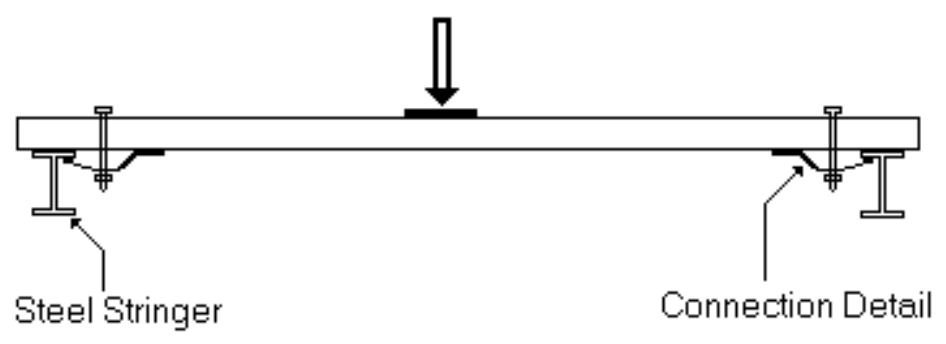

Figure 4.4.1: Profile View of Location for Patch Load 


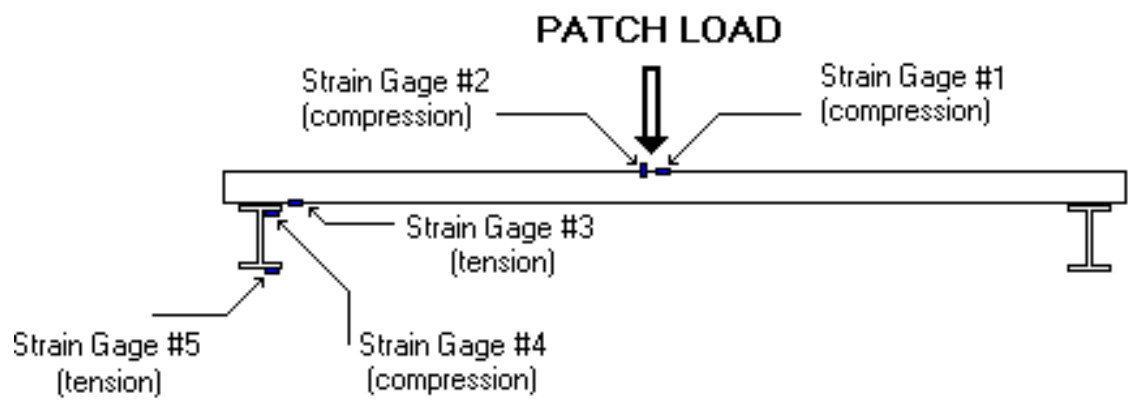

Figure 4.4.2: Profile View of Patch Load with Respective Strain Gage Location

\subsection{Testing}

This research experiment focused on two different types of test methods. A fatigue test was performed on both of the models, with two separate forms of static tests conducted at predetermined intervals of fatigue cycles.

\subsubsection{Fatigue Testing}

Performance of a fatigue test involves the application of a cyclic loading onto the selected material during an allotted time frame. The purpose of this test is to determine a threshold level of stress range induced by truckloads for stressed timber decks as a function of timber deck depth and stringer spacing. Through this type of test procedure, the limiting stress can be calculated. The limiting stress is typically referred to as the endurance or fatigue limit of the material.

An MTS hydraulic actuator was incorporated to apply the fatigue loading on both test subjects associated with this experiment. The cyclic loading for this situation was sinusoidal in nature, and it varied in intensity from 2 to 26 kip range. The frequency of cycle assertion on both models was 1.2 Hertz. which corresponds to 1.2 impact cycles per 
second. The first model was subjected to a total of $1,000,000$ cycles and the second model received 2,000,000 cycles. (Occurrences regarding the differences in cyclic proportions will be detailed in the experimental results associated with Chapter 5.) The fatigue testing for both models was temporarily paused at intervals of every 250,000 cycles to perform two independent sets of static tests.

\subsubsection{Static Testing}

A static test is generally defined as the application of a motionless load onto a material in order to evaluate specific structural characteristics. This type of testing is typically performed to establish tolerance levels of stress associated with certain loading conditions. For the two models corresponding to this experiment, a typical three-point bending test was performed. A schematic diagram assessing specifics relative to threepoint bending tests is displayed in Figure 4.5.2.

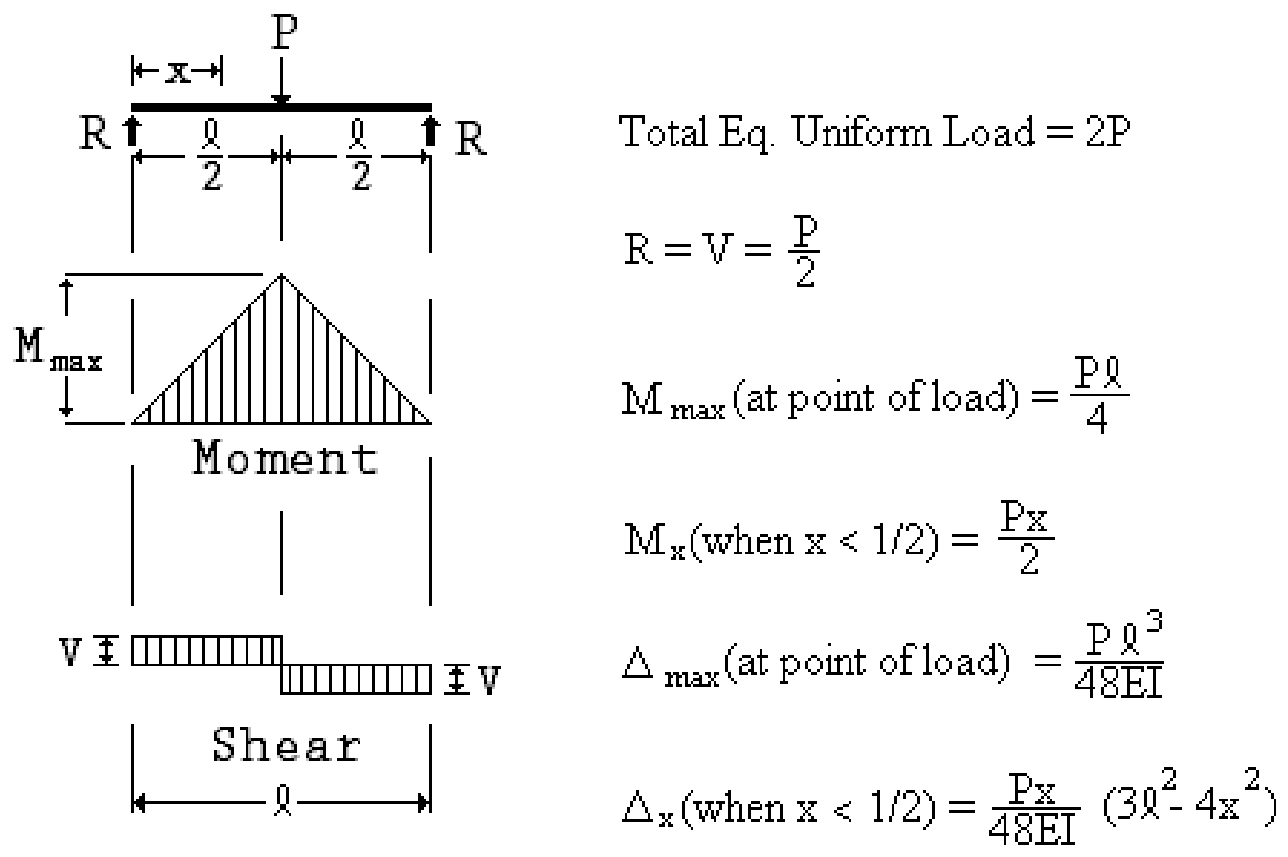

Figure 4.5.2: Beam Diagram and Equations for Three-Point Bending Test 


\subsubsection{Half-Pin Test}

At intervals of every 250,000 cycles, two separate static tests were performed to indicate the structural integrity of both models following periodical conclusions of cyclic loading. The first static test performed was denoted as the half-pin test. For this procedure, alternating connectors were removed before testing was initiated. Figure 4.3.2 is a plan view of the timber decking detailing the alignment and connector removal process associated with this type of simulation. The purpose of this experiment was to adequately monitor the performance of the deck in relation to the actual spacing of detail assembly. The half-pin static test had a varying load ranging from 0 to 10 kips, and recordings were performed at 0.5 kip intervals.

\subsubsection{Full-Pin Test}

At the conclusion of the half-pin test, the connectors were re-inserted and a subsequent full-pin test was conducted on the model. The loading range for this type of test was between 0 and 20 kips, with 1 kip interval recordings. With the completion of both test procedures, the fatigue test was placed back on-line for an additional series of 250,000 cycles. A complete graphical representation of all static test outcomes is displayed on pages 101 to 159 in the appendix. 


\section{Chapter 5}

\section{Experimental Results}

\subsection{Introduction}

Experimental testing is conducted to gain a better understanding for the performance of structural materials. New structures are generally constructed with a combination of materials (e.g.; steel stringers and timber deck) to increase efficiency while driving down perspective costs. The combination of materials working in conjunction with each other is known as compositeness, and it is essential to the overall performance of a structure. For this experiment, the composite action between the timber deck and the steel stringers was closely monitored with a series of strain gages and dial indicators.

\subsection{Composite Action}

The composite action between the timber deck and the steel stringers was monitored primarily with strain gages \#3 and \#4. These two gages were placed adjacent to each other with gage \#3 on the timber deck and gage \#4 on the steel stringer. This area was closely monitored because this is where the induced stress on the timber deck is transferred over to the steel stringer. If the stress reading from gage \#4 is equal to the reading from gage $\# 3$, then the composite action is considered perfect. This reflects that 
the connectors are working perfectly, and there are no subsequent losses associated with the combination of the two distinctively different types of materials.

Strain gage and dial indicator readings were taken during the static testing portion of the experiment. Static tests were conducted at intervals of 250,000 fatigue cycles. The first static test performed was the half-pin test. As mentioned in Section 4.2.5.1, this type of test required the removal of specific connector assemblies. When this test was concluded, the connectors were re-positioned and a full-pin static test was performed on the specimen as detailed in section 4.2.5.2. This series of testing was conducted to draw comparisons between the performances of the two decks in relation to the spacing of the connections.

\subsection{Load Distribution}

The load distribution for individual stringers can be calculated directly from deflection recordings. In many instances, the contribution of individual stringers may not be proportional. This effect can be detrimental in the overall performance of the bridge. To determine the percentage of load contributions of each stringer, respective deflections associated with that stringer must be divided by the summation of all incorporated stringer deflections. These calculations were not performed for the two models used in this experiment due to the concentrically positioned patch loading in combination with pre-existing symmetrical loading conditions. 


\subsection{Performance Results}

As previously mentioned, two separate static tests were performed on the models periodically to determine the structural integrity under a series of loading conditions. The first static test was referred to as the half-pin test. This method involved removing two connectors from each side of the deck before the loading took place. Strain and deflection measurements were recorded on the half-pin test every 0.5 kips up to a maximum value of 10 kips. At the conclusion of this test, the load was removed and the connectors were replaced for the second type of static test. The second static test was documented as the full-pin test because normal connection detail was implemented for this series of experimental testing. During this procedure, strain and deflection measurements were recorded at 1 kip intervals up to a maximum value of 20 kips. To exemplify the results of the testing, several essential tables and graphs have been incorporated in this report with additional illustrative information assembled in the appendix.

\subsubsection{Model I Performance Results}

One million cyclic loadings ranging between the interval of 2 kips and 26 kips were placed on Model I. A detrimental crushing effect on the middle laminate, located directly under the patch load, was noticeable at the completion of the fatigue testing. The cause of this failure was presumptuously caused by a shift in the testing apparatus. Once the shift occurred, the load came down on the deck at a continuous angled pattern for the duration of the resulting test.

As described with great detail in Section 5.3.2, two million cycles were placed on the second model in an attempt to distinguish whether the test equipment caused the 
failure rather than the actual model. Model II had the same length and width, but a smaller depth by 1.5 inches. At the conclusion of the two million fatigue cycles, no visible damage was detected on the top surface of the second deck. By placing twice the loading cycles required on a smaller deck, supports the assumption that the failure exhibited by Model I was caused by an error in the test setup instead of any inherent defects in the timber deck.

The most essential series of data collection came from recordings of strain gages $\# 3$ and \#4. This is the area where the composite effectiveness is displayed. Strain gage \#3 was placed on the bottom of the timber deck, and strain gage \#4 was placed on the top flange of the steel stringer. Due to geometric constraints, the two gages were not placed directly over one another, but were instead placed as close to one another as possible. This action will contribute to a small error that will not allow for perfect compositeness to be attainable. Actual error calculations were not performed for this research project and consequently are not accounted for in respective data results. Theoretically, perfect composite action would be reflected by equivalent strain readings from gages \#3 and \#4. This would entail that all the induced strain on the timber deck was perfectly translated over to the steel stringer. This is the ideal condition because the load merely passes through the deck leaving no residual strains. Table 5.3.1.1 displays the recordings for strain gage \#3 and \#4 for the half-pin static testing of Model I. 
Table 5.3.1.1: Microstrain Comparison for Gage \#3 and \#4 of Bridge \#1 (Half Pin) for 10 kip Center Loading

\begin{tabular}{|c|c|c|c|c|}
\hline $\begin{array}{c}\text { Completed } \\
\text { Fatigue Cycles }\end{array}$ & $\begin{array}{c}\text { Strain Gage \#3 } \\
\text { Recording }\end{array}$ & $\begin{array}{c}\text { Strain Gage \#4 } \\
\text { Recording }\end{array}$ & $\begin{array}{c}\text { Difference in } \\
\text { Absolute Strains }\end{array}$ & $\begin{array}{c}\text { Percent } \\
\text { Difference }\end{array}$ \\
\hline 0 & 251 & 189 & 62 & 24.7 \\
\hline 250,000 & 259 & 183 & 76 & 29.3 \\
\hline 500,000 & 237 & 225 & 12 & 5.1 \\
\hline 750,000 & 242 & 205 & 37 & 15.3 \\
\hline $1,000,000$ & 291 & 212 & 79 & 27.1 \\
\hline
\end{tabular}

Results depicted in the Percent Difference column reveal values in the same general region for compositeness. The only seemingly uncharacteristic value was displayed at the 500,000 count-fatigue completion testing, which resulted in a value of 5.1 percent difference. This figure could be representative of the steel stringers digging into the timber deck. After 500,000 cycles, the timber deck may have started crushing, therefore displacing a significant portion of composite action. Once the deck settled, the stringer was able to dig into the wood fibers and regain this compositeness. This is only an assumption, and due to the singularity of this occurrence, the relative value is typically discarded from calculations. Inclusion of this value led to an average calculation of 20.3 percent difference between gage \#3 and \#4. This value increased to 24.1 when the 5.1 percent difference figure was discarded. Figures 5.3.1.1 and 5.3.1.2 further illustrate relative strain performance from all five separate gage assertions. Figure 5.3.1.1 is a graph relative to the first static half-pin test conducted on Model I. Figure 5.3.1.2 displays the results gathered from the last static half-pin test of the respective model. The graphs detail the load in comparison to the individual strain gage recordings.

Table 5.3.1.2 displays the recordings for strain gages \#4 and \#5 for the half-pin static testing of Model I. Results from this comparison are not as critical as the prior 
composite action results, but do provide some additional collaborating evidence. In this testing procedure, strain gage \#4 was positioned on the top flange and strain gage \#5 was placed on the bottom flange of the corresponding steel stringer. The gages were mounted in a parallel manner and opposing data outputs were continuously recorded.

Table 5.3.1.2: Microstrain Comparison for Gage \#4 and \#5 of Bridge \#1 (Half Pin) for 10 kip Center Loading

\begin{tabular}{|c|c|c|c|c|}
\hline $\begin{array}{c}\text { Completed } \\
\text { Fatigue Cycles }\end{array}$ & $\begin{array}{c}\text { Strain Gage \#4 } \\
\text { Recording }\end{array}$ & $\begin{array}{c}\text { Strain Gage \#5 } \\
\text { Recording }\end{array}$ & $\begin{array}{c}\text { Difference in } \\
\text { Absolute Strains }\end{array}$ & $\begin{array}{c}\text { Percent } \\
\text { Difference }\end{array}$ \\
\hline 0 & 189 & 125 & 64 & 33.9 \\
\hline 250,000 & 183 & 94 & 89 & 48.6 \\
\hline 500,000 & 225 & 129 & 96 & 42.7 \\
\hline 750,000 & 205 & 149 & 56 & 27.3 \\
\hline $1,000,000$ & 212 & 271 & 59 & 27.8 \\
\hline
\end{tabular}

Percent difference values of strain in this comparison reflect the transfer action transcribed from the top flange of the steel stringer to the preceding bottom flange of the subsequent stringer. Results yielding from this comparison were considerably different from the preceding timber deck to steel stringer values displayed in Table 5.3.1.1. Average values from this category were 36.1 , as opposed to either incidence of 20.3 or 24.1, respectively. Lack of strain transfer in the steel stringer is believed to be contributive to certain geometric design inefficiencies.

Figure 5.3.1.1 is a graphical representation of the initial half-pin static test conducted on Model I. Each of the five lines displayed in the graph represent subsequent strain recordings for respective locations as detailed in Section 4.3 of this report. 


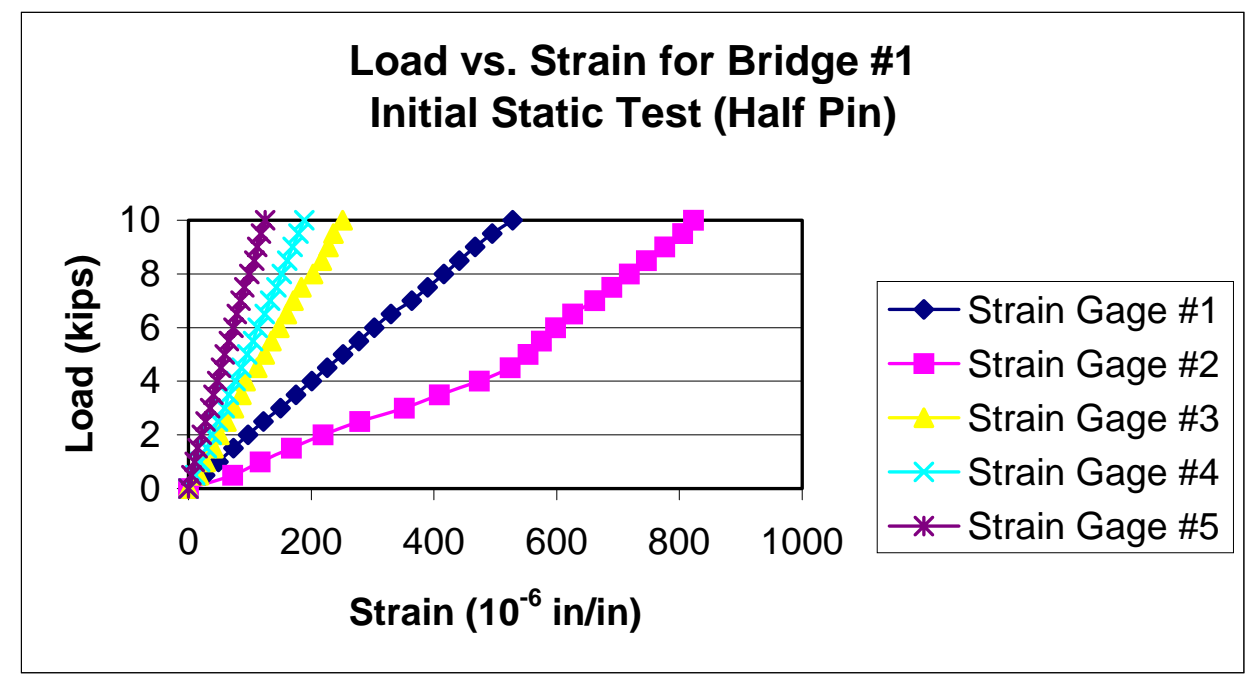

Figure 5.3.1.1: Initial Static Test (Half Pin) Graph for Bridge \#1

Figure 5.3.1.2 is a graph of the final half-pin static test performed on Model I. An entire compilation of graphs for both of the models is included in the appendix, however the initial and final graphs were embodied in this section for comparison of the respective models performance transgression.

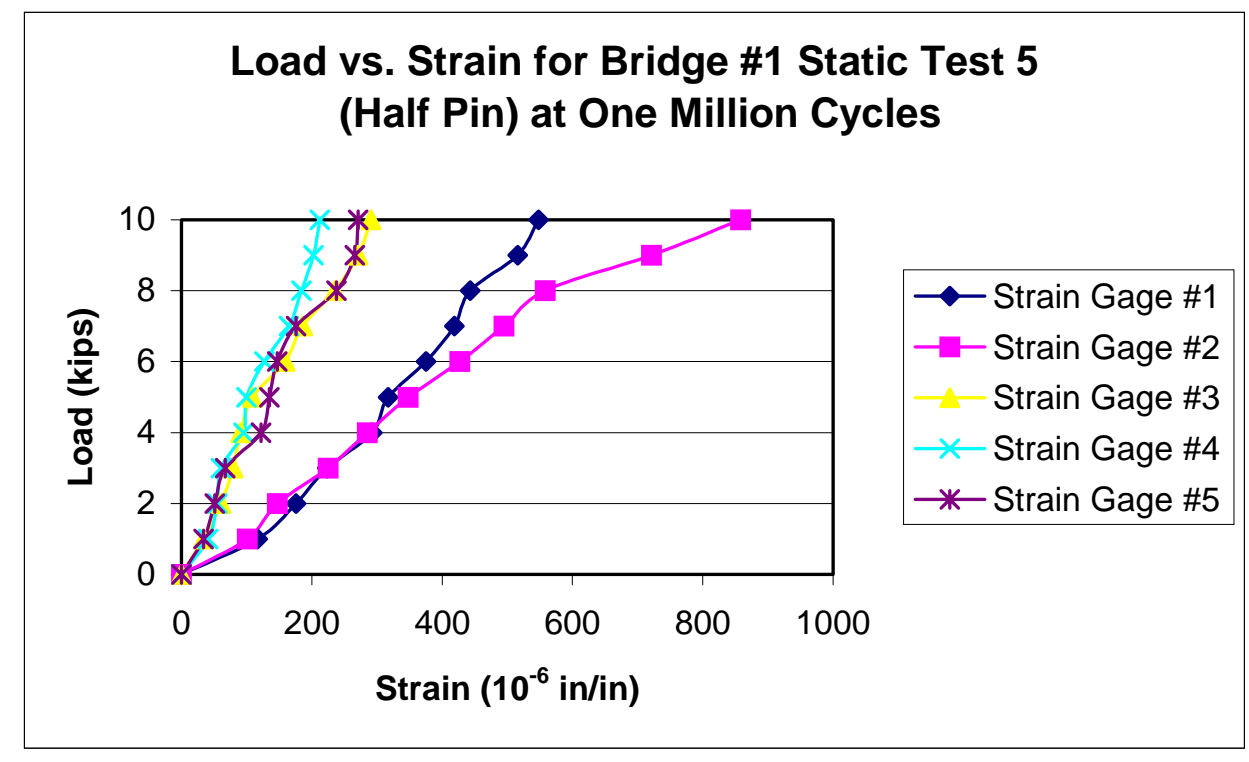

Figure 5.3.1.2: Static Test \#5 (Half Pin) Graph for Bridge \#1 
Table 5.3.1.3 displays the recordings of deflection measurements for the half-pin static testing of Model I. Proper monitoring of the deflection readings for salient regions is essential for performing accurate stiffness assessments.

Table 5.3.1.3: Deflection Comparison of Bridge \#1 (Half Pin) for 10 kip Centered Loading

\begin{tabular}{|c|c|c|c|}
\hline $\begin{array}{c}\text { Completed Fatigue } \\
\text { Cycles }\end{array}$ & $\begin{array}{c}\text { Dial Indicator \#1 } \\
\left(\mathbf{1 0}^{-3} \text { in }\right)\end{array}$ & $\begin{array}{c}\text { Dial Indicator \#2 } \\
\left(\mathbf{1 0}^{-\mathbf{3}} \mathbf{i n}\right)\end{array}$ & $\begin{array}{c}\text { Dial Indicator \#3 } \\
\left(\mathbf{1 0}^{-3} \text { in }\right)\end{array}$ \\
\hline 0 & 32 & 262 & 95 \\
\hline 250,000 & 29 & 208 & 93 \\
\hline 500,000 & 29 & 223 & 105 \\
\hline 750,000 & 25 & 214 & 107 \\
\hline $1,000,000$ & 34 & 244 & 108 \\
\hline
\end{tabular}

As indicated in Table 5.3.1.3, no exceptional changes in deflection were apparent during the allotted time frame of the fatigue testing.

With this in consideration, dial indicator \#1 was positioned at one corner of the deck to monitor the lifting/peeling affects created from geometrically centered loadings. Actual recordings from this gage were initially projected as negative values due to the opposing direction of typical deflections. Results were transformed into positive figures merely for illustrative purposes. Dial indicator \#2 was placed directly under the timber deck in the geometric center congruent with the location of the patch loading. Dial indicator \#3 was positioned mid-span of steel stringer parallel to the longitudinal center of the timber decking. A schematic of all strain and deflection monitoring devices was given in Section 4.3 of this report, and referral to this section should be made for any additional information.

Deflection results from Table 5.3.1.3 reveal consistency; further supplying evidence that the failure experienced by this model was primarily caused by a mechanical 
delinquency. If this were not the case, excessive loading during the fatigue testing would have caused the crushing condition experienced by the deck. This phenomenon would have been fully portrayed in the deflection comparison values of dial indicator \#2 in Table 5.3.1.3.

Figures 5.3.1.3 and 5.3.1.4 are the subsequent graphs associated with deflection values of Model I. Similarly to graphs 5.3.1.1 and 5.3.1.2; these graphs provide the initial and final results of the half-pin static testing for comparison purposes. An entire insertion of graphical interpretation of deflection recordings for this model is included in the appendix of this report.

As mentioned previously from results pertaining to Table 5.3.1.3, the deflection results are congruent over the life cycle of this test model. In fact, close examination of the two graphs reveals almost identical patterns. This trend reflects positively to the durability issues relative to the specific model.

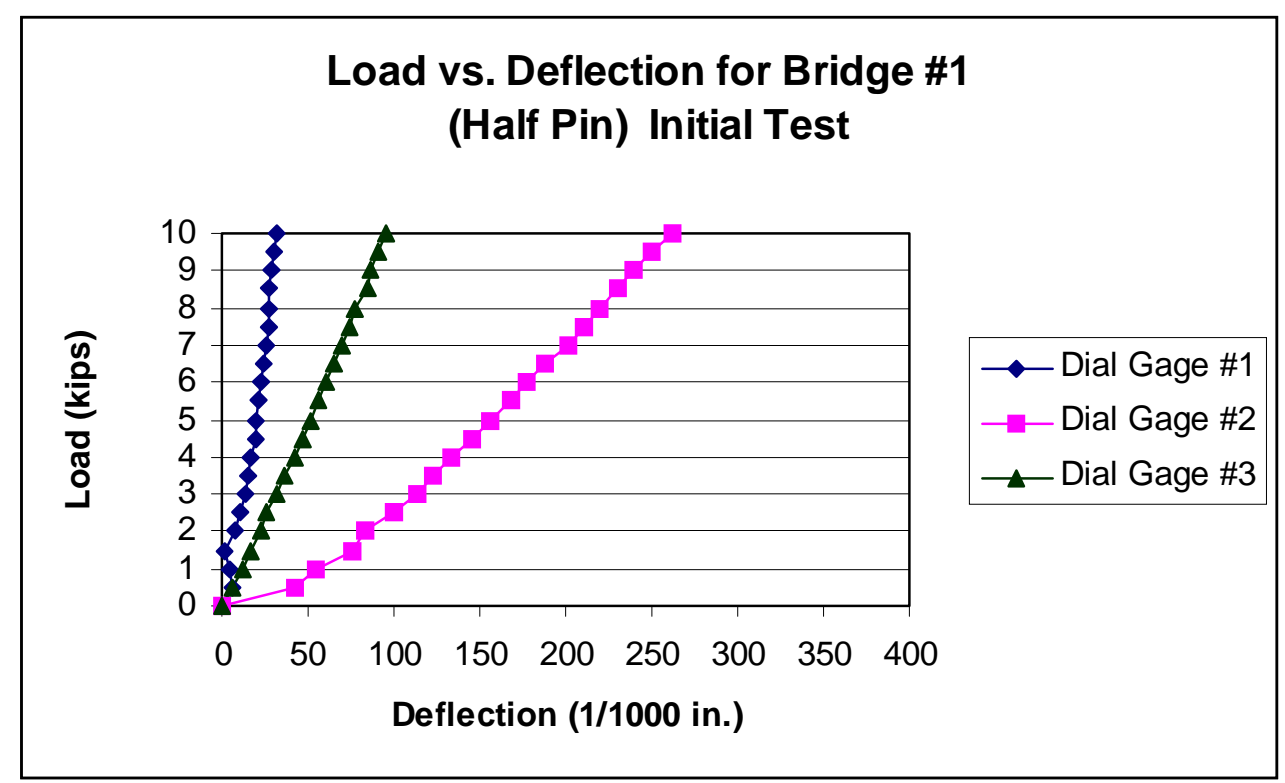

Figure 5.3.1.3: Initial Deflection (Half Pin) Graph for Bridge \#1 


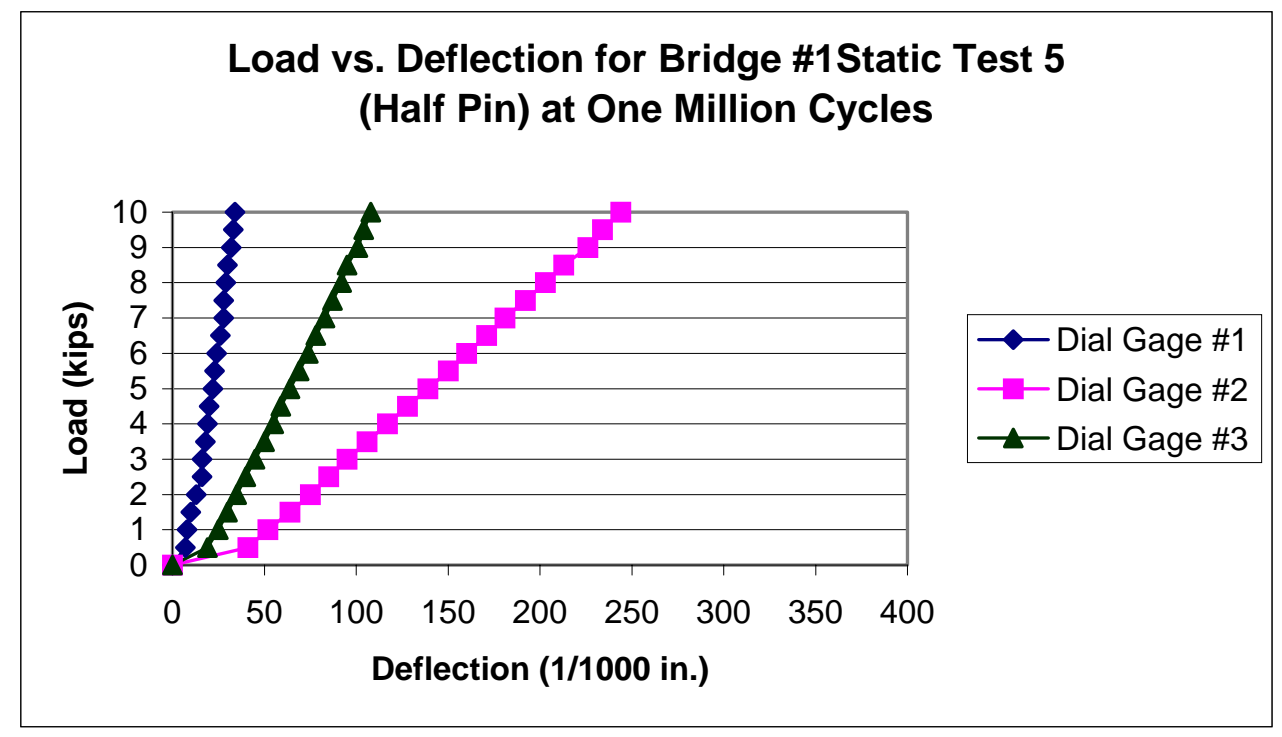

Figure 5.3.1.4: Deflection Test \#5 (Half Pin) Graph for Bridge \#1

Immediately after closure of the individual half-pin tests, the models were transformed back into the initial loading stages. This involved the complete removal of the loading, and repositioning of previously removed connection assemblies. The model was then prepared for the second stage of static testing. This procedure was denominated as full-pin static testing, but this series was similar to the preceding experiments. For this situation, interval recordings of 1 kip were performed on the specimen up to a maximum value of 20 kips. The tables and figures incorporated in this section of the report are identical to the ones associated with the half-pin static testing of Model I, except for the increase in applied loadings.

Table 5.3.1.4 depicts the strain comparison for gages \#3 and \#4 for the full-pin static testing of Model I. Similar to the half-pin test; the only seemingly uncharacteristic value was displayed at the 500,000 count-fatigue completion testing. Conversely from the half-pin results however, the unequivocally higher value associated with this category was noted. A value resulting in 24.9 percent difference was obtained for this section, 
which was almost three times greater than the next descending figure. This non-typical occurrence reflects proportionally to the half-pin testing for the same model, however no explanation can be provided at this time for the opposing order of values obtained from both tests.

Table 5.3.1.4: Microstrain Comparison for Gage \#3 and \#4 of Bridge \#1 (Full Pin) for 20 kip Center Loading

\begin{tabular}{|c|c|c|c|c|}
\hline $\begin{array}{c}\text { Completed } \\
\text { Fatigue Cycles }\end{array}$ & $\begin{array}{c}\text { Strain Gage \#3 } \\
\text { Recording }\end{array}$ & $\begin{array}{c}\text { Strain Gage \#4 } \\
\text { Recording }\end{array}$ & $\begin{array}{c}\text { Difference in } \\
\text { Absolute Strains }\end{array}$ & $\begin{array}{c}\text { Percent } \\
\text { Difference }\end{array}$ \\
\hline 0 & 332 & 356 & 24 & 7.2 \\
\hline 250,000 & 451 & 411 & 40 & 8.9 \\
\hline 500,000 & 382 & 477 & 95 & 24.9 \\
\hline 750,000 & 386 & 366 & 20 & 5.2 \\
\hline $1,000,000$ & 373 & 355 & 18 & 4.8 \\
\hline
\end{tabular}

Comparisons can also be drawn regarding values extruded from Tables 5.3.1.1

and 5.3.1.4. Values from respective tables accentuate strain accumulations in response to connector spacing dimensions. An average percent difference of 24.1 was tabulated for the half-pin and 6.5 for the full-pin models. This comparison produces an irrefutable conclusion to connection alignment procedure to maximize composite action responses between timber deck and supporting steel stringers. To be more precise, significantly greater composite action distribution is experienced when additional connectors are installed to reduce the effective spacing.

One final observation made from Table 5.3.1.4, is that the composite action between the timber deck and steel stringer appears to consecutively improve with the number of cycles, after the 500,000 count. This may be a resultant of the steel stringers digging into the timber deck. As the steel stringers embed into the wood fibers, the composite action lost from the initial crushing of the timber is reinserted. 
Table 5.3.1.5 is the compilation of recordings for gages \#4 and \#5 in correlation with full-pin testing of Model I. The average value for the percent difference in this category was 38.6. Values obtained from this procedure were once again considerably different from the composite values between the deck and stringers.

Table 5.3.1.5: Microstrain Comparison for Gage \#4 and \#5 of Bridge \#1 (Full Pin) for 20 kip Center Loading

\begin{tabular}{|c|c|c|c|c|}
\hline $\begin{array}{c}\text { Completed } \\
\text { Fatigue Cycles }\end{array}$ & $\begin{array}{c}\text { Strain Gage \#4 } \\
\text { Recording }\end{array}$ & $\begin{array}{c}\text { Strain Gage \#5 } \\
\text { Recording }\end{array}$ & $\begin{array}{c}\text { Difference in } \\
\text { Absolute Strains }\end{array}$ & $\begin{array}{c}\text { Percent } \\
\text { Difference }\end{array}$ \\
\hline 0 & 356 & 241 & 115 & 32.3 \\
\hline 250,000 & 411 & 235 & 176 & 42.8 \\
\hline 500,000 & 477 & 281 & 196 & 41.1 \\
\hline 750,000 & 366 & 235 & 131 & 35.8 \\
\hline $1,000,000$ & 355 & 209 & 146 & 41.1 \\
\hline
\end{tabular}

Figures 5.3.1.5 and 5.3.1.6 are graphical comparisons of the load versus strain in the initial and final stages of the full-pin testing conducted on Model I, respectively.

Statistics from these two graphs reflect ample evidence of composite action reduction, i.e. transfer of force resistance (loss) from the deck to the supporting stringers.

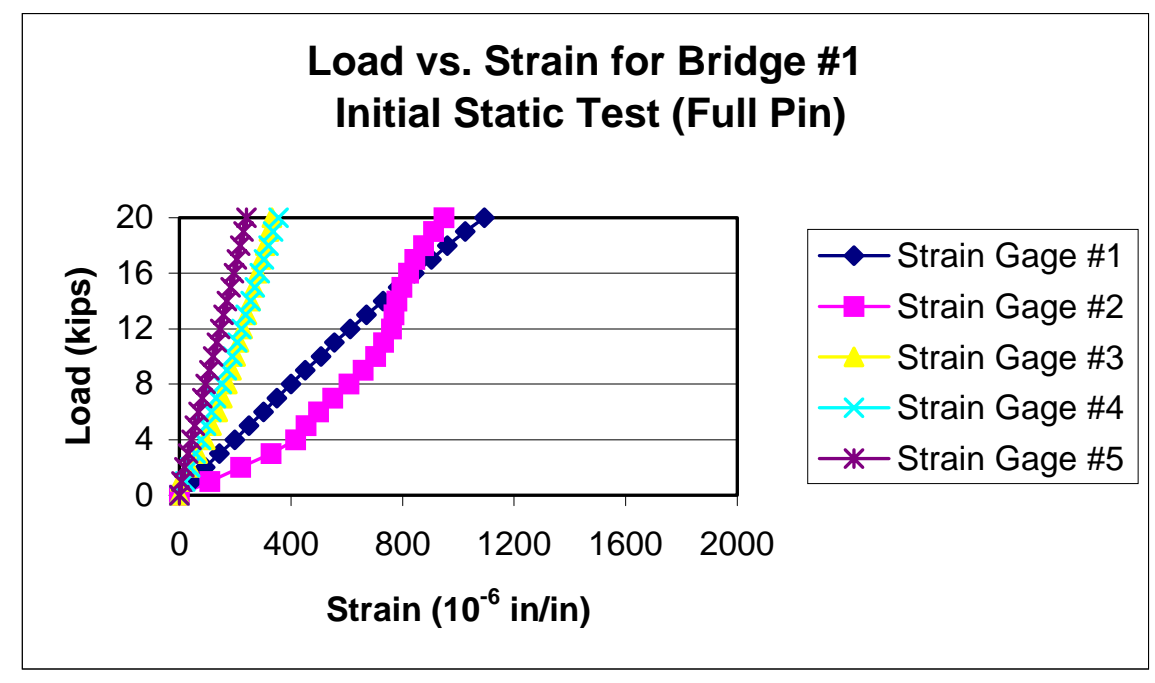

Figure 5.3.1.5: Initial Static Test (Full Pin) Graph for Bridge \#1 


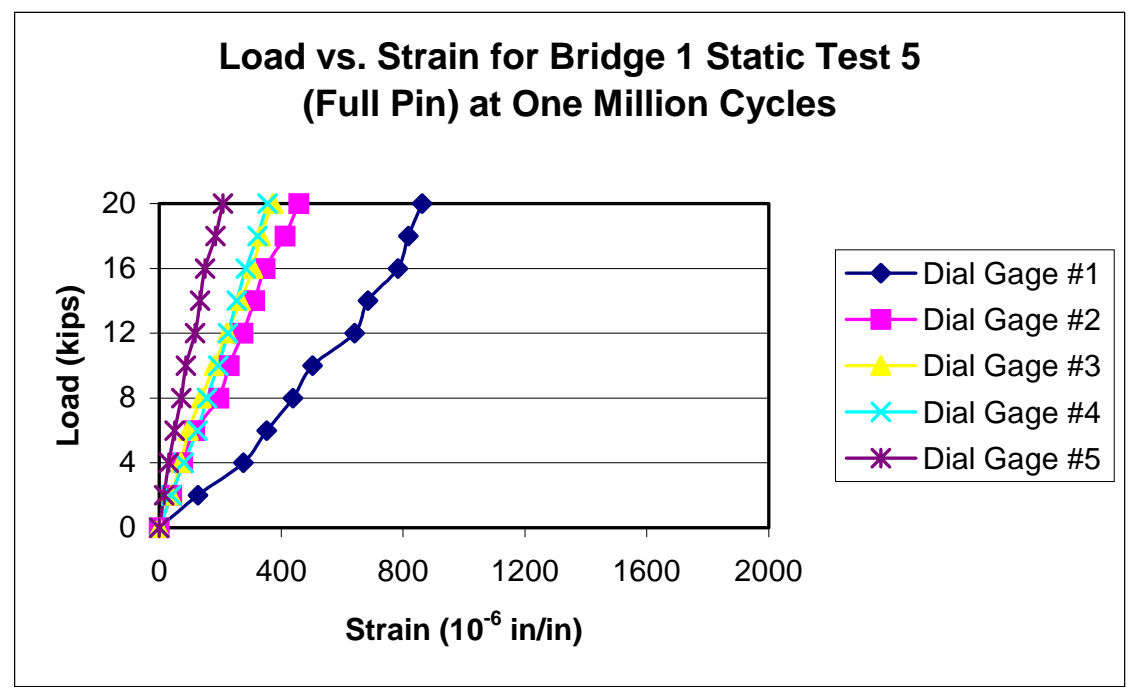

Figure 5.3.1.6: Static Test \#5 (Full Pin) Graph for Bridge \#1

Table 5.3.1.6 depicts the deflection comparison characteristics for the full-pin static testing of Model I. Values from this comparison reflect sufficient results pertaining to stiffness ratios. This conclusion can be drawn because of the relatively small changes of deflection recorded by all three positional indicators over the course of one million fatigue cycles. Dial indicator \#1, which monitors the lifting action of the timber deck over the support, displayed a total variance of 0.004 inches during the course of the experiment. Dial indicator \#2 showed the maximum changes with a value of 0.022 inches. This indicator was placed under the middle of the timber deck to account for maximum local deflection calculations. Dial indicator \#3 was positioned under the middle of the steel stringer to monitor global deflections, and this value changed by only 0.010 inches during the testing. This pattern suggests that there are no irregularities in the overall performance of the model relative to topics encompassing stiffness attributes. 
Table 5.3.1.6: Deflection Comparison of Bridge \#1 (Full Pin) for 20 kip Center Loading

\begin{tabular}{|c|c|c|c|}
\hline $\begin{array}{c}\text { Completed Fatigue } \\
\text { Cycles }\end{array}$ & $\begin{array}{c}\text { Dial Indicator \#1 } \\
\left(\mathbf{1 0}^{-3} \text { in }\right)\end{array}$ & $\begin{array}{c}\text { Dial Indicator \#2 } \\
\left(\mathbf{1 0}^{-\mathbf{3}} \mathbf{i n}\right)\end{array}$ & $\begin{array}{c}\text { Dial Indicator \#3 } \\
\left(\mathbf{1 0}^{-\mathbf{3}} \text { in }\right)\end{array}$ \\
\hline 0 & 47 & 412 & 176 \\
\hline 250,000 & 39 & 364 & 164 \\
\hline 500,000 & 41 & 392 & 177 \\
\hline 750,000 & 48 & 376 & 181 \\
\hline $1,000,000$ & 43 & 434 & 186 \\
\hline
\end{tabular}

Figures 5.3.1.7 and 5.3.1.8 are graphs relative to the full-pin deflection values of Model I. The two graphs provide initial and final results of the full-pin static testing for comparison purposes. An entire list of graphs is included in the appendix section of this report.

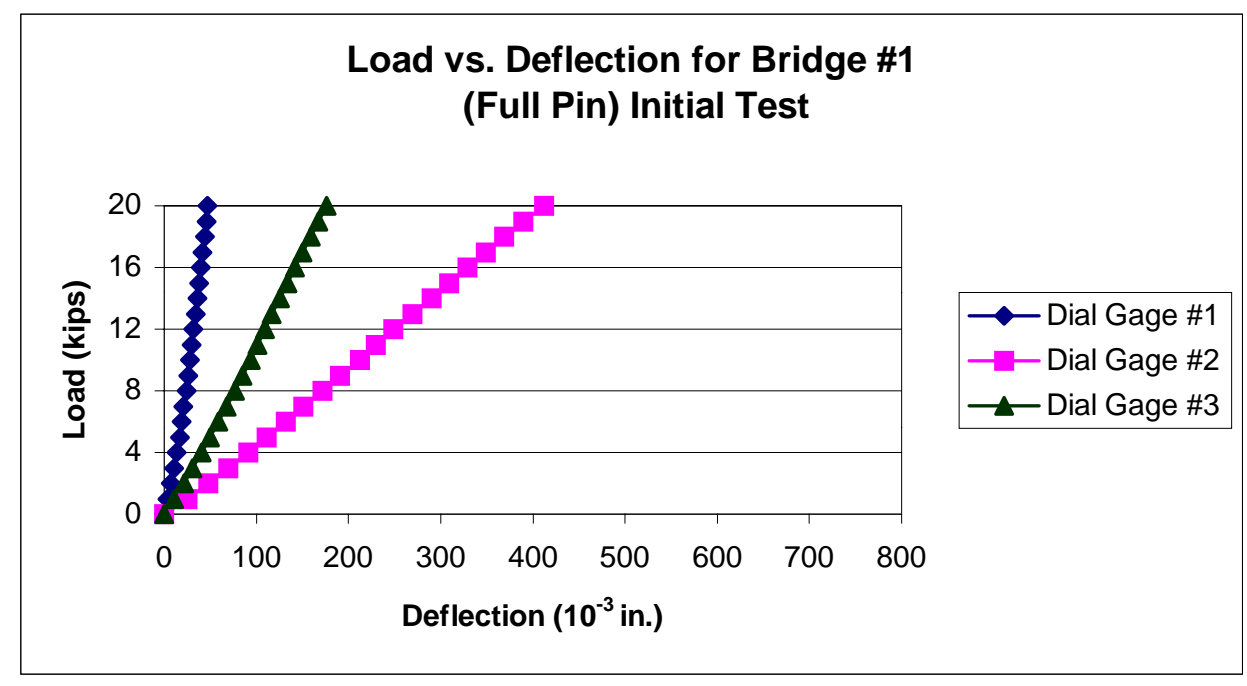

Figure 5.3.1.7: Initial Deflection (Full Pin) Graph for Bridge \#1

As mentioned previously from results pertaining to Table 5.3.1.6, the deflection results are congruent over the life cycle of this test model. Further analysis reveals consistent deflection results in comparison to half-pin versus full-pin tests. Values from associated graphs show differences in loading from 10 kips (half-pin) to 20 kips (full-pin) 
causes an increase in deflection that can approximately be linear. This occurrence is typical in both initial and final deflection graphs of Model I.

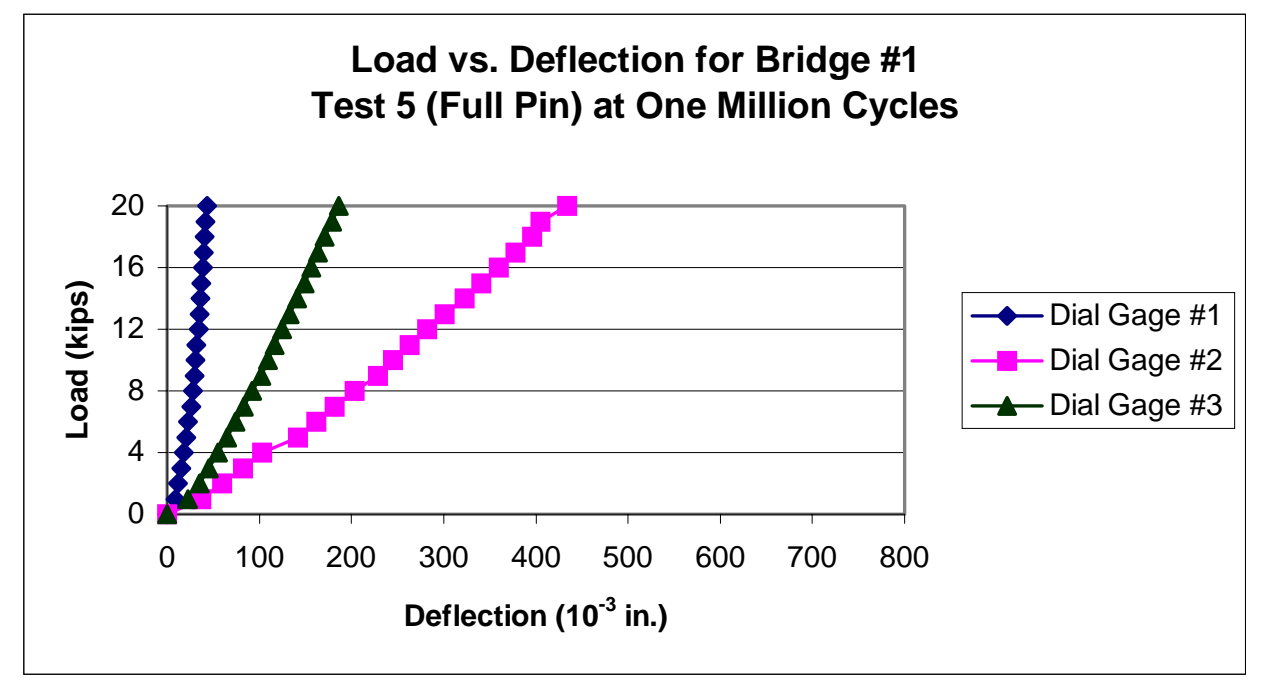

Figure 5.3.1.8: Deflection Test \#5 (Full Pin) Graph for Bridge \#1

\subsubsection{Model II Performance Results}

Two million cyclic loadings ranging between the interval of 2 kips and 26 kips were placed on Model II. The increase in loading is supposed to determine the cause for the failure of Model I, which was noticeable after only one million cycles. At the conclusion of the two million fatigue cycles no visible damage was detected on the top surface of the timber deck.

Essential data was consistently recorded from strain gages \#3 and \#4. The area near Gage \#3 and \#4 location is where the compositeness between steel stringer and timber deck is displayed. Strain gage placement for Model II was identical to the prior test case. Results from the comparison are detailed in Table 5.3.2.1. Inconclusive data were recorded after intervals of 1.25 million, 1.5 million, and 1.75 million fatigue cycles. 
Accountability for this problem may have been linked to gage malfunctioning stemming from repeated loadings.

Average values representing the percent difference associated with the half-pin static testing were found to equal 90.5 when the disputed figures were included in the calculations. This figure decreased dramatically to an average of 45.0 when the problematic numbers were excluded from the results.

Table 5.3.2.1: Microstrain Comparison for Gage \#3 and \#4 of Bridge \#2 (Half Pin) for 10 kip Center Loading

\begin{tabular}{|c|c|c|c|c|}
\hline $\begin{array}{c}\text { Completed } \\
\text { Fatigue Cycles }\end{array}$ & $\begin{array}{c}\text { Strain Gage \#3 } \\
\text { Recording }\end{array}$ & $\begin{array}{c}\text { Strain Gage \#4 } \\
\text { Recording }\end{array}$ & $\begin{array}{c}\text { Difference in } \\
\text { Absolute Strains }\end{array}$ & $\begin{array}{c}\text { Percent } \\
\text { Difference }\end{array}$ \\
\hline 0 & 251 & 185 & 66 & 26.3 \\
\hline 250,000 & 269 & 183 & 86 & 32.0 \\
\hline 500,000 & 234 & 183 & 51 & 21.8 \\
\hline 750,000 & 305 & 134 & 171 & 56.1 \\
\hline $1,000,000$ & 361 & 136 & 225 & 62.3 \\
\hline $1,250,000$ & 107 & 127 & 20 & 18.7 \\
\hline $1,500,000$ & 27 & 115 & 88 & 326 \\
\hline $1,750,000$ & 33 & 129 & 96 & 291 \\
\hline $2,000,000$ & 118 & 202 & 84 & 71.2 \\
\hline
\end{tabular}

Table 5.3.2.2 details comparisons recorded from strain gages \#4 and \#5. All values in this category appeared to be consistent with an average value computed to be equivalent to 46.6 percent difference in strain. 
Table 5.3.2.2: Microstrain Comparison for Gage \#4 and \#5 of Bridge \# 2 (Half Pin) for 10 kip Center Loading

\begin{tabular}{|c|c|c|c|c|}
\hline $\begin{array}{c}\text { Completed } \\
\text { Fatigue Cycles }\end{array}$ & $\begin{array}{c}\text { Strain Gage \#4 } \\
\text { Recording }\end{array}$ & $\begin{array}{c}\text { Strain Gage \#5 } \\
\text { Recording }\end{array}$ & $\begin{array}{c}\text { Difference in } \\
\text { Absolute Strains }\end{array}$ & $\begin{array}{c}\text { Percent } \\
\text { Difference }\end{array}$ \\
\hline 0 & 185 & 109 & 76 & 41.2 \\
\hline 250,000 & 183 & 106 & 77 & 42.1 \\
\hline 500,000 & 183 & 79 & 104 & 56.8 \\
\hline 750,000 & 134 & 74 & 60 & 44.8 \\
\hline $1,000,000$ & 136 & 73 & 63 & 46.3 \\
\hline $1,250,000$ & 127 & 70 & 57 & 44.9 \\
\hline $1,500,000$ & 115 & 66 & 49 & 42.6 \\
\hline $1,750,000$ & 129 & 65 & 64 & 49.6 \\
\hline $2,000,000$ & 202 & 98 & 104 & 51.5 \\
\hline
\end{tabular}

Figures 5.3.2.1 and 5.3.2.2 graphically display the strain attributes for the half-pin static testing of Model II. Figure 5.3.2.1, details results attained from initial static testing, and Figure 5.3.2.2 represents the strain configurations after the completion of two million fatigue cycles. Although gage \#3 concluded with a value of 118 micro-strains at the end of the last test, a significant portion of composite action was lost during the intermediate stages of testing. This incidence is adequately reflected in Figures 5.3.2.1 and 5.3.2.2. In the first of these two figures, gage \#3 ascends linearly with a constant slope. For this case, a maximum composite action is reflected in the earliest stages of loading, as denoted by the overlapping effect of gages \#3 and \#4. As the load progresses, the two respective gage recordings slowly begin to diverge, and continue to diverge until the completion of testing. This occurrence is typical for the given circumstances, i.e. as the load increases, the composite action decreases proportionally. Strain gage \#3 does not reflect this pattern very well in Figure 5.3.2.2. In this case, the gage moves sporadically and even approaches zero on two separate occasions (A value of zero constitutes a complete loss of composite action between the timber deck and steel stringer). Strain 
gage \#3 did manage to rebound back in typical fashion after reaching an approximate loading of 7 kips. Once this value was attained, the graphical line continued in a similar manner as was evident in the initial static test. Once again, this may very well be a condition of the wide flange stringer digging into the wood, which in turn sporadically improves the composite action.

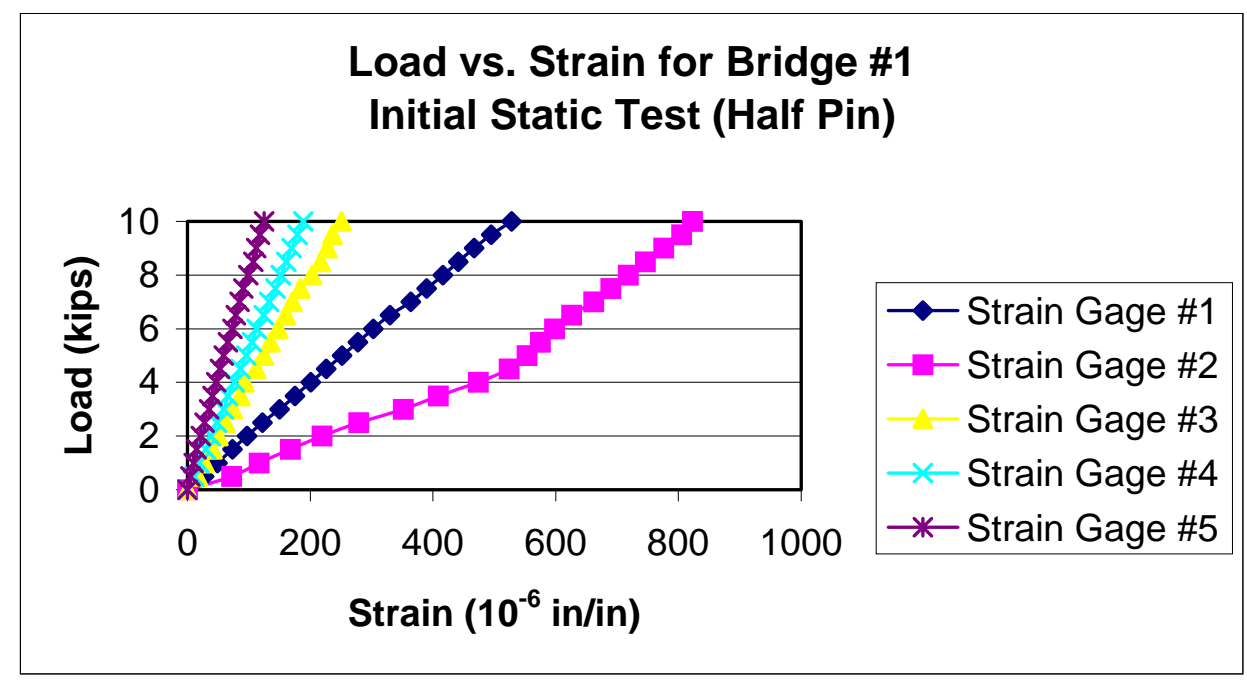

Figure 5.3.2.1: Initial Static Test (Half Pin) Graph for Bridge \#2

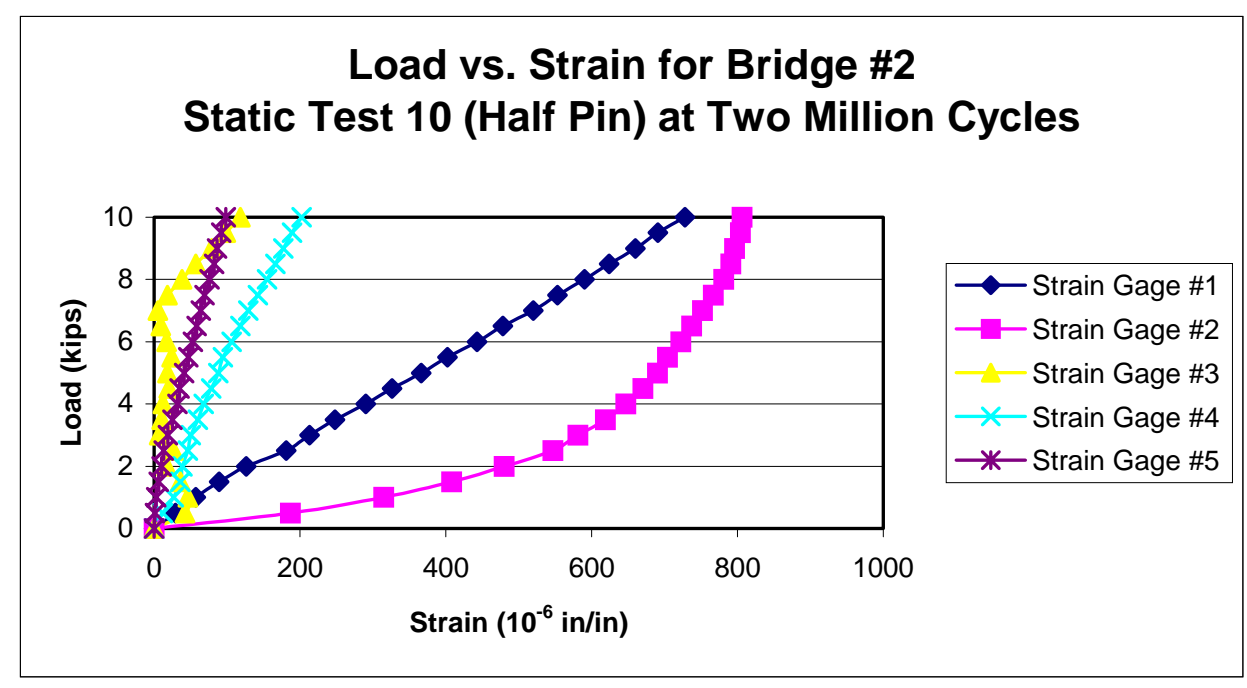

Figure 5.3.2.2: Static Test \#10 (Half Pin) Graph for Bridge \#2 
Table 5.3.2.3 details the deflection results attained in the half-pin static testing of Model II. Values in this category were reflective to results achieved from the first model. Values remained reasonably constant throughout the experiment signifying adequate performance results in conjunction to relative stiffness values.

Table 5.3.2.3: Deflection Comparison of Bridge \#2 (Half Pin) for 10 kip Center Loading

\begin{tabular}{|c|c|c|c|}
\hline $\begin{array}{c}\text { Completed Fatigue } \\
\text { Cycles }\end{array}$ & $\begin{array}{c}\text { Dial Indicator \#1 } \\
\left(\mathbf{1 0}^{-3} \text { in }\right)\end{array}$ & $\begin{array}{c}\text { Dial Indicator \#2 } \\
\left(\mathbf{1 0}^{-\mathbf{3}} \mathbf{i n}\right)\end{array}$ & $\begin{array}{c}\text { Dial Indicator \#3 } \\
\left.\mathbf{( 1 0}^{-\mathbf{3}} \text { in }\right)\end{array}$ \\
\hline 0 & 54 & 334 & 84 \\
\hline 250,000 & 46 & 268 & 78 \\
\hline 500,000 & 45 & 281 & 80 \\
\hline 750,000 & 26 & 280 & 79 \\
\hline $1,000,000$ & 37 & 265 & 79 \\
\hline $1,250,000$ & 27 & 265 & 77 \\
\hline $1,500,000$ & 34 & 266 & 81 \\
\hline $1,750,000$ & 32 & 250 & 76 \\
\hline $2,000,000$ & 33 & & \\
\hline
\end{tabular}

Figures 5.3.2.3 and 5.3.2.4 deal with the deflection comparisons for half-pin test results of Model II.

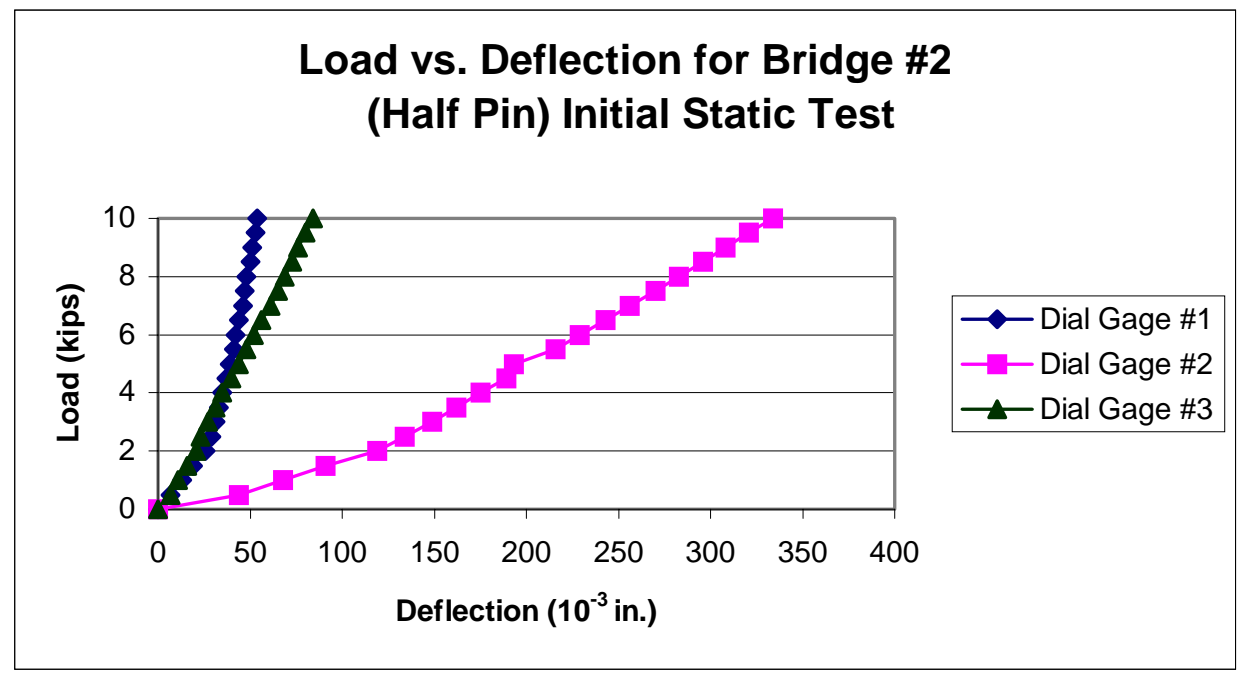

Figure 5.3.2.3: Initial Deflection (Half Pin) Graph for Bridge \#2 


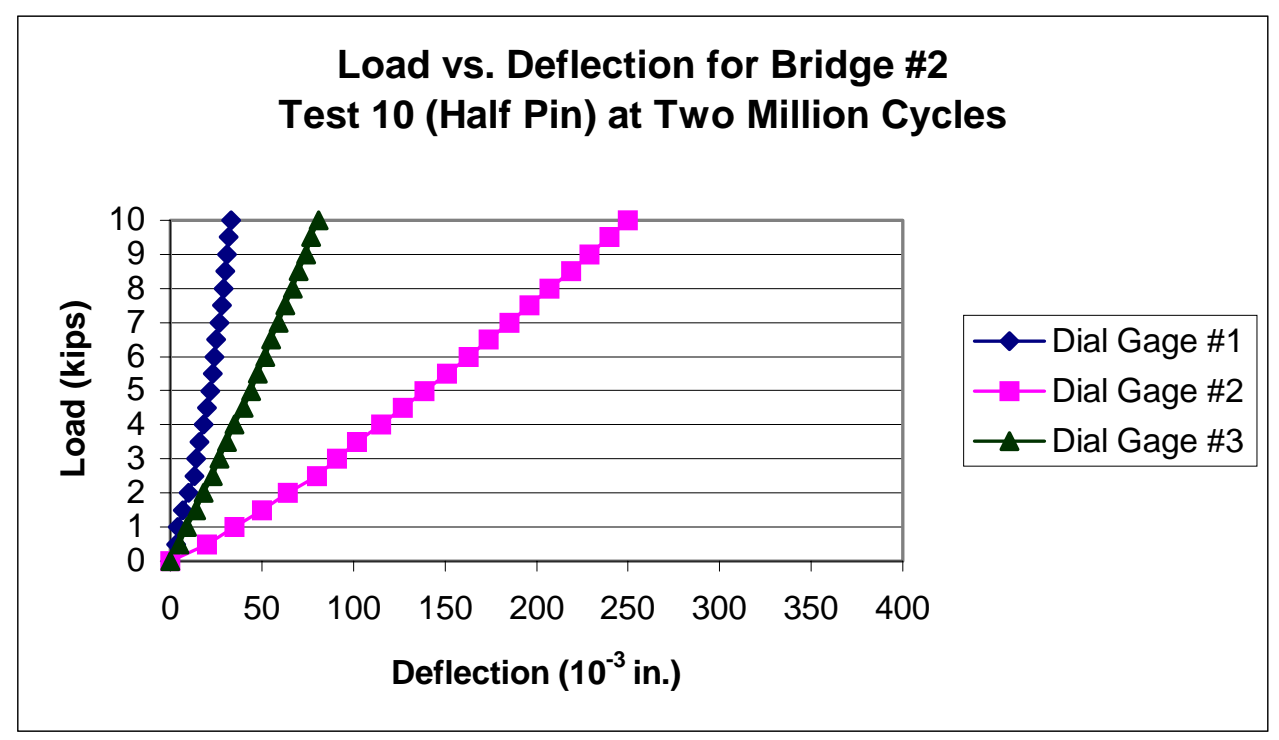

Figure 5.3.2.4: Deflection Test \#10 (Half Pin) Graph for Bridge \#2

The two graphs neglected to reveal any significant changes over the duration of the entire testing procedure. This further supports the assumption that an adequate stiffness of the decking is properly maintained for the entire fatigue life of the bridge model.

Table 5.3.2.4 gives a direct comparison for strain gages \#3 and \#4 in response to full-pin static testing of Model II. Unusual results were recorded after 0.25 million, 1.25 million, 1.5 million, and 1.75 million completed cycles. Except for the results at the end of 0.5 million cycles, these variations were also noted from the first model. Technical difficulties associated with this test were also assumed to be strain gage contingent. Average calculations of the entire compilation yield a resulting value of 90.3 percent difference in strain. With the removal of inconclusive values, this figure reduces to a difference of 28.3 percent. These calculations are indicative to the first experimental model that displayed values of 90.5 and 45.0, respectively. 
Table 5.3.2.4: Microstrain Comparison for Gage \#3 and \#4 of Bridge \#2 (Full Pin) for 20 kip Center Loading

\begin{tabular}{|c|c|c|c|c|}
\hline $\begin{array}{c}\text { Completed } \\
\text { Fatigue Cycles }\end{array}$ & $\begin{array}{c}\text { Strain Gage \#3 } \\
\text { Recording }\end{array}$ & $\begin{array}{c}\text { Strain Gage \#4 } \\
\text { Recording }\end{array}$ & $\begin{array}{c}\text { Difference in } \\
\text { Absolute Strains }\end{array}$ & $\begin{array}{c}\text { Percent } \\
\text { Difference }\end{array}$ \\
\hline 0 & 330 & 354 & 24 & 7.3 \\
\hline 250,000 & 458 & 379 & 79 & 17.2 \\
\hline 500,000 & 396 & 383 & 13 & 3.3 \\
\hline 750,000 & 384 & 270 & 114 & 29.7 \\
\hline $1,000,000$ & 161 & 261 & 100 & 62.1 \\
\hline $1,250,000$ & 53 & 264 & 211 & 398 \\
\hline $1,500,000$ & 116 & 268 & 152 & 131 \\
\hline $1,750,000$ & 114 & 234 & 120 & 105 \\
\hline $2,000,000$ & 277 & 440 & 163 & 58.8 \\
\hline
\end{tabular}

Table 5.3.2.5 lists comparisons between strain gages \#4 and \#5 for full-pin static testing of Model II.

Table 5.3.2.5: Microstrain Comparison for Gage \#4 and \#5 of Bridge \#2 (Full Pin) for 20 kip Center Loading

\begin{tabular}{|c|c|c|c|c|}
\hline $\begin{array}{c}\text { Completed Fatigue } \\
\text { Cycles }\end{array}$ & $\begin{array}{c}\text { Strain Gage \#4 } \\
\text { Recording }\end{array}$ & $\begin{array}{c}\text { Strain Gage \#5 } \\
\text { Recording }\end{array}$ & $\begin{array}{c}\text { Difference in } \\
\text { Absolute Strains }\end{array}$ & $\begin{array}{c}\text { Percent } \\
\text { Difference }\end{array}$ \\
\hline 0 & 354 & 213 & 141 & 39.8 \\
\hline 250,000 & 379 & 212 & 167 & 44.1 \\
\hline 500,000 & 383 & 199 & 110 & 48.0 \\
\hline 750,000 & 270 & 160 & 99 & 40.7 \\
\hline $1,000,000$ & 261 & 162 & 105 & 37.9 \\
\hline $1,250,000$ & 264 & 159 & 116 & 43.3 \\
\hline $1,500,000$ & 268 & 152 & 84 & 35.9 \\
\hline $1,750,000$ & 234 & 150 & 226 & 51.4 \\
\hline $2,000,000$ & 440 & 214 & & \\
\hline
\end{tabular}

Results from this study are congruent throughout the entire examination. Averages were tabulated at 42.3 percent difference. A comparable figure of 46.6 percent 
difference in strain was attained previously from Model I. This merely demonstrates a substantial consistency in the supporting stringer, and provides no significant bearing on the composite action occurring between the timber and steel materials.

Figure 5.3.2.5 is a graphical interpretation of the initial strain conditions recorded in the full-pin static test performed on the second model.

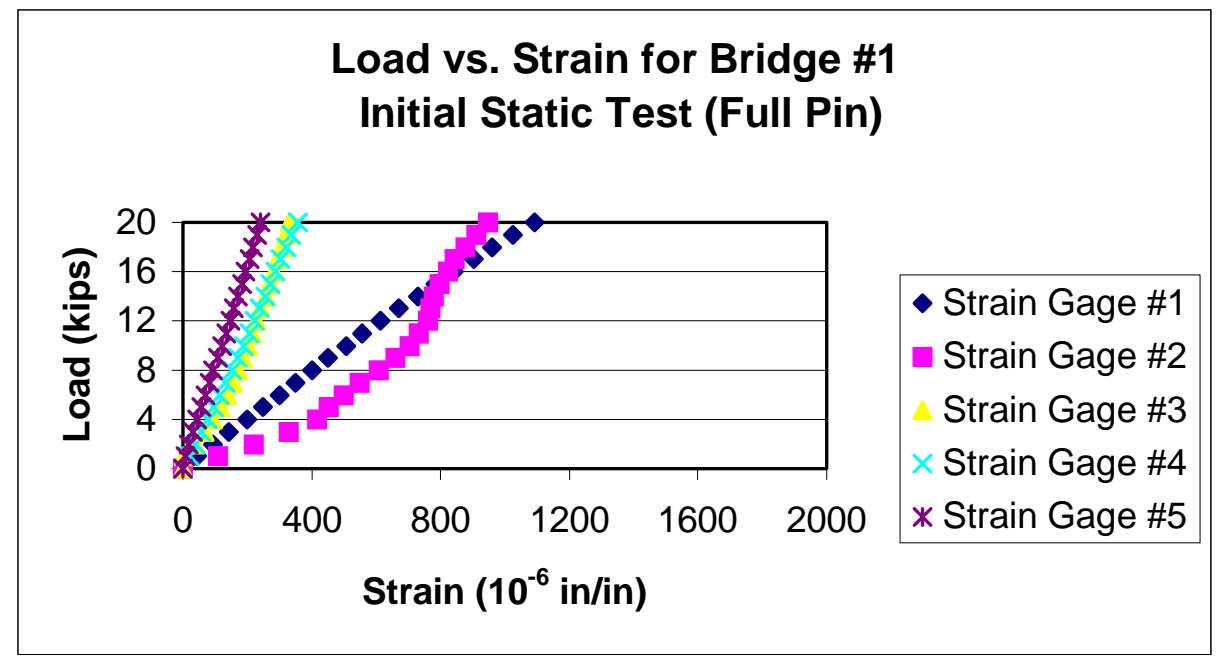

Figure 5.3.2.5: Initial Static Test (Full Pin) Graph for Bridge \#2

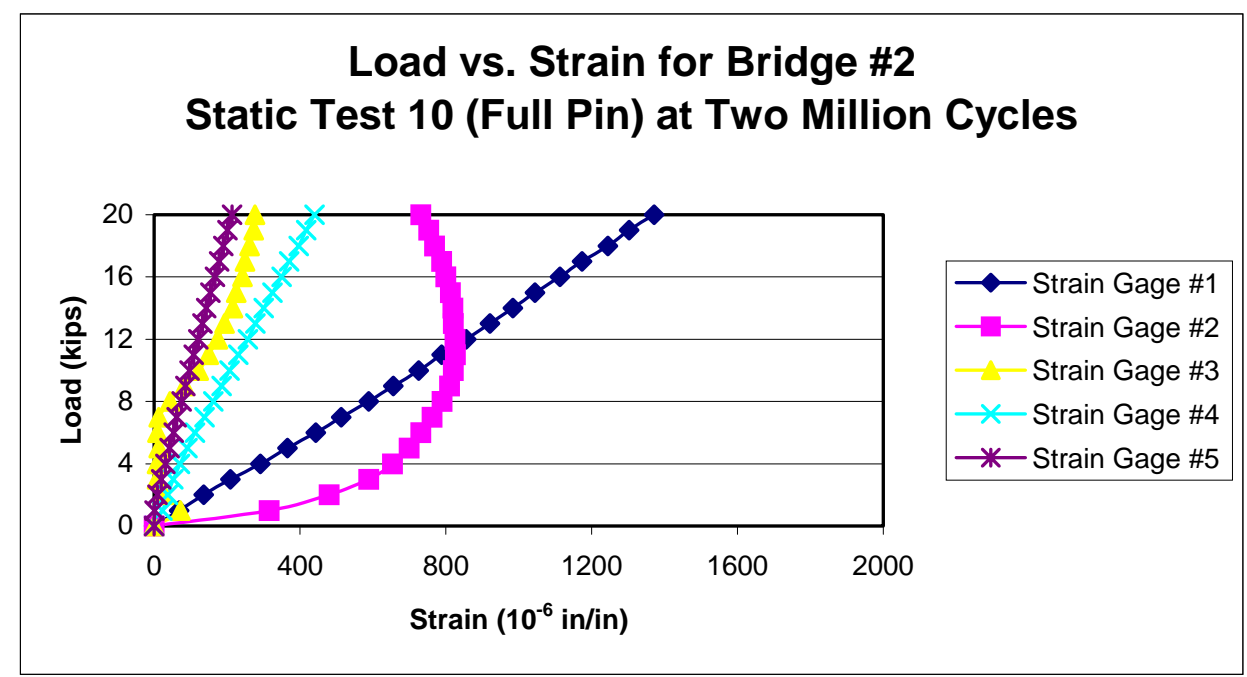

Figure 5.3.2.6: Static Test \#10 (Full Pin) Graph for Bridge \#2 
Results from Figure 5.3.2.5 reveal effective compositeness demonstrated by gages \#3 and \#4. This occurrence is not repeated, however through the entire series of static tests as demonstrated by Figure 5.3.2.6.

Finally, the last set of comparison to be made in this section concern the deflections from Model II. The first type of comparison for this category is concentrated in Table 5.3.2.6. Results from this section demonstrate adequate stiffness contributions from the timber deck system. Dial indicator \#2 declines considerably between the first interval, but then appears to settle out for the rest of the experiment. Dial indicators \#1 and \#3 also display descending patterns that seem to be steadily maintained over the duration of testing.

Table 5.3.2.6: Deflection Comparison of Bridge \#2 (Full Pin) for 20 kip Centered Loading

\begin{tabular}{|c|c|c|c|}
\hline $\begin{array}{c}\text { Completed Fatigue } \\
\text { Cycles }\end{array}$ & $\begin{array}{c}\text { Dial Indicator \#1 } \\
\left(\mathbf{1 0}^{-3} \mathbf{i n}\right)\end{array}$ & $\begin{array}{c}\text { Dial Indicator \#2 } \\
\left(\mathbf{1 0}^{-3} \mathbf{i n}\right)\end{array}$ & $\begin{array}{c}\text { Dial Indicator \#3 } \\
\left(\mathbf{1 0}^{-3} \text { in }\right)\end{array}$ \\
\hline 0 & 75 & 540 & 147 \\
\hline 250,000 & 68 & 465 & 140 \\
\hline 500,000 & 62 & 461 & 137 \\
\hline 750,000 & 54 & 483 & 148 \\
\hline $1,000,000$ & 53 & 476 & 140 \\
\hline $1,250,000$ & 50 & 462 & 140 \\
\hline $1,500,000$ & 52 & 460 & 141 \\
\hline $1,750,000$ & 50 & 462 & 146 \\
\hline $2,000,000$ & 51 & 445 & \\
\hline
\end{tabular}

Graphs displayed in Figures 5.3.2.7 and 5.3.2.8 represent deflection recordings for initial and final full-pin static testing for Model II. 


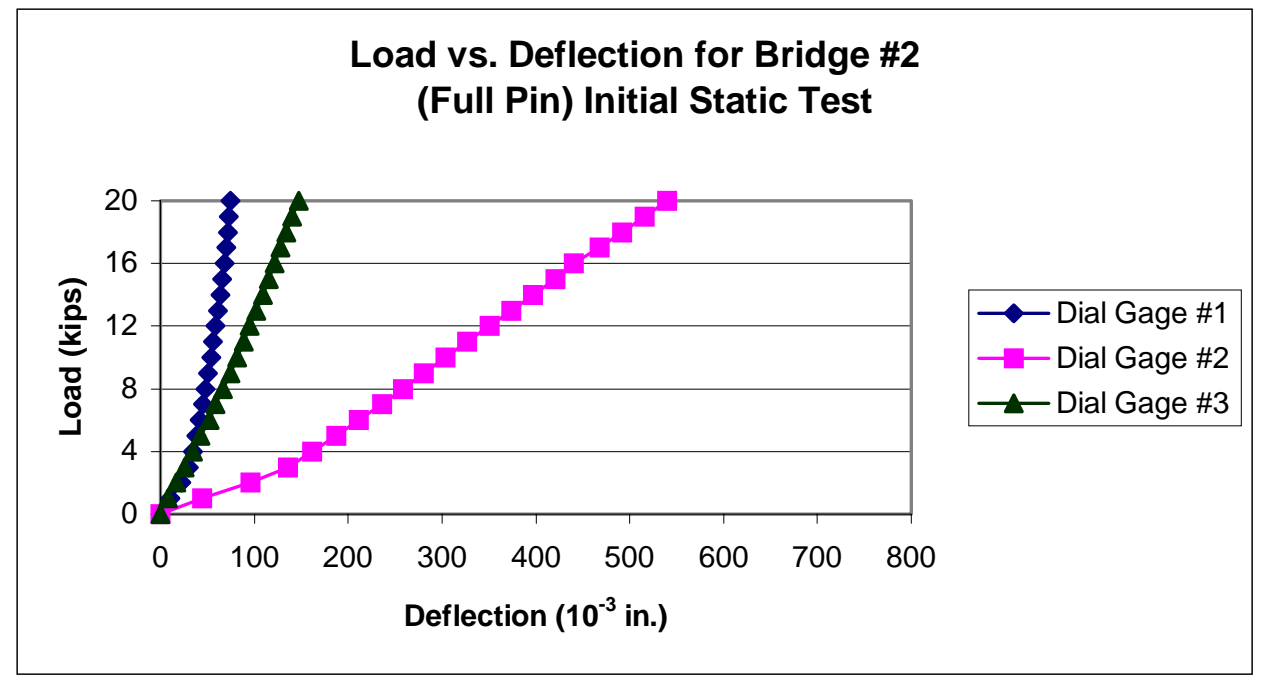

Figure 5.3.2.7: Initial Deflection (Full Pin) Graph for Bridge \#2

Results from this procedure are similar to previous examples and display no obvious pattern changes in deflection measurements over the life cycle of the subsequent model.

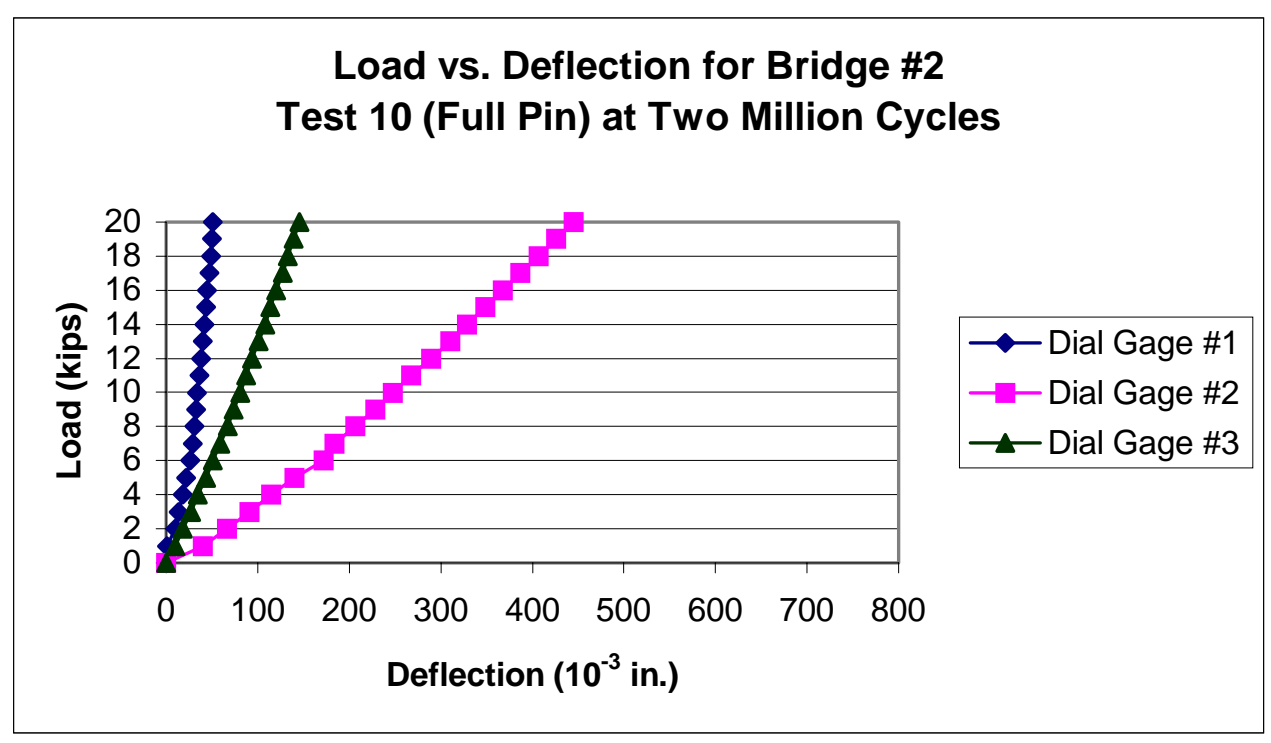

Figure 5.3.2.8: Deflection Test \#10 (Full Pin) Graph for Bridge \#2 
Overall performance comparisons between Model I and Model II revealed no significant differences. Graphical presentations for individual static testing displayed pattern-forming results typical of one another. Graphs of intermediate stages listed in the appendix give further credibility to this trend.

As a major observation, a trend is made apparent that the wide flange steel stringers are cutting into portions of the timber deck after so many cycles, and thus creating an increase in the composite action. Although the exact turning point of the transfer differed in the two tests, this trend was reflected in both models. The reason for this difference is assumed to be associated with the changes in depth and stiffness. 


\section{Chapter 6}

\section{Analysis and Discussion}

\subsection{Introduction}

The intentions behind the procedures of this experiment was to gain further understanding of specific interactions associated with positioning a timber gluedlaminated deck on top of supporting steel stringers. The overall goal for this project was to continually increase the structural efficiency of the timber bridge until performance values are comparable to figures associated with typical concrete and steel design applications. This is an on-going investigation and continual progress is being accomplished by the Constructed Facilities Center of West Virginia University with the completion of every research project, in this area.

Substantial progress contributions stemming from previously related topics have allowed for certain refinements in testing parameters for this specific project. Results detailed by $\mathrm{Wu}$ (10) compared the performance of the WVU connectors to similar models. Evidence supporting the performance of WVU connection detail was accepted by this investigator, and consequently left untested during the course of the project. Another topic of concern was the tensile force remaining in the connector under repeated loadings. Vijayachandran (6) researched this material extensively during his studies at West Virginia University, and comparisons evaluated in his report yielded adequate 
results. Because of this work, general performance evaluations associated with this type of connection detail was also excluded from this study.

Relative topics of concern for this study were compared in the previous chapter and provided no individual observations. Recognition of this pattern-forming trend must now be compared to theoretical calculations in an attempt to provide accountability regarding quantitative performance recordings prior to delivery of any accredited recommendations.

\subsection{Composite Action Evaluation}

The single most important topic resulting from this experiment is the composite action associated with the timber deck and steel stringers. Comparison of this attribute is performed with the actual experimental recordings of applicable strain and deflection measurements versus theoretical values calculated from rudimentary design equations.

The first evaluation of composite action is associated with theoretical and experimental values of global deflections. The theoretical equation for deflection of a simply supported beam with one concentrated load at the geometric center of the span is shown in Figure 6.1.1.

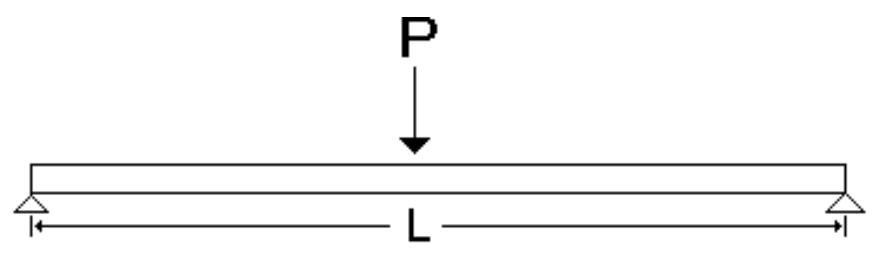

$$
\triangle=\frac{\mathrm{P} \mathrm{L}^{3}}{48 \mathrm{E} \mathrm{I}}
$$

Figure 6.1.1: Deflection Diagram and Equation for Simply Supported Beam 
where:

$$
\begin{aligned}
& \Delta=\text { deflection }(\text { in }) \\
& \mathrm{P}=\text { magnitude of concentrated load }(\mathrm{lb}) \\
& \mathrm{L}=\text { center-to-center beam spacing }(\mathrm{in})=117 \mathrm{inch} \\
& \mathrm{E}=\text { modulus of elasticity of steel stringer }\left(\mathrm{lb} / \mathrm{in}^{2}\right)=30 \times 10^{6} \mathrm{psi} \\
& \mathrm{I}=\text { moment of inertia about bending axis }\left(\mathrm{in}^{4}\right)
\end{aligned}
$$

Substitution of constant values into this equation yields the following:

$$
\Delta=20,000 \mathrm{lb} / 2 \text { stringers } \times(117 \mathrm{in})^{3} / 48 \times\left(30 \times 10^{6} \mathrm{lb} / \mathrm{in}^{2}\right) \times \mathrm{I}_{\mathrm{eff}}
$$

The only variable in this equation is $\mathrm{I}_{\mathrm{eff}}$, and this symbolic notation represents the effective moment of inertia.

Simplification of known values reduces the equation to:

$$
\Delta=16,016,130,000 \mathrm{lb}-\mathrm{in}^{3} / 1,440,000,000 \mathrm{lb} / \mathrm{in}^{2} \mathrm{x} \mathrm{I} \mathrm{I}_{\mathrm{eff}}
$$

Furthermore,

$$
\Delta=11.122 \mathrm{in}^{5} / \mathrm{I}_{\mathrm{eff}}
$$


Here, the effective moment of inertia can be incorporated as:

$$
\mathrm{I}_{\mathrm{eff}}=\mathrm{I}_{\text {stringer }}+\mathrm{I}_{\text {deck }}
$$

Solution to this equation must be split into two separate sections in order to account for the varying dimensions associated with the depth of subsequent models.

The expression necessary for solving the moment of inertia is given as:

$$
\mathrm{I}_{\text {eff }}=\mathrm{I}_{\text {stringer }}+\left[\left(\mathrm{b}_{\mathrm{eff}} \times \mathrm{h}^{3}\right) / 12\right] / \eta
$$

In this formula,

$$
\begin{aligned}
& I_{\text {stringer }}=82.8 \text { in }^{4} \\
& b_{\text {eff }}=\text { effective base of the timber deck } \\
& h=\text { height of the timber deck } \\
& \eta=\text { modular ratio of elasticity. }
\end{aligned}
$$

where:

$$
\eta=\mathrm{E}_{\mathrm{S}} / \mathrm{E}_{\mathrm{T}}=30 \times 10^{6} \mathrm{lb} / \mathrm{in}^{2} / 1.6 \times 10^{6} \mathrm{lb} / \mathrm{in}^{2} \cong 18.75
$$

Although this equation is not totally applicable for this situation, i.e. a stress laminated timber bridge deck model stiffened with wide flange steel stingers, it was selected because it conveys the "worst" case scenario. To further elaborate, this equation signifies two materials working independently of one another. In other words, effective moment of inertia calculations are made by simply adding together the two separate 
materials, without any account for compositeness. If the two materials produce a perfect composite action, then the effective moment of inertia will quadruple in value. This will cause a significant reduction in the deflection because of the direct correlation. In the case of the timber deck and steel stringers, only a partial compositeness is contained and fluctuates between fatigue cycles.

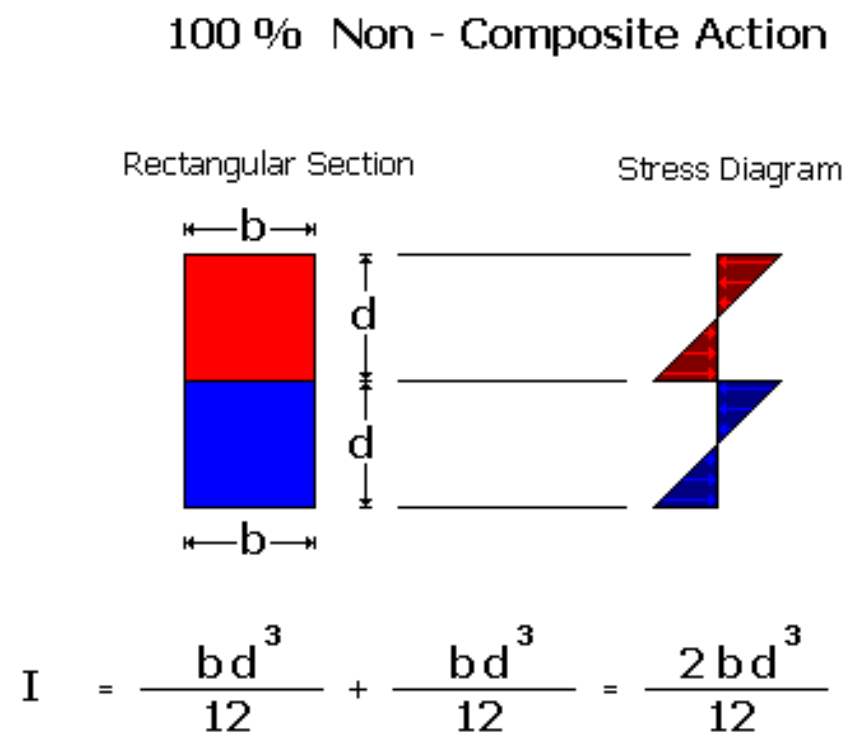

(Eq. 2)

Figure 6.1.2: Moment of Inertia Equation for Non-Composite Section

\section{$100 \%$ Composite Action}

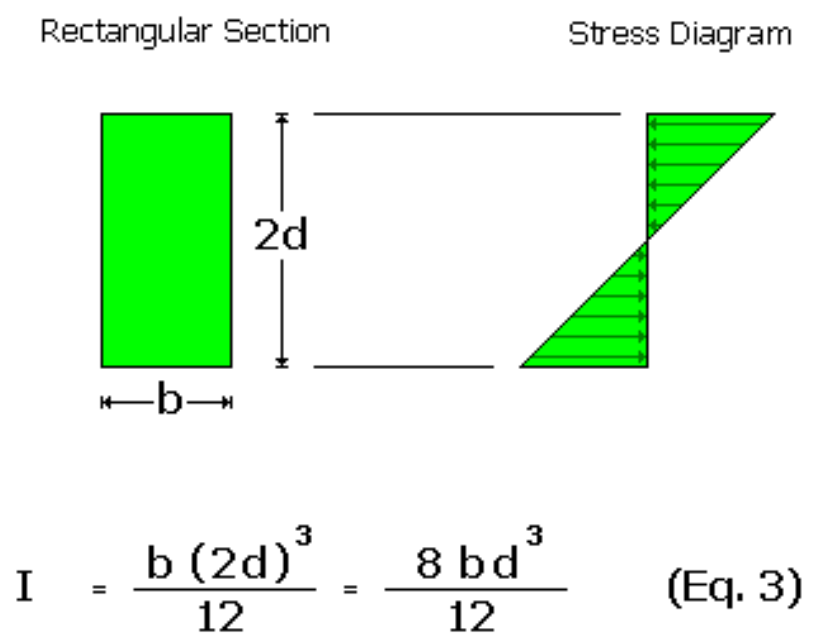

Figure 6.1.3: Moment of Inertia Equation for Non-Composite Section 
Figures 6.1.2 and 6.1.3 displays the basic methodology associated with the two distinct differences relative to effective inertia calculations.

\section{For Model I:}

$$
\begin{aligned}
& \Delta=11.122 \mathrm{in}^{5} / 82.8 \mathrm{in}^{4}+\left[12 \mathrm{in} \mathrm{x}(7.5 \mathrm{in})^{3} / 12\right] / 18.75 \\
& \Delta=11.122 \mathrm{in}^{5} / 82.8 \mathrm{in}^{4}+22.5 \mathrm{in}^{4} \\
& \Delta=11.122 \mathrm{in}^{5} / 105.3 \mathrm{in}^{4} \\
& \Delta=0.106 \mathrm{in}
\end{aligned}
$$

\section{For Model II:}

$$
\begin{aligned}
& \Delta=11.122 \mathrm{in}^{5} / 82.8 \mathrm{in}^{4}+\left[12 \mathrm{in} \mathrm{x}(6.0 \mathrm{in})^{3} / 12\right] / 18.75 \\
& \Delta=11.122 \mathrm{in}^{5} / 82.8 \mathrm{in}^{4}+11.52 \mathrm{in}^{4} \\
& \Delta=11.122 \mathrm{in}^{5} / 94.32 \mathrm{in}^{4} \\
& \Delta=0.118 \mathrm{in}
\end{aligned}
$$

Results from this theoretical computation reveal that the anticipated global deflection associated with this formula should be close to 0.106 inches for Model I, and 0.118 inches for Model II. These values are expected when the models are subjected to a 20,000 pound concentric loading, with center-to-center span of 9.75 feet. In this equation, the load was divided into half because of equal amounts of contribution provided by the two supporting stringers. This may not be the case, however, for various applications 
warranting the necessity for extreme prudence in supplemental bridge design compilations. It is also worth mentioning that the values inserted for the moment of inertia were a combination of the steel stringer and effective portion of the timber decking.

For comparison purposes, Table 6.1.1 shows experimental values obtained from both models, along with theoretical comparisons. An additional column listing adjusted values of experimentally obtained calculations has also been introduced for further comparison purposes. The adjusted values reflect changes made in calculating the effective width of the two models. An effective width of 9 inches was used for adjusted values for Model I, and 14 inches for Model II. This is in comparison to the value of 12 inches used in experimentally obtained calculations. Values acquired in this section pertain to effective base calculations detailed in Section 6.5.

Results from this comparison reflect the accuracy of theoretical computations regarding global deflection characteristics. Maximum difference between the two methods was observed in static test \#5 of Model I. This difference in value was found to be 0.031 inches or approximately $1 / 30$ of an inch. The minimum difference was observed in static test \#2 and \#7 of Model II. Experimentally obtained values in this circumstance matched perfectly to theoretically defined equations of deflection.

Overall values in this section of the evaluation phase reveal that performances of the models considering deflection attributes was regarded as typical given the described condition. In other words, no uncharacteristic patterns were apparent in the composite action of the two test models in terms of global deflection. 
Table 6.1.1: Comparison of Global Exp. Deflection vs. Theoretical Deflection for Respective Models

\begin{tabular}{|c|c|c|c|c|c|c|}
\hline Model \# & $\begin{array}{c}\text { Static } \\
\text { Test \# } \\
\text { (Full Pin) }\end{array}$ & $\begin{array}{l}\text { Experimental } \\
\text { Deflection (in) }\end{array}$ & $\begin{array}{l}\text { Adj. Exp. } \\
\text { Deflection } \\
\qquad(\text { in })^{\Theta}\end{array}$ & $\begin{array}{l}\text { Theoretical } \\
\text { Deflection } \\
\text { (in) }\end{array}$ & $\begin{array}{c}\text { \% Diff. } \\
\text { Exp. vs. } \\
\text { Theory }(\%)\end{array}$ & $\begin{array}{l}\% \text { Diff Exp. } \\
\text { vs. Adj. (\%) }\end{array}$ \\
\hline \multirow{5}{*}{$\begin{array}{c}\text { Model } \\
\text { I }^{*}\end{array}$} & 1 & .127 & .114 & .109 & 14.2 & 10.2 \\
\hline & 2 & .115 & .114 & .109 & 5.2 & 0.87 \\
\hline & 3 & .128 & .114 & .109 & 14.8 & 10.9 \\
\hline & 4 & .132 & .114 & .109 & 17.4 & 13.6 \\
\hline & 5 & .137 & .114 & .109 & 20.4 & 16.8 \\
\hline \multirow{10}{*}{$\begin{array}{l}\text { Model } \\
\text { II }^{* *}\end{array}$} & 1 & .123 & .118 & .120 & 18.4 & 4.1 \\
\hline & 2 & .116 & .118 & .120 & 14.3 & 1.7 \\
\hline & 3 & .113 & .118 & .120 & 12.4 & 4.4 \\
\hline & 4 & .129 & .118 & .120 & 21.6 & 8.5 \\
\hline & 5 & .124 & .118 & .120 & 18.9 & 4.8 \\
\hline & 6 & .126 & .118 & .120 & 20.0 & 6.3 \\
\hline & 7 & .118 & .118 & .120 & 15.5 & 0 \\
\hline & 8 & .116 & .118 & .120 & 14.3 & 1.7 \\
\hline & 9 & .117 & .118 & .120 & 14.9 & 0.9 \\
\hline & 10 & .122 & .118 & .120 & 17.8 & 3.3 \\
\hline
\end{tabular}

*Values of Experimental Deflection for Model I were adjusted to account for support settlement occurring under fatigue testing. In the laboratory setup, Celotex padding was placed under the supports to defer slippage between the steel girder and the concrete floor. Separate testing indicated a displacement of 0.049 inches to the padding under simulated conditions.

** Only fifty percent of this figure (0.025) was deducted from Model II because the same padding was used for both tests, and the majority of displacement for the padding transpired during the first one million cycles.

${ }^{\Theta}$ Adjusted values pertain to effective base figures necessary for moment of inertia calculations. In Model I, an adjusted value of 9 inches was inserted, and 14 inches was used for Model II. Further information regarding the selection of these quantities can be found in Section 6.5 of this report. 
The next evaluation of composite action is associated with the theoretical and experimental values of global strain engagement. Formulas necessary for theoretical computations were previously expressed in Figure 4.5.2. The formula shown in this figure is valid only in the case of a simply supported model with a concentrated load positioned in the geometric center. References should be made to Figure 4.5.2 for additional information.

The theoretical equation for stress of a simply supported beam with a concentrated load at the geometric center of the span is:

$$
\sigma=\mathrm{Mc} / \mathrm{I}
$$

where:

$$
\begin{aligned}
& \sigma=\text { maximum normal stress in the member }\left(\mathrm{lb} / \mathrm{in}^{2}\right) \\
& \mathrm{M}=\text { resultant internal moment }(\mathrm{lb}-\mathrm{in}) \\
& \mathrm{c}=\text { perpendicular distance from neutral axis to } \\
& \quad \text { a point furthest away from neutral axis (in) } \\
& \mathrm{I}=\text { moment of inertia of cross sectional area }\left(\mathrm{in}^{4}\right)
\end{aligned}
$$

Utilizing the fundamental principle that stress $(\sigma)$ is equal to strain $(\varepsilon)$ multiplied by the modulus of elasticity $(\mathrm{E})$, which is valid only in the elastic region, the equation converts to:

$$
\varepsilon=\mathrm{Mc} / \mathrm{EI}
$$


Substitution of $\mathrm{M}=\mathrm{PL} / 4$ for a simply supported beam with a concentric load at the geometric center reduces the equation to:

$$
\varepsilon=\mathrm{PLc} / 4 \mathrm{EI}
$$

where:

$$
\begin{aligned}
& \mathrm{P}=\text { magnitude of concentrated load (lb) } \\
& \mathrm{L}=\text { center-to-center beam spacing (in) }
\end{aligned}
$$

Substitution of constant values into this equation yields the following:

$$
\varepsilon=20,000 \mathrm{lb} / 2 \text { stringers } \mathrm{x} 117 \text { in } \mathrm{x} 3.965 \mathrm{in} / 4 \times 30 \times 10^{6} \mathrm{lb} / \mathrm{in}^{2} \times \mathrm{I}_{\mathrm{eff}}
$$

Similar to the representative equation accounting for global deflection attributes, the only variable remaining in this equation is the effective moment of inertia.

Simplification of the known values in this formula reduces the equation to:

$$
\varepsilon=4,639,050 \mathrm{lb}-\mathrm{in}^{2} / 120,000,000 \mathrm{lb} / \mathrm{in}^{2} \mathrm{x} \mathrm{I}_{\mathrm{eff}}
$$

Furthermore,

$$
\varepsilon=0.03865875 \mathrm{in}^{4} / \mathrm{I}_{\mathrm{eff}}
$$


In this equation, the value for $\mathrm{I}_{\mathrm{eff}}$ is regarded as the same figure obtained previously in the global deflection calculations. Therefore, calculations regarding theoretical strain values can now be expressed in terms of subsequent models.

\section{For Model I:}

$$
\varepsilon=0.03865875 \mathrm{in}^{4} / 105.3 \mathrm{in}^{4}=367 \times 10^{-6} \mathrm{in} / \mathrm{in}
$$

\section{For Model II:}

$$
\varepsilon=0.03865875 \mathrm{in}^{4} / 94.32 \mathrm{in}^{4}=410 \times 10^{-6} \mathrm{in} / \mathrm{in}
$$

Actual values for strain are dimensionless, but typically represented as in/in. Results from this theoretical computation reveal that the anticipated strain associated with this formula should be close to $367 \times 10^{-6} \mathrm{in} / \mathrm{in} 0.000367 \mathrm{inch} / \mathrm{inch}$ for Model I and $410 \mathrm{x}$ $10^{-6} \mathrm{in} /$ in for Model II when subjected to a 20,000 pound concentric loading, with a center-to-center span of 9.75 feet. For comparison purposes, Table 6.2.2 shows experimental values obtained from both models, along with theoretical comparisons. An additional column has also been included listing adjusted values of experimentally obtained calculations for further comparison purposes. Values acquired in this section pertain to effective base calculations detailed in Section 6.5. 
Table 6.1.2: Comparison of Global Exp. Strain vs. Theoretical Strain for Respective Models

\begin{tabular}{|c|c|c|c|c|c|c|}
\hline Model \# & $\begin{array}{c}\text { Static Test \# } \\
\text { (Full Pin) }\end{array}$ & $\begin{array}{c}\text { Experimental } \\
\text { Strain Value } \\
\left(10^{-4} \text { in/in }\right)\end{array}$ & $\begin{array}{c}\text { Adj. Exp. Strain } \\
\text { Value } \\
\left(10^{-4} \mathrm{in} / \mathrm{in}\right)^{\Theta}\end{array}$ & $\begin{array}{c}\text { Theoretical } \\
\text { Strain Value } \\
\left(10^{-4} \mathrm{in} / \mathrm{in}\right)\end{array}$ & $\begin{array}{c}\% \text { Diff. } \\
\text { Exp. vs. } \\
\text { Theory (\%) }\end{array}$ & $\begin{array}{l}\% \text { Diff Exp. } \\
\text { vs. Adj. (\%) }\end{array}$ \\
\hline \multirow{5}{*}{ Model I } & 1 & 3.56 & 3.87 & 3.67 & 3.1 & 8.7 \\
\hline & 2 & 4.11 & 3.87 & 3.67 & 10.7 & 5.8 \\
\hline & 3 & 4.77 & 3.87 & 3.67 & 23.1 & 18.9 \\
\hline & 4 & 3.66 & 3.87 & 3.67 & 0.3 & 5.7 \\
\hline & 5 & 3.55 & 3.87 & 3.67 & 3.4 & 9.0 \\
\hline \multirow{10}{*}{ Model II } & 1 & 3.54 & 4.02 & 4.10 & 15.8 & 13.6 \\
\hline & 2 & 3.79 & 4.02 & 4.10 & 8.2 & 6.1 \\
\hline & 3 & 3.83 & 4.02 & 4.10 & 7.0 & 5.0 \\
\hline & 4 & 2.60 & 4.02 & 4.10 & 57.7 & 54.6 \\
\hline & 5 & 2.70 & 4.02 & 4.10 & 51.9 & 48.9 \\
\hline & 6 & 2.61 & 4.02 & 4.10 & 57.1 & 54.0 \\
\hline & 7 & 2.64 & 4.02 & 4.10 & 55.3 & 52.3 \\
\hline & 8 & 2.68 & 4.02 & 4.10 & 53.0 & 50.0 \\
\hline & 9 & 2.34 & 4.02 & 4.10 & 75.2 & 7.8 \\
\hline & 10 & 4.40 & 4.02 & 4.10 & 6.8 & 8.6 \\
\hline
\end{tabular}

${ }^{\Theta}$ Adjusted values pertaining to this figure are congruent with figures expressed in Table 6.1.1.

Results from this comparison reflect the accuracy of theoretical computations regarding strain characteristics. Maximum differences between the two methods came in static test \#9 of Model II. This difference in value was found to be 0.000176 inch/inch. The minimum difference was observed in static test \#4 of Model I. The obtained value in this circumstance was equal to 0.00001 inch/inch.

It should be noted that experimental values were consistently lesser than expected figures. Resulting values displayed fluctuating patterns considered to be unreliable, however both models recordings appeared to approach anticipated figures with escalating increments. With this in mind, expected and obtained values in this section reveal typical 
performances of the models strain attributes regarding overall conditions, and raise questions regarding effective base calculations. In other words, no uncharacteristic patterns were apparent in the composite action of the two test models in terms of global strain effects.

\subsection{Load Distribution Evaluation}

Load distribution is generally regarded as the ability of the deck to transfer applied loads to the supporting stringers. Theoretical calculations based on this principal, combined with experimental results, demonstrate efficiency ratings of stringer correlations. Typically, load distribution evaluations are performed on structures containing three or more stringers. The reason for this is due to the fact that the majority

of cases encompassing only two supports commonly adhere to symmetrical loading conditions. This entails that each of the two separate stringers accounts for exactly onehalf of the total load. Bridge models I and II from this experiment, were both constructed with two symmetrically positioned steel stringers. With this situation as just described, the assumption of equivalent load distribution was made and therefore no experimental evaluations were performed on either model. Referrals should be made to the work completed by Vijayachandran (6) concerning further investigations focusing on load distribution calculations.

\subsection{Fatigue Response Evaluation}

Fatigue is generally defined as a componential break down of material when subjected to a cyclic repetition of mechanical loadings. Fatigue response is an essential 
evaluation because relatively small loadings can ultimately lead to fractural conditions when performed in millions of cycles. The nature of this failure occurs initially with microscopic cracks formulating in localized regions. The cracks perpetuate with continual loadings ultimately reducing the effective cross-sectional area of the material. Eventually, the effective area can no longer sustain the repetitive loadings causing the occurrence of sudden fracture. Although any type of failure is unwarranted, sudden fractures are the most detrimental because they generally exhibit catastrophic conditions. To account for this type of failure, repetitive loadings of at least one million cycles were placed on the individual models. Loadings utilized in this experiment are designated by the American Association of State Highway and Transportation Officials (AASHTO) as HS-20 loading conditions. During the course of fatigue testing, static test were conducted at intervals of 250,000 cycles giving sufficient data recordings to perform the proper evaluations.

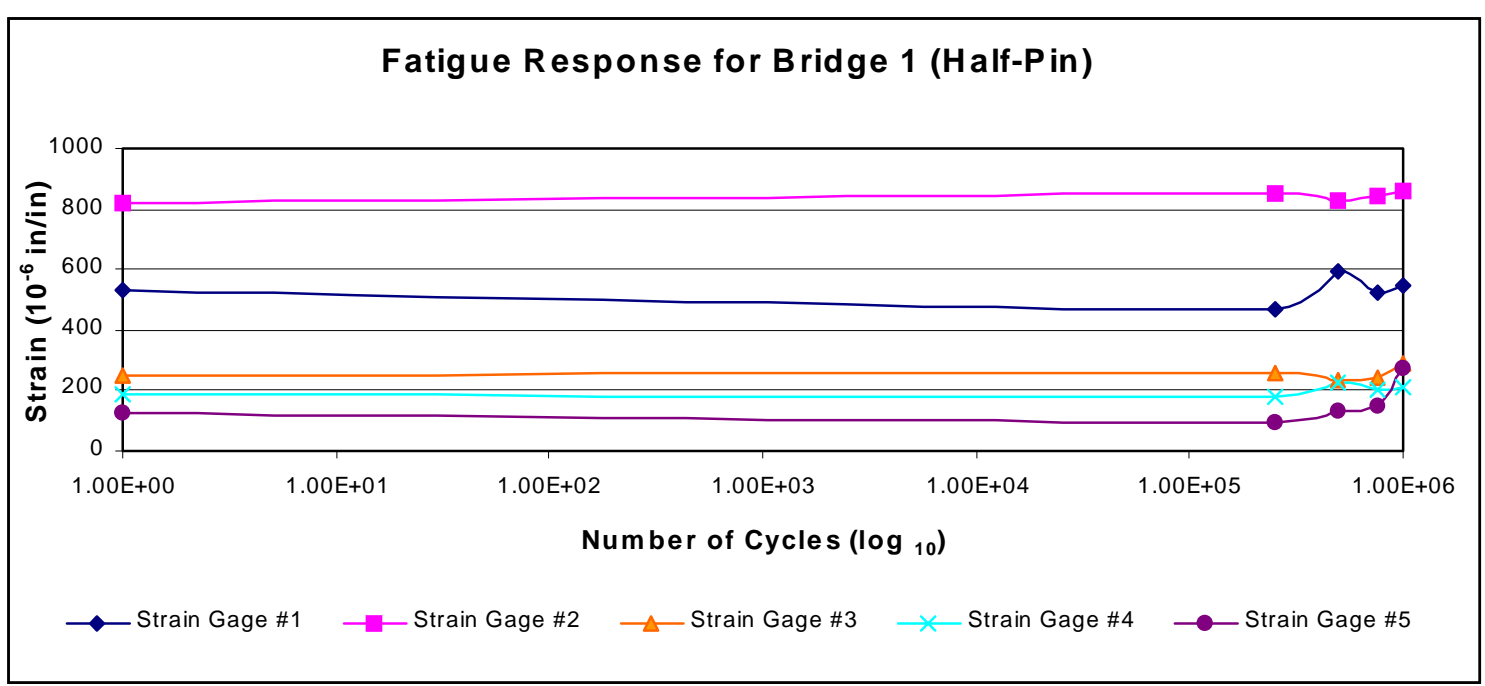

Figure 6.3.1: Fatigue Response Graph for Model \#1 (Half-Pin) 
Figure 6.3.1 displays the fatigue response associated with all five enlisted strain gages relative to the completion of the half-pin static testing of Model I.

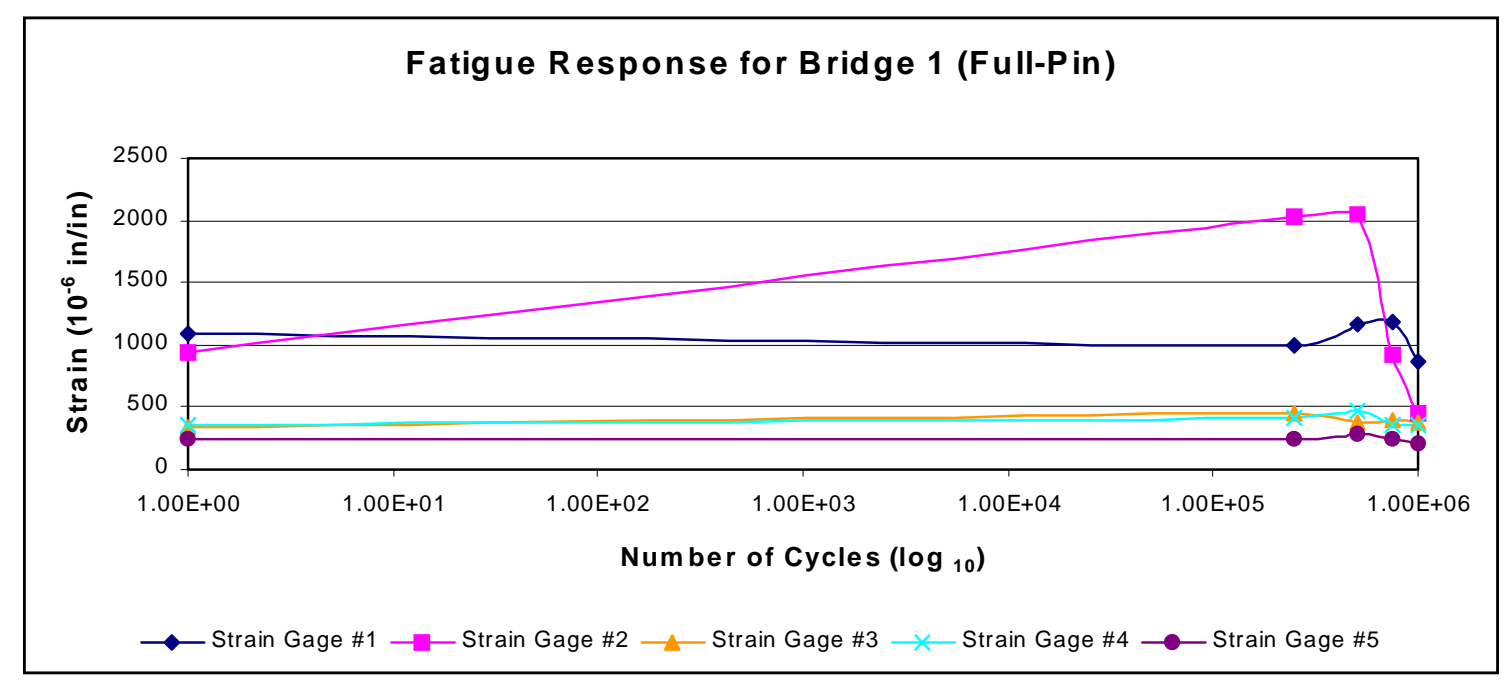

Figure 6.3.2: Fatigue Response Graph for Model \#1 (Full-Pin)

Figure 6.3.2 correlates the fatigue response of the five strain gages to the completion of the full-pin static testing of Model I.

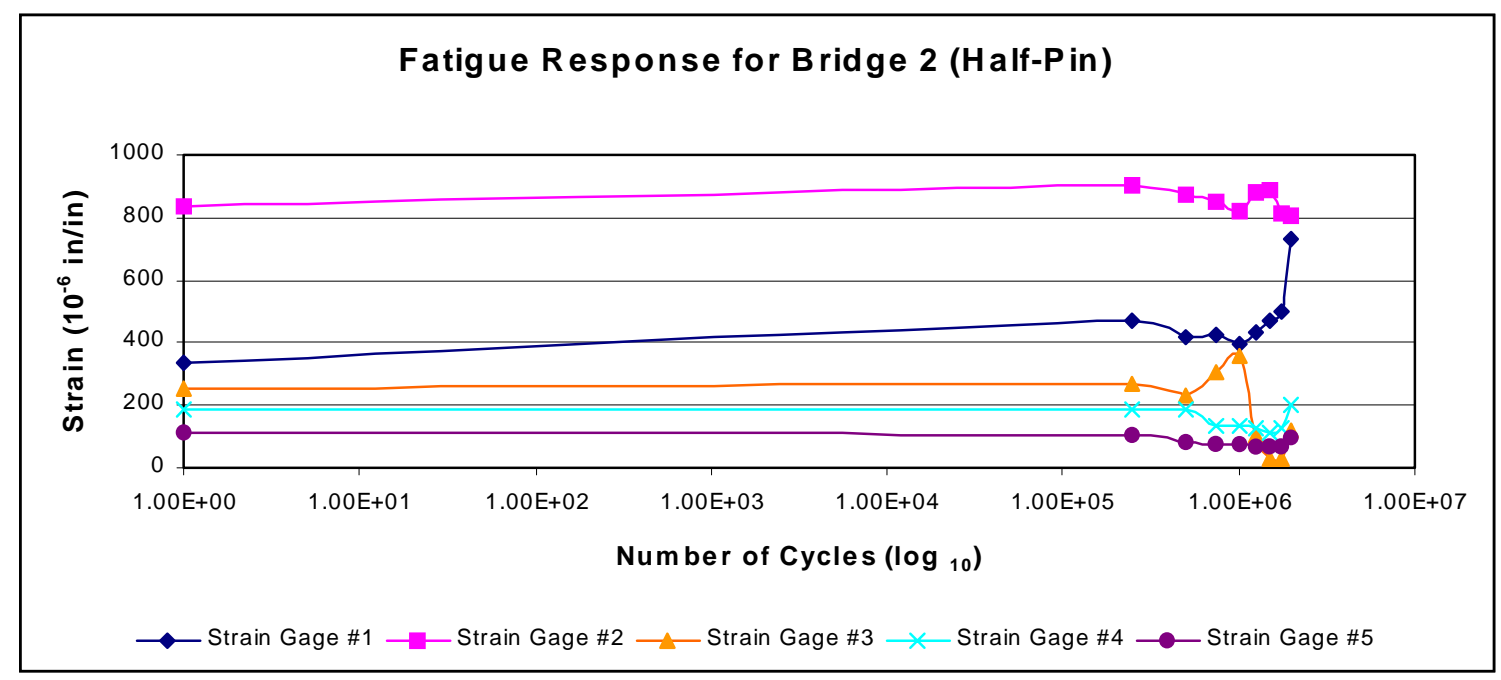

Figure 6.3.3: Fatigue Response Graph for Model \#2 (Half-Pin) 
Fatigue response graphs representative of half-pin and full-pin static testing of Model II are shown in Figures 6.3.3 and 6.3.4, respectively.

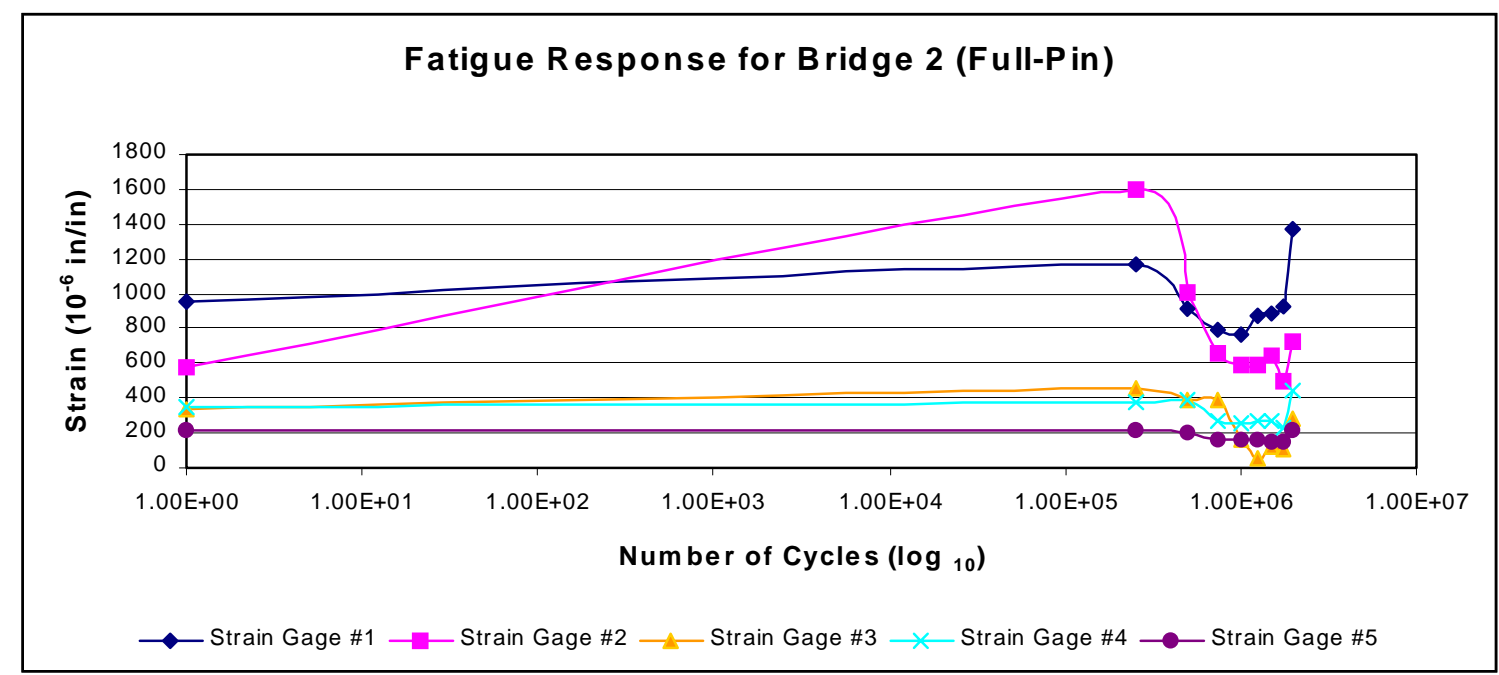

Figure 6.3.4: Fatigue Response Graph for Model \#2 (Full-Pin)

Graphical comparisons between the four representatives reveal trends of decreasing strain values generating around one million cycles. This pattern is most likely attributed to microscopic cracking of the decking in an effort to relieve excessive strain propagations. This type of pattern is generally regarded as typical in terms of the material selection, and no apparent problems are revealed from this practice of fatigue test simulations.

\subsection{Global Deflection Evaluation}

Global deflection evaluations were previously performed in Section 6.1. In this section, the theoretical value for deflection was found to be 0.106 inches for Model I, and 0.118 inches for Model II. These figures were then compared to the experimental values 
obtained from individual static tests conducted on both test models. A subsidiary comparison regarding the effective base of the timber deck was also included in this section. Experimental results were then compared with adjusted values and theoretical figures, to conclude differences associated with global deflection values. Values obtained from Table 6.1 reveal average experimental deflections to be equivalent to 0.128 inches for Model I and 0.120 inches for Model II, respectively.

In the calculations corresponding to global deflection, the attained values were not adjusted for shear deflection because of the relatively insignificant contributions. The rudimentary computation for shear deflection is:

$$
\Delta_{\text {shear }}=\mathrm{kPL} / 4 \mathrm{AG}
$$

where:

$$
\begin{aligned}
& \Delta=\text { deflection }(\text { in }) \\
& \mathrm{k}=\text { shape factor } \cong 1.0 \\
& \mathrm{P}=\text { magnitude of concentrated load }(\mathrm{lb}) \\
& \mathrm{L}=\text { center-to-center beam spacing }(\mathrm{in}) \\
& \mathrm{G}=\text { shear modulus of elasticity for wood }\left({\left.\mathrm{lb} / \mathrm{in}^{2}\right)}^{2}\right. \\
& \mathrm{A}=\text { effective area }\left(\mathrm{in}^{2}\right)
\end{aligned}
$$

Furthermore,

$$
\mathrm{G}=\mathrm{E} / 2(1+\mathrm{v}) \cong 90 \times 10^{3} \text { psi for wood }
$$


Substitution of values and solution of this equation yields:

$$
\Delta_{\text {shear }}=1.0 \times 10,000 \mathrm{lb} \times 69 \mathrm{in} / 4 \times 12 \mathrm{in} \times 7.5 \mathrm{in} \times 90 \times 10^{3} \mathrm{psi}
$$

Therefore,

$$
\Delta_{\text {shear }}=0.022 \text { in (very small!) }
$$

\subsection{Local Deflection Evaluation}

Local deflection evaluations are performed on the timber deck portion situated directly under the patch loading. Data resulting from this section exhibit potential irregularities concerning vertical slippage of individual laminates procuring from the excessive pounding action associated with the dynamic fatigue test operation. The basis of the theoretical approach for calculating local deflection contributions is relative to the global deflection formula previously displayed in Figure 6.1.1. Relevant timber material properties are substituted into the deflection equation replacing steel values to account for localized effects. Actual values can then be inserted so that the equation takes the following shape:

$$
\Delta=\mathrm{PL}^{3} / 48 \mathrm{EI}
$$

In this equation, the modulus of elasticity (E) for the incorporated species of glued-laminated timber was found in the National Design Specification (NDS) to be equivalent to $1,600,000$ psi. Additional changes to the equation resulted in an induced 
variance of the moment of inertia (I) subsequent to the two collective models. Nominal dimensions of the decking also attributed to substantial differences in relevant inertial provisions. Representative length (L) calculations enlisted in the preceding formula were indicative of reflective quarter-points corresponding to appropriate steel stringer positioning. These expressions reduced the rudimentary equation for local deflection attributes into a series of constants combined with only one variable. The load (P) was the first constant, and it was consistently maintained at a pressure of 20,000 pounds. The effective length was also introduced as a constant value of 69 inches. The decision to incorporate this figure was based on typical applications of quarter point inductions recommended in the $16^{\text {th }}$ edition of Standard Specifications for Highway Bridges. This value was determined by taking the overall spacing between the two supports and adding one quarter of the flange length of each stringer. The recommended value for the modulus of elasticity was already expressed at 1,600,000 psi, leaving only the variable for the moment of inertia for mentioning. The formula used in calculating the moment of inertia for each case was taken as:

$$
\mathrm{I}=\left(\mathrm{b}_{\mathrm{eff}} \mathrm{x} \mathrm{h} \mathrm{h}^{3}\right) / 12
$$

This expression is typically referred as the general formula for calculating the moment of inertia, and it is valid only for the case of existing rectangular cross-sectional specimens where:

$$
\begin{aligned}
& b_{\text {eff }}=\text { effective base of the timber deck } \\
& h=\text { height of the timber deck }
\end{aligned}
$$


Research previously performed by Barger (3) suggests that the effective base associated with timber decking is approximately equivalent to one-sixth of its original dimension. Original base compilations for each model tested in this project were equivalent to 72 inches, which would suggest an effective span in the general region of 12 inches. Table 6.5 details the experimentally obtained deflection values with several subsequent theoretical computations for beneficial comparisons. Selective theoretical formulations were depicted according to effective base configurations of 8 inches, 10 inches, 12 inches, and 15 inches, respectively. Supporting computations are also included detailing aspects for the two separate cases for demonstrational purposes.

\section{$\underline{\text { For Model I: }}$}

$$
\begin{aligned}
& \Delta=\mathrm{PL}^{3} / 48 \mathrm{EI} \\
& \Delta=(20,000 \mathrm{lb}) \times(69 \mathrm{in})^{3} / 48 \times\left(1.6 \times 10^{6}{\left.\mathrm{lb} / \mathrm{in}^{2}\right) \times \mathrm{I}}\right. \\
& \Delta=6,570,180,000 \mathrm{lb}-\mathrm{in}^{3} /\left[76,800,000 \mathrm{lb} / \mathrm{in}^{2} \times\left(\left(\mathrm{b}_{\mathrm{eff}} \times \mathrm{h}^{3}\right) / 12\right)\right] \\
& \Delta=6,570,180,000 \mathrm{lb}-\mathrm{in}^{3} /\left[76,800,000 \mathrm{lb} / \mathrm{in}^{2} \times\left(\mathrm{b}_{\mathrm{eff}} \times(7.5 \mathrm{in})^{3} / 12\right)\right] \\
& \Delta=6,570,180,000 \mathrm{lb}-\mathrm{in}^{3} /\left[2,700,000,000 \mathrm{lb}-\mathrm{in} \times \mathrm{b}_{\mathrm{eff}}\right] \\
& \Delta=2.4334 \mathrm{in}^{2} / \mathrm{b}_{\mathrm{eff}}
\end{aligned}
$$

Selected values for the effective width can now be substituted into the simplified equation to obtained associated theoretical deflection values. 


$$
\begin{aligned}
& \Delta_{(\text {beff }=8,)}=2.4334 \mathrm{in}^{2} / 8 \mathrm{in}=0.304 \mathrm{in} \\
& \Delta_{\left(\text {beff }=10^{\prime \prime}\right)}=2.4334 \mathrm{in}^{2} / 10 \mathrm{in}=0.243 \mathrm{in} \\
& \Delta_{\left(\text {beff }=12^{\prime \prime}\right)}=2.4334 \mathrm{in}^{2} / 12 \mathrm{in}=0.203 \mathrm{in} \\
& \Delta_{\left(\text {beff }=15^{\prime \prime}\right)}=2.4334 \mathrm{in}^{2} / 15 \mathrm{in}=0.162 \mathrm{in}
\end{aligned}
$$

\section{For Model II:}

$$
\begin{aligned}
& \Delta=\mathrm{PL}^{3} / 48 \mathrm{EI} \\
& \Delta=(20,000 \mathrm{lb}) \times(69 \mathrm{in})^{3} / 48 \times\left(1.6 \times 10^{6}{\left.\mathrm{lb} / \mathrm{in}^{2}\right) \times \mathrm{I}}=6,570,180,000 \mathrm{lb}-\mathrm{in}^{3} /\left[76,800,000 \mathrm{lb} / \mathrm{in}^{2} \times\left(\left(\mathrm{b}_{\mathrm{eff}} \times \mathrm{h}^{3}\right) / 12\right)\right]\right. \\
& \Delta=6,570,180,000 \mathrm{lb}-\mathrm{in}^{3} /\left[76,800,000 \mathrm{lb} / \mathrm{in}^{2} \times\left(\mathrm{b}_{\mathrm{eff}} \times(6.0 \mathrm{in})^{3} / 12\right)\right] \\
& \Delta=6,570,180,000 \mathrm{lb}-\mathrm{in}^{3} /\left[1,382,400,000 \mathrm{lb}-\mathrm{in} \times \mathrm{b}_{\mathrm{eff}}\right] \\
& \Delta=4.7527 \mathrm{in}^{2} / \mathrm{b}_{\mathrm{eff}}
\end{aligned}
$$

Implementation of proposed effective width dimensions into this simplified equation provides the following theoretical deflection values.

$$
\begin{aligned}
& \Delta_{\left(\text {beff }=8^{\prime \prime}\right)}=0.594 \\
& \Delta_{(\text {beff }=10 ”)}=0.475 \\
& \Delta_{(\text {beff }=12 ”)}=0.396 \\
& \Delta_{(\text {beff }=15, ")}=0.317
\end{aligned}
$$


Table 6.5: Comparison of Local Exp. Deflection vs. Theoretical Deflections for 20 kip loadings.

\begin{tabular}{|c|c|c|c|c|c|c|}
\hline $\begin{array}{c}\text { Model } \\
\#\end{array}$ & $\begin{array}{c}\text { Static Test \# } \\
\text { (Full Pin) }\end{array}$ & $\begin{array}{c}\text { Experimental } \\
\text { Deflection } \\
\text { (in) }\end{array}$ & $\begin{array}{c}\text { Theoretical } \\
\text { Deflection } \\
\text { beff }=8 \text { ', } \\
\text { (in) }\end{array}$ & $\begin{array}{l}\text { Theoretical } \\
\text { Deflection } \\
\text { beff }=10 "^{\text {(in) }}\end{array}$ & $\begin{array}{l}\text { Theoretical } \\
\text { Deflection } \\
\text { beff }=12, \\
\text { (in) }\end{array}$ & $\begin{array}{l}\text { Theoretical } \\
\text { Deflection } \\
b_{\text {eff }}=15 " \\
\text { (in) }\end{array}$ \\
\hline \multirow{5}{*}{ Model I } & 1 & .285 & .304 & .243 & .203 & .162 \\
\hline & 2 & .249 & .304 & .243 & .203 & .162 \\
\hline & 3 & .264 & .304 & .243 & .203 & .162 \\
\hline & 4 & .248 & .304 & .243 & .203 & .162 \\
\hline & 5 & .302 & .304 & .243 & .203 & .162 \\
\hline \multirow{10}{*}{$\begin{array}{c}\text { Model } \\
\text { II }\end{array}$} & 1 & .393 & .594 & .475 & .396 & .317 \\
\hline & 2 & .325 & .594 & .475 & .396 & .317 \\
\hline & 3 & .324 & .594 & .475 & .396 & .317 \\
\hline & 4 & .384 & .594 & .475 & .396 & .317 \\
\hline & 5 & .335 & .594 & .475 & .396 & .317 \\
\hline & 6 & .326 & .594 & .475 & .396 & .317 \\
\hline & 7 & .320 & .594 & .475 & .396 & .317 \\
\hline & 8 & .320 & .594 & .475 & .396 & .317 \\
\hline & 9 & .321 & .594 & .475 & .396 & .317 \\
\hline & 10 & .299 & .594 & .475 & .396 & .317 \\
\hline
\end{tabular}

Results from this comparison reflect the accuracy of theoretical computations regarding localized deflection characteristics associated with timber materials. From Table 6.5, conflicting circumstances are noticeable regarding effective width performances corresponding to the two separate models.

For the case of the first model, the effective width is apparently poised between values of 8 inches and 10 inches. In the second model, this trend is indicative of an effectiveness ratio ranging between values of 12 inches and 15 inches. To further illustrate this phenomenon, subsequent computations were performed to determine average values obtained experimentally regarding localized deflection characteristics of 
the two models. Average deflection values were found to be equivalent to 0.2696 inches for Model I, and 0.3347 inches for Model II. Average values obtained in the first model suggests an effective width of approximately 9 inches, while the second model's average pertains to an effective width in the vicinity of 14 inches.

Selective variance attributions of effective width calculations for the two models is intriguing, and a perfect explanation for the correlating differences can not be given with total confidence; however, the reason for this incident is believed to be contributive to the relative stiffness effects associated with the two separate decks. The depth of the first model is 7.5 inches accounting for a superior stiffness ratio over the 6.0 inch depth of the second model. This added stiffness inhibits a portion of the rotational motion experienced in the supporting steel stringers. Without the ability to rotate as well as the second model, the first model succumbs to larger concentrations of localized shear deflection consequently reducing the effective width aspects of the decking. In the majority of materials, diminutive values of localized shear deflection attributes are relinquished from supporting calculations to simplify the procedure. This practice of exclusion can constitute problems, however, in association with timber materials where the localized shear deflection is regarded as very influential in the overall performance aspects. Generally, a material will sag proportionally under the duress of subsequent loadings. This pattern is typically indicative of the selected material properties and applicable geometric loading conditions. Curvature of the sag is usually smooth and gradually increases in correlation to the loading demonstrating the magnitude of the overall local deflection characteristics. In some circumstances, a significantly noticeable pultrusion can be detected directly under the induced loading. At this location, the 
previously smooth curvature appears out of context detailing the significant effects of local shear deflection. This detrimental effect generally constitutes approximately 8 to 10 percent of the overall localized deflection in timber.

\subsection{Prestress Loss Evaluation}

The subject of bar force losses is always a prevalent matter of concern in any type of prestressing application. Initial forces bestowed on a material offer additional strength gains resulting from confinement principles, and therefore are typically included in the design procedure. Portions of prestress losses are unavoidable, but accounted for in the design approach with a number of safety measures. Problems arise when prestress losses become sufficiently greater than anticipated, which can often result in some manner of failure.

In this project, the two models were periodically monitored for bar force losses. The experimental research approach instituted for this project mandated that the forces were to be monitored a total of three times during the process of fatigue testing. The first test was to be performed after the first rotation of fatigue cycling. The second series of monitoring was concluded after three days of fatigue testing, and the third test came after one week of simulation was completed. Recordings of bar forces in this report are merely approximations and not actual quantitative results.

Conclusion of this series of testing revealed only a single incidence of substantial bar force loses. This episode was displayed after the first rotation of Model I. After reinstitution of prestress forces, the model demonstrated no further effects stemming from 
this circumstance. Assumptions formed regarding this situation focus on the issue of moisture content levels contained in the first model.

\subsection{Allowable Bending Stress Evaluation}

For the purpose of precautionary measures, a final evaluation of this report focuses on the allowable bending stress pertaining to timber bridge materials. This type of check is performed to ensure that the invoked stresses are acceptable based on allotted design practices. Wood design manuals enlisting timber design strengths are generally required to accomplish this task. As mentioned in previous sections of this report, the National Design Specification (NDS) manual was incorporating for determining associated design strengths. With the assistance of the manual, the allowable stress can be evaluated through the following design formula listed as:

$$
\mathrm{f}_{\mathrm{b}} \leq \mathrm{F}_{\mathrm{b}}
$$

where:

$$
\begin{aligned}
& \mathrm{f}_{\mathrm{b}}=\text { bending stress maintained by the structure } \\
& \mathrm{F}_{\mathrm{b}}{ }^{\prime}=\text { allowable bending stress relative to material properties }
\end{aligned}
$$

The value for the actual bending stress, $\mathrm{f}_{\mathrm{b}}$, is typically the initial calculation made when performing this type of evaluation. Therefore, beginning with this format, the general formula for bending stress is:

$$
\mathrm{f}_{\mathrm{b}}=\mathrm{Mc} / \mathrm{I}=\mathrm{M} / \mathrm{S}
$$


where once again:

$$
\begin{aligned}
M= & \text { resultant internal moment }(\mathrm{lb}-\mathrm{in}) \\
\mathrm{c}= & \text { perpendicular distance from neutral axis to } \\
& \text { a point furthest away from neutral axis (in) } \\
\mathrm{I}= & \text { moment of inertia of cross sectional area }\left(\mathrm{in}^{4}\right)
\end{aligned}
$$

and

$$
\mathrm{S}=\text { elastic section modulus }\left(\text { in }^{3}\right)
$$

For a rectangular section, this equation reduces to:

$$
f_{b}=M / S=6 M /\left(b_{\text {eff }} \times d^{2}\right)
$$

where:

$$
\begin{aligned}
& b_{\text {eff }}=\text { effective base of the deck (in) } \\
& d=\text { depth of the deck (in) }
\end{aligned}
$$

For further reduction of this formula, three separate conditions associated with typical bridge design must first be satisfied.

(1.) Limitations regarding actual spacing requirements imply an overall reduction in effective spacing length from 69 inches to a maximum of 36 inches. 
(2.) Decks containing several stringers, perform as a continuous beam, therefore the effective deck span will be approximately equivalent to $0.8 \times 36$ in $\cong 28.8$ in

Relatively small effective spans, such as in this case, tend to exhibit similar characteristics as associated with distributed loads as opposed to concentric point loads. In this case, the bending moment can be further reduced to $\mathrm{M}=\mathrm{wL}^{2} / 8=\mathrm{PL} / 8$ instead of $\mathrm{M}=\mathrm{PL} / 4$.

Continuing on with this application, leads to the substitution of $\mathrm{M}=\mathrm{PL} / 8$ into the calculations further reducing the equation to:

$$
f_{b}=6(P L / 8) /\left(b_{\text {eff }} \times d^{2}\right)
$$

Furthermore,

$$
f_{b}=0.75 P L /\left(b_{\text {eff }} \times d^{2}\right)
$$

Insertion of dimensional values transforms the equation into the following form:

$$
f_{b}=0.75 \times 20,000 \mathrm{lb} \times 28.8 \mathrm{in} / \mathrm{b}_{\text {eff }} \times \mathrm{d}^{2}
$$

Simplification to this equation leads to:

$$
f_{b}=432,000 l b-i n / b_{\text {eff }} \times d^{2}
$$


Solution to this equation must be split into separate sections in order to account for the varying dimensions associated with the depth of the subsequent models.

\section{For Model 1:}

$$
\begin{aligned}
& f_{b(\text { beff }=9 \text { in })}=432,000 \mathrm{lb} \text {-in } / 9 \text { in } \times(7.5 \text { in })^{2}=854 \mathrm{lb} / \mathrm{in}^{2} \\
& f_{b(\text { beff }=12 \text { in })}=432,000 \mathrm{lb} \text {-in } / 12 \text { in } \times(7.5 \mathrm{in})^{2}=640 \mathrm{lb} / \mathrm{in}^{2}
\end{aligned}
$$

\section{For Model 2:}

$$
\begin{aligned}
& \mathrm{f}_{\mathrm{b}(\text { beff }=12 \text { in })}=432,000 \mathrm{lb} \text {-in } / 12 \text { in } \mathrm{x}(6.0 \mathrm{in})^{2}=1,000 \mathrm{lb} / \mathrm{in}^{2} \\
& \left.\mathrm{f}_{\mathrm{b}(\text { beff }}=14 \text { in }\right) \\
& =432,000 \mathrm{lb}-\text { in } / 14 \text { in } \mathrm{x}(6.0 \mathrm{in})^{2}=858 \mathrm{lb} / \mathrm{in}^{2}
\end{aligned}
$$

The completion of that formula leads to developing the allowable bending stress design approach. The general formula utilized to produce a design number is shown below in the following format:

$$
F_{b}{ }^{\prime}=F_{b} \times C_{D} \times C_{M} \times C_{t} \times C_{V}
$$

where:

$\mathrm{F}_{\mathrm{b}}=$ basic design strength, and the $\mathrm{C}$ values are reduction factors reflective of different situations that may be exhibited by the timber material. A full listing and explanation of this formula is explicitly detailed in the NDS manual, and should be referred to for further clarification. 
Continuing on with the formula by substituting quantities for the variables yields:

$$
\mathrm{F}_{\mathrm{b}}{ }^{\prime}=2,200 \mathrm{lb} / \mathrm{in}^{2}(0.9)(0.8)(1.0)(0.896)
$$

Solution of this equation provides the following design strength:

$$
\mathrm{F}_{\mathrm{b}}{ }^{\prime}=1,419 \mathrm{lb} / \mathrm{in}^{2}
$$

With solutions to the two separate formulas, they can now be compared to determine whether the bending stress is allowable.

Therefore,

$$
\mathrm{f}_{\mathrm{b}} \leq \mathrm{F}_{\mathrm{b}}{ }^{\prime}=1,419 \mathrm{lb} / \mathrm{in}^{2}
$$

For Model I:

$$
\begin{aligned}
& \left.\mathrm{f}_{\mathrm{b}(\text { beff }}=9 \text { in }\right) \\
& \left.\mathrm{f}_{\mathrm{b}(\mathrm{beff}}=12 \mathrm{in}\right) \\
& =640 \mathrm{lb} / \mathrm{in}^{2}
\end{aligned}
$$

For Model II:

$$
\begin{gathered}
\mathrm{f}_{\mathrm{b}(\text { beff }=12 \text { in })}=1,000 \mathrm{lb} / \mathrm{in}^{2} \\
\mathrm{f}_{\mathrm{b}(\text { beff }=14 \text { in })}=858 \mathrm{lb} / \mathrm{in}^{2}
\end{gathered}
$$


Comparison between the respective values reveals that the design strength relative to the glued-laminated timber decking is substantially greater than the actual bending stress for each case. This implies for the necessity of a reduction in current spacing of stringers to a maximum distance of 36 inches. 


\section{Chapter 7}

\section{Summary, Conclusions, and Recommendations}

\subsection{Summary}

The objective of this project was to simulate a stress laminated timber bridge deck model stiffened with wide flange steel stingers for performance monitoring. The simulation accounted for typical HS-20 repetitive loadings offered by a mechanically controlled actuator. The bridge model tested in this experiment is depicted as a prestressed glued-laminated timber deck supported by steel stringers. The main focus of this project was to monitor certain aspects associated with the structural efficiency of the system. To account for these different aspects, a series of static and fatigue tests were performed at decisive intervals of the research program. The evaluations derived in this report were based on a total of two individual models. The two models shared many common characteristics and displayed several comparable results. Both models were constructed in the major units laboratory at West Virginia University. After erection, the models were performance tested in the Major Units Laboratory.

Model I consisted of dimensions measuring $6 \mathrm{ft} \times 10 \mathrm{ft} \times 7.5 \mathrm{in}$. A fatigue test was placed on this model attributing to one million cycles. At the completion of this test, detrimental effects to the surface area of the decking were noticeable (refer to Section 5.3.1). Assumptions regarding contributions for this failure were made, and adjustments to the load inclination of the actuator were performed based on these assumptions. 
Model II had similar dimensions measuring $6 \mathrm{ft}$ x $10 \mathrm{ft}$ x $6.0 \mathrm{in}$. The fatigue tests performed on this model encompassed two million fatigue cycles. The additional cycles were placed on this model to account for the theory of improper alignment of the load actuator. After the completion of this testing, no residual deformations were noticeable on the surface of the deck. This observation supports the assumption relative to the error experienced in the first model.

\subsection{Conclusions}

Results and comparison evaluations performed in preceding sections of this report contribute to the determination of several conclusions attributed to the glued-laminated timber decking system fastened to supporting steel stringers.

1. Losses associated with compositeness in correlation with connection detail are substantial, however significant forces are maintained throughout fatigue cycling encounters. Both models performed continuously well regardless of composite losses.

2. Spacing of connection detail is critical in maximizing structural efficiency of timber and steel bridge material combinations. Greater effects of compositeness were associated with two foot spacing of connectors as opposed to the four foot spacing.

3. Global bending deflection values performed similar to anticipated predictions based on theoretical computations. The maximum value of global deflection obtained through experiment was 0.137 inches. This value was found after one million cycles were placed 
on Model I. Also shear deflections are negligible based on computations performed in Section 6.4.

4. Global strain values also maintained considerable performance evaluations based on similar theoretical computations. The maximum value of global strain obtained through experiment was $4.77 \times 10^{-4} \mathrm{inch} / \mathrm{inch}$. This value was found after the completion of 500,00 fatigue cycles placed on Model I.

5. Typical fatigue response criteria generated effective patterns when converted to equivalent traffic flows reflective of rural locations. In general, timber appears to be an excellent alternative for bridges in locations where the average daily flow of traffic is less than 400 vehicles. In this type of situation, rudimentary calculations of fatigue determined that the structure should surpass all design applications.

6. Diminutive bar force losses exhibited minimal effects regarding deflection responses expressed by the overall system performance. Deflection values appeared to remain relatively constant throughout static testing of both models.

7. Bending stresses maintained by the structure satisfies the allowable bending stress equation detailed in the National Design Specification (NDS). This situation represents a typical bridge application with effective stringer spacing consisting of less than 36 inches. 
8. Fabrication of the bridge is relatively easy, and requires only a minimal amount of training. Predrilled holes in the laminated panels ensure proper alignment and eliminate the need for skilled labor. Application of WVU connector is a straight-forward procedure.

9. Effective width values vary according to actual dimensions of the decking, and can only be approximated with the equation of one-sixth of the total span.

10. The composite action experienced through the WVU connector significantly increases the overall effectiveness of the bridge.

\subsection{Recommendations}

Based on the results incorporated in this report and additional projects accredited in the literature review, some general recommendations can be established regarding the best approach for constructing timber bridges in the future. In general, short span prestressed timber bridges appear to be a reliable alternative in rural bridge design applications. Pure aesthetics responsive to timber construction add to the allure of this optional approach. Incorporation of steel stringers offers adequate stiffness contributions, while serving to lower overall project costs and nominal space requirements. Additional stringer implementation, along with an increased deck thickness, should satisfy imposing design equations. Bridge applications will also benefit by this combination with significantly reduced strain and deflection values. It should be noted that results from this

study were gathered under ideal controlled conditions, and actual environmental patterns may vary analytical interpolations. Therefore, close monitoring is requested for additional 
timber bridges to account for uncontrollable field conditions. Rudimentary calculations define the predicted life span for this bridge to easily surpass any basic design frames. This calculation is merely theoretical in nature and actual results may provide sources of contradiction. 


\section{References}

(1.) Analysis and Design of Stress-Laminated Timber Bridge Decks, Petro, Samer, Thesis, West Virginia University, 1993

(2.) Behavior of Timber Deck-Steel Stringer Bridges Subjected to Gravity Loads, Kalomallos, Dimitrios, Thesis, West Virginia University, 1989

(3.) Experimental and Theoretical Evaluation of Stress-Laminated Timber T-, Bulb T-, and Box-Systems, L. Shelton, Barger, Jr., Thesis, West Virginia University, 1995

(4.) Modern Timber Bridges of West Virginia, Vol. I and II, Dickson, Barry, 1995

(5.) Monitoring of Stress Laminated Bridges, GangaRao, Hota; Dickson, Barry; Raju, Penmatsa, CFC Report \#91-156

(6.) Performance of Stress-Laminated Wood Deck on Steel Stringers, Vijayachandran, Vijith, Thesis, West Virginia University, 1996

(7.) Standard Specifications for Highway Bridges, $16^{\text {th }}$ edition, 1996, American Association of State Highway and Transportation Officials (AASHTO)

(8.) Structural Monitoring of Stress-Laminated Timber Bridges in West Virginia, Dickson, Barry, CFC Report \#93-164, 1995

(9.) Structural Monitoring of Stress-Laminated Timber Bridges in West Virginia, Dickson, Barry, CFC Report \#96-238, 1996

(10.) The Behavior of Bolt Anchors for Timber Deck on Steel Stringers, Wu, Shaojie, Thesis, West Virginia University, 1990

(11.) Timber Bridges-Design, Construction, Inspection, and Maintenance, Ritter, Michael, 1990 


\section{Appendix}

The following section contains the complete set of graphs associated with every static test performed on the two models. There are four separate graphs representing the completion of every 250,000-fatigue cycles. The four graphs are divided into half, with two graphs designated for the half-pin testing and the other two graphs for the full-pin testing (refer to Section 4.5.2 for an explanation on the variations of static testing selected for this project). Of the two graphs designated for each type of testing, one graph accounts for strain readings, while the other graph represents deflections.

The total amount of graphs incorporated in the appendix is sixty, with twenty graphs representing Model I and the remaining forty graphs accounting for Model II. Each graph is listed chronologically by performed static tests. The number of fatigue cycles in comparison to static test is as follows:

\section{$\underline{\text { Test \# Completed Cycles }}$}

For Model I:

$\begin{array}{lc}\text { Initial Static Test } & 0 \\ \text { Static Test \#2 } & 250,000 \\ \text { Static Test \#3 } & 500,000 \\ \text { Static Test \#4 } & 750,000 \\ \text { Static Test \#5 } & 1,000,000\end{array}$

For Model II:

$\begin{array}{lc}\text { Initial Static Test } & 0 \\ \text { Static Test \#2 } & 250,000 \\ \text { Static Test \#3 } & 500,000 \\ \text { Static Test \#4 } & 500,000^{*} \\ \text { Static Test \#5 } & 750,000 \\ \text { Static Test \#6 } & 1,000,000 \\ \text { Static Test \#7 } & 1,250,000 \\ \text { Static Test \#8 } & 1,500,000 \\ \text { Static Test \#9 } & 1,750,000 \\ \text { Static Test \#10 } & 2,000,000\end{array}$

\footnotetext{
* Two separate tests were conducted after 500,000 fatigue cycles because of a delay for routine maintenance of the testing apparatus.
} 


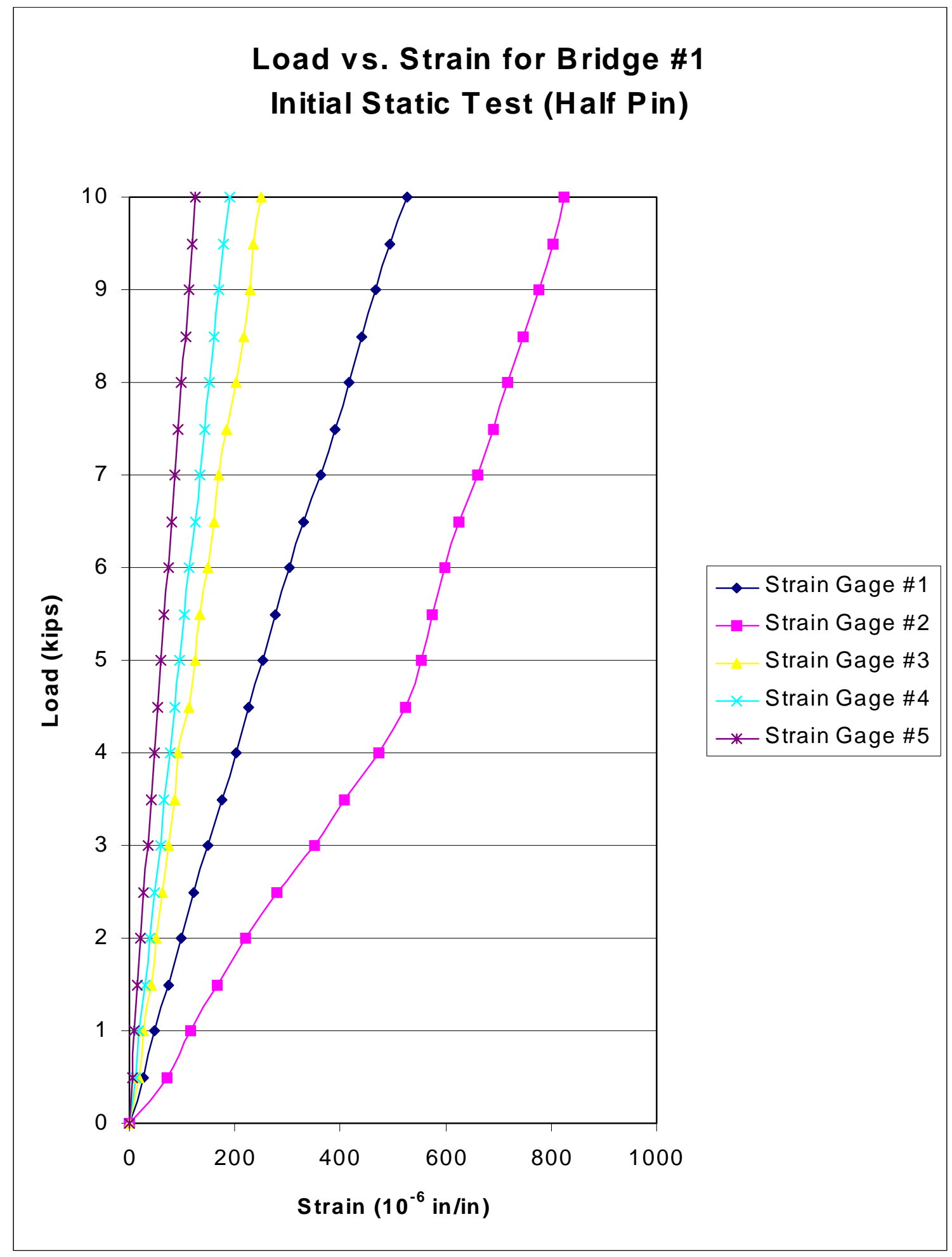

A.1 Initial Strain (Half Pin) Graph for Bridge \#1 


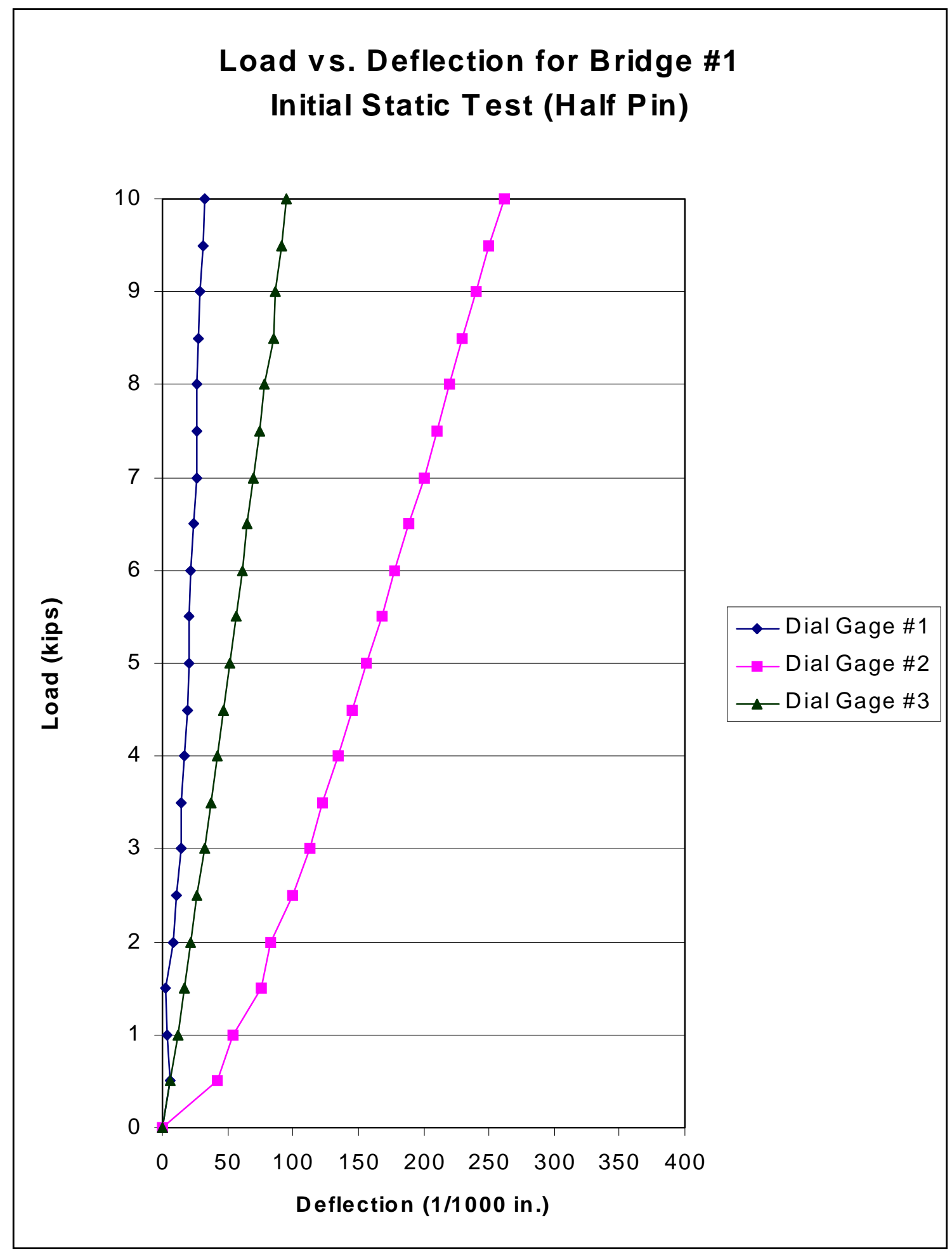

A.2 Initial Deflection (Half Pin) Graph for Bridge \#1 


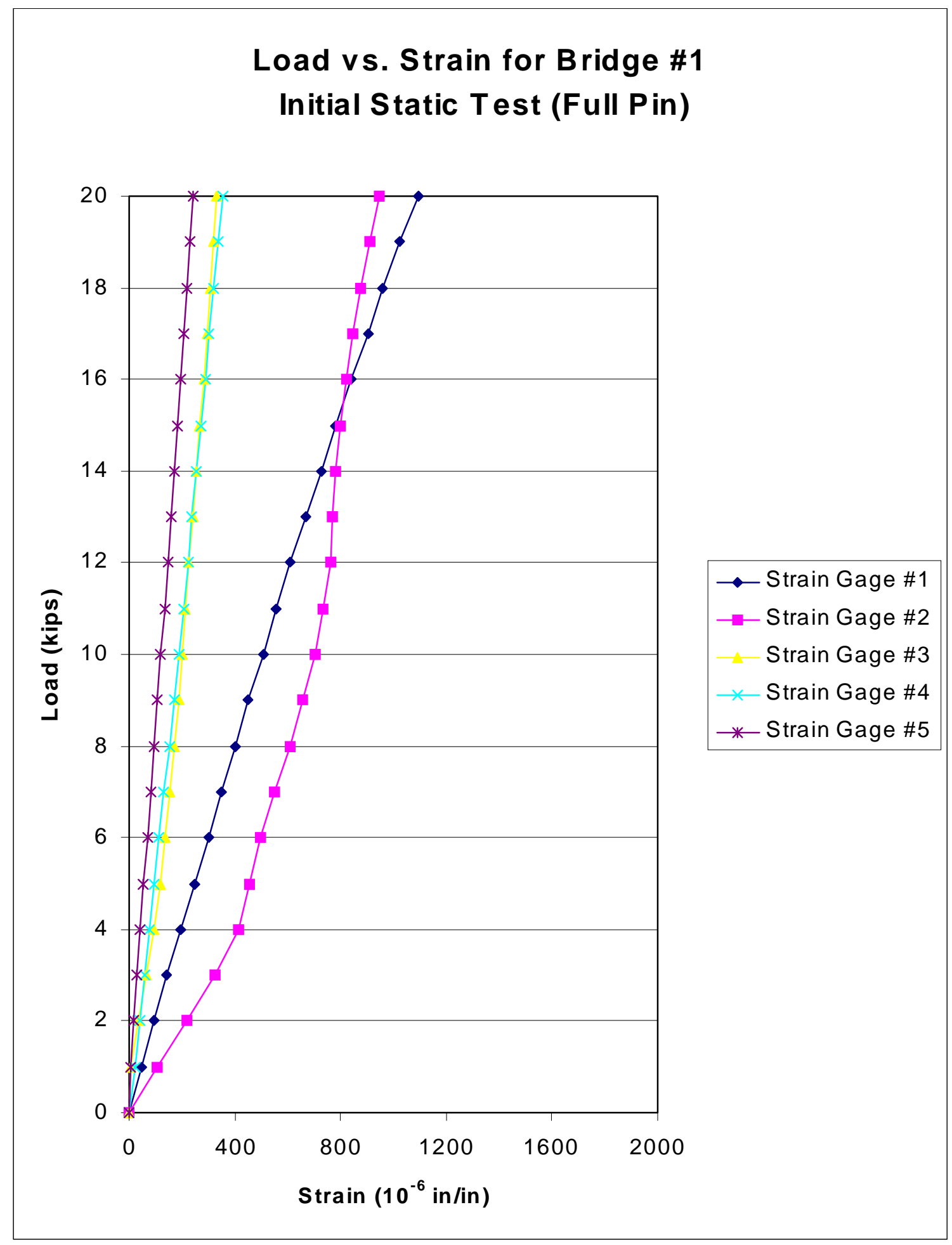

A.3 Initial Strain (Full Pin) Graph for Bridge \#1 


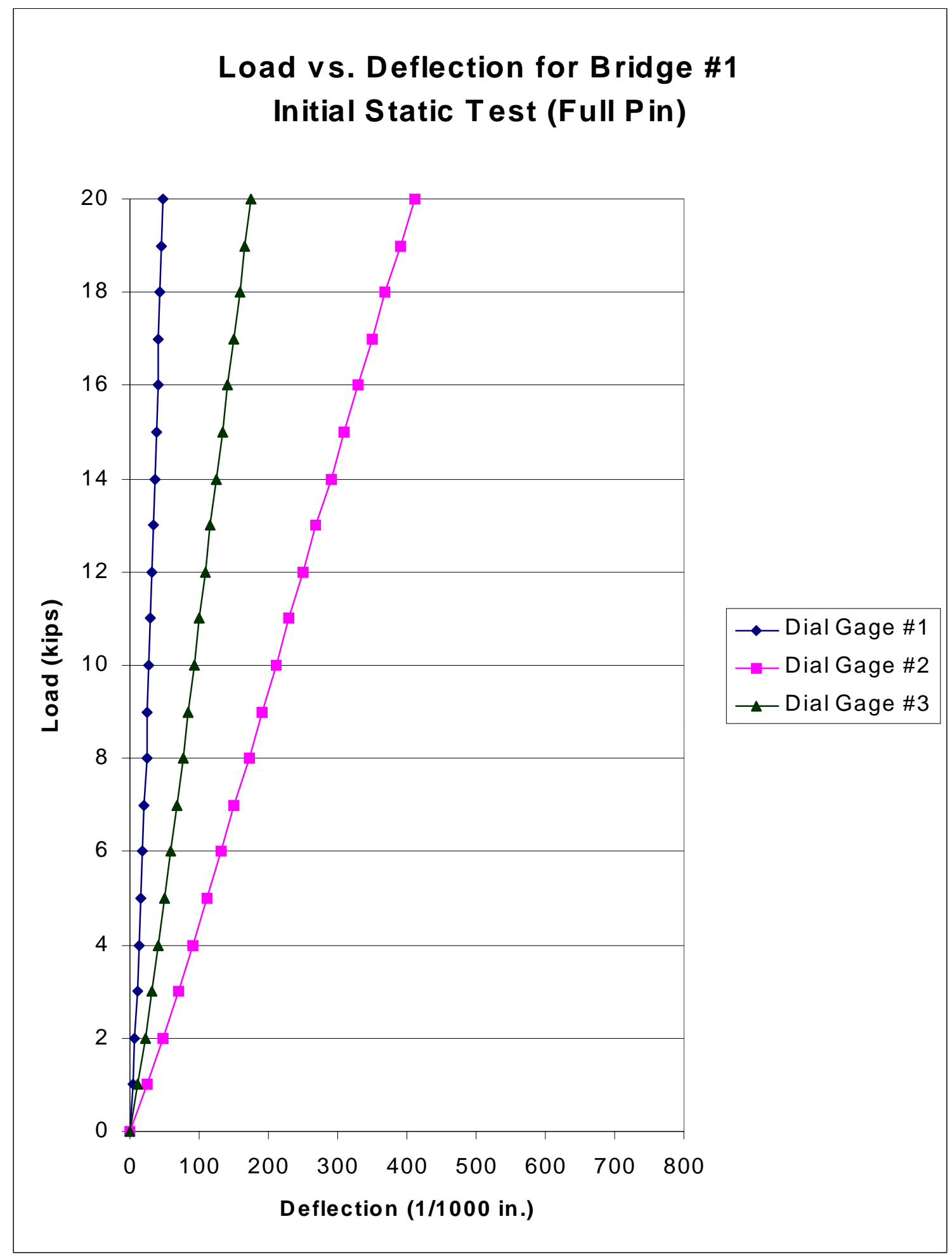

A.4 Initial Deflection (Full Pin) Graph for Bridge \#1 


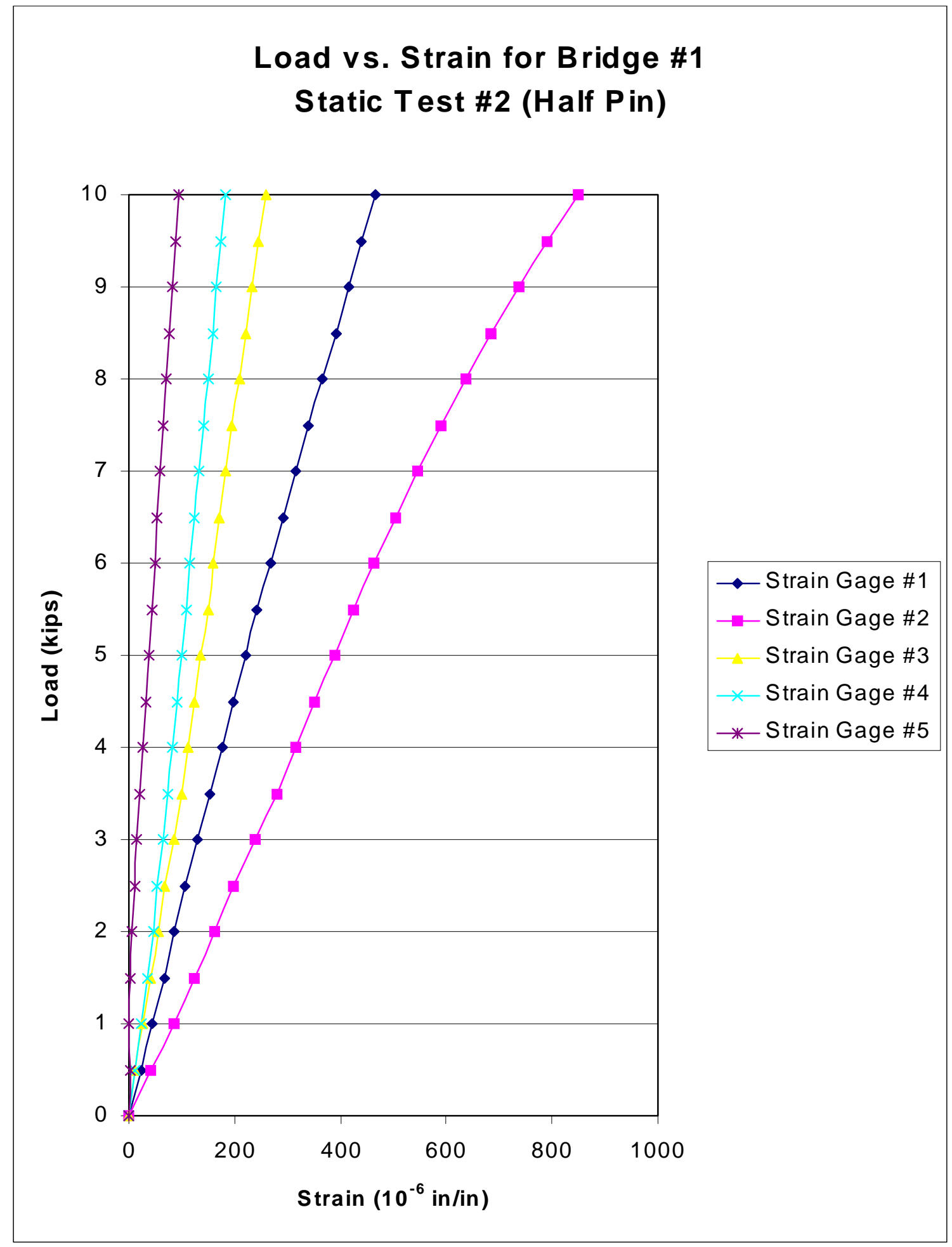

A.5 Strain Test \#2 (Half Pin) Graph for Bridge \#1 


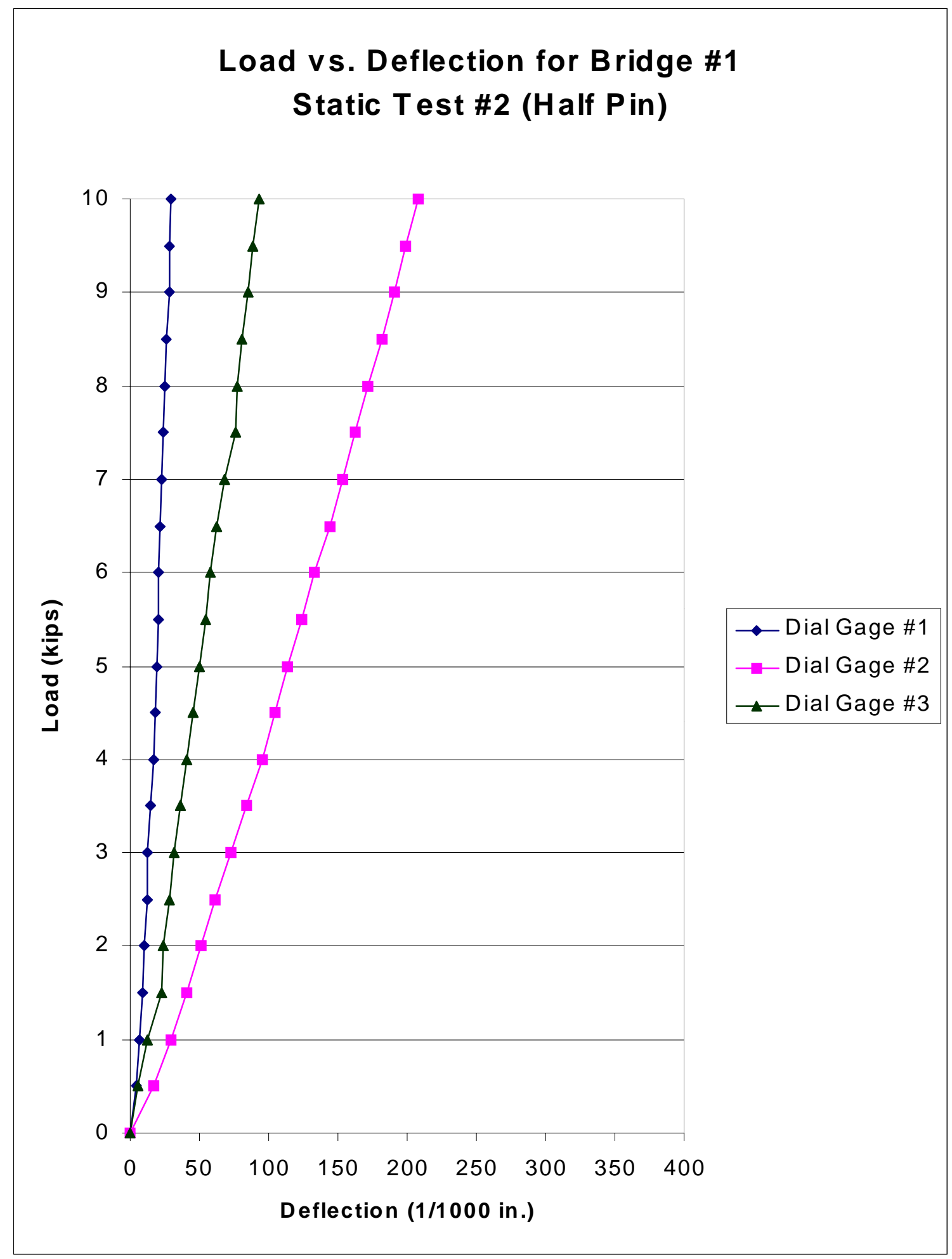

A.6 Deflection Test \#2 (Half Pin) Graph for Bridge \#1 


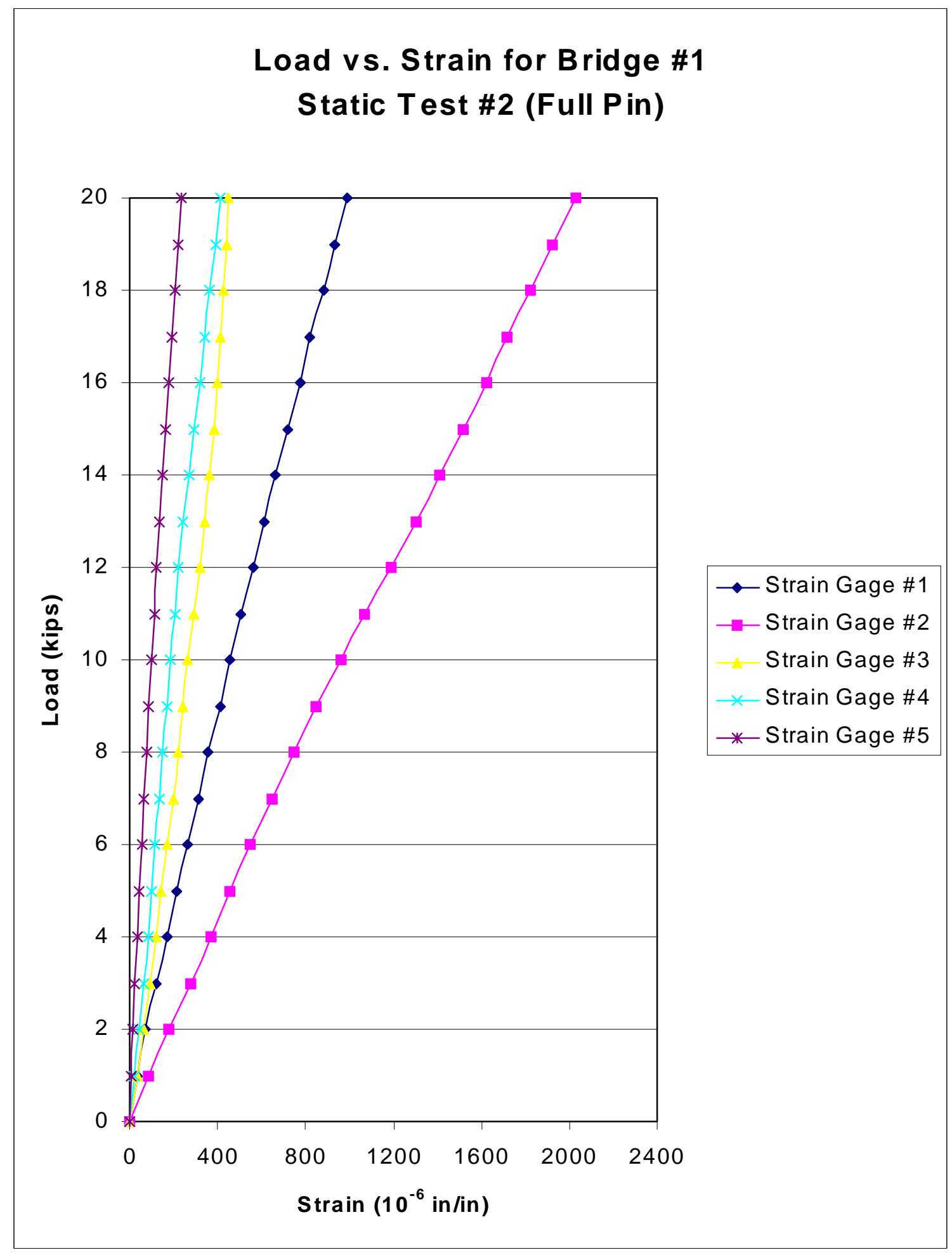

A.7 Strain Test \#2 (Full Pin) Graph for Bridge \#1 


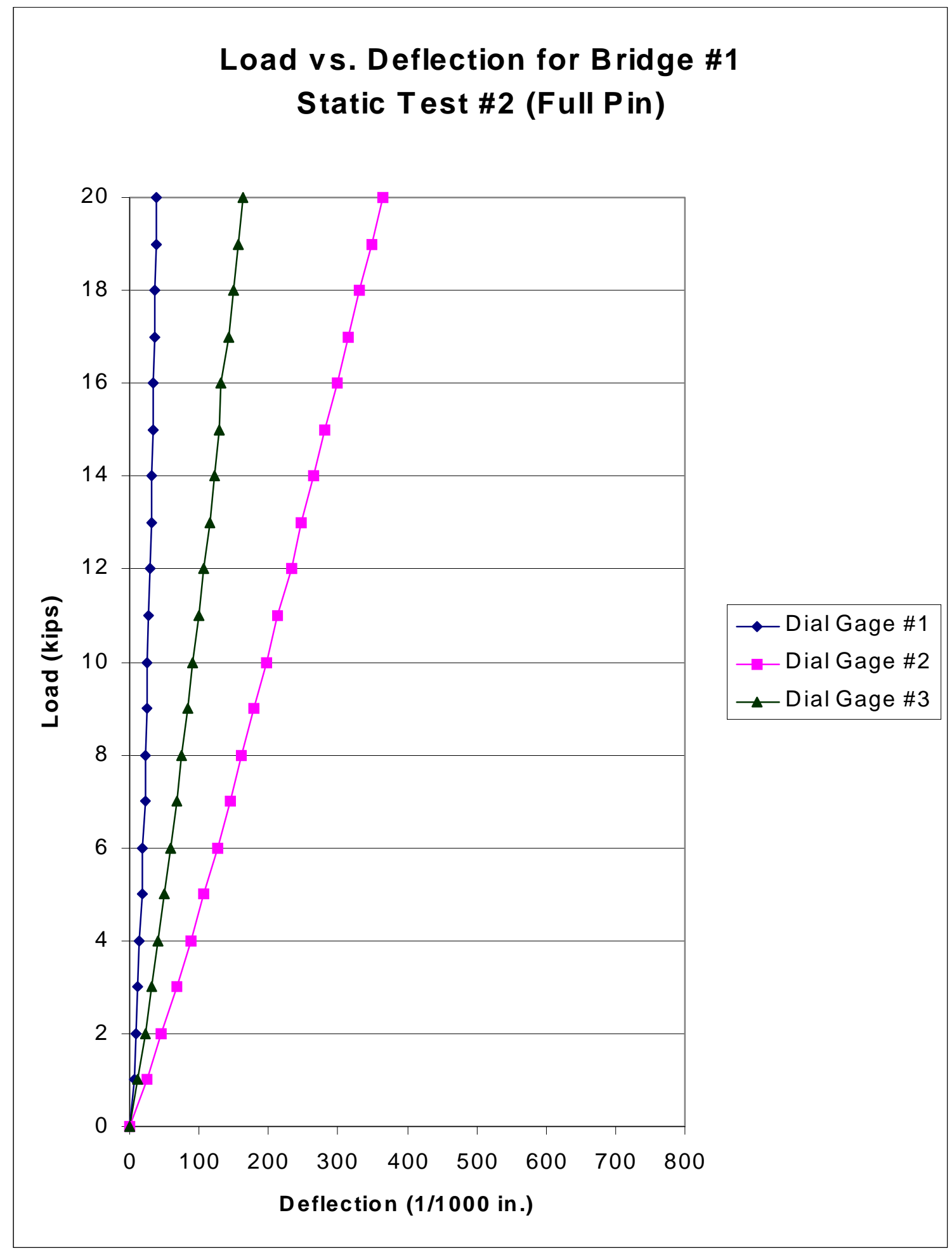

A.8 Deflection Test \#2 (Full Pin) Graph for Bridge \#1 


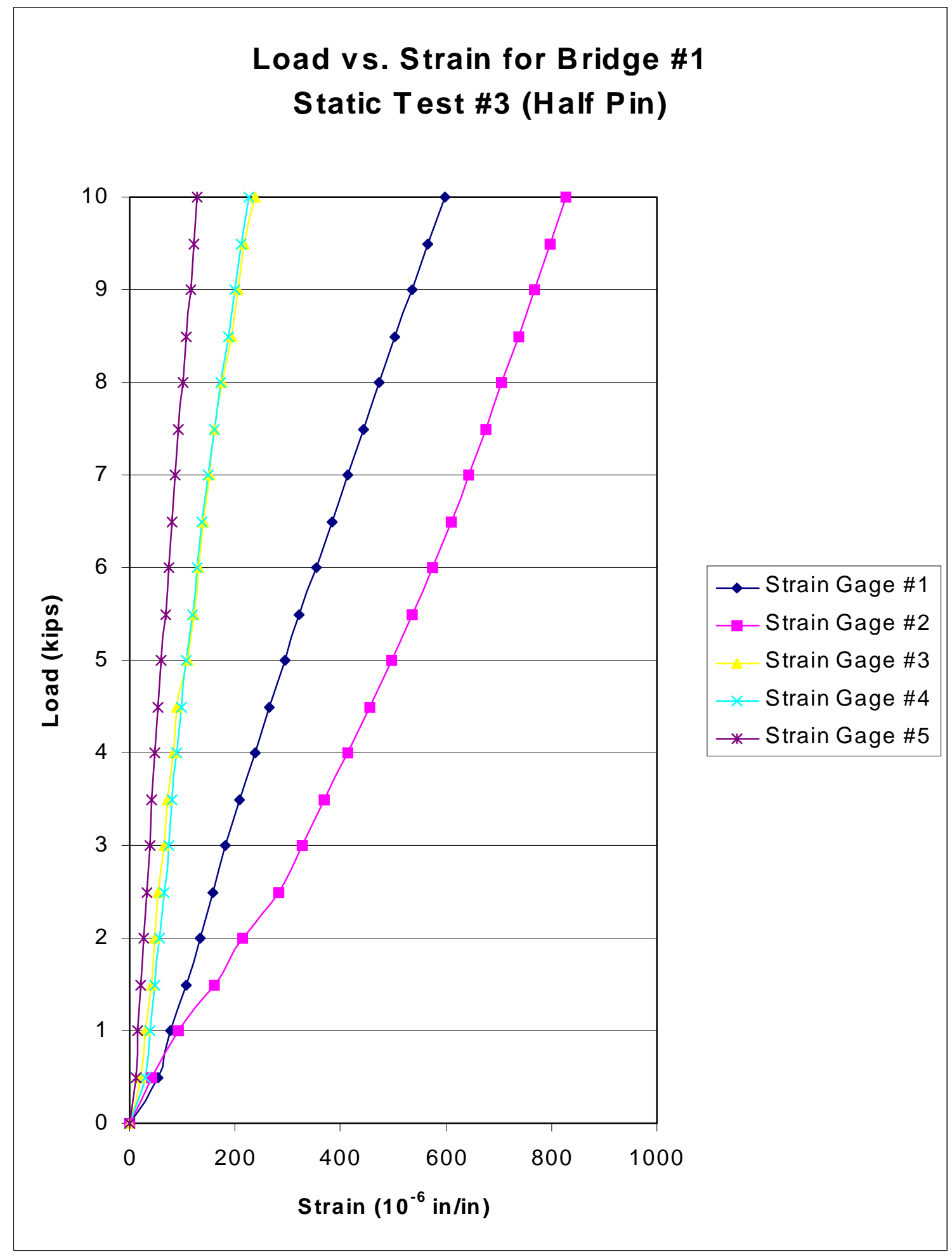

A.9 Strain Test \#3 (Half Pin) Graph for Bridge \#1 


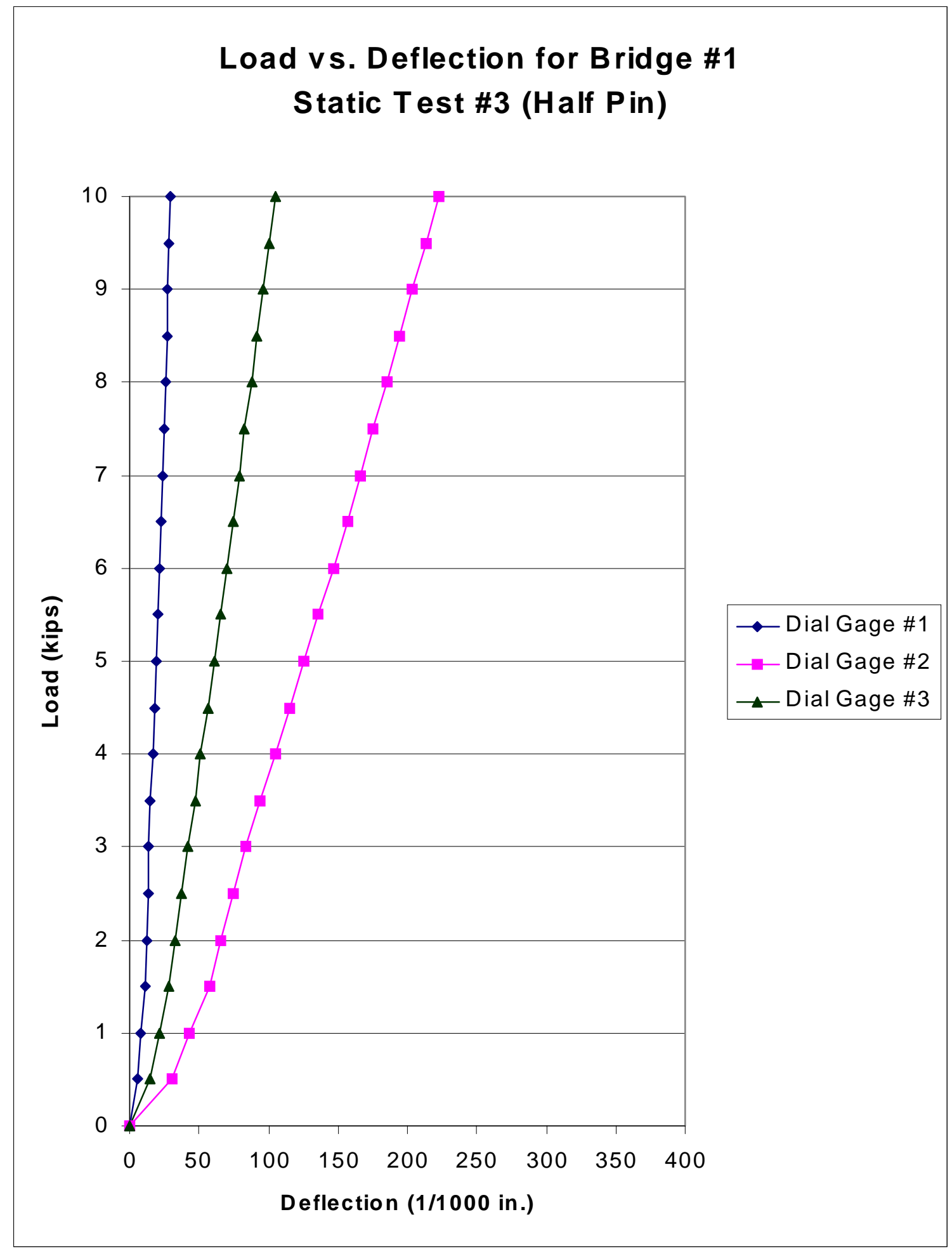

A.10 Deflection Test \#3 (Half Pin) Graph for Bridge \#1 


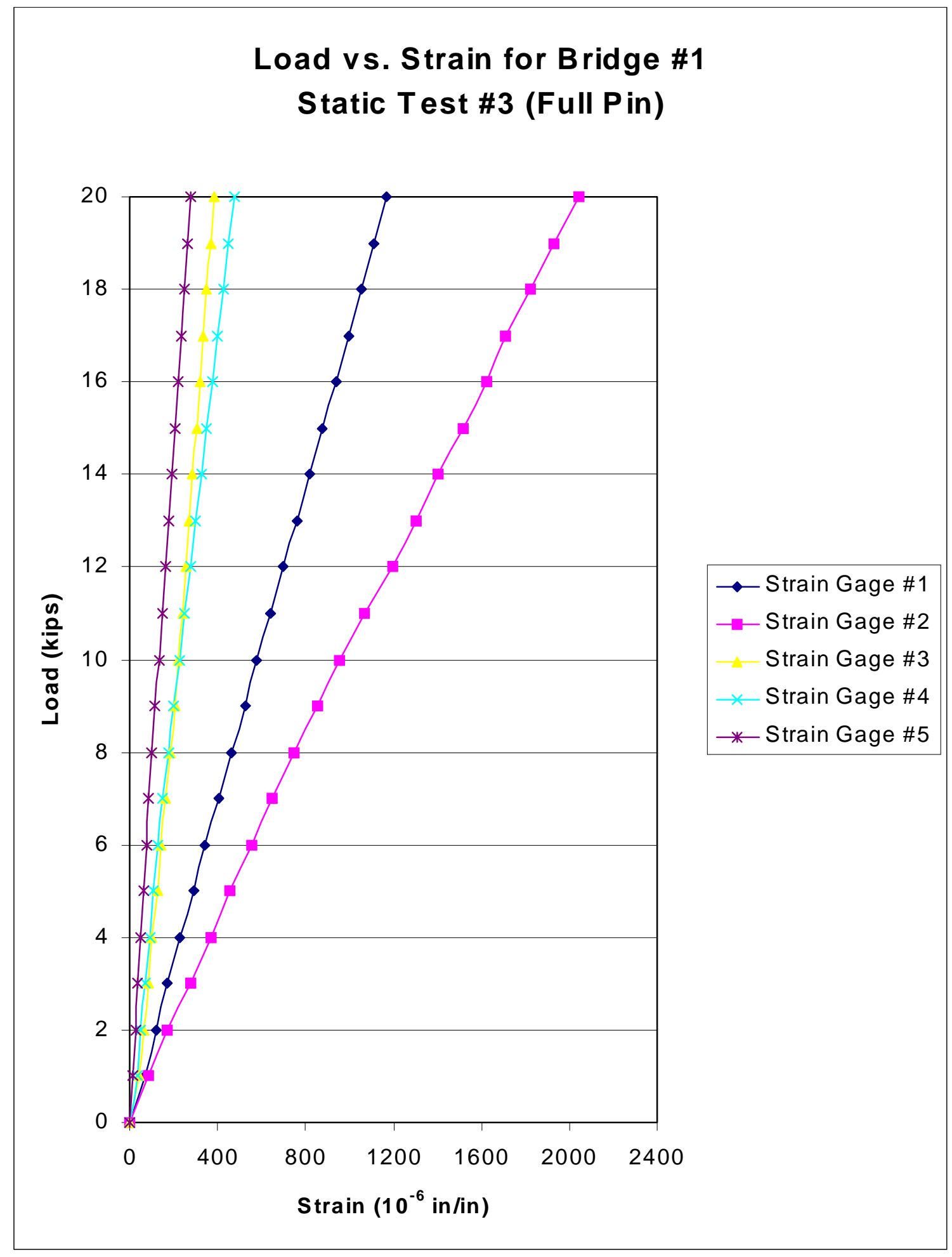

A.11 Strain Test \#3 (Full Pin) Graph for Bridge \#1 


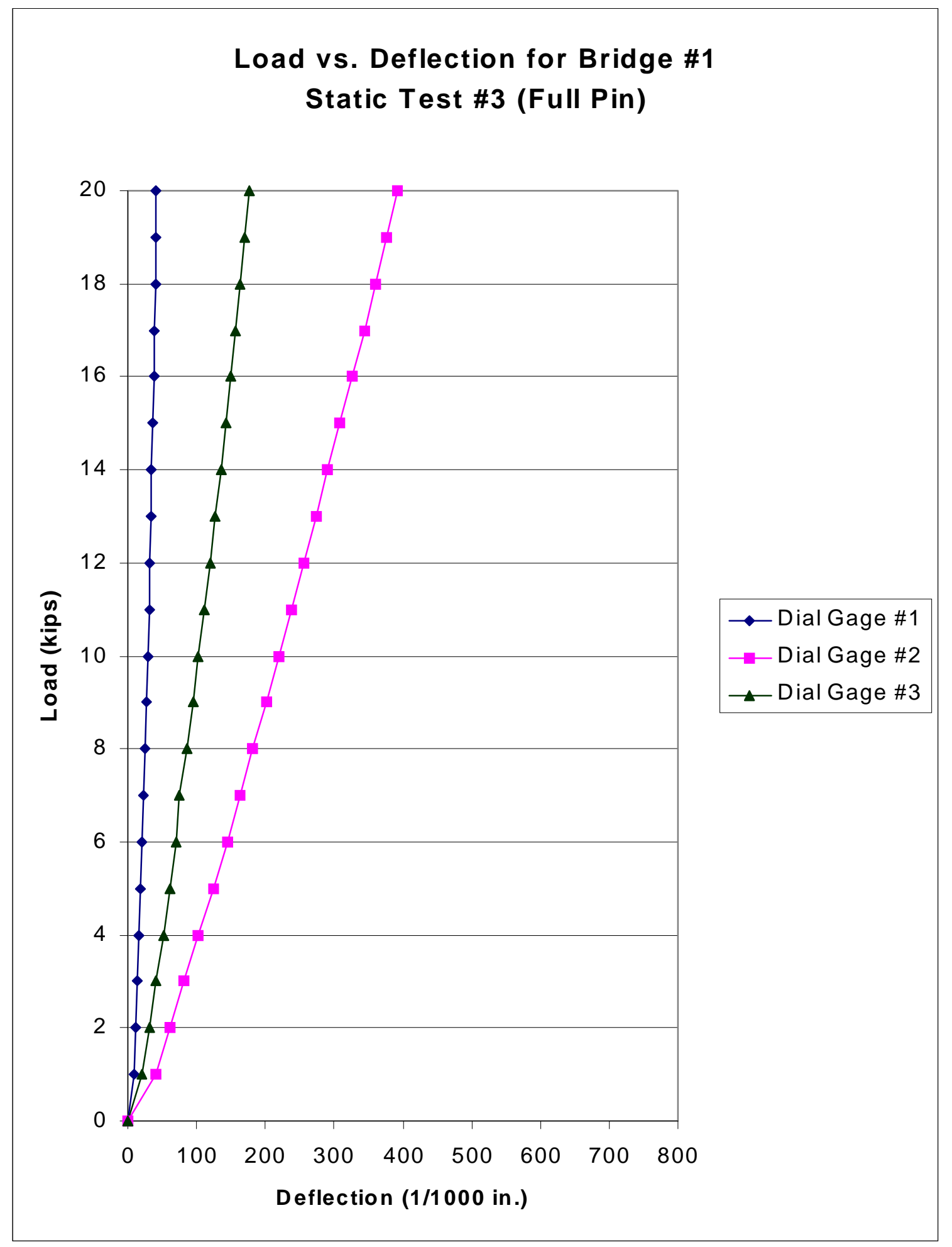

A.12 Deflection Test \#3 (Full Pin) Graph for Bridge \#1 


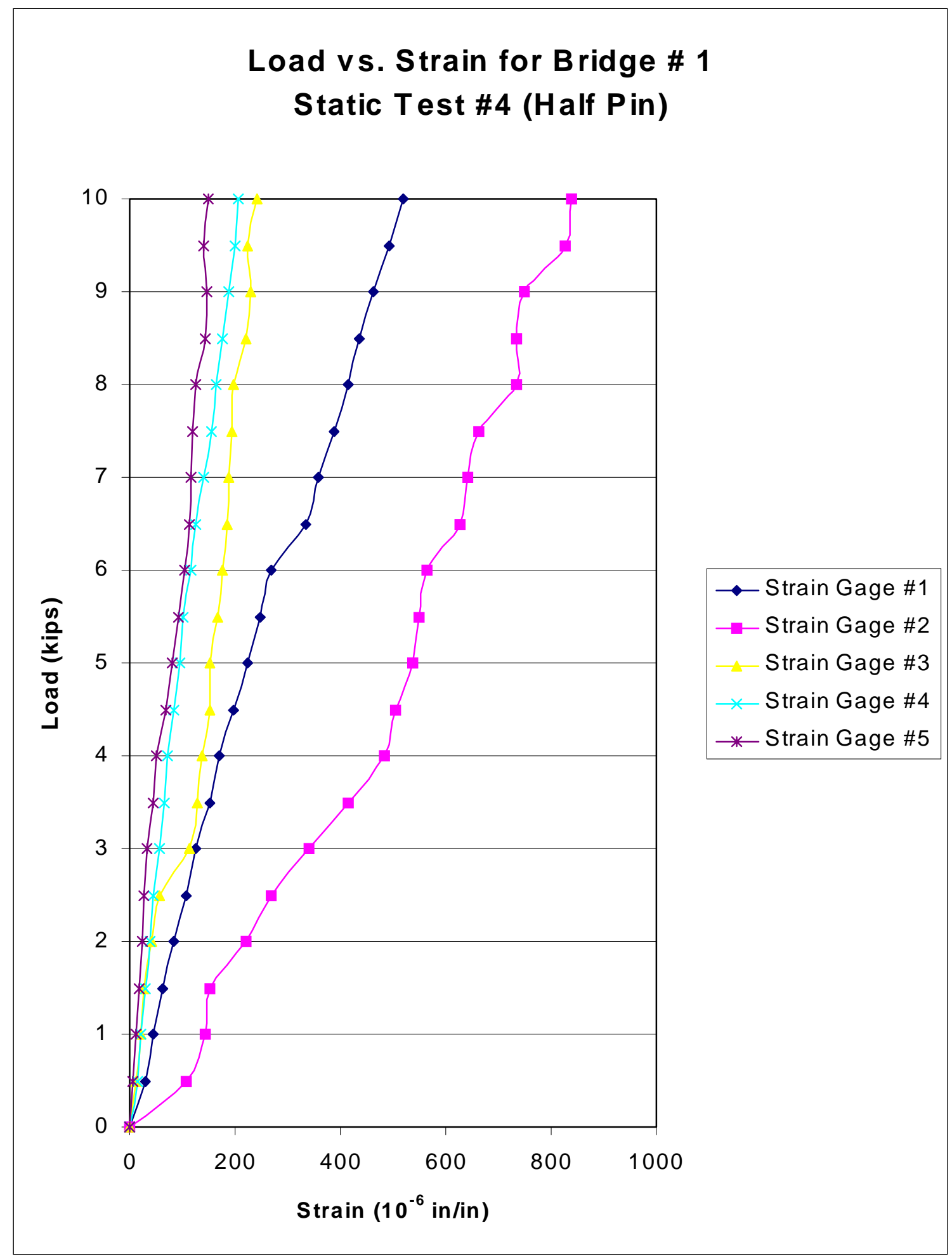

A.13 Strain Test \#4 (Half Pin) Graph for Bridge \#1 


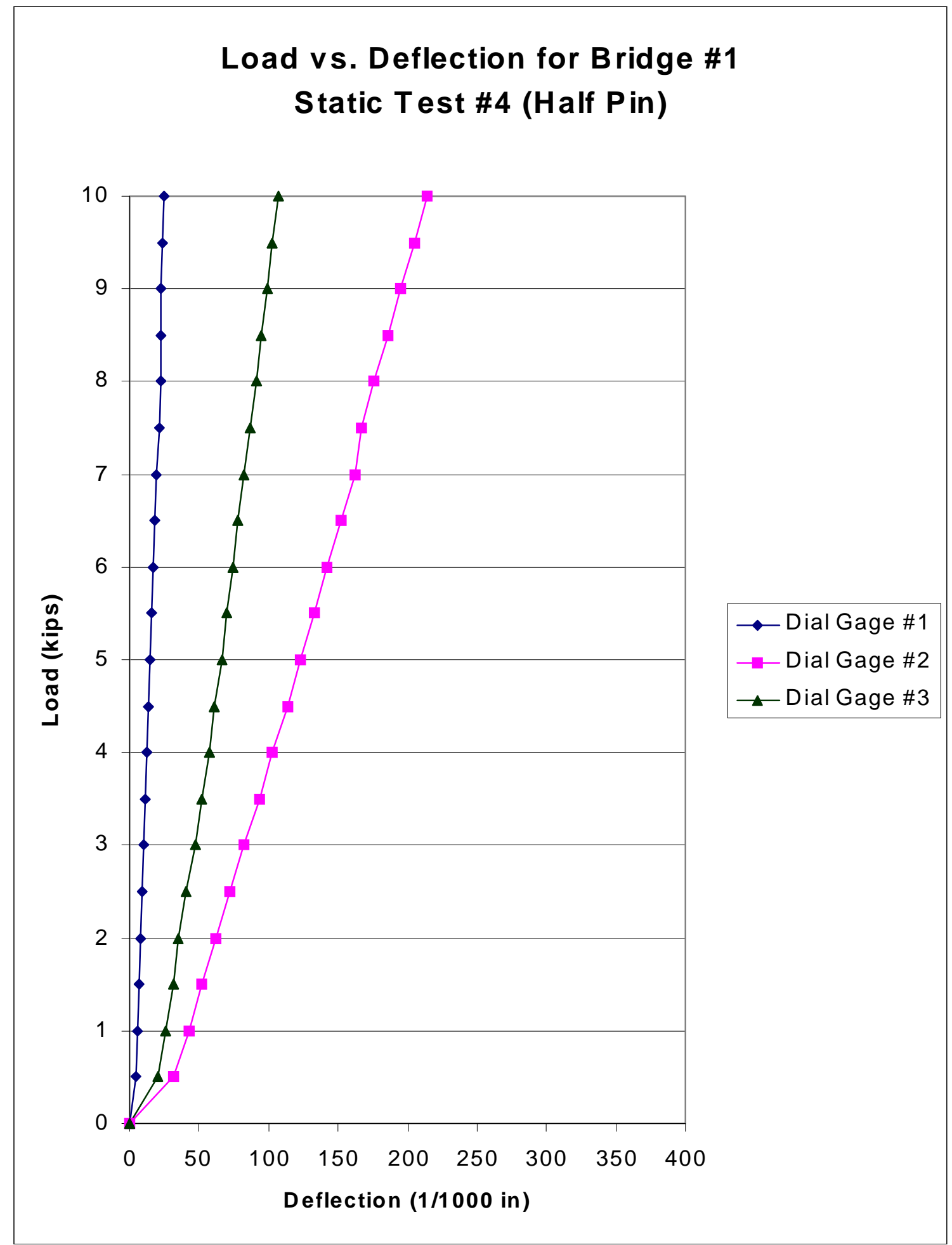

A.14 Deflection Test \#4 (Half Pin) Graph for Bridge \#1 


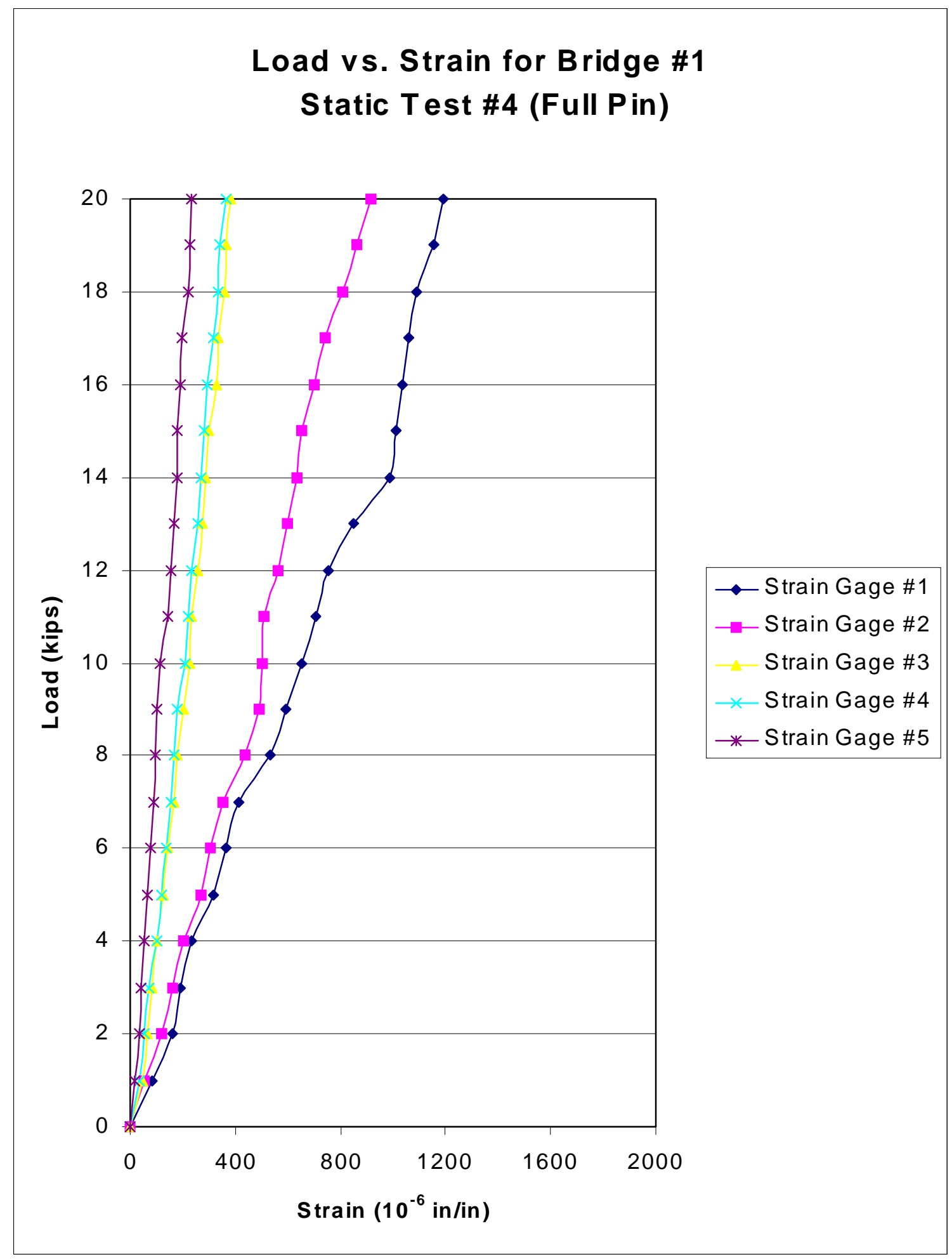

A.15 Strain Test \#4 (Full Pin) Graph for Bridge \#1 


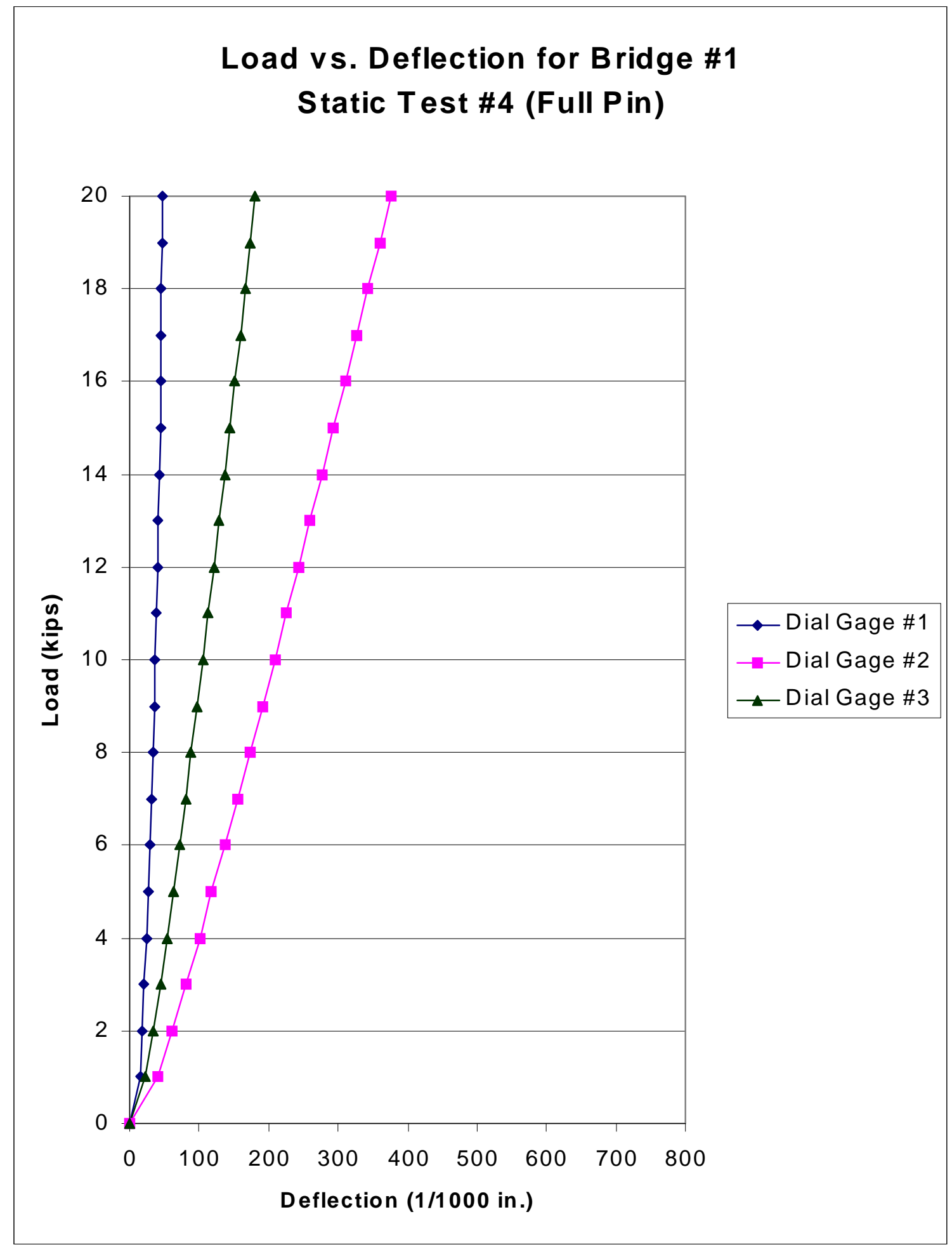

A.16 Deflection Test \#4 (Full Pin) Graph for Bridge \#1 


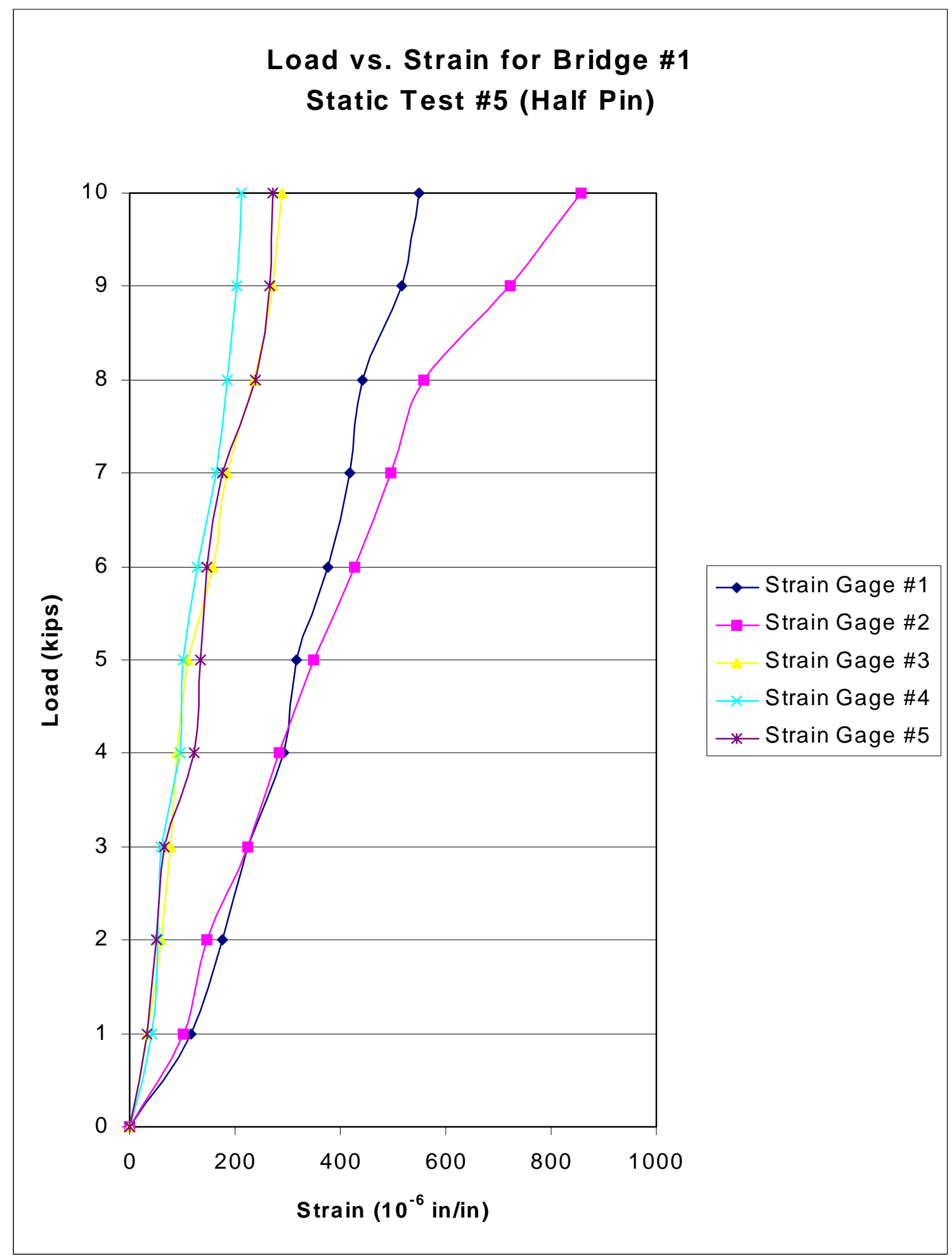

A.17 Strain Test \#5 (Half Pin) Graph for Bridge \#1 


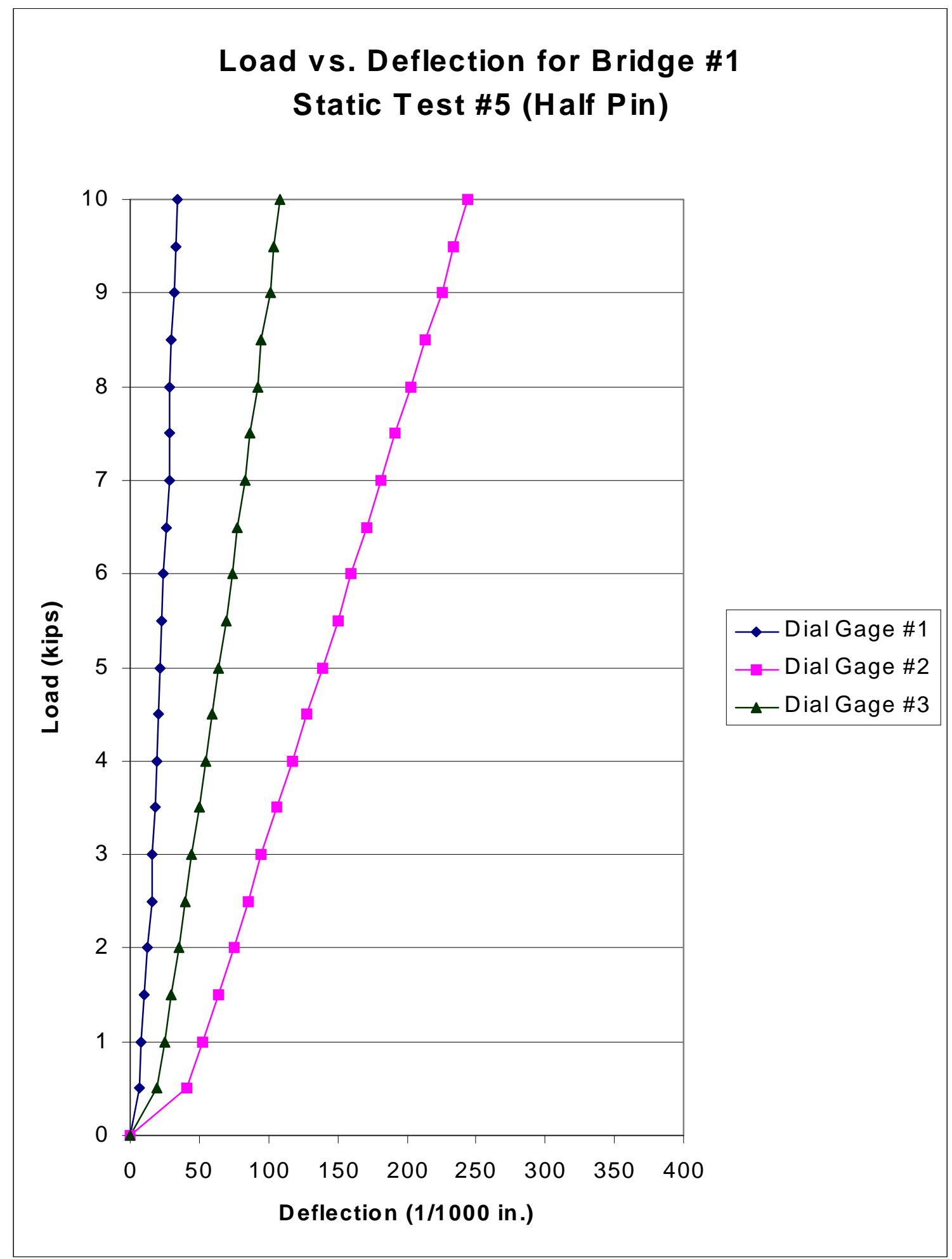

A.18 Deflection Test \#5 (Half Pin) Graph for Bridge \#1 


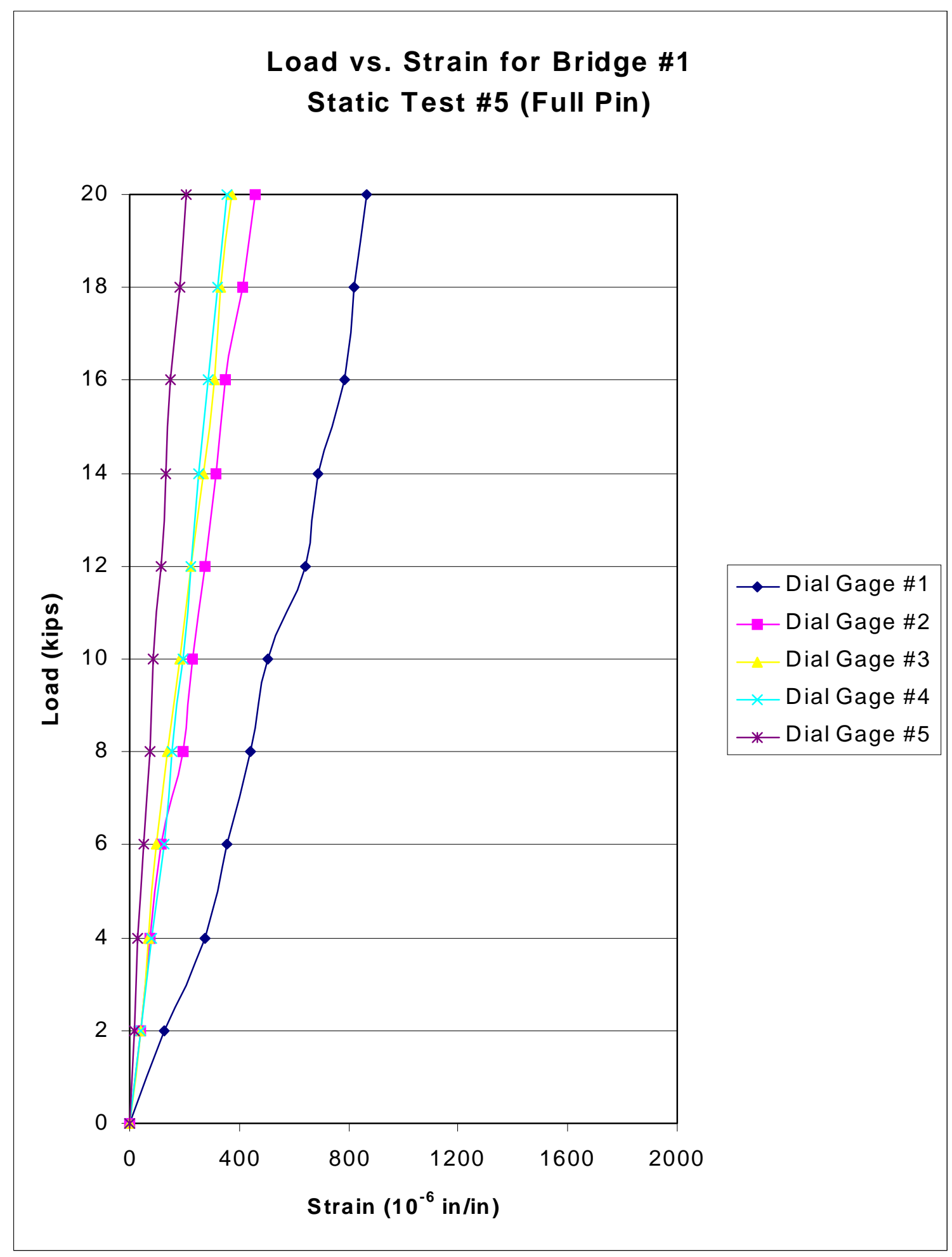

A.19 Strain Test \#5 (Full Pin) Graph for Bridge \#1 


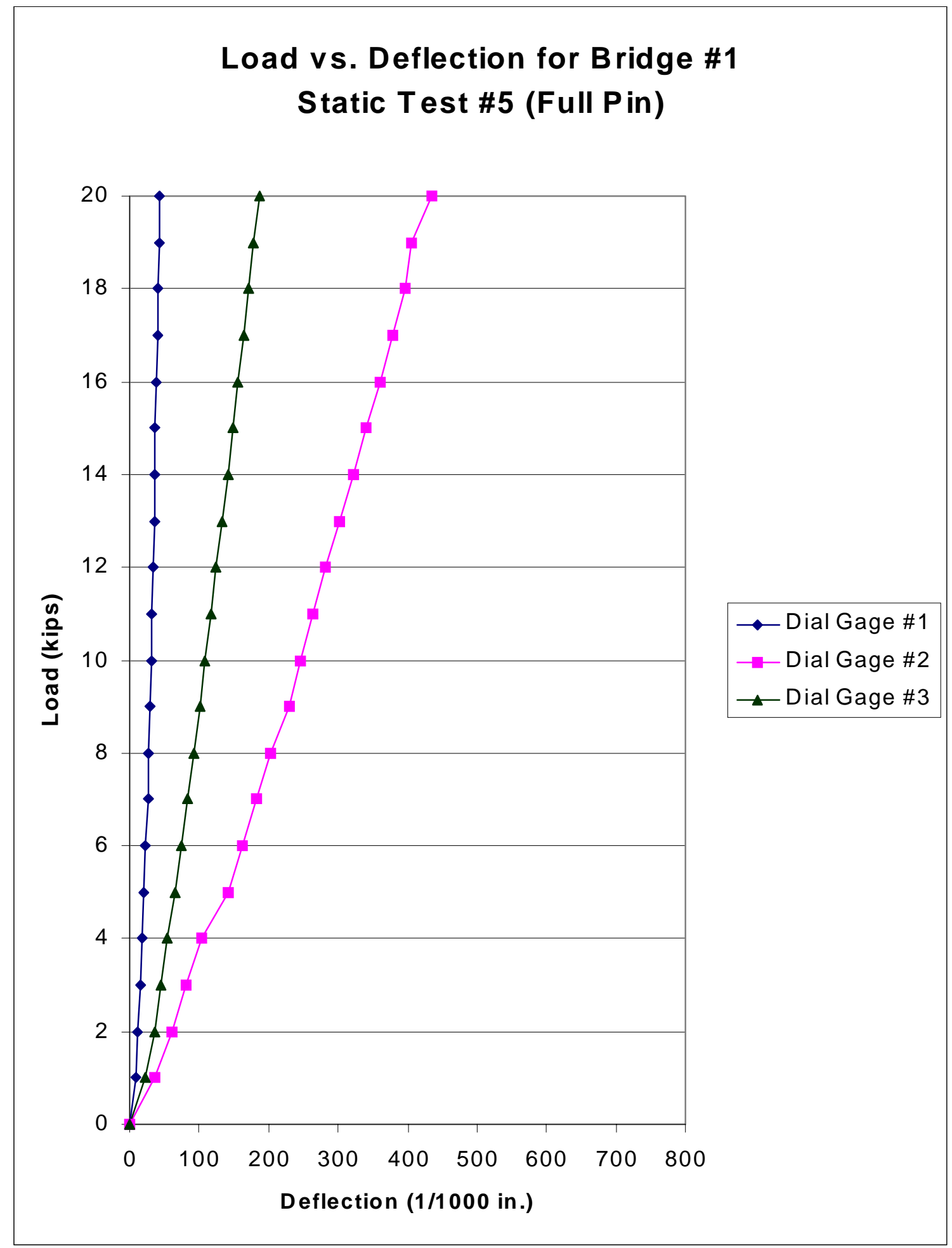

A.20 Deflection Test \#5 (Full Pin) Graph for Bridge \#1 


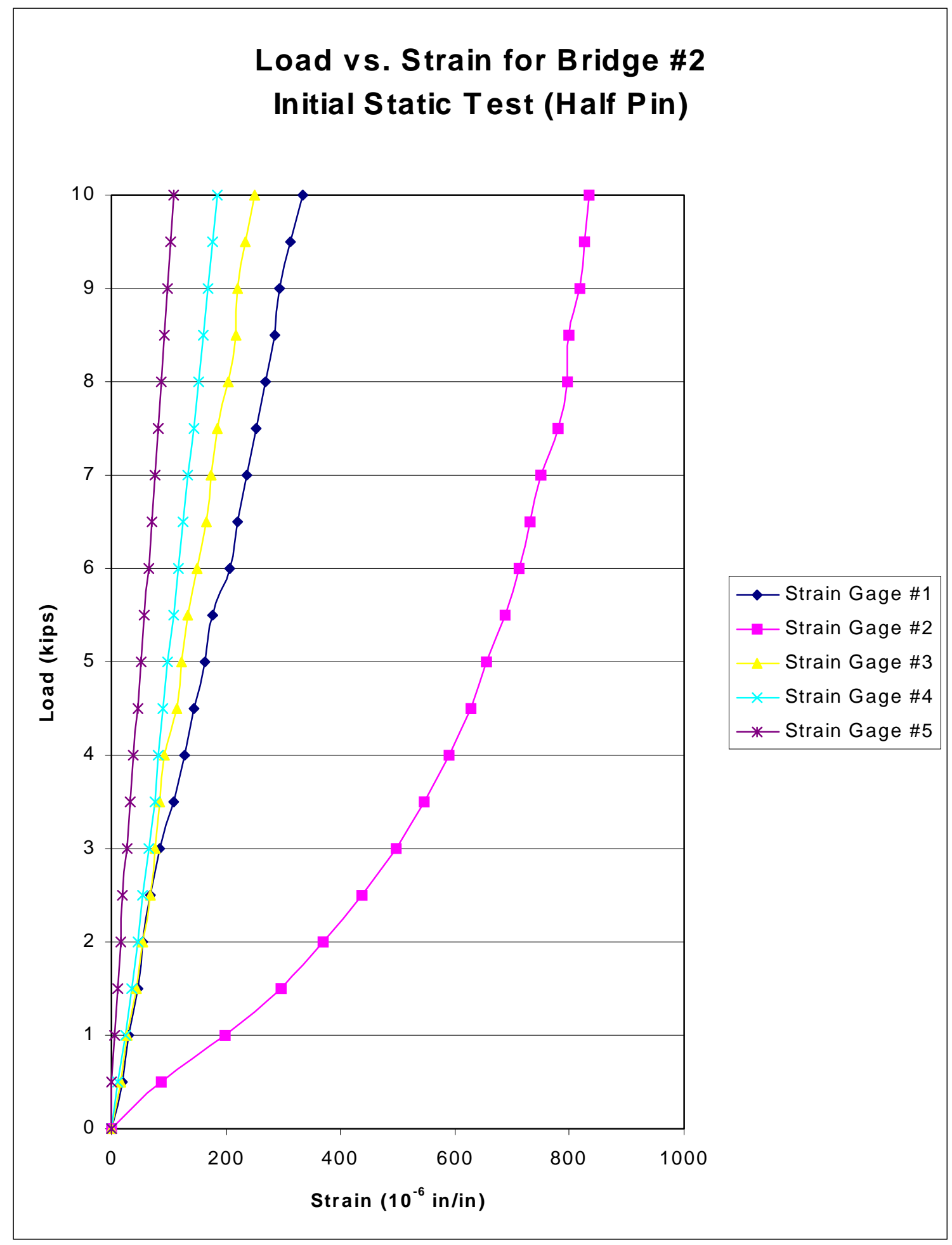

A.21 Initial Strain Test (Half Pin) Graph for Bridge \#2 


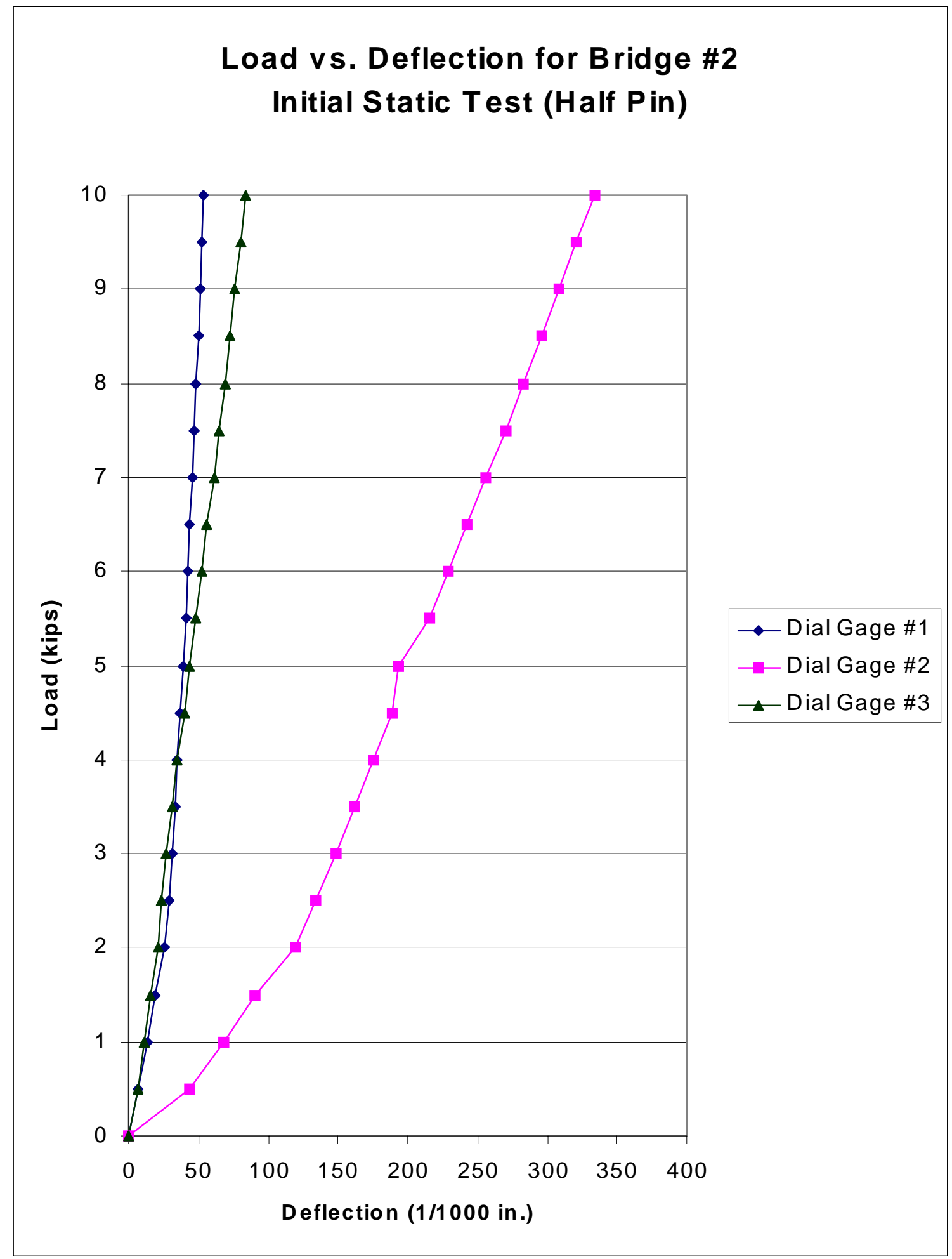

A.22 Initial Deflection Test (Half Pin) Graph for Bridge \#2 


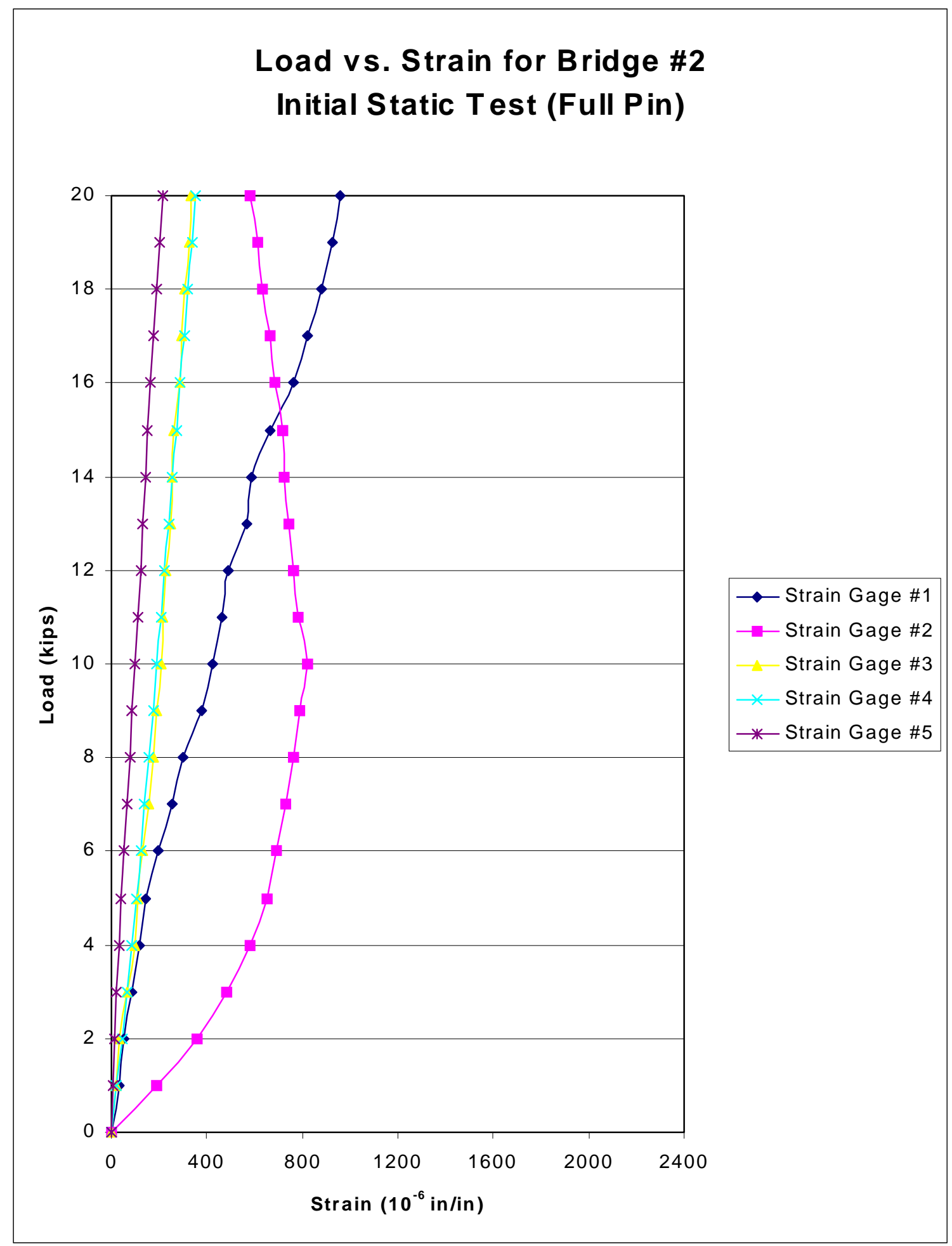

A.23 Initial Strain Test (Full Pin) Graph for Bridge \#2 


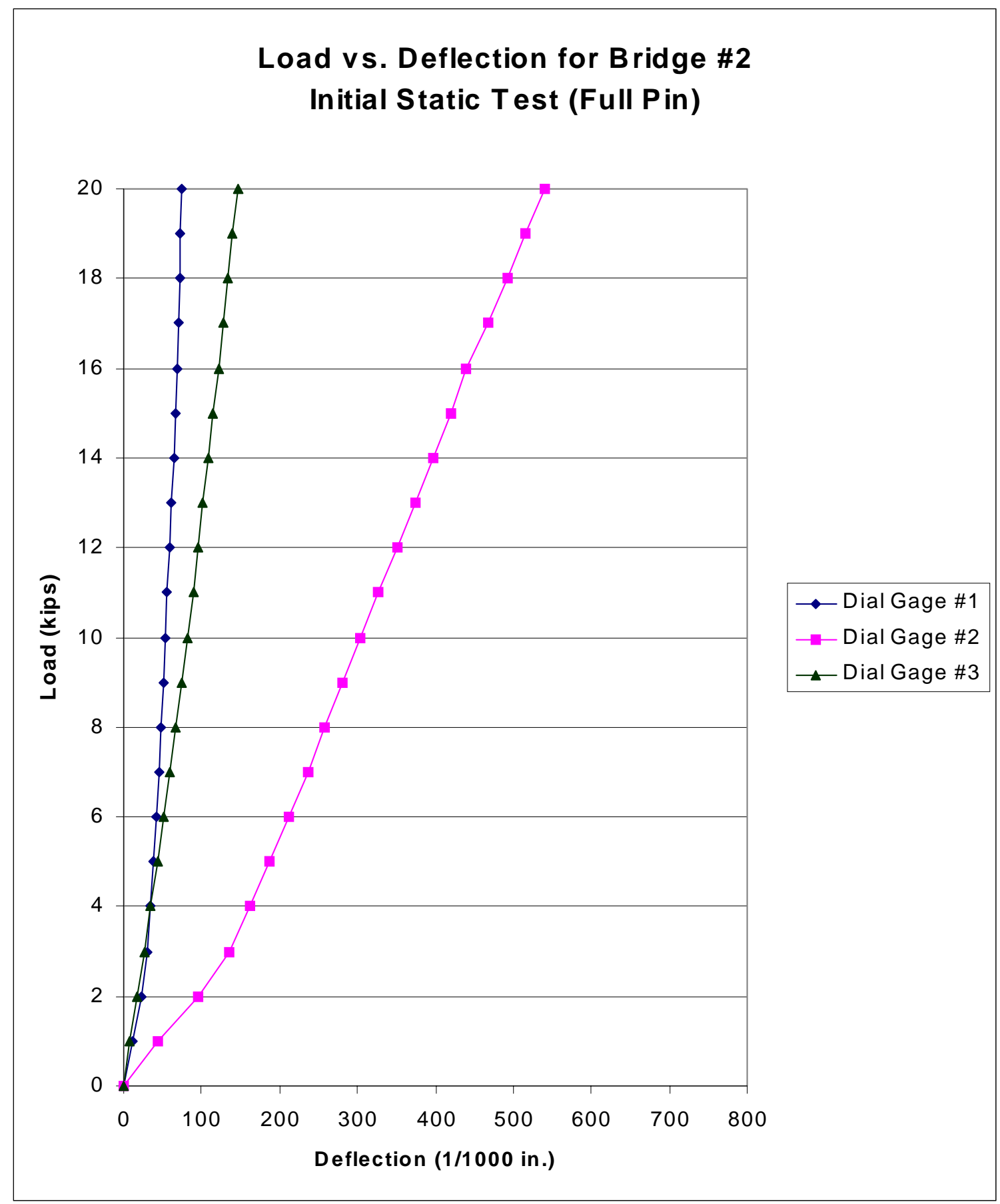

A.24 Initial Deflection Test (Half Pin) Graph for Bridge \#2 


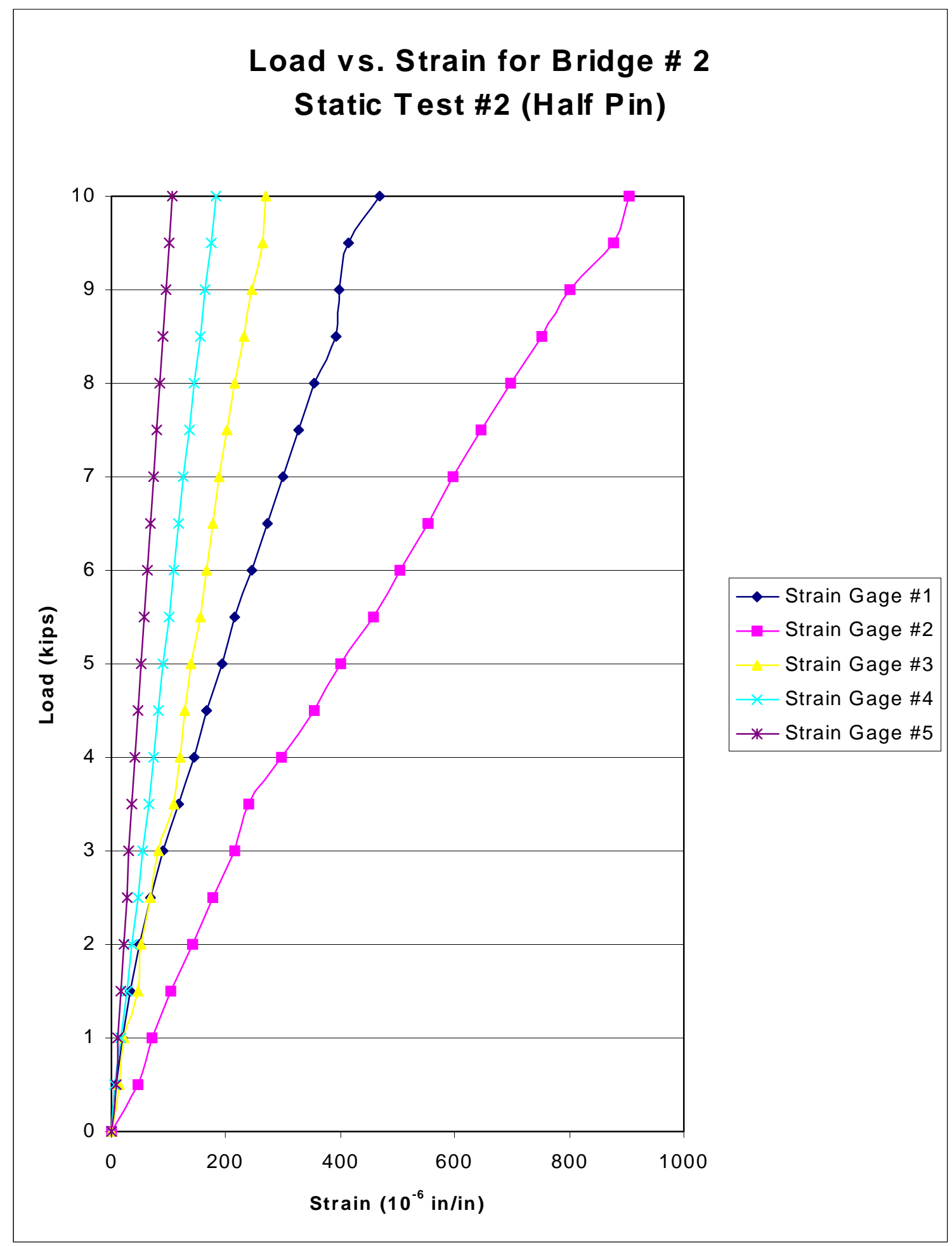

A.25 Strain Test \#2 (Half Pin) Graph for Bridge \#2 


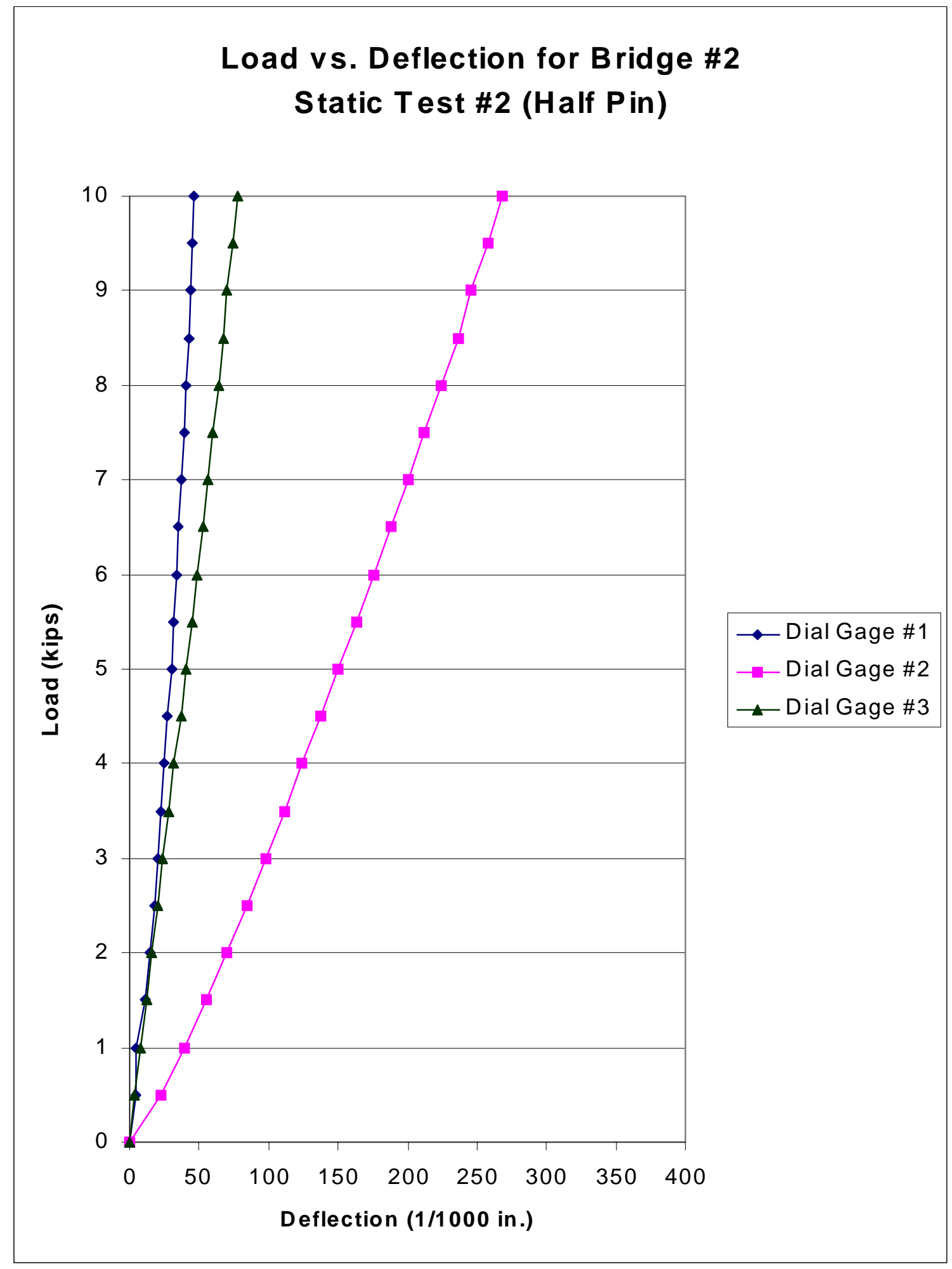

A.26 Deflection Test \#2 (Half Pin) Graph for Bridge \#2 


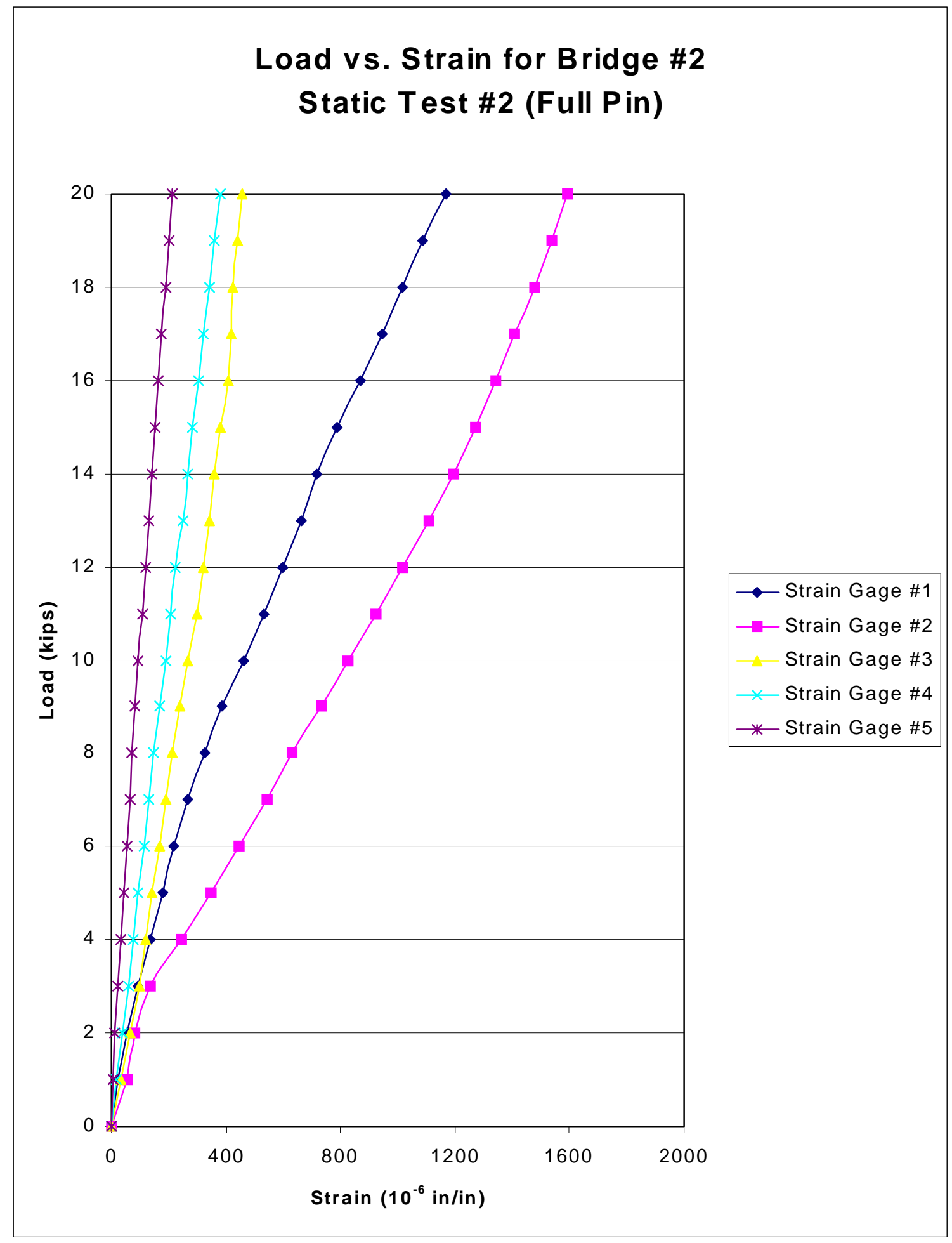

A.27 Strain Test \#2 (Full Pin) Graph for Bridge \#2 


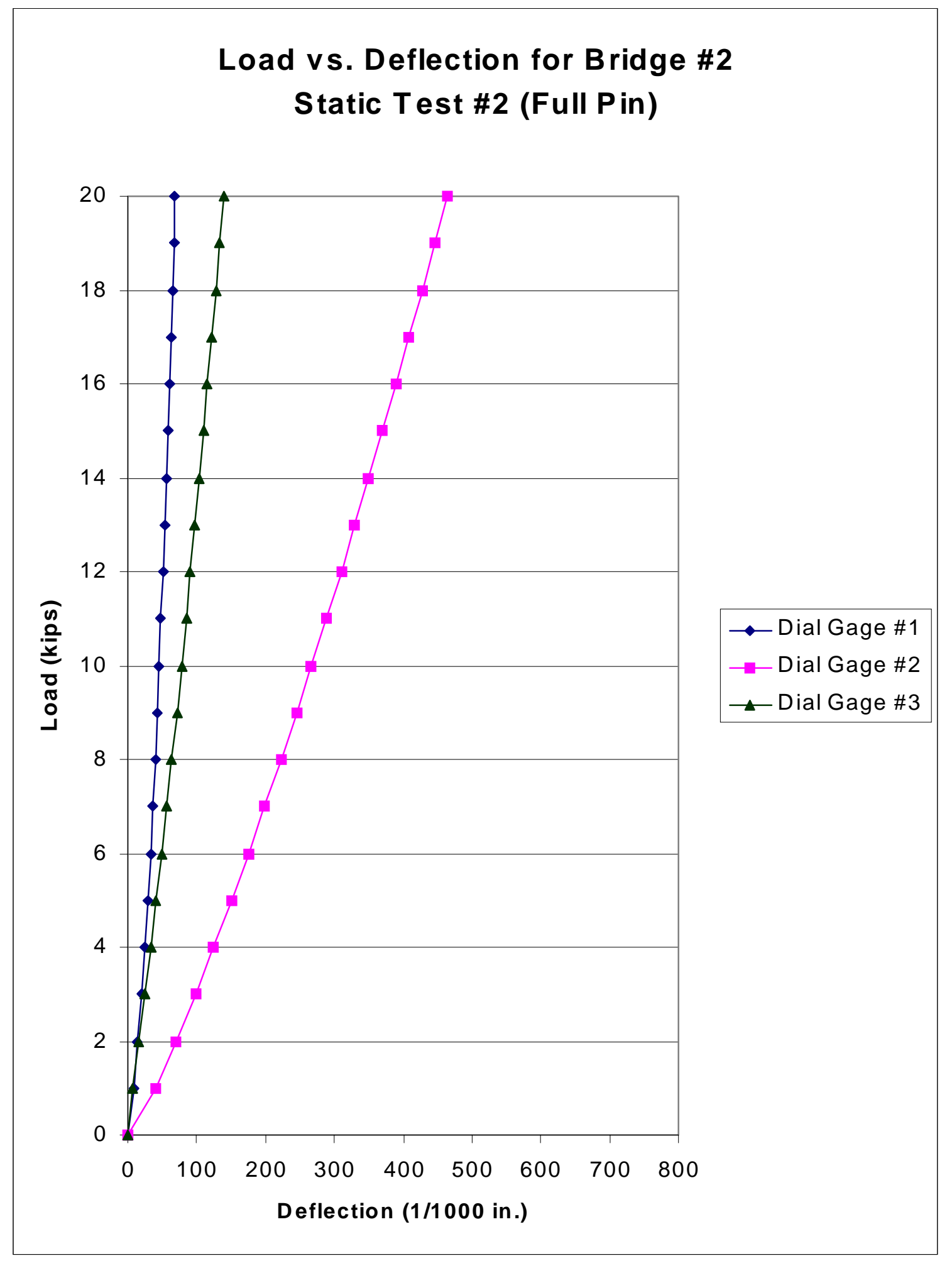

A.28 Deflection Test \#2 (Full Pin) Graph for Bridge \#2 


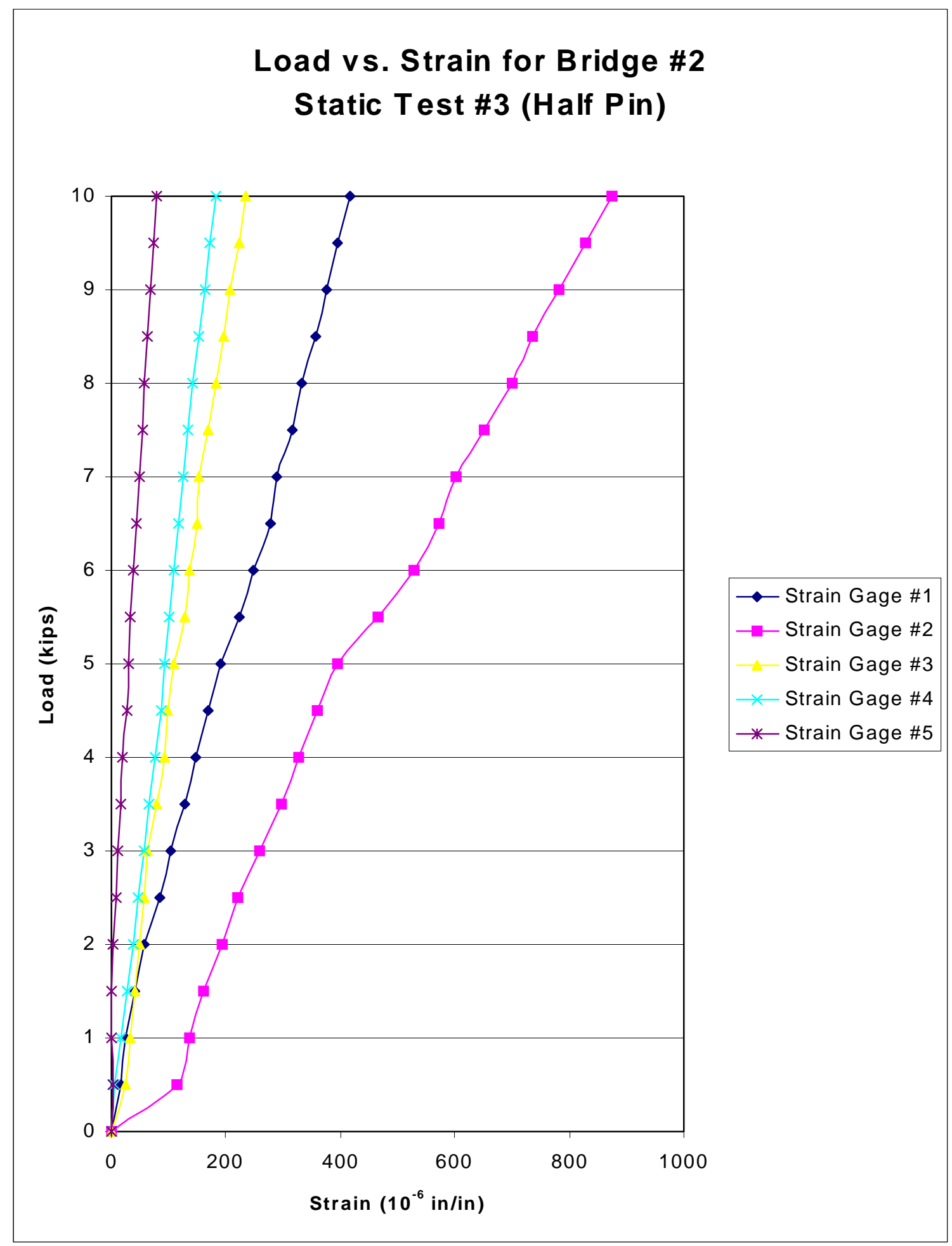

A.29 Strain Test \#3 (Half Pin) Graph for Bridge \#2 


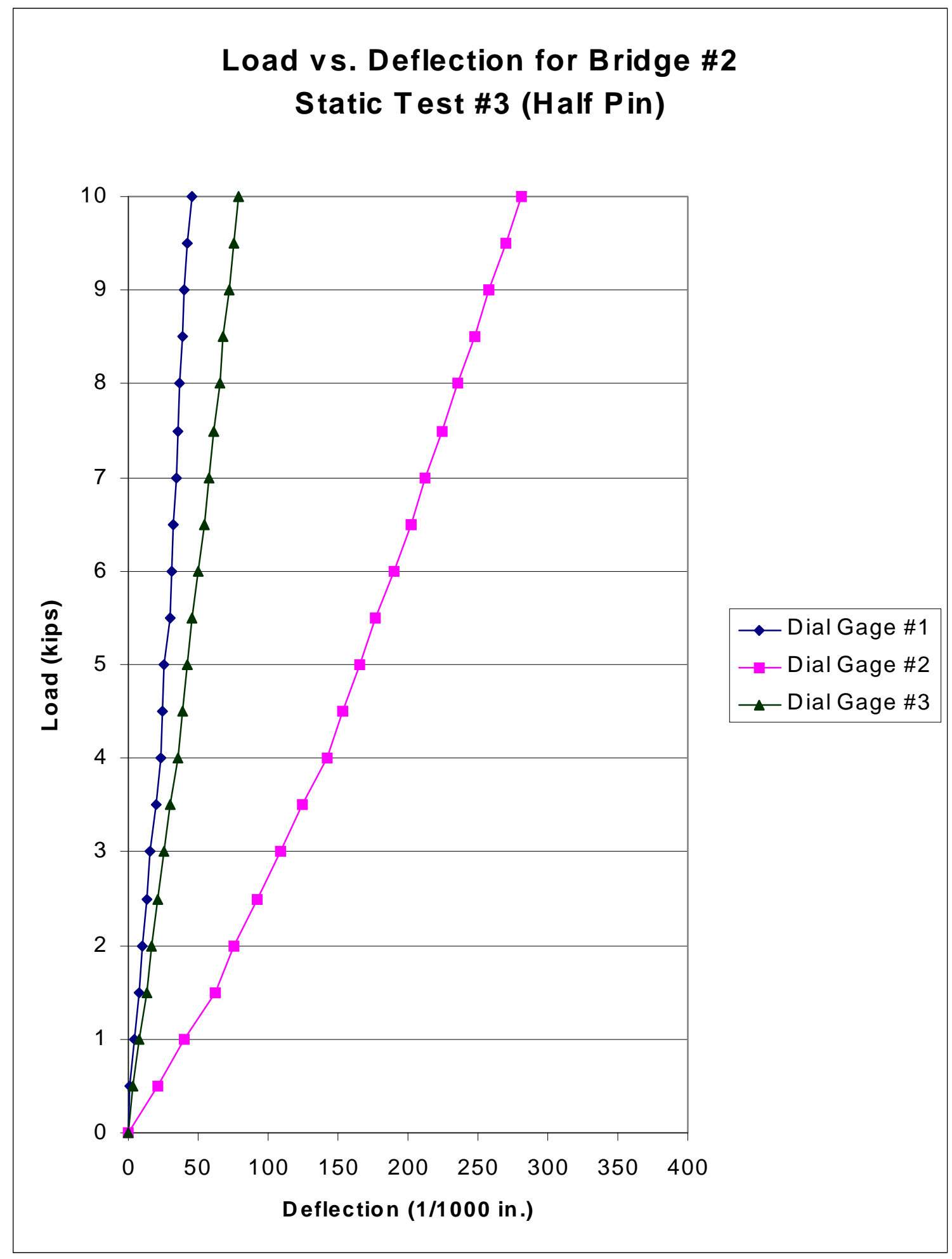

A.30 Deflection Test \#3 (Half Pin) Graph for Bridge \#2 


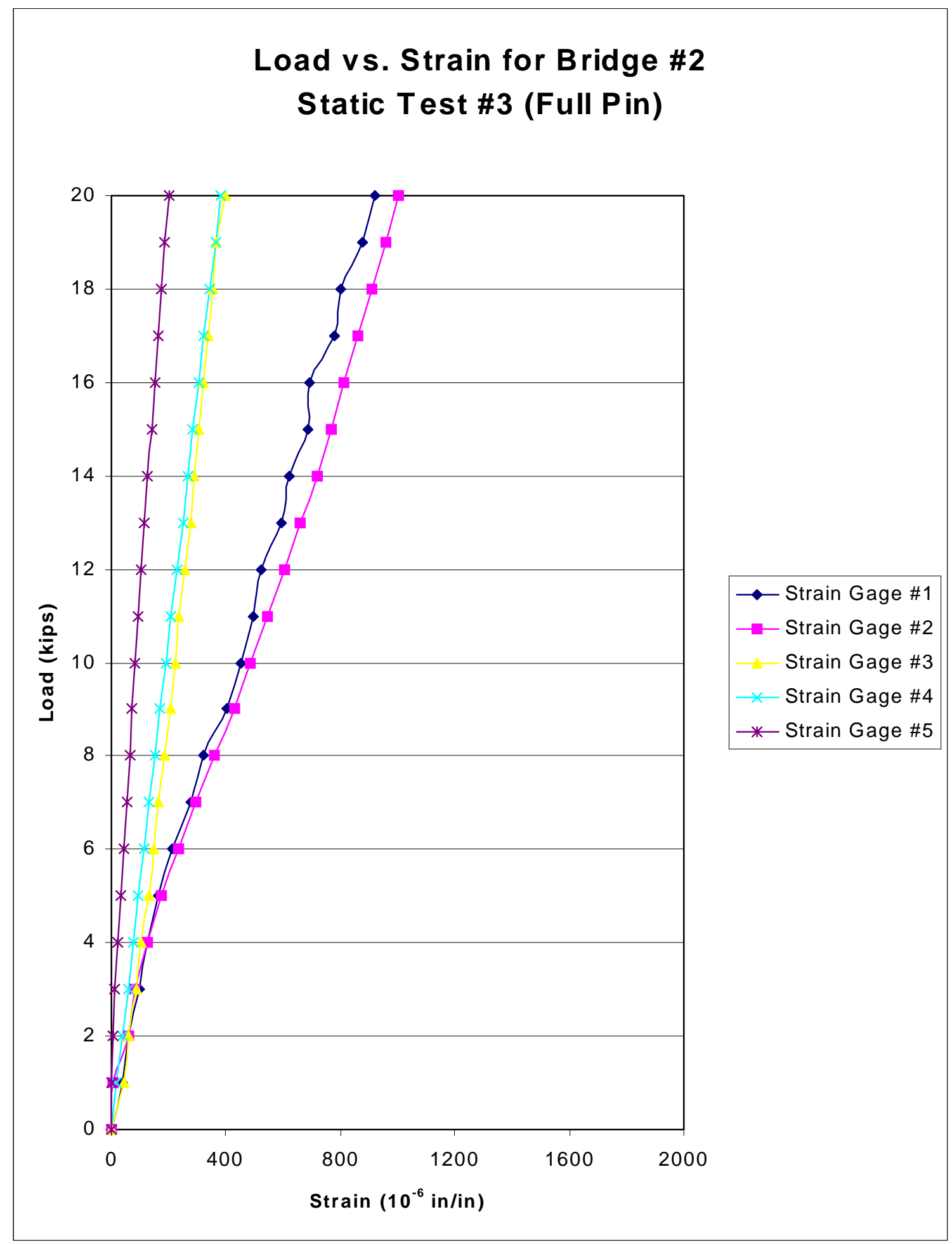

A.31 Strain Test \#3 (Full Pin) Graph for Bridge \#2 


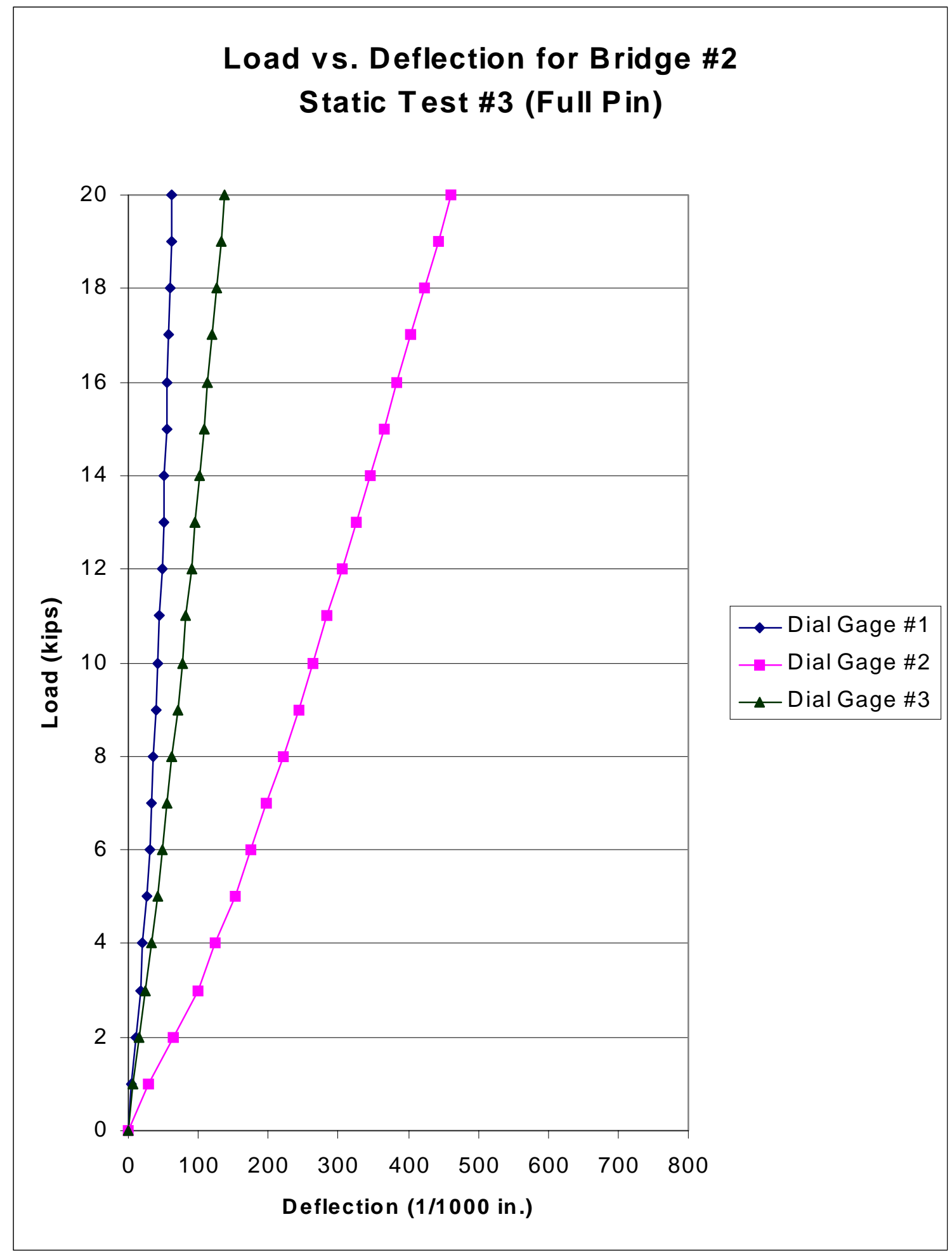

A.32 Deflection Test \#3 (Full Pin) Graph for Bridge \#2 


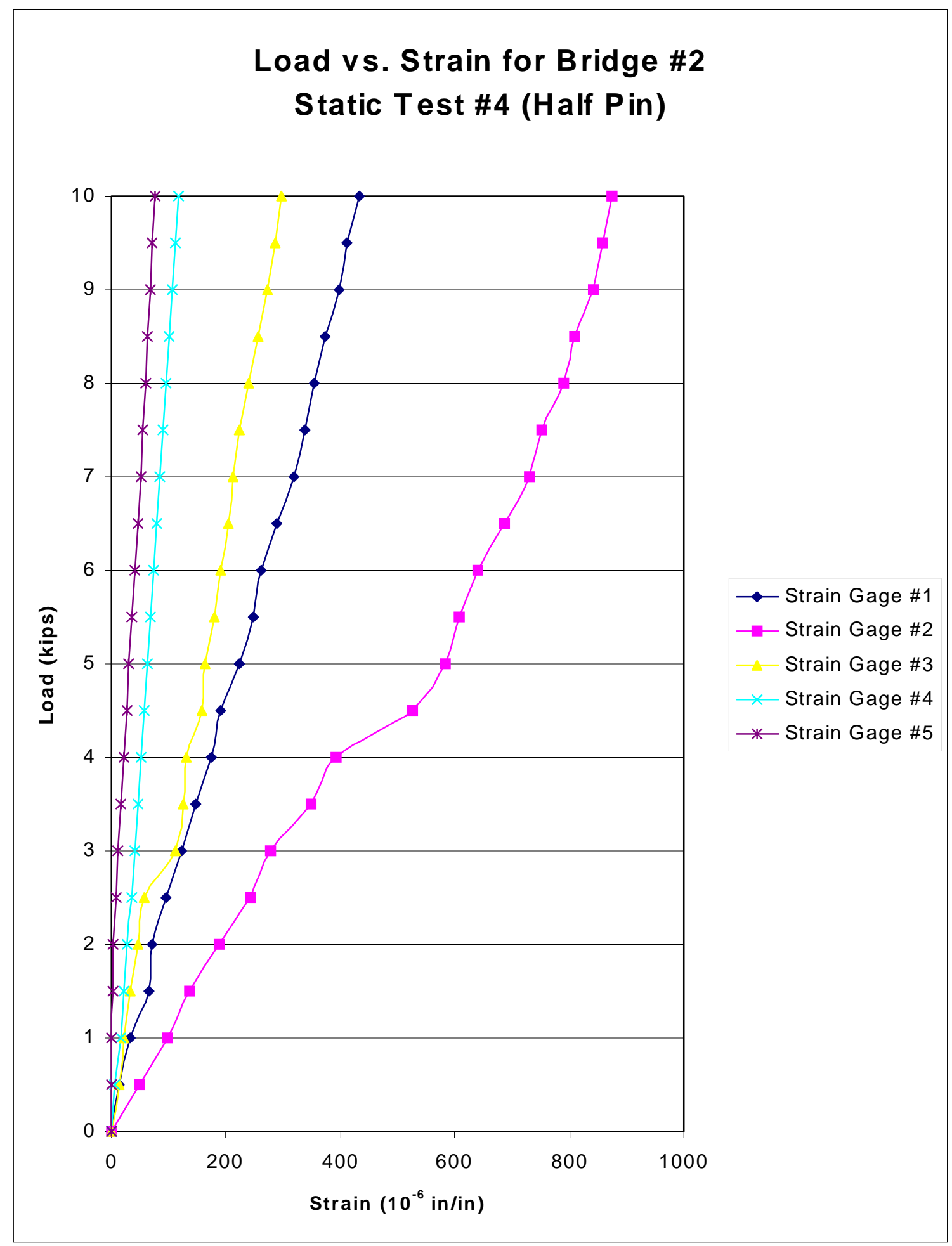

A.33 Strain Test \#4 (Half Pin) Graph for Bridge \#2 


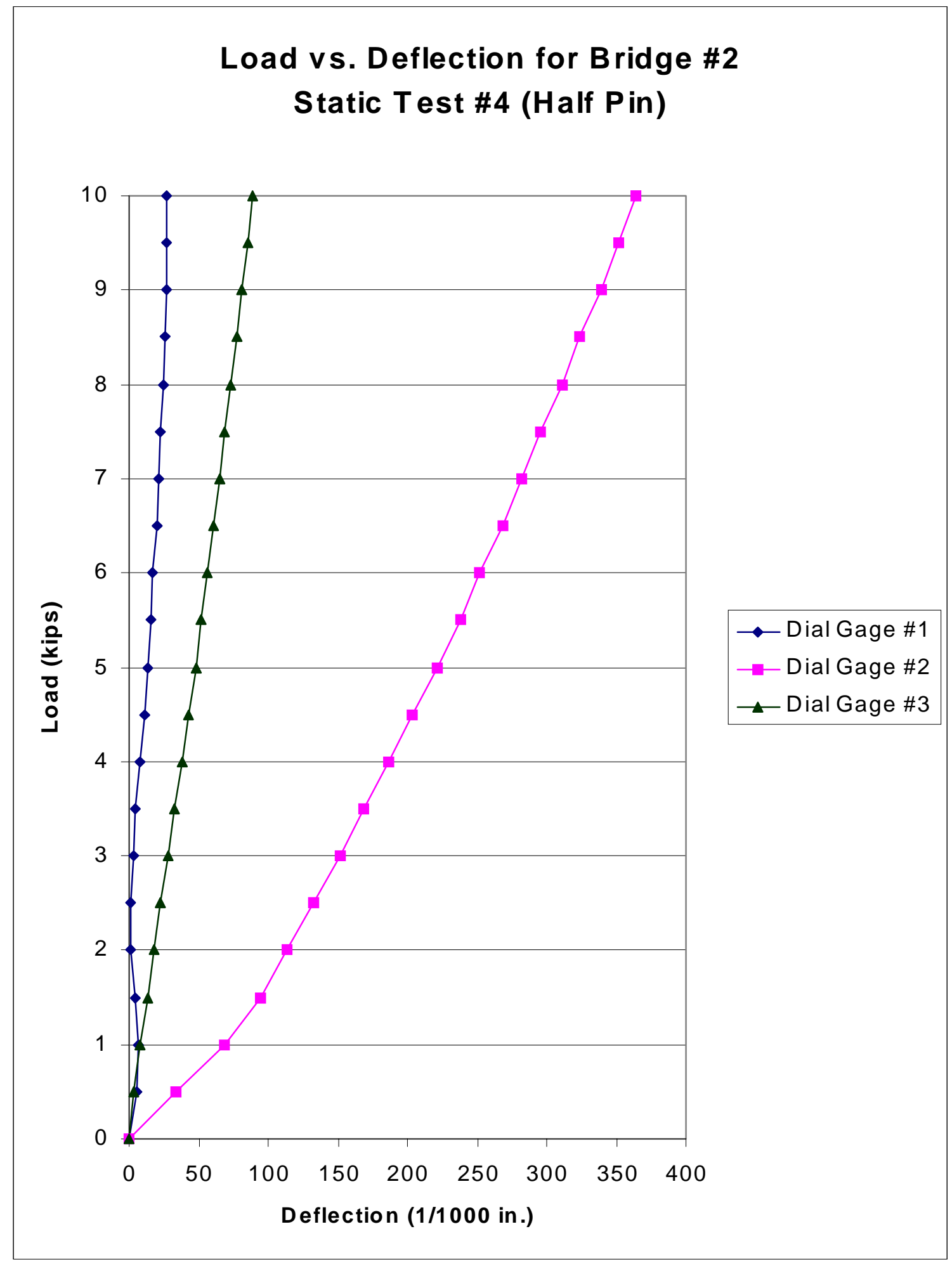

A.34 Deflection Test \#4 (Half Pin) Graph for Bridge \#2 


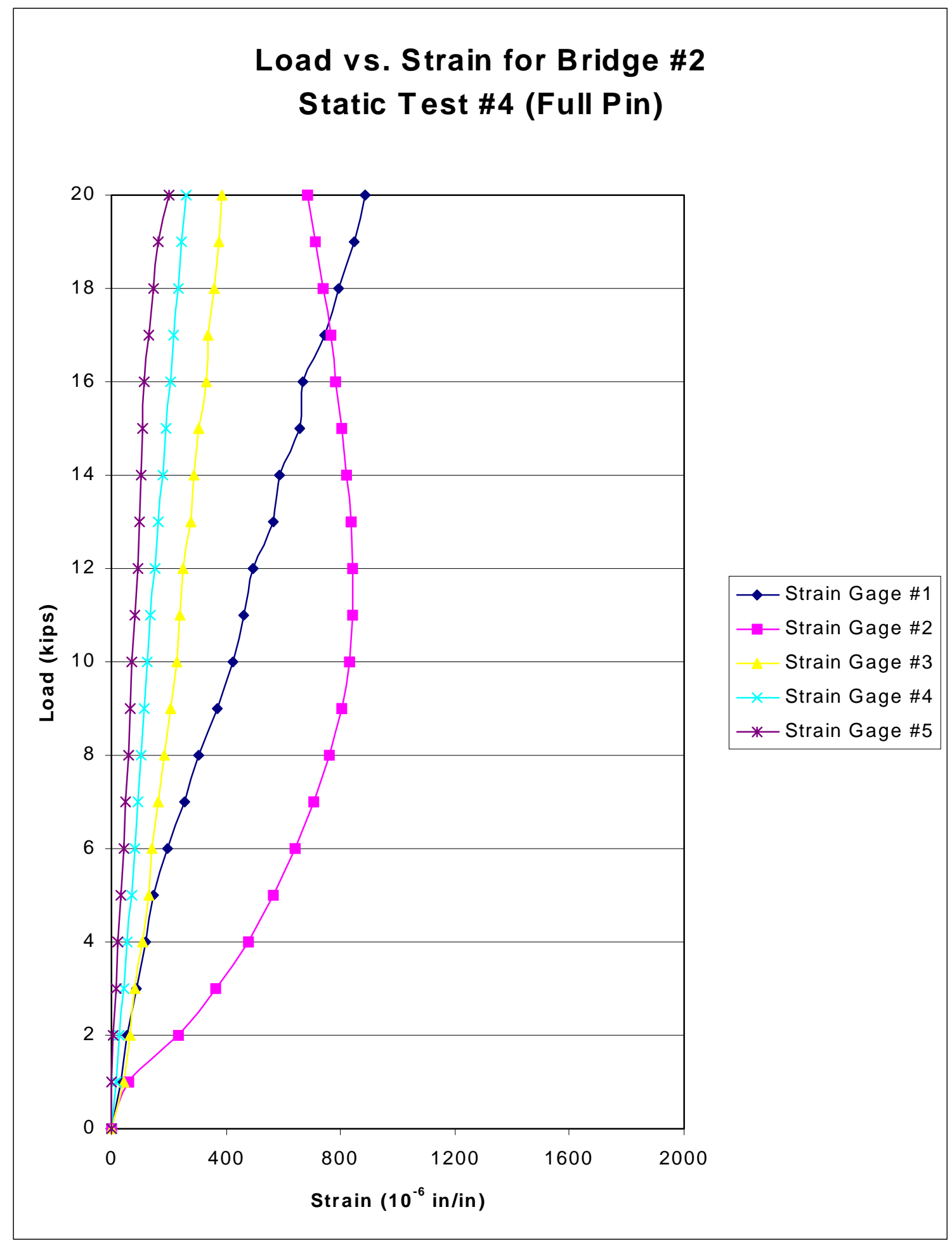

A.35 Strain Test \#4 (Full Pin) Graph for Bridge \#2 


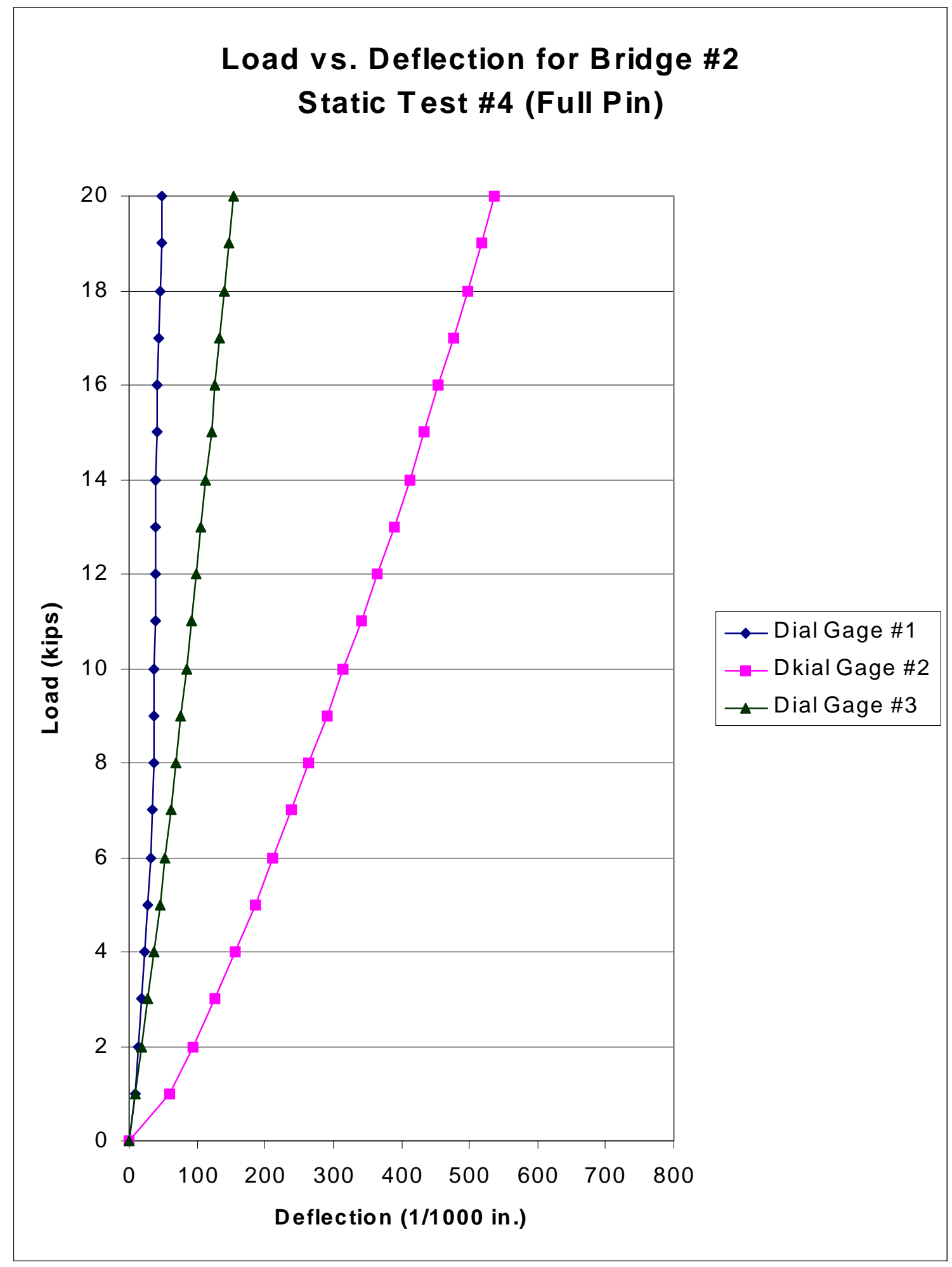

A.36 Deflection Test \#4 (Full Pin) Graph for Bridge \#2 


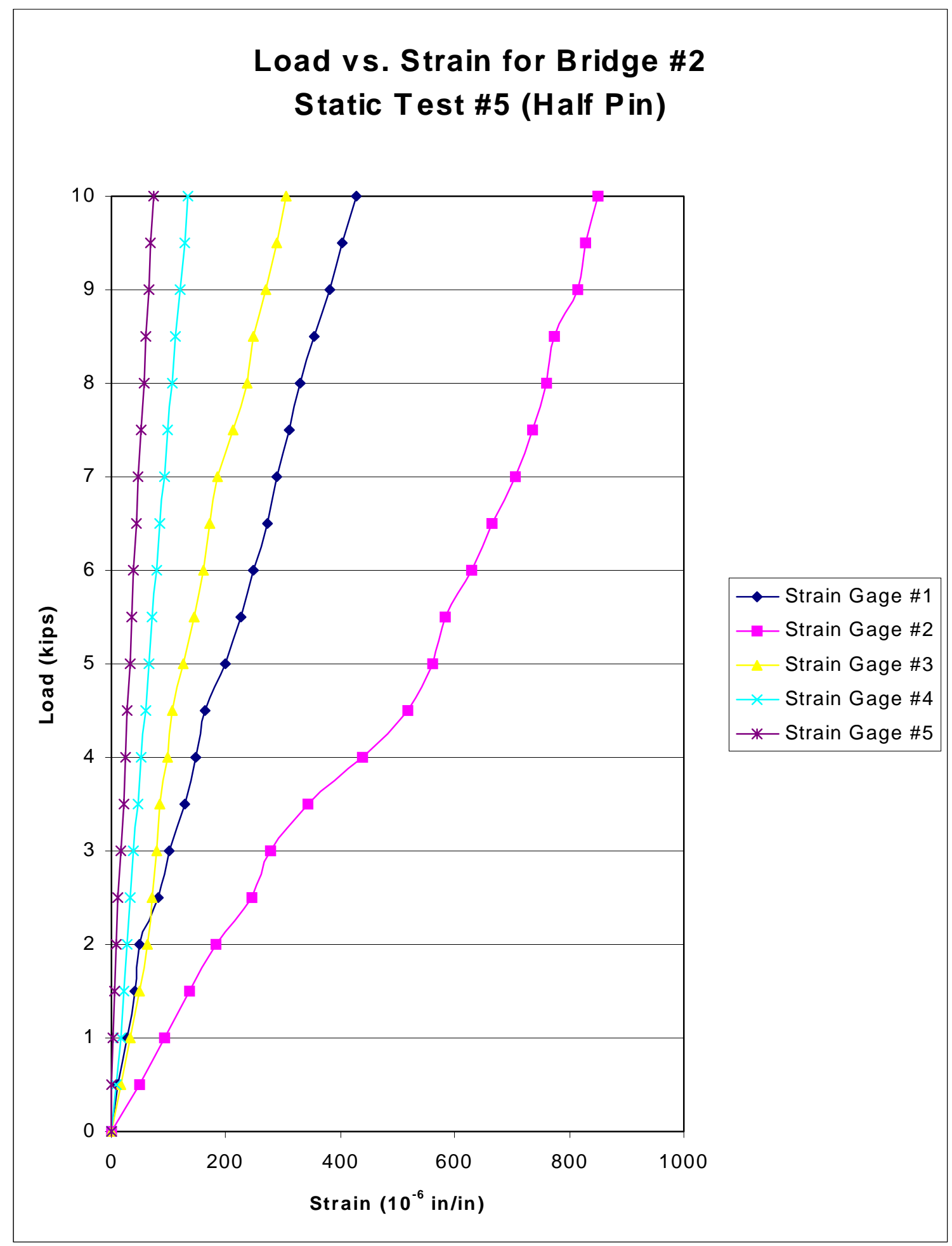

A.37 Strain Test \#5 (Half Pin) Graph for Bridge \#2 


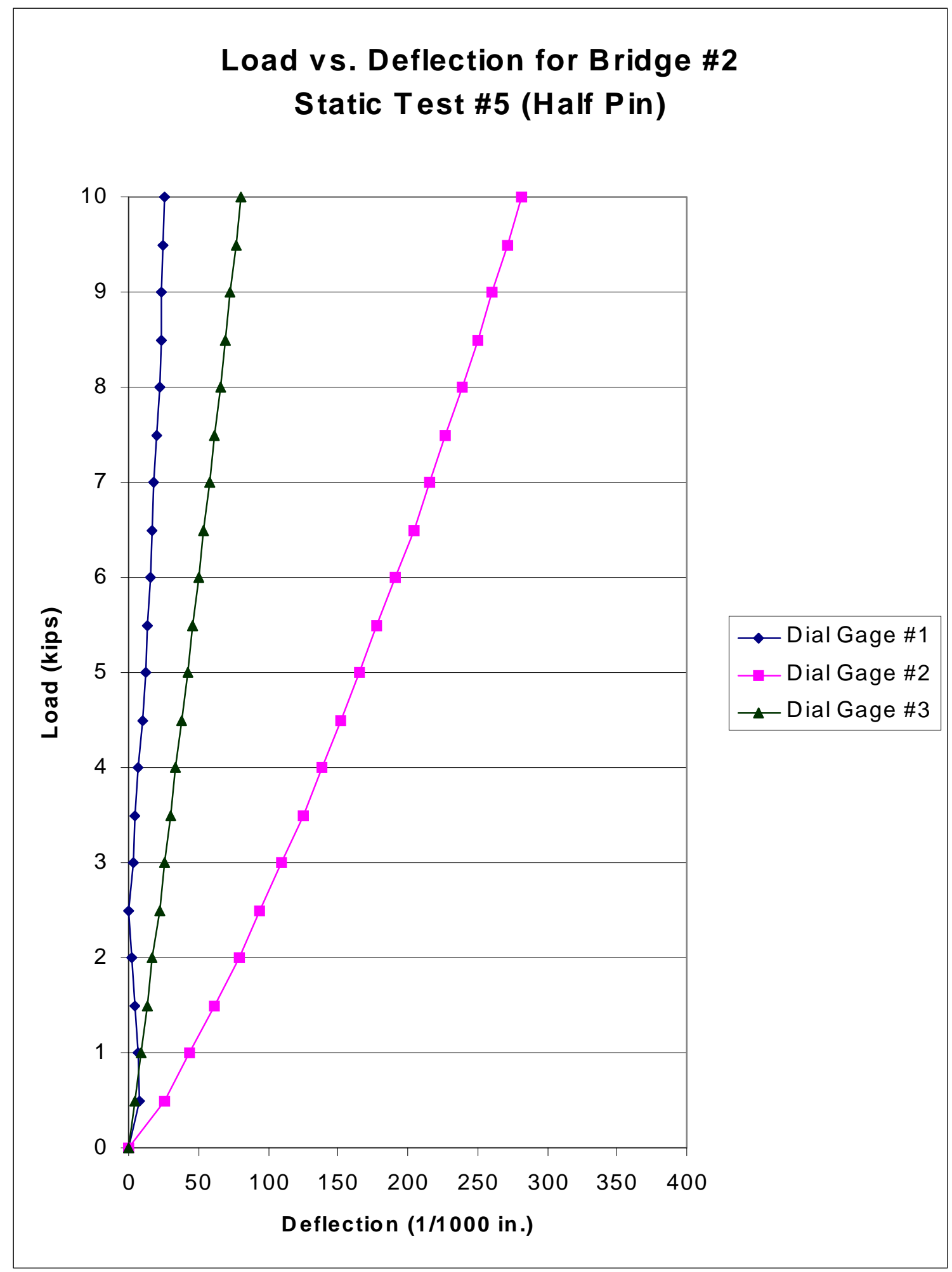

A.38 Deflection Test \#5 (Half Pin) Graph for Bridge \#2 


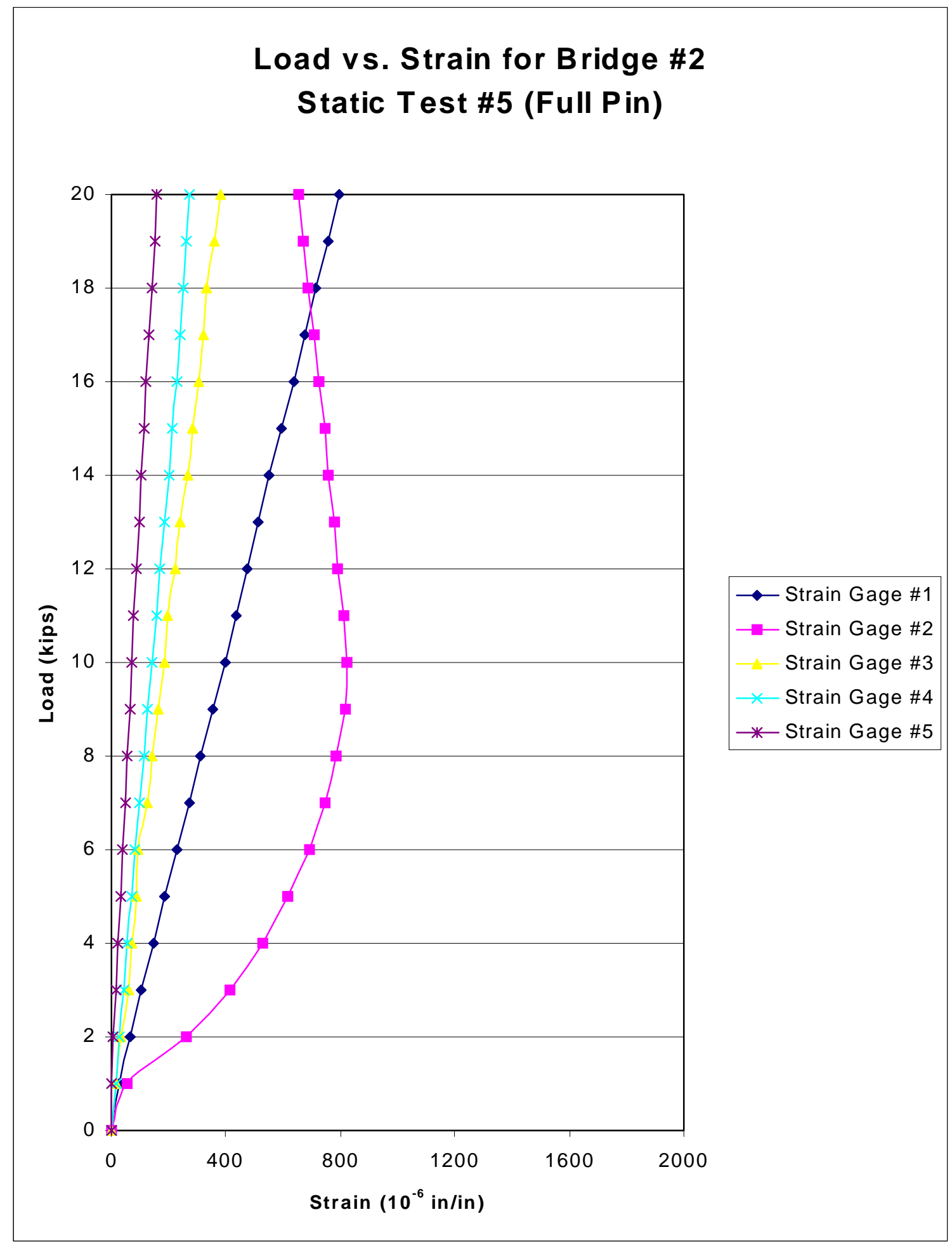

A.39 Strain Test \#5 (Full Pin) Graph for Bridge \#2 


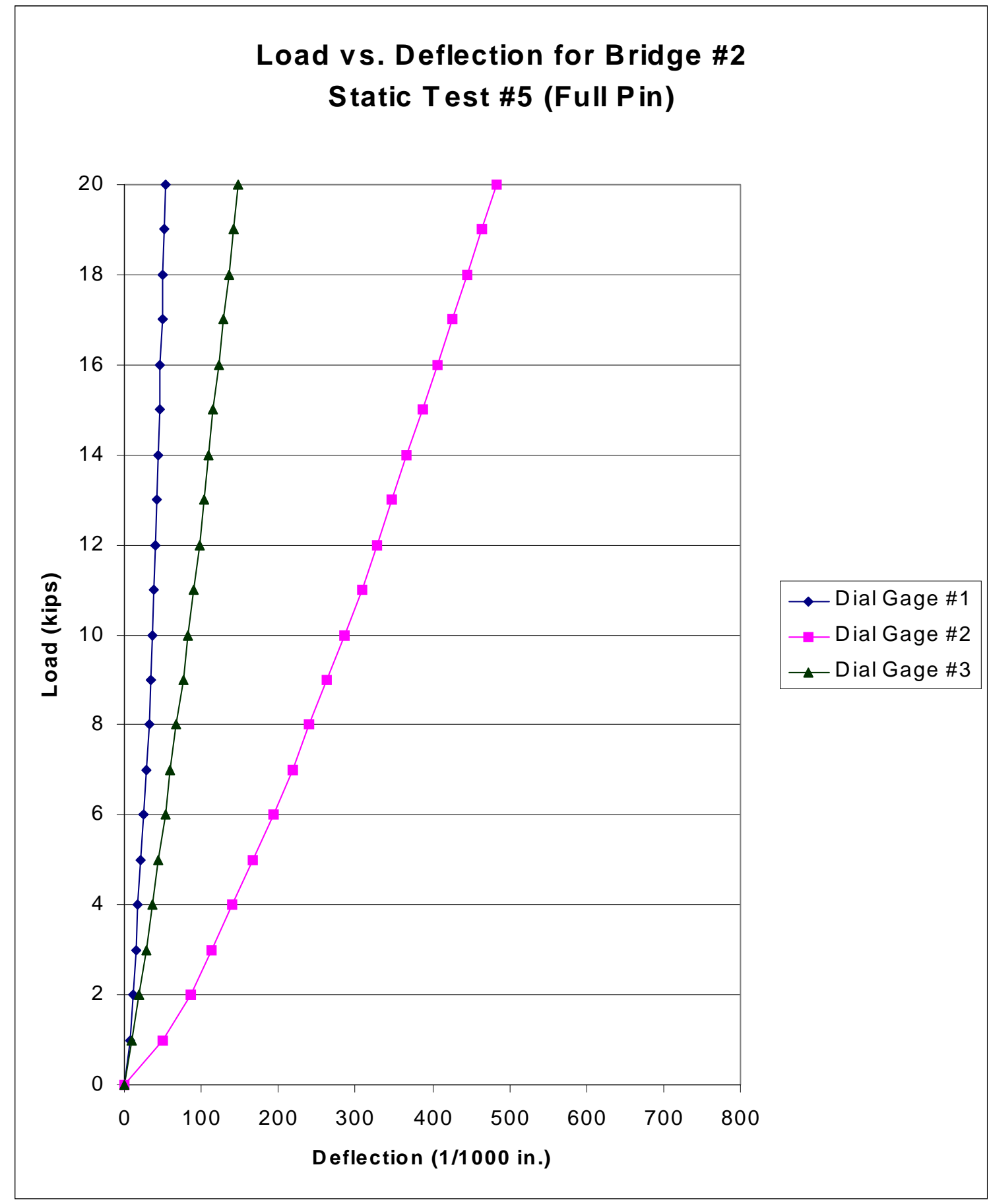

A.40 Deflection Test \#5 (Full Pin) Graph for Bridge \#2 


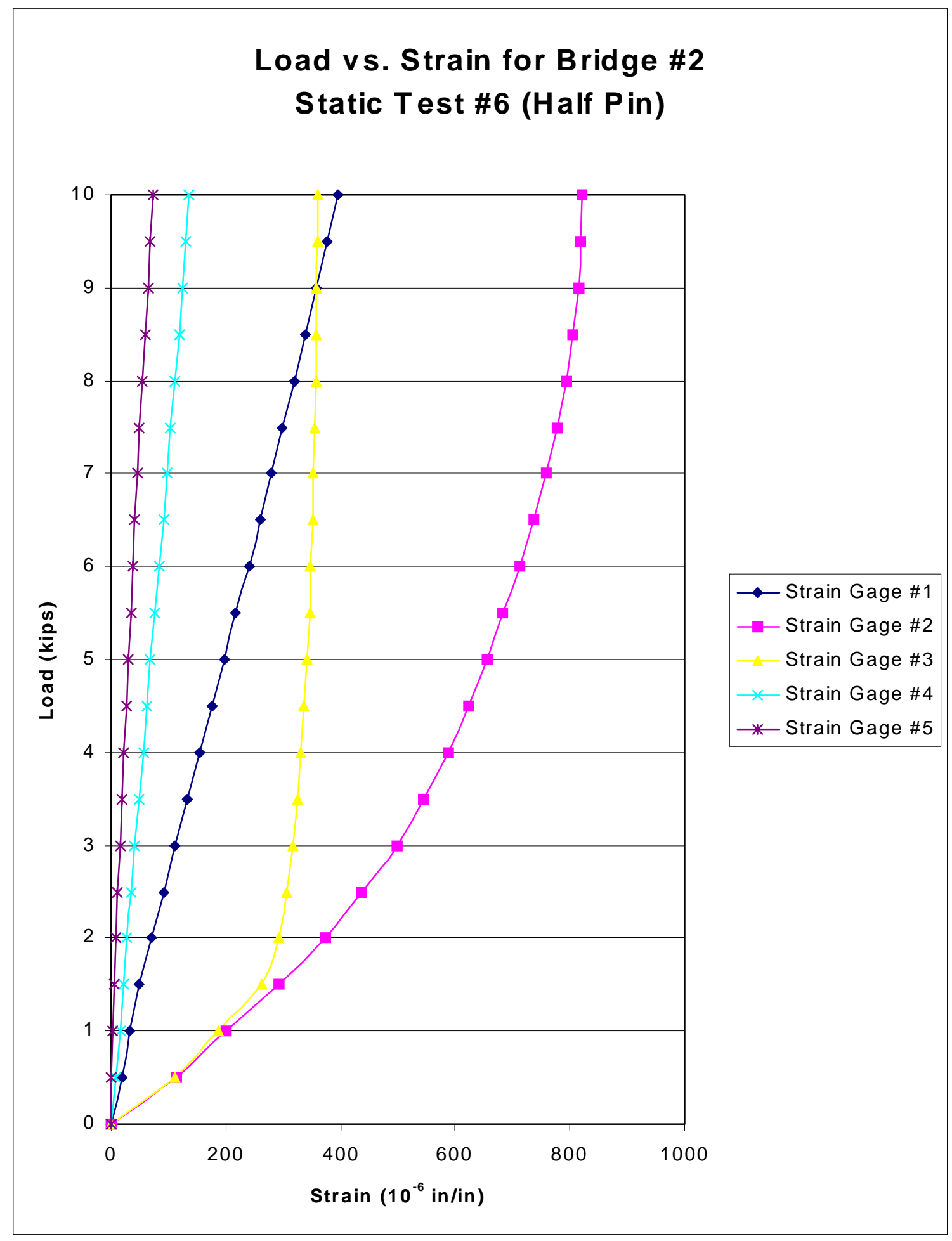

A.41 Strain Test \#6 (Half Pin) Graph for Bridge \#2 


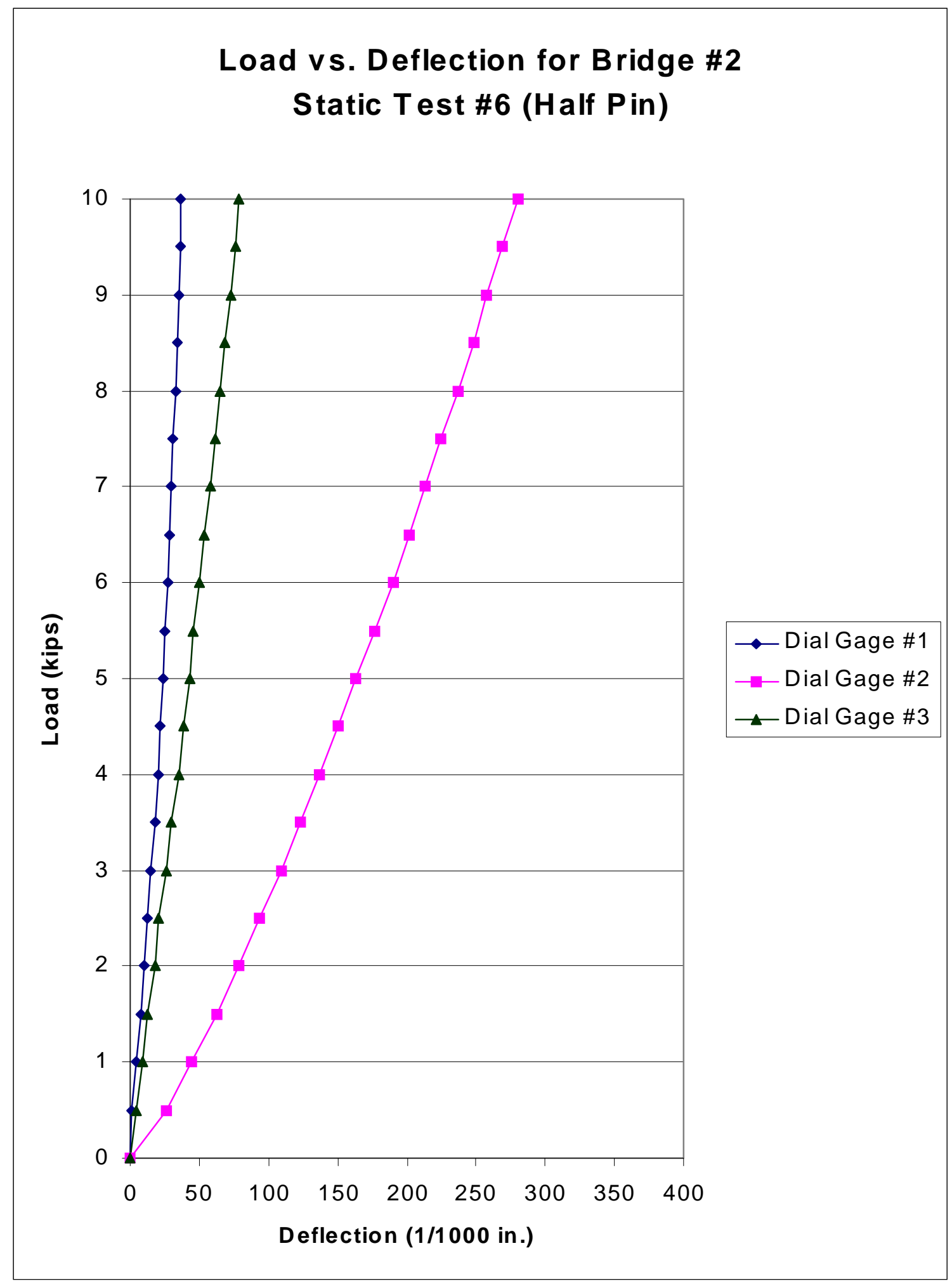

A.42 Deflection Test \#6 (Half Pin) Graph for Bridge \#2 


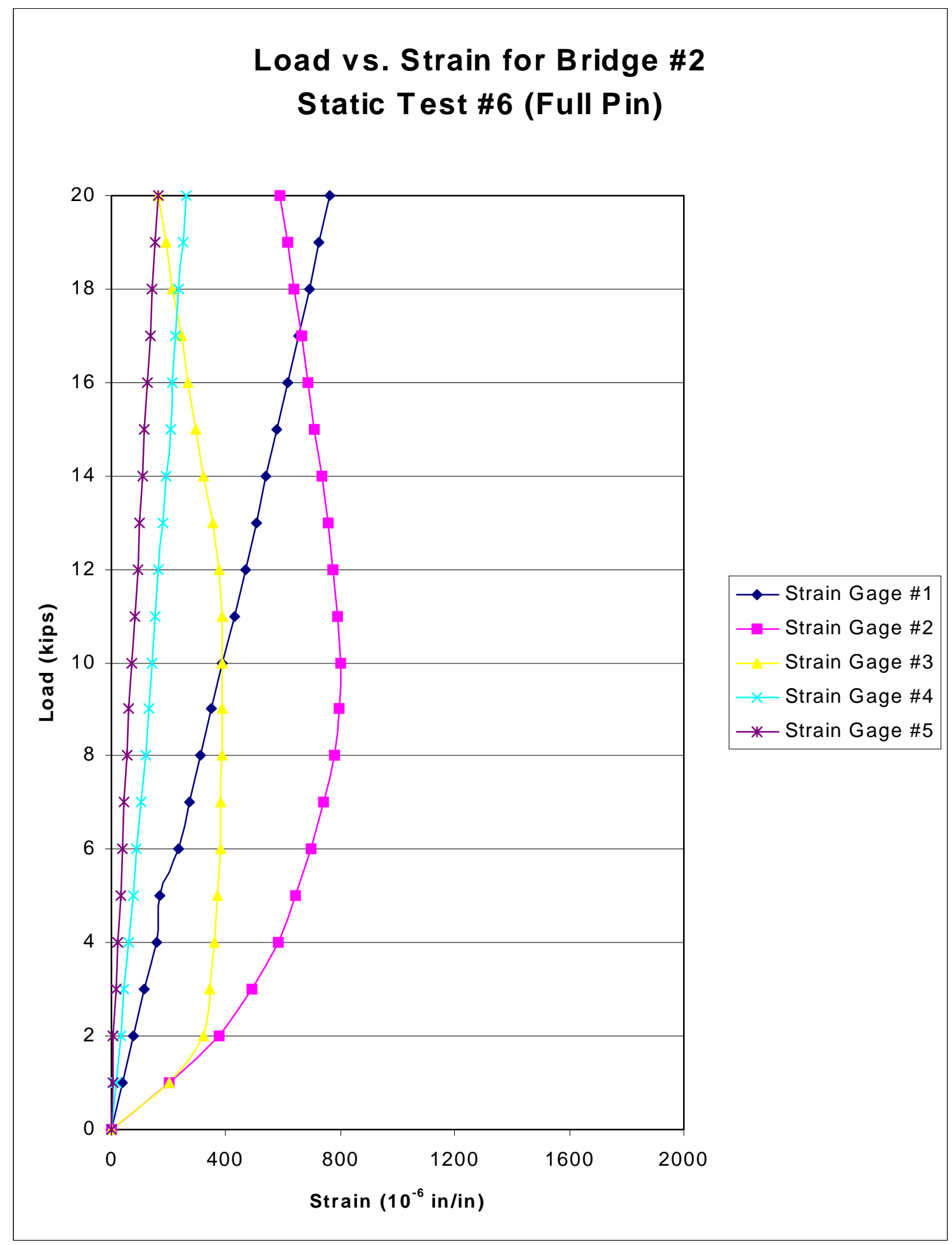

A.43 Strain Test \#6 (Full Pin) Graph for Bridge \#2 


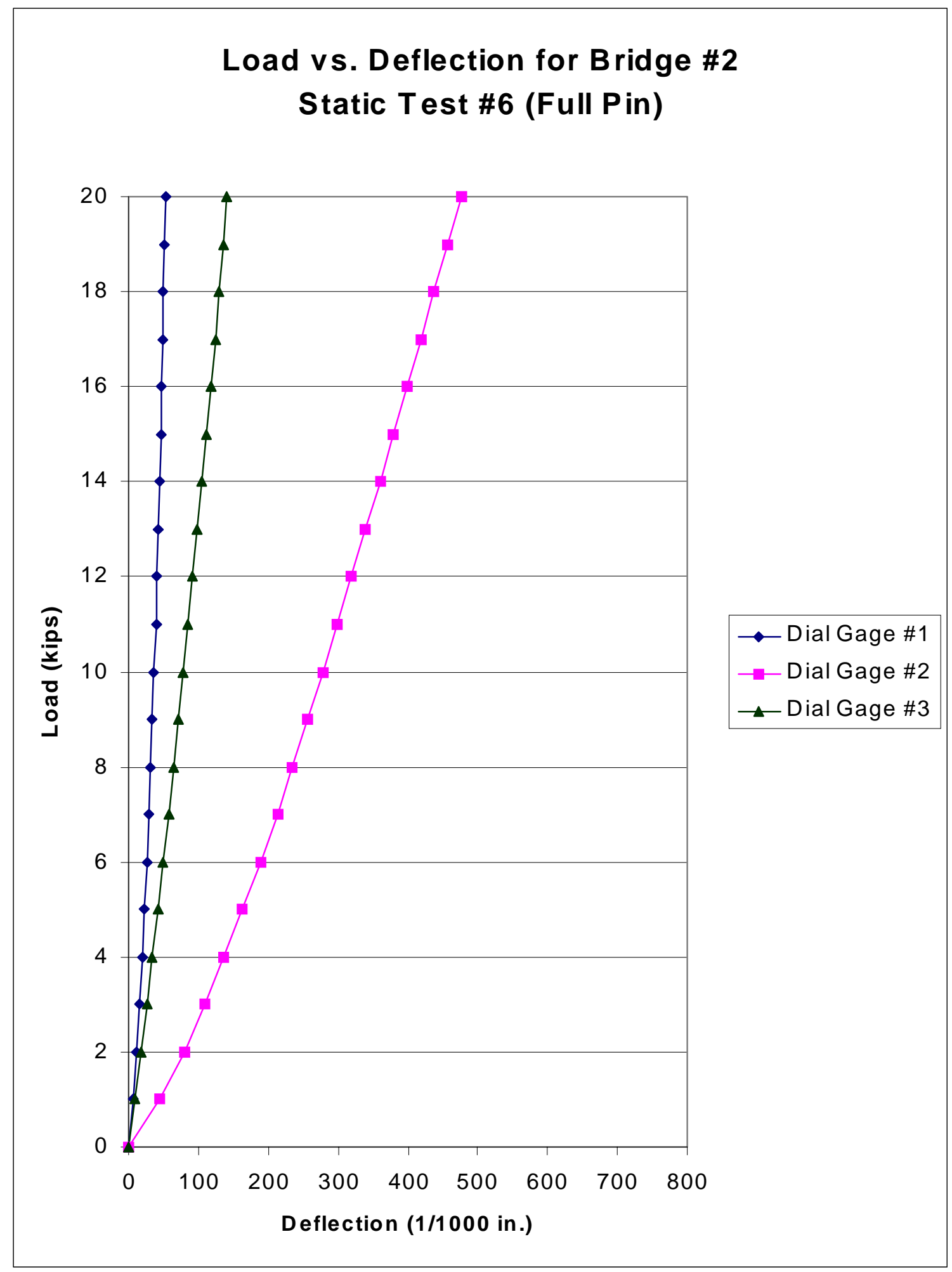

A.44 Deflection Test \#6 (Full Pin) Graph for Bridge \#2 


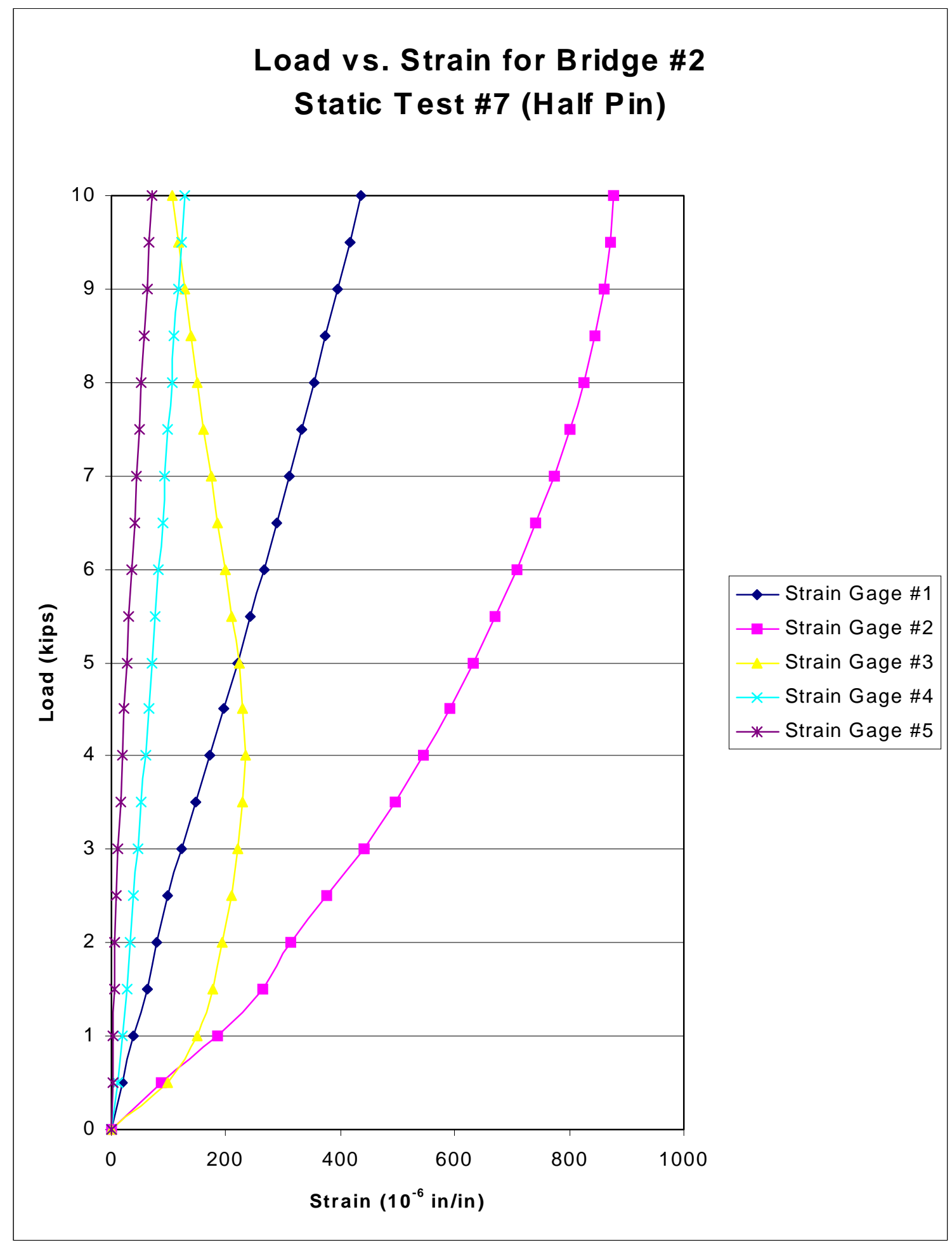

A.45 Strain Test \#7 (Half Pin) Graph for Bridge \#2 


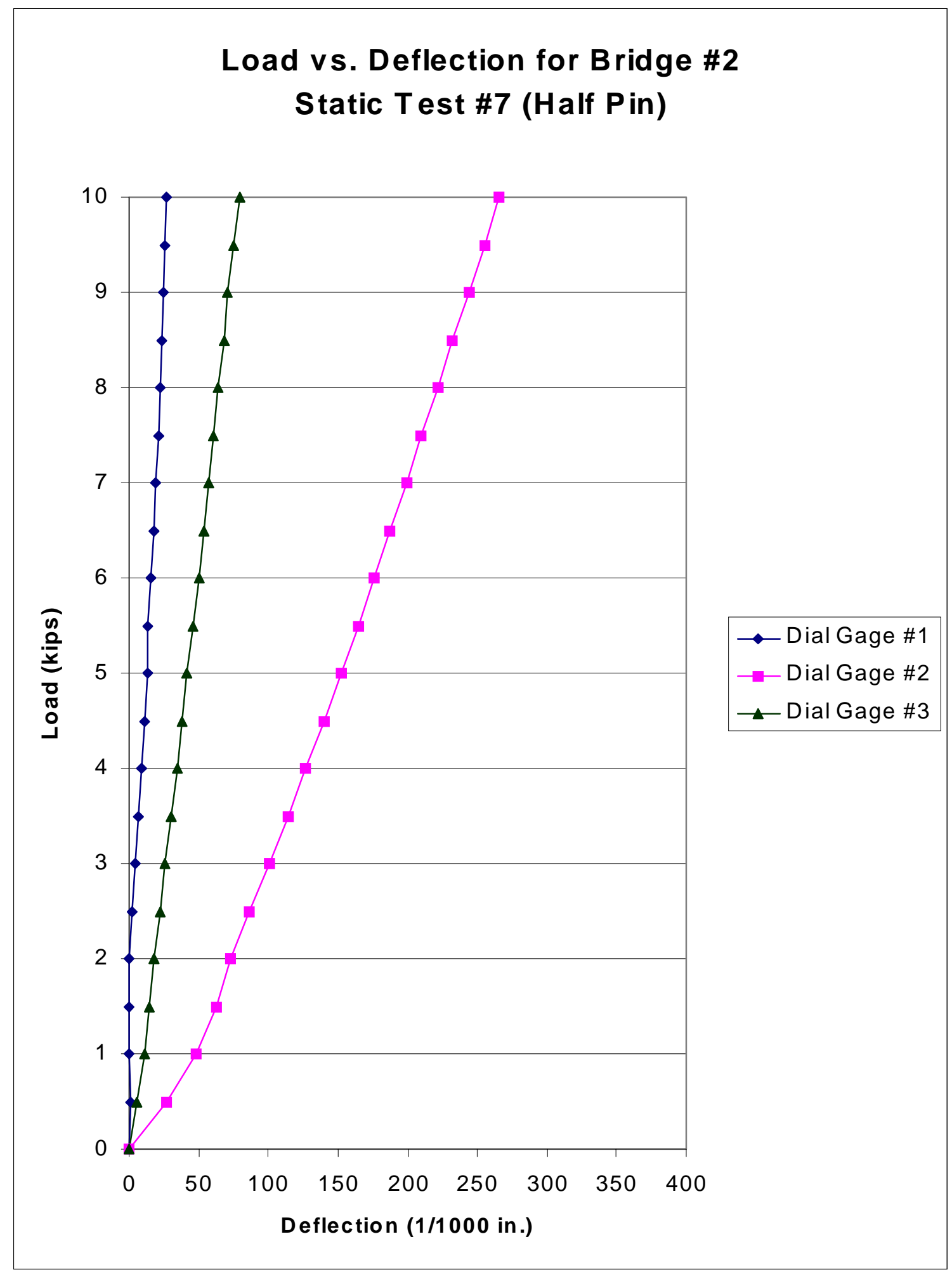

A.46 Deflection Test \#7 (Half Pin) Graph for Bridge \#2 


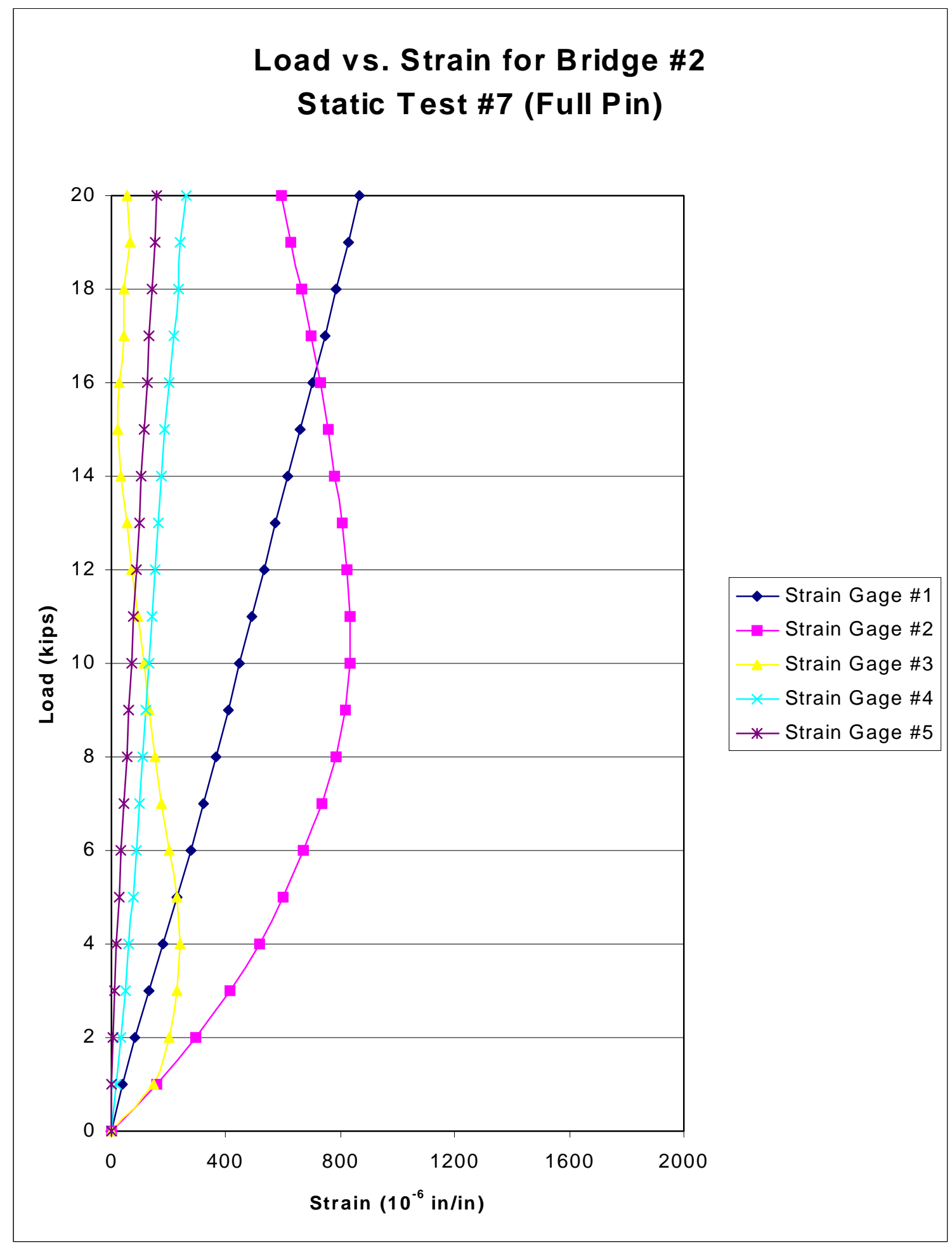

A.47 Strain Test \#7 (Full Pin) Graph for Bridge \#2 


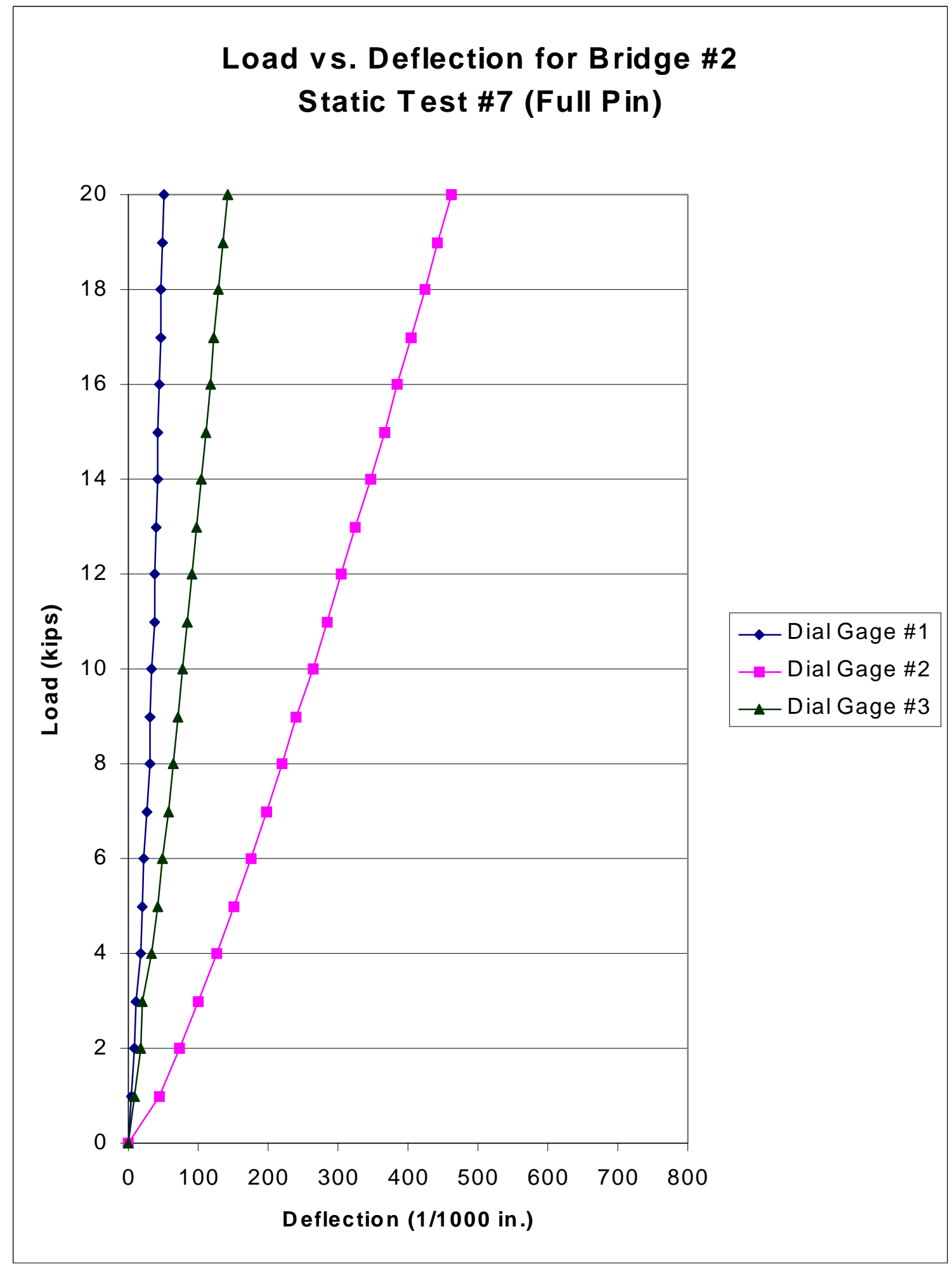

A.48 Deflection Test \#7 (Full Pin) Graph for Bridge \#2 


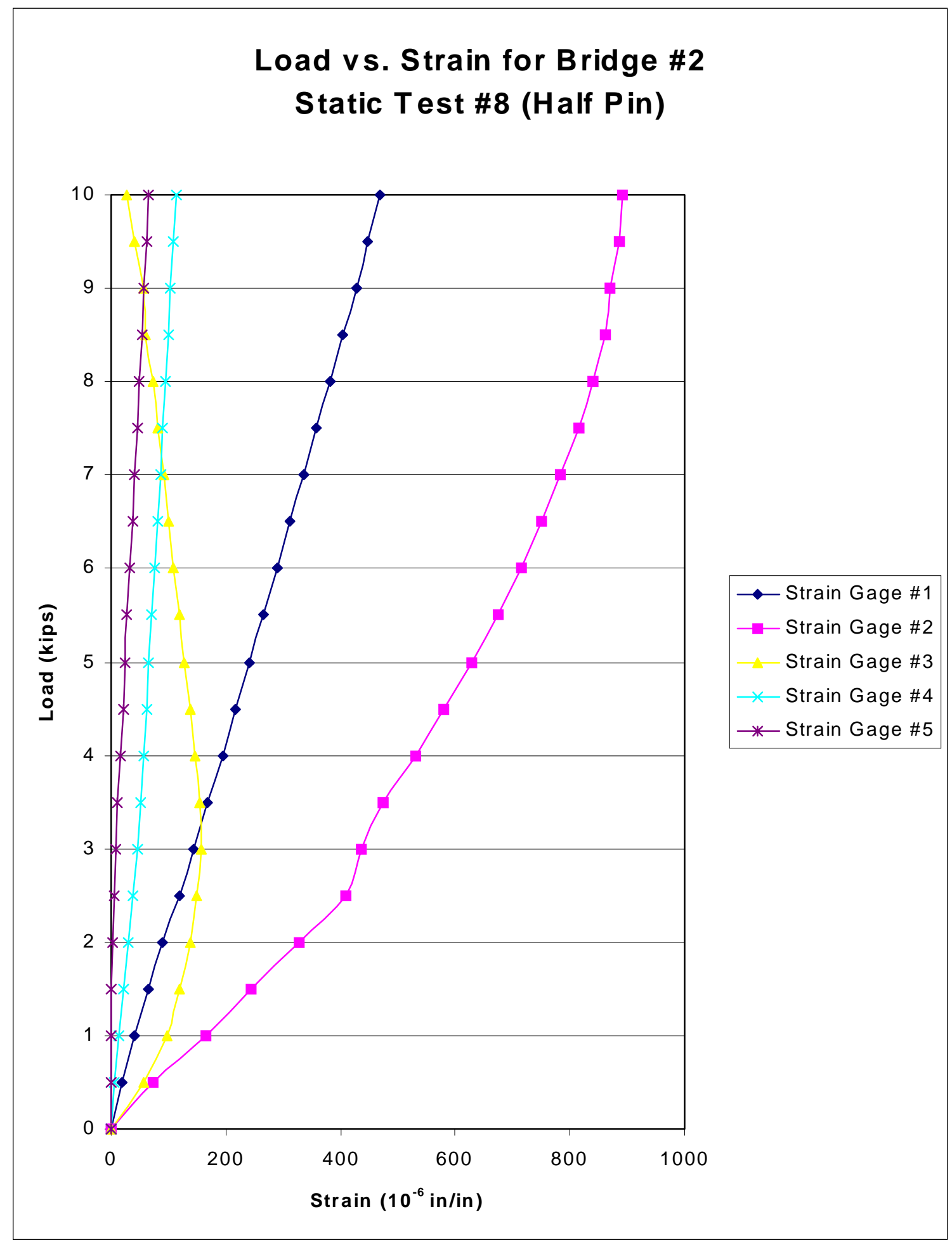

A.49 Strain Test \#8 (Half Pin) Graph for Bridge \#2 


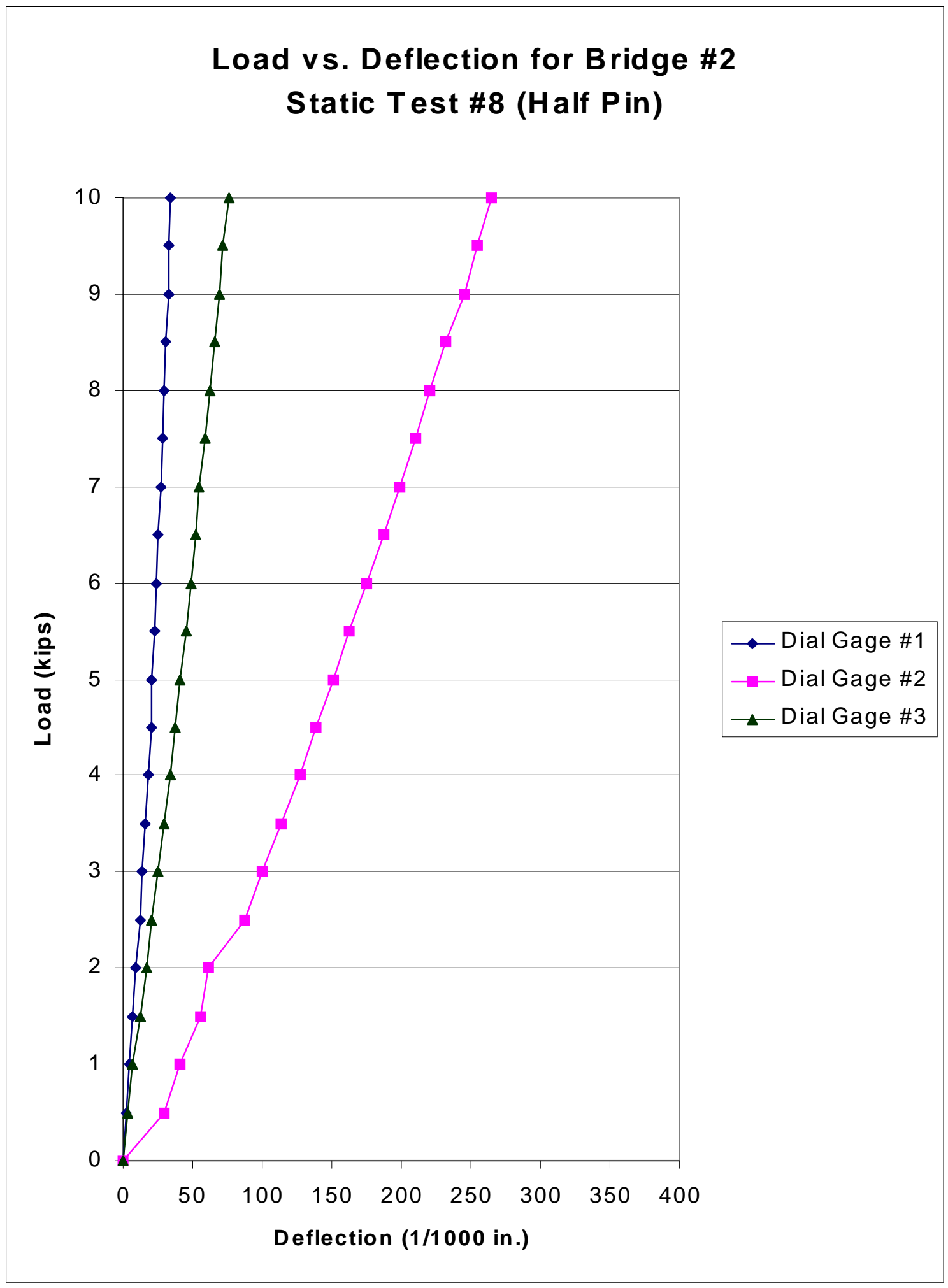

A.50 Deflection Test \#8 (Half Pin) Graph for Bridge \#2 


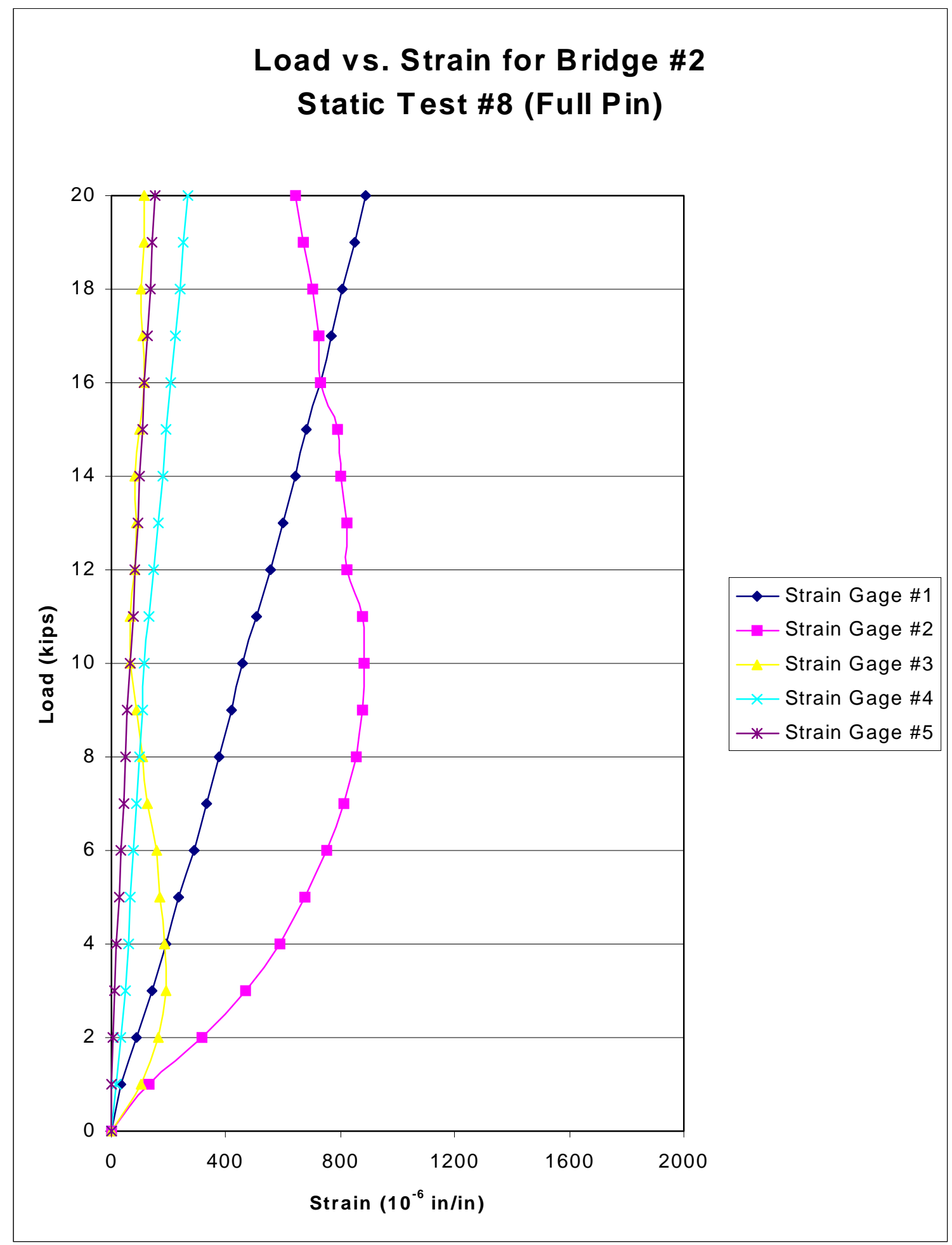

A.51 Strain Test \#8 (Full Pin) Graph for Bridge \#2 


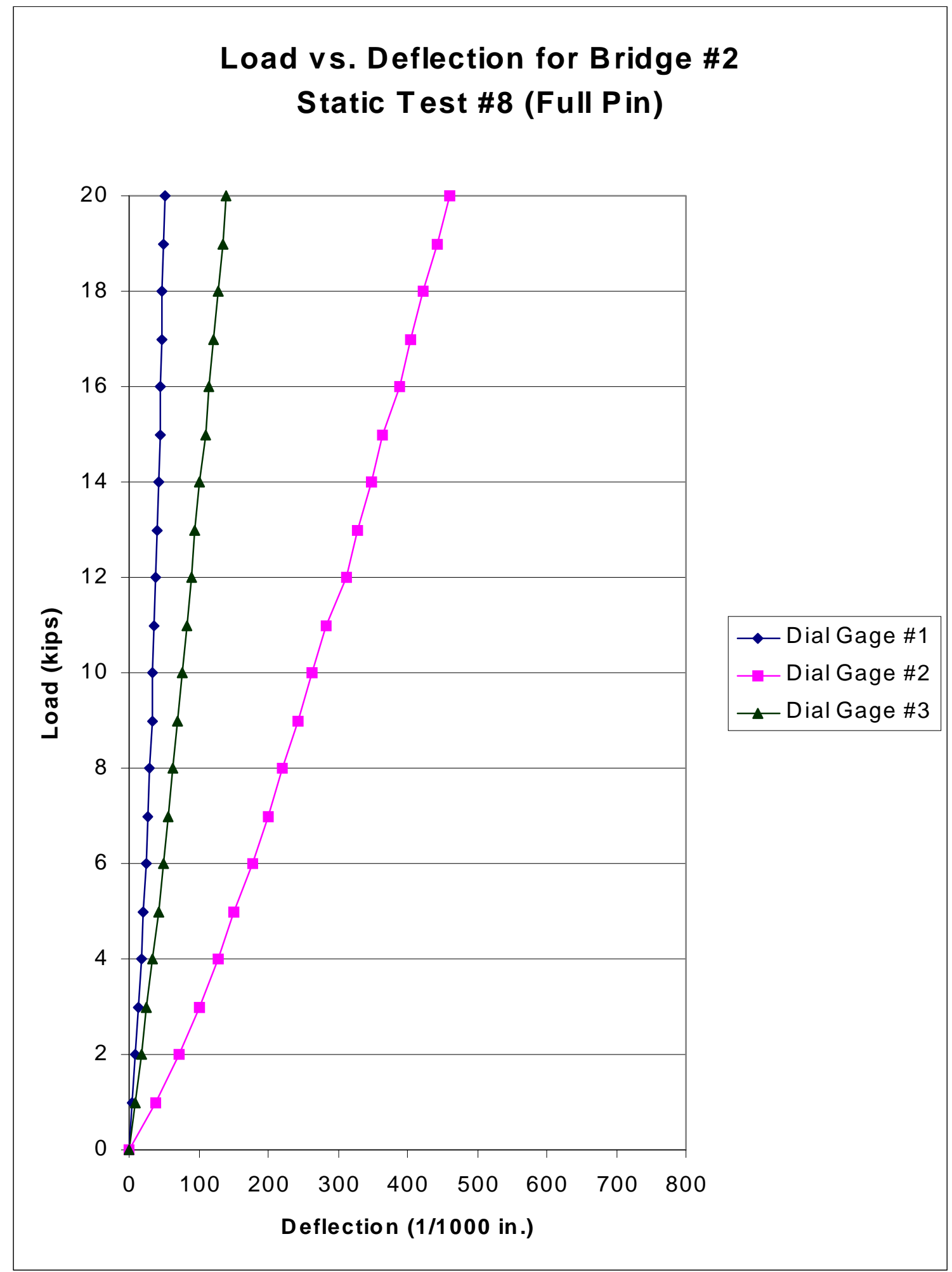

A.52 Deflection Test \#8 (Full Pin) Graph for Bridge \#2 


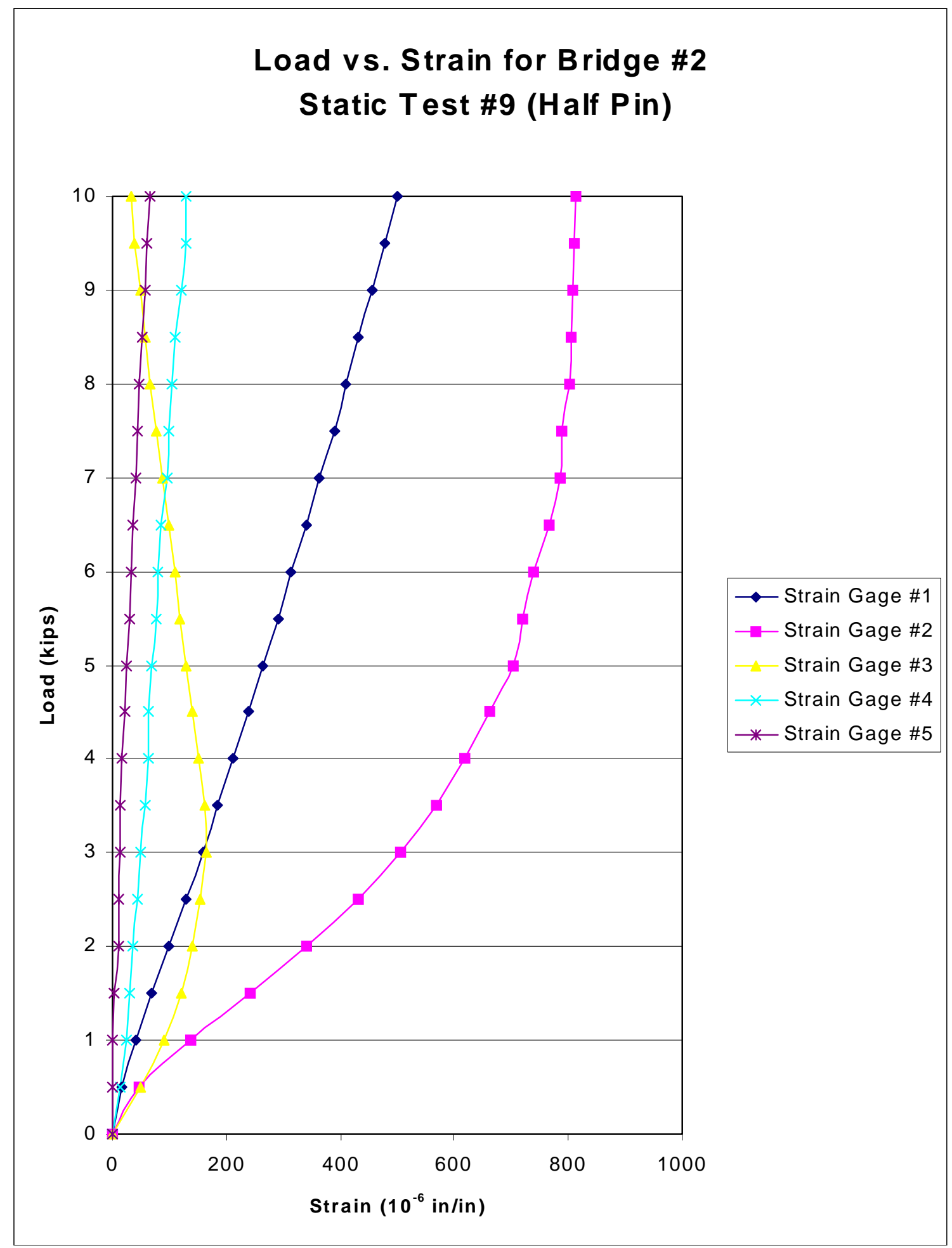

A.53 Strain Test \#9 (Half Pin) Graph for Bridge \#2 


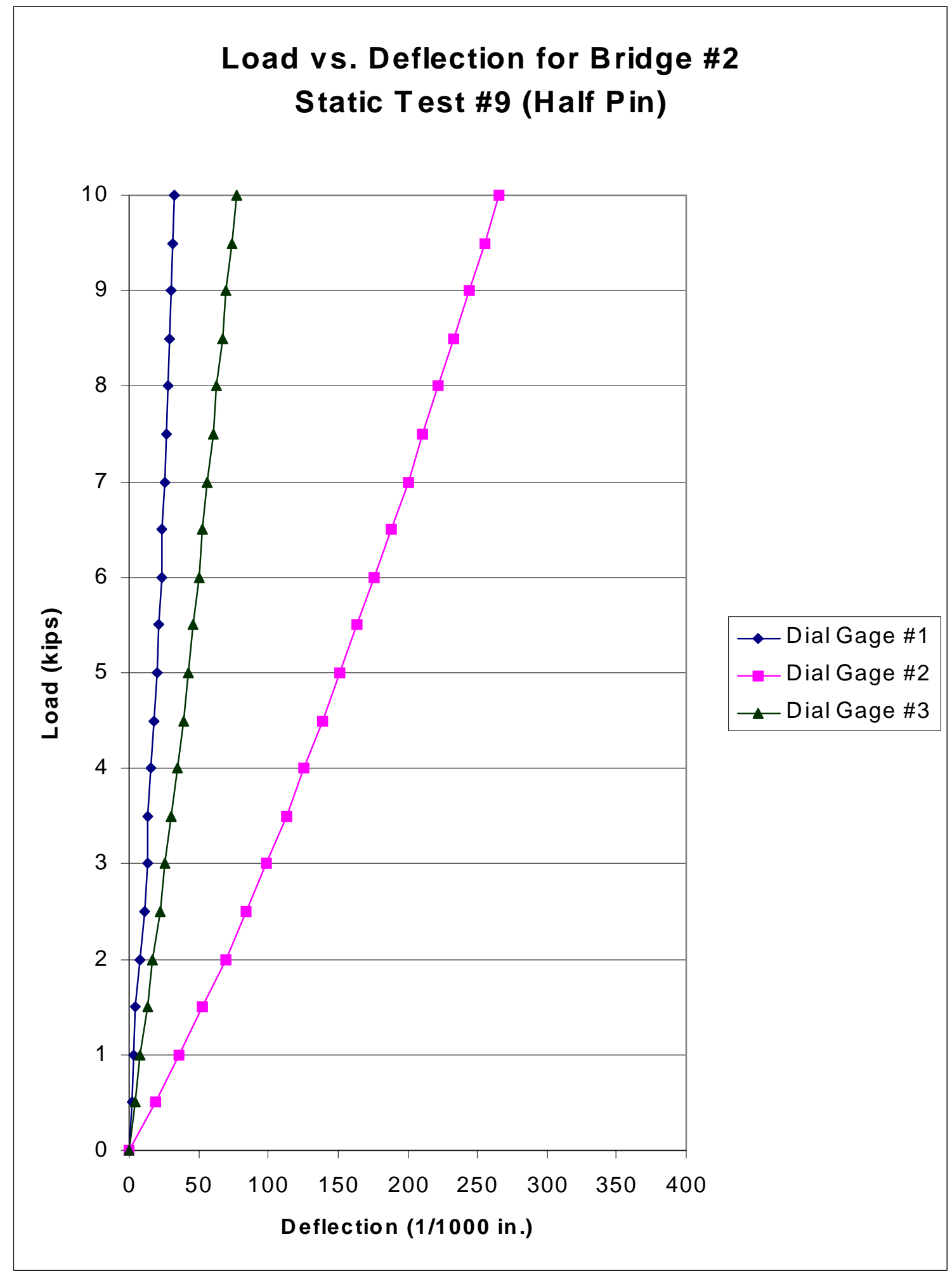

A.54 Deflection Test \#9 (Half Pin) Graph for Bridge \#2 


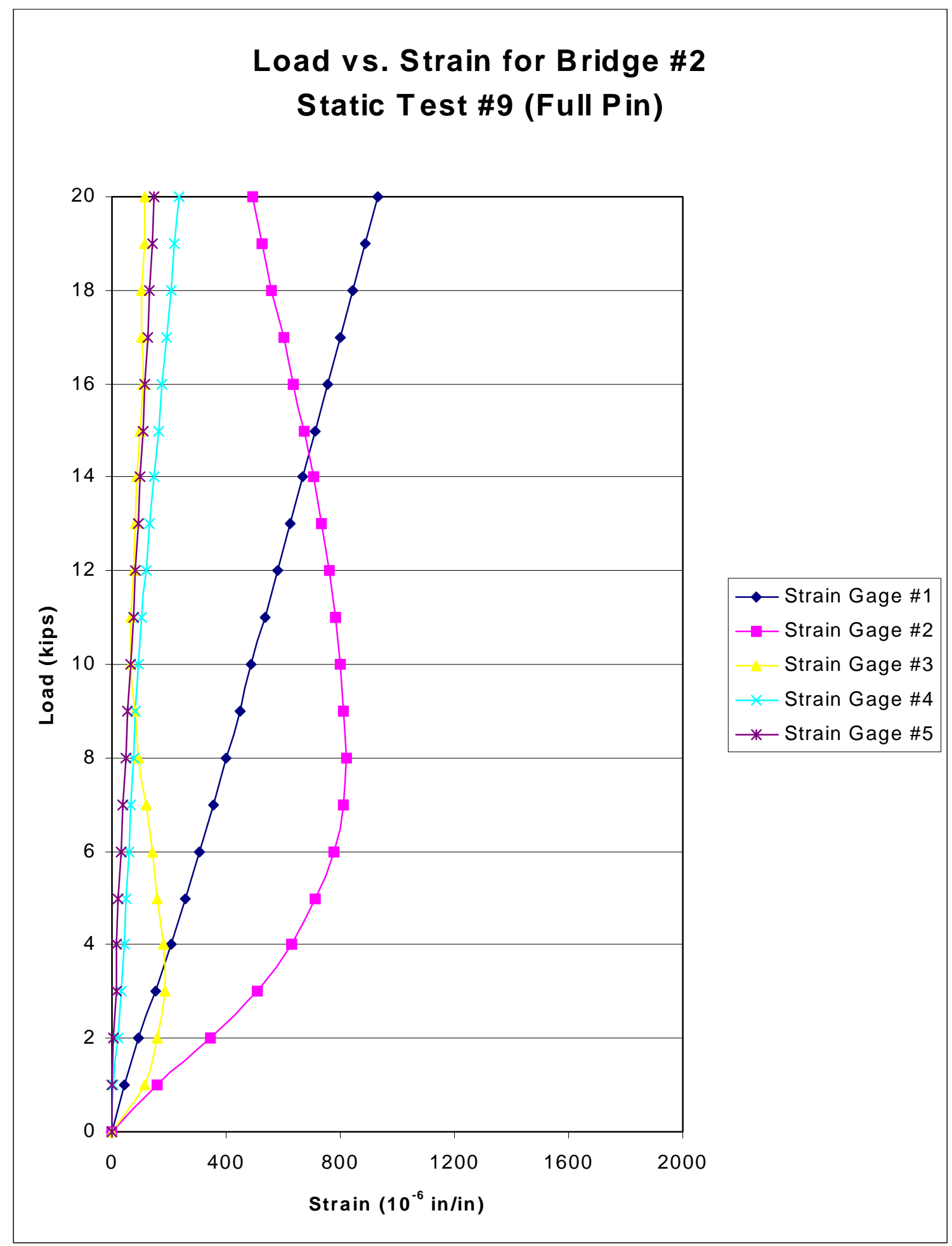

A.55 Strain Test \#9 (Full Pin) Graph for Bridge \#2 


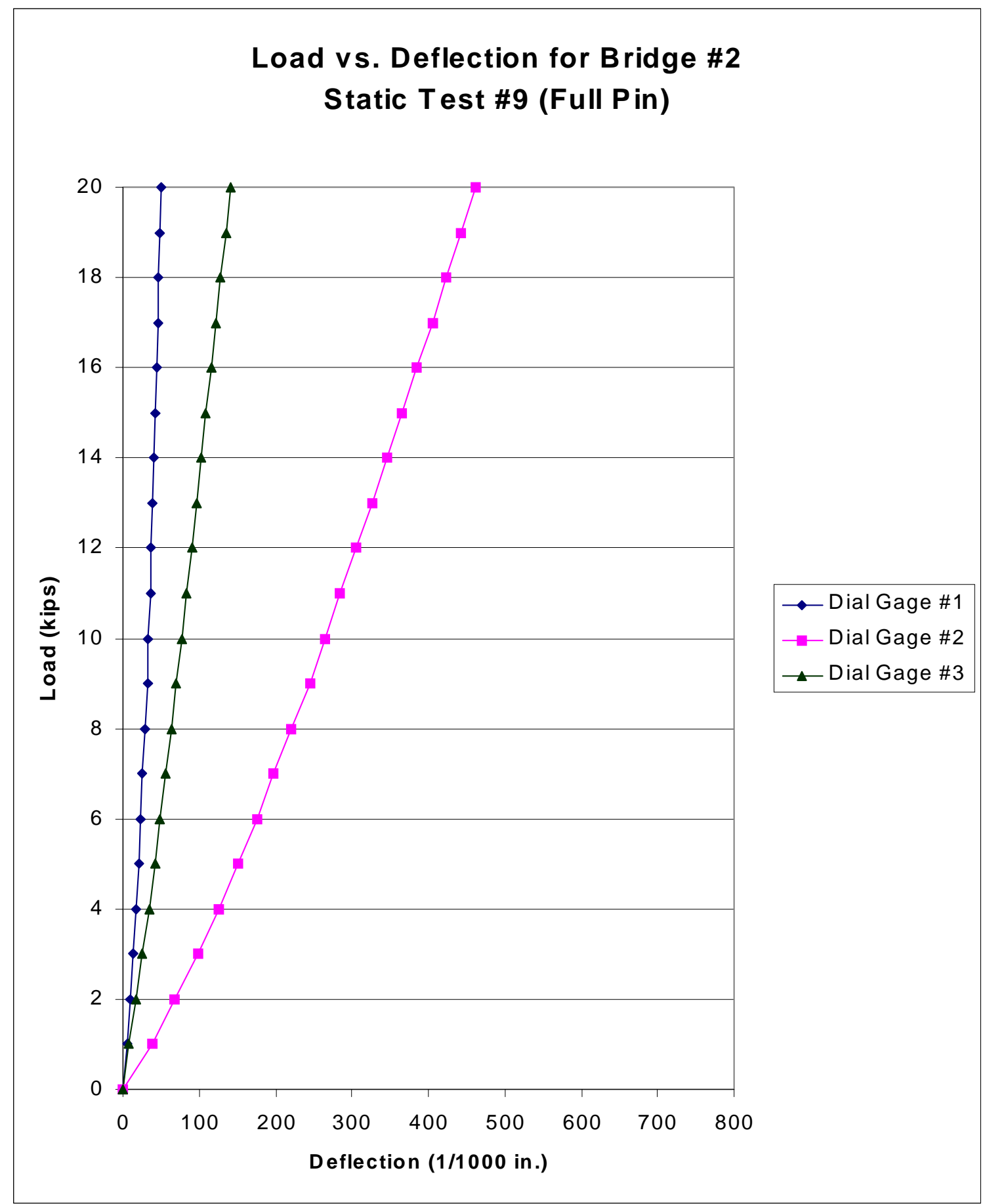

A.56 Deflection Test \#9 (Full Pin) Graph for Bridge \#2 


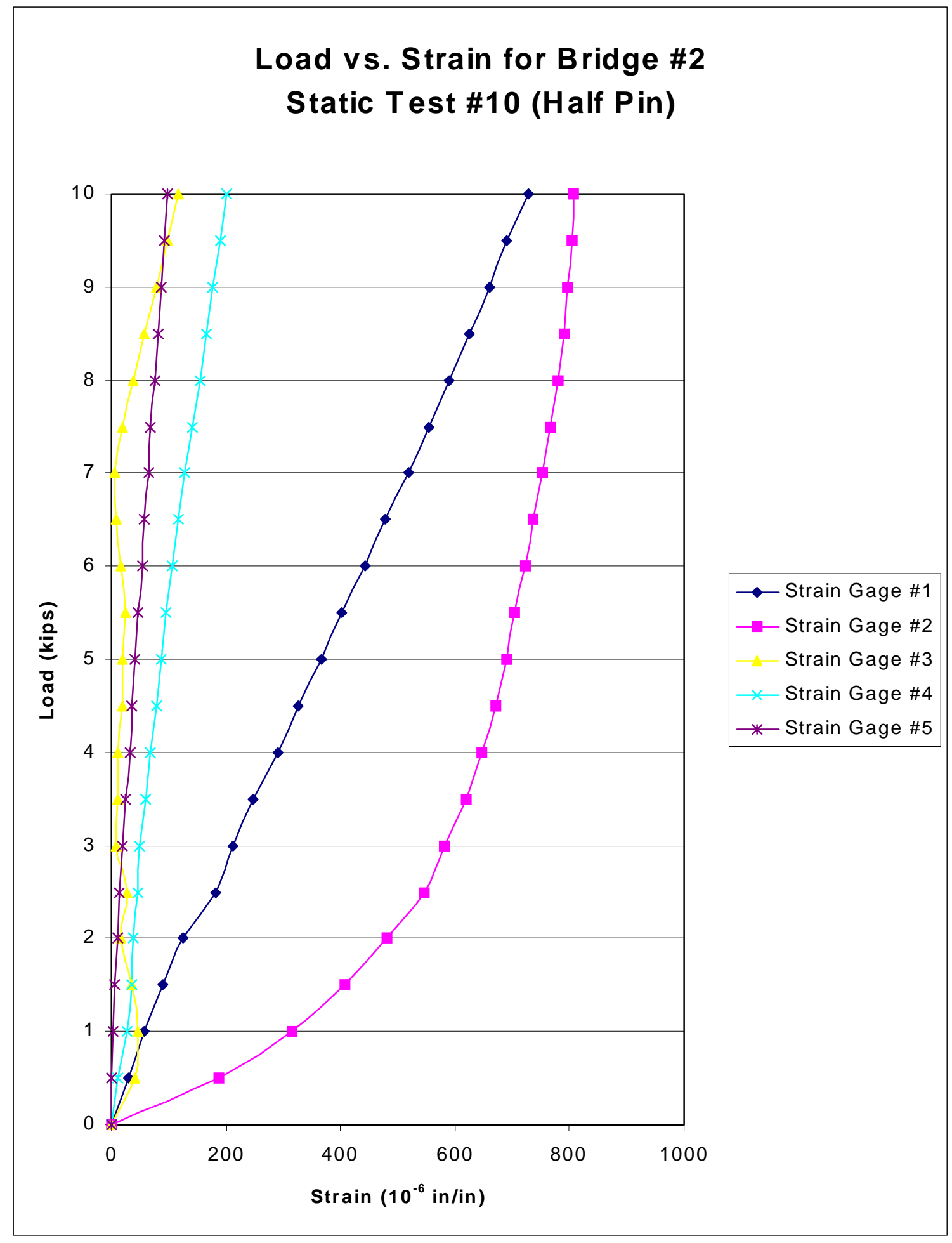

A.57 Strain Test \#10 (Half Pin) Graph for Bridge \#2 


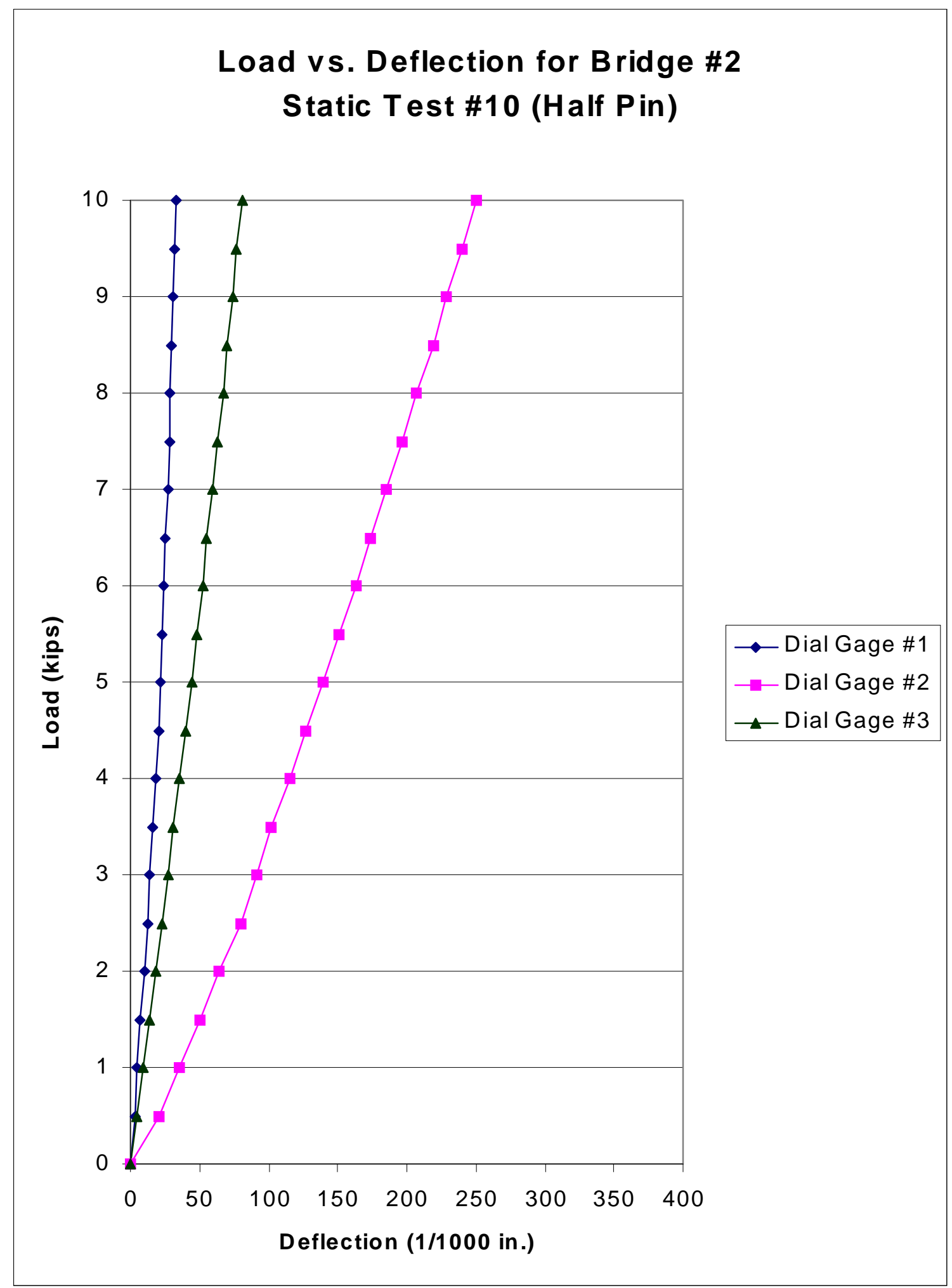

A.58 Deflection Test \#10 (Half Pin) Graph for Bridge \#2 


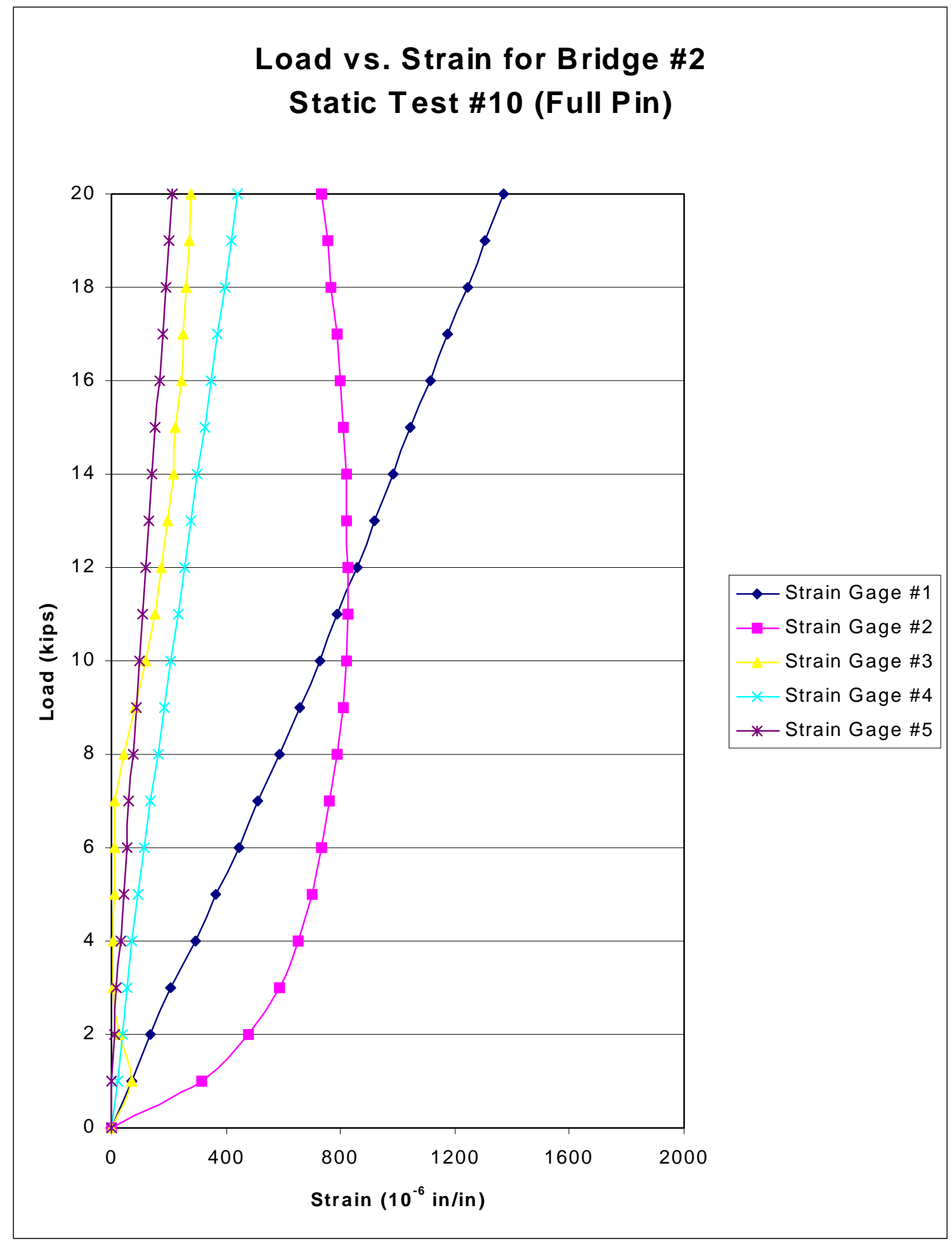

A.59 Strain Test \#10 (Full Pin) Graph for Bridge \#2 


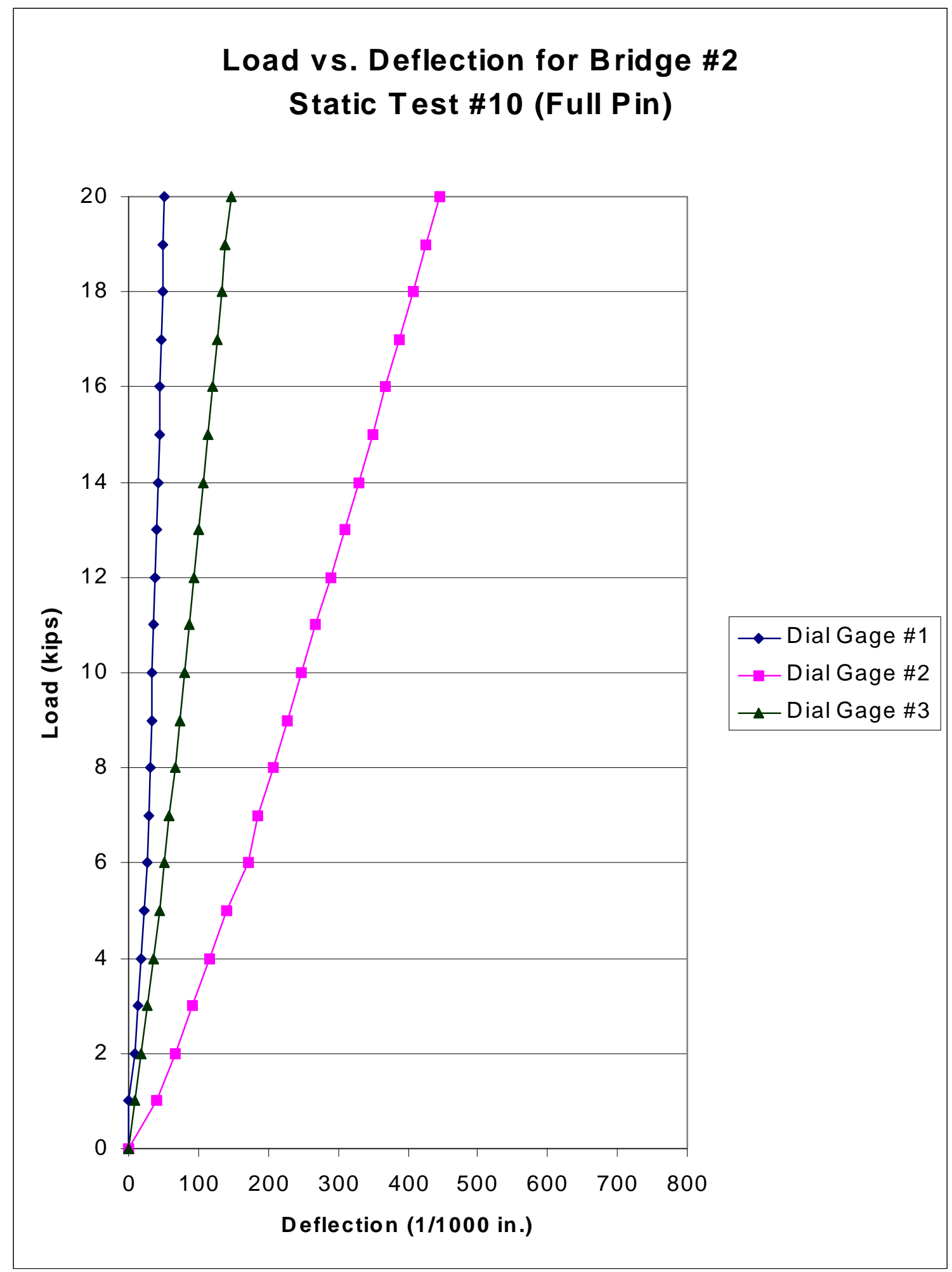

A.60 Deflection Test \#10 (Full Pin) Graph for Bridge \#2 